\title{
Photovoltaic Performance and Reliability Workshop
}

Ben Kroposki, Workshop Chairman

Sheraton Denver West

Lakewood, Colorado

September 4-6, 1996

National Renewable Energy Laboratory 1617 Cole Boulevard

Golden, Colorado 80401-3393

A national laboratory of the U.S. Department of Energy

Managed by Midwest Research Institute for the U.S. Department of Energy under Contract No. DE-AC36-83CH10093

Prepared under Task No. PV660101

October 1996 
NOTICE: This report was prepared as an account of work sponsored by an agency of the United States govemment. Neither the United States govemment nor any agency thereof, nor any of their employees, makes any warranty, express or implied, or assumes any legal liability or responsibility for the accuracy, completeness, or usefulness of any information, apparatus, product, or process disclosed, or represents that its use would not infringe privately owned rights. Reference herein to any specific commercial product, process, or senvice by trade name, trademark, manufacturer, or otherwise does not necessarily constitute or imply its endorsement, recommendation, or favoring by the United States govemment or any agency thereof. The views and opinions of authors expressed herein do not necessarily state or reflect those of the United States govemment or any agency thereof. 


\section{Preface}

This proceedings is the compilation of papers presented at the ninth PV Performance and Reliability Workshop held at the Sheraton Denver West Hotel on September 4-6, 1996. This years workshop included presentations from twenty-five speakers and had over one hundred attendees. All of the presentations that were given are included in this proceedings.

The PV Performance and Reliability Workshop is one of the few occasions where the entire PV community (manufacturers, researchers, system designers, and customers) can get together and discuss technical issues related to photovoltaics. This workshop offers extended presentations and discussions that allow attendees to voice their opinions on the topics of performance and reliability.

Several topics of interest were discussed and are listed below:

1. Defining service lifetime and Developing models for PV module lifetime

2. Examining and determining failure and degradation mechanisms in PV modules

3. Combining IEEE/IEC/UL testing procedures

4. AC Module performance and reliability testing

5. Inverter reliability/qualification testing

6. Standardization of utility interconnect requirements for PV systems

7. Need activities to separate variables by testing individual components of PV systems (e.g. cells, modules, batteries, inverters, charge controllers) for individual reliability and then test them in actual system configurations

8. More results reported from field experience on modules, inverters, batteries, and charge controllers from field deployed PV systems

9. System certification and standardized testing for stand-alone and grid-tied systems

I would like to acknowledge the following people for their work on the program committee; Al Czanderna, Dick DeBlasio, Keith Emery, David King, Tom McMahon, Carl Osterwald, Troy Strand, and Mike Thomas. These people were instrumental in providing the program structure and agenda. I also would like to thank Heather Bulmer for coordinating the actual workshop and making it run smoothly. Also thanks to DOE, NREL and Sandia National Labs for supporting this workshop as a mechanism for technology transfer between the research laboratories and the PV industry.

Ben Kroposki

Workshop Chairman 


\section{Photovoltaic Performance and Reliability Workshop \\ September 4-6, 1996 \\ Table of Contents}

Preface.

Ben Kroposki, National Renewable Energy Laboratory

Table of Contents.

Attendance List

Opening Session.................................................................................................

DOE Perspectives on PV.

Philip Overholt, Department of Energy

Overview of Current Issues: PV Cell and Module Performance and Reliability...

Al Czanderna, National Renewable Energy Laboratory

Photovoltaic Systems Performance and Reliability:

Myths, Facts, and Concems - A 1996 Perspective.

Mile Thomas, Sandia National Laboratories

Cell, Module, and System Performance..........................................................

Uncertainties in PV Performance Indicators for Service Life Prediction.

Keith Emery, National Renewable Energy Laboratory

Determination of the Internal Series Resistance of Photovoltaic Cells.

Alan Delahoy, Energy Photovoltaics, Inc.

Thin Film Module Characterization.

Ingrid Eisgruber, Materials Research Group

An Evaluation of Long-Term System Degradation at PVUSA

Tim Townsend, Endecon Engineering

Array Utilization in Hybrid Systems..

Rick Chapman, Sandia National Laboratories

Comparison of Array Performance at NREL

Troy Srand, National Renewable Energy Laboratory

The AC Photovoltaic Module.

Steven Strong, Solar Design Associates, Inc.

Use of Irradiance and Temperature Data to Predict AC Module Lifetime.

Clayton Handleman, Ascension Technology, Inc.

Cell and Module Reliability

Accelerated Environmental Testing for Screening and Lifetime Predication 
Stability Issues Related to CdTe PV Modules.

Peter Myers, ITN Energy Systems

Encapsulant Adhesion and Solder Bond Integrity in Field-Aged Modules.

Michael Quintana, Sandia National Laboratories

Interconnect Reliability Tests for Alternative Module Construction

Rob Spotts, Photocomm

PV Module Qualification Test Experiences and Results

Bob Hammond, Arizona State University

System Reliability.

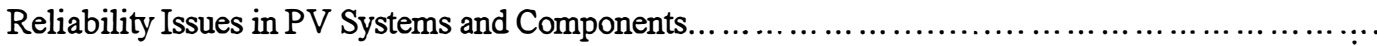

Chuck Whitaker, Endecon Engineering

Cost and Performance Consequences of NEC and UL Requirements

John Wiles, Southwest Technology Development Institute

Advanced Test and Bum-in Program for Photovoltaic Inverters.

Christopher Freitas, Trace Engineering

The PCS - An Integral Component of System Performance and Reliability.....

Kevin Dennis, Omnion Power Engineering Corp.

Photovoltaic Hybrid System Performance Comparisons: Prediction Versus Field Results

Steven Durand, Southwest Technology Development Institute

PV Applications and Field Experience.

PSN's Recent Experience.

Cary Lane, Photovoltaic Service Network

Energy Utilization in PV Systems......

John Stevens, Sandia National Laboratories

Experiences with Upper Great Lakes Stand-Alone Systems

Cedric Currin, Currin Corp.

Photovoltaic -Diesel Hybrid Power System: Carol Spring Telecommunication Site.

Richard Lambeth, Arizona Public Service Company 


\section{Attendee List}

PV Performance and Reliability Workshop

September 4-6, 1996

Steven Durand

New Mexico State University

Southwest Technology Dev. Inst.

1505 Payne Street

Las Cruces, NM 88003-0001

Phone: (505) 646-4247

Fax: (505) 646-3841

EMail:

Ingrid Eisgruber

Materials Research Group

12441 W. 49th Avenue, Ste 2

Wheat Ridge, CO 80033-1927

Phone: (303) 425-6688

Fax: (303) 425-6562

EMail:

Keith Emery

National Renewable Energy Lab

1617 Cole Boulevard

Golden, CO 80401

Phone: (303)-384-6632

Fax: (303) 384-6604

EMail: keith_emery@nrel.gov

Francesca Ferrazza

Eurosolare S.p.A.

Via Augusto D'Andrea 6

Nettuno 00048

Italy

Phone: +396985601

Fax: $\quad+3969850267$

EMail:

Halden Field

National Renewable Energy Lab

1617 Cole Boulevard

Golden, CO 80401

Phone: (303)-384-6685

Fax: (303) 384-6604

EMail: halden_field@nrel.gov
Christopher Freitas

Trace Engineering

5916 195th N.E.

Arlington, WA 98223

Phone: (360)-435-8826

Fax: (360)-435-2229

EMail: cfreitas@traceengineering.co $\mathrm{m}$

Daniel Friedman

National Renewable Energy Lab

1617 Cole Boulevard

Golden, CO 80401

Phone: (303)-384-6472

Fax: (303)-384-6531

EMail:

James Galica

Springborn Testing \& Research

10 Water Street

Enfield, CT 06082

Phone: (860) 749-8371

Fax: $\quad$ (860) 749-8234

EMail:

Troy Glatfelter

United Solar Systems Corp.

1100 W. Maple Road

Troy, MI 48084

Phone: (810)-362-4170

Fax: $\quad$ (810)-362-4442

EMail:

Stephen Glick

National Renewable Energy Lab

SERF 15313 Denver West Pkwy.

Golden, CO 80401

Phone: (303) 384-6712

Fax: (303) 384-6490

EMail: 


\section{Attendee List}

PV Performance and Reliability Workshop

September 4-6, 1996

Ronald Gonsiorawski

ASE Americas

4 Surburban Park Drive

Billerica, MA 01824

Phone: (508)-667-5900 x217

Fax: $\quad$ (508) 663-7555

EMail:

Robert Hammond

Arizona State University

1971 E. Huntington Drive

Tempe, AZ 85287-5806

Phone: (602)-965-0377

Fax: (602)-838-2379

EMail: b.hammond@asu.edu

Dennis Hansen

PacifiCorp

201 South Main, Suite 2000

Salt Lake City, UT 84140-0020

Phone: (801)-220-4816

Fax: (801)-220-2258

EMail: dennis_j.hansen@upl.com

Robert Hansen

National Renewable Energy Lab

1617 Cole Boulevard

Golden, CO 80401

Phone: (303)-384-6104

Fax:

EMail:

Neil Heeke

Golden Photon, Inc.

4545 Mclntyre Street

Golden, CO 80403

Phone: (303) 271-7178

Fax: $\quad$ (303) 271-7410

EMail:
Christy Herig

National Renewable Energy Lab

1617 Cole Boulevard

Golden, CO 80401

Phone: (303) 384-6546

Fax: (303) 384-6490

EMail: herigc@tcplink.nrel.gov

Mandy Herner

Public Service Co. of Colorado

550 15th Street, Ste 800

Denver, CO 80202-4256

Phone: (303) 571-7243

Fax: (303) 571-7868

EMail: mherner@msp.psco.com

Steve Hester

Utility Photovoltaic Group

1800 M Street NW

Washington, DC 20036

Phone: (202)-857-0898

Fax: (202)-223-5537

EMail: shester@ttcorp.com

James F. Hoelscher

DynCorp

6101 Stevenson Avenue

Alexandria, VA 22304

Phone: (703) 461-2069

Fax: (703) 461-2020

EMail: jimh@dyniet.com

John Hoffner

Planergy, Inc.

Barton Oaks Plaza Two, Suite 495

Austin, TX 78746

Phone: (512) 327-6830

Fax: (512) 327-2553

EMail: renmotion@aol.com 


\section{Attendee List}

PV Performance and Reliability Workshop

September 4-6, 1996

Stephen Hogan

Spire Corp.

One Patriots Park

Bedford, MA 01730

Phone: (617)-275-6000

Fax: $\quad(617)-275-7470$

EMail:

Roland Hulstrom

National Renewable Energy Lab

1617 Cole Boulevard

Golden, CO 80401

Phone: (303)-384-6420

Fax: (303)-384-6490

EMail:

Gary Jorgensen

National Renewable Energy Lab

1617 Cole Boulevard

Golden, CO 80401

Phone: (303)-275-3773

Fax: (303) 275-4053

EMail:

Ted Kalal

Omnion

2010 Energy Drive

P.O. Box 879

East Troy, WI 53120

Phone: (414)-642-7200

Fax: (414)-642-7760

EMail:

Peter Kane

Evergreen Solar, Inc.

211 Second Avenue

Watham, MA 02154

Phone: (617) 890-7117

Fax: (617) 890-7141

EMail:
Greg Kern

Ascension Technology, inc 2805 Wilderness Place

Suite \#900

Boulder, CO 80301

Phone: (303)-417-1418

Fax: (303)-417-1423

EMail:

David King

Sandia National Laboratories

Department 6219

MS-0752

Albuquerque, NM 87185

Phone: (505) 844-8220

Fax: (505) 284-3239

EMail: dking@sandia.gov

Jay Kratochvil

Sandia National Laboratories

P.O. Box 5800, MS-0752

Albuquerque, NM 87124

Phone: (505) 844-0036

Fax: (505) 844-6541

EMail: jakrato@sandia.gov

Ben Kroposki

National Renewable Energy Lab

1617 Cole Boulevard

Golden, CO 80401

Phone: (303)-384-6170

Fax: (303)-384-6790

EMail: kroposkib@tcplink.nrel.gov

Raymond Kruzek

Radiant Technology Corp.

1340 N. Jefferson Street

Anaheim, CA 92807

Phone: (714)-961-0200

Fax: (714)-961-0500

EMail: 


\section{Attendee List}

PV Performance and Reliability Workshop

September 4-6, 1996

Sarah Kurtz

National Renewable Energy Lab

1617 Cole Boulevard

Golden, CO 80401

Phone: (303) 384-6475

Fax: (303) 384-6531

EMail:

Richard Lambeth

Arizona Public Service Co.

P.O. Box 53933, MS-3035

Phoenix, AZ 85072-3933

Phone: (602) 371-6628

Fax: (602) 371-7717

EMail: rlambeth@apsc.com

Cary Lane

NEOS Corporation

165 S. Union Blvd.,

Suite 260

Lakewood, CO 80228

Phone: (303)-980-1969

Fax: (303)-980-1030

EMail: caryneos@aol.com

\section{Len Loomans}

Remote Power, Inc.

12301 N. Grant Street

Suite 230

Denver, CO 80241

Phone: (303) 452-9383

Fax: $\quad$ (303) $452-9519$

EMail:

Warren Louis

ITN Energy Systems

12401 W. 49th Avenue

Wheat Ridge, CO 80033

Phone: (303) 420-1141

Fax: (303) 420-1551

EMail:
Alexander Maish

Sandia National Laboratories

P.O. Box 5800, MS-0752

Albuquerque, NM 87185

Phone: (505)-844-8771

Fax: (505) 844-6548

EMail: abmaish@sandia.gov

Thomas McMahon

National Renewable Energy Lab

1617 Cole Boulevard

Golden, CO 80401

Phone: (303) 384-6762

Fax: (303) 384-6790

EMail:

Peter Meyers

ITN Energy Systems

12401 West 49th Avenue

Wheat Ridge, CO 80033

Phone: (303) 420-1141

Fax: (303) 420-1551

EMail:

Richard Mitchell

National Renewable Energy Lab

1617 Cole Boulevard

Golden, CO 80401

Phone: (303)-384-6479

Fax: (303)-384-6490

EMail:

Daryl Myers

National Renewable Energy Lab

1617 Cole Boulevard

Golden, CO 80401

Phone: (303)-384-6768

Fax: (303)-384-6790

EMail: 


\section{Attendee List}

PV Performance and Reliability Workshop

September 4-6, 1996

George O'Sullivan

Abacus Controls Inc.

80 Readington Road

Somerville, NJ 08876

Phone: (908) 526-6010

Fax: $\quad$ (908) 526-6866

EMail:

Carl Osterwald

National Renewable Energy Lab

1617 Cole Boulevard

Golden, CO 80401

Phone: (303) 384-6764

Fax: (303) 384-6790

EMail: carl_osterwald@nrel.gov

Larry Ottoson

National Renewable Energy Lab

1617 Cole Boulevard

Golden, CO 80401

Phone: (303) 384-6188

Fax: (303) 384-6790

EMail:

Philip Overholt

U.S. Department of Energy

1000 Independence Avenue, S.W.

Washington, DC 20585-0121

Phone: (202) 586-8110

Fax: (202) 586-5127

EMail: philip.overholt@hq.doe.gov

John Pern

National Renewable Energy Lab

1617 Cole Boulevard

Golden, CO 80401

Phone: (303)-384-6615

Fax: (303)-384-6490

EMail:
Art Peterson

Niagara Mohawk Power Corp.

300 Erie Blvd West

Research \& Development, D-G

Syracuse, NY 13202

Phone: (315)-428-6654

Fax: (315)-428-6503

EMail:

Michael Quintana

Sandia National Laboratories

P.O. Box 5800, MS-0752

Org. 6219

Albuquerque, NM 87124

Phone: (505) 844-0474

Fax: (505) 844-6541

EMail:

Markus Real

Alpha Real Ag

Feldeggstrasse 89

Zurich $\mathrm{CH}-8008$

Switzerland

Phone: 41-1-383 0208

Fax: $\quad 41-1-3831895$

EMail:

Geoffrey Rich

Solar Cells, Inc.

1702 N. Westwood Avenue

Toledo, $\mathrm{OH} 43607$

Phone: (419)-534-3377

Fax: (419)-534-2794

EMail:

Lorenzo Roybal

National Renewable Energy Lak

1617 Cole Boulevard

Golden, CO 80401

Phone: (303) 384-6489

Fax:

EMail: 


\section{Attendee List}

PV Performance and Reliability Workshop

September 4-6, 1996

\author{
Steve Rummel \\ National Renewable Energy Lab \\ 1617 Cole Boulevard \\ Golden, CO 80401 \\ Phone: (303)-384-6287 \\ Fax: (303)-384-6790 \\ EMail:
}

Dan Sanchez

U.S. Department of Energy

P.O. Box 5400

Albuquerque, NM 87185

Phone: (505)-845-4417

Fax: (505)-845-4430

EMail:

Robert Spotts

Photocomm, Inc.

7681 E. Gray Road

Scottsdale, AZ 85260

Phone: (602)-948-8003

Fax: (602)-483-6431

EMail:

Byron Stafford

National Renewable Energy Lab

1617 Cole Boulevard

Golden, CO 80401

Phone: (303)-384-6426

Fax: (303)-384-6490

EMail:

John Stevens

Sandia National Laboratories

P.O. Box 5800, MS-0753

Albuquerque, NM 87185-0753

Phone: (505) 844-7717

Fax: (505) 844-6541

EMail: jwsteve@sandia.gov
Troy Strand

Advanced Energy Systems

P.O. Box 262 Riverview Mill

Wilton, $\mathrm{NH} 03086$

Phone: (603) 654-9322

Fax: (603) 654-9324

EMail: tstrand@advancedenergy.com

Steven Strong

Solar Design Associates, Inc.

P.O. Box 242

Harvard, MA 01451

Phone: (508) 456-6855

Fax: (508) 456-3030

EMail: sda@solardesign.com

Thomas Surek

National Renewable Energy Lab

1617 Cole Boulevard

Golden, CO 80401

Phone: (303)-384-6471

Fax: (303)-384-6530

EMail:

Amy Swartzlander

National Renewable Energy Lab

1617 Cole Boulevard

Golden, CO 80401

Phone: (303) 384-6664

Fax:

EMail:

Roger Taylor

National Renewable Energy Lab

1617 Cole Boulevard

Golden, CO 80401

Phone: (303)-384-6432

Fax: (303)-384-6490

EMail: 


\section{Attendee List}

PV Performance and Reliability Workshop

September 4-6, 1996

Cathy Thomas

AstroPower, Inc.

58 Democrat Raod

Mickleton, NJ 08056-1104

Phone: (302) 366-0400

Fax: (302) 368-6474

EMail: cjthomas@astropower.com

Holly Thomas

National Renewable Energy Lab

1617 Cole Boulevard

Golden, CO 80401

Phone: (303)-384-6400

Fax: (303) 384-6490

EMail:

Michael Thomas

Sandia National Laboratories

P.O. Box 5800

MS-0753

Albuquerque, NM 87185-0753

Phone: (505)-844-1548

Fax: (505)-844-6541

EMail:

John Thornton

National Renewable Energy Lab

1617 Cole Boulevard

Golden, CO 80401

Phone: (303)-384-6469

Fax: (303)-384-6490

EMail:

Eric Tornstrom

ASE Americas

4 Suburban Park Drive

Billerica, MA 01821

Phone: (508) 667-5900 x231

Fax: (508) 663-7555

EMail:
Tim Townsend

Endecon

Box 354

Davis, CA 95617

Phone: (916)-753-0795

Fax: $\quad$ (916)-753-8469

EMail:

John Tuttle

National Renewable Energy Lab

1617 Cole Boulevard

Golden, CO 80401

Phone: (303)-384-6534

Fax: (303)-384-6430

EMail:

Harin Ullal

National Renewable Energy Lab

1617 Cole Boulevard

Golden, CO 80401

Phone: (303)-384-6486

Fax: (303)-384-6430

EMail: ullal@nrel.gov

G.G. Ventre

Florida Solar Energy Center

1679 Clearlake Road

Cocoa; FL 32922

Phone: (407) 638-1470

Fax: $\quad$ (407) 638-1010

EMail: ventre@fsec.ucf.edu

Bolko von Roedern

National Renewable Energy Lab

1617 Cole Boulevard

Golden, CO 80401

Phone: (303)-384-6480

Fax: (303)-384-6531

EMail: vonroedb@tcplink.nrel.gov 


\section{Attendee List}

PV Performance and Reliability Workshop

September 4-6, 1996

William Wallace

National Renewable Energy Lab

1617 Cole Boulevard

Golden, CO 80401

Phone: (303)-384-6476

Fax: (303)-384-6490

EMail:

John Webb

National Renewable Energy Lab

1617 Cole Boulevard

Golden, CO 80401

Phone: (303) 384-6703

Fax: (303) 384-6604

EMail:

Chuck Whitaker

Endecon Engineering

3160 Crow Canyon Road

Ste.\# 240

San Ramon, CA 94583

Phone: (510)-867-3360

Fax: (510)-867-3362

EMail: chuckw@endecon.com

John Wiles

New Mexico State University

Southwest Technology

Development Inst.

Box 30001, Dept. 3 Solar

Las Cruces, NM 88003

Phone: (505)-646-6105

Fax: (505)-646-3841

EMail:

Dennis Willett

Siemens Solar Ind.

P.O. Box 6032

Camarillo, CA 93010

Phone: (805) 388-6279

Fax: (805) 388-6580

EMail: dwillitt@vcnet.com
Ed Witt

National Renewable Energy Lab

1617 Cole Blvd.

Golden, CO 80401

Phone: (303)-384-6402

Fax: (303) 384-6481

EMail: witt@tcplink.nrel.gov

John Wohlgemuth

Solarex

630 Solarex Ct.

Frederick, MD 21703

Phone: (301)-698-4375

Fax: (301)-698-4201

EMail: jwohlgemuth@solarex.com

Ken Zweibel

National Renewable Energy Lab

1617 Cole Boulevard

Golden, CO 80401

Phone: (303)-384-6441

Fax: (303)-384-6430

EMail: zweibelk@tcplink.nrel.gov 


\section{Opening Session}




\title{
DOE Perspectives on PV
}

\author{
Presented by \\ Philip N. Overholt
}

Office of Photovoltaic and Wind Technologies 


\section{Status of DOE PV Program}

- Budget

- FY 96 adjustments complete

- FY 97 Budget looks healthy

$\vec{\sim}$

- Selected Program Areas

- PV BONUS delivering products for buildings.

- PV MaT bringing module and system costs down.

- UPVG placing systems in the field.

- PV4U clearing barriers. 


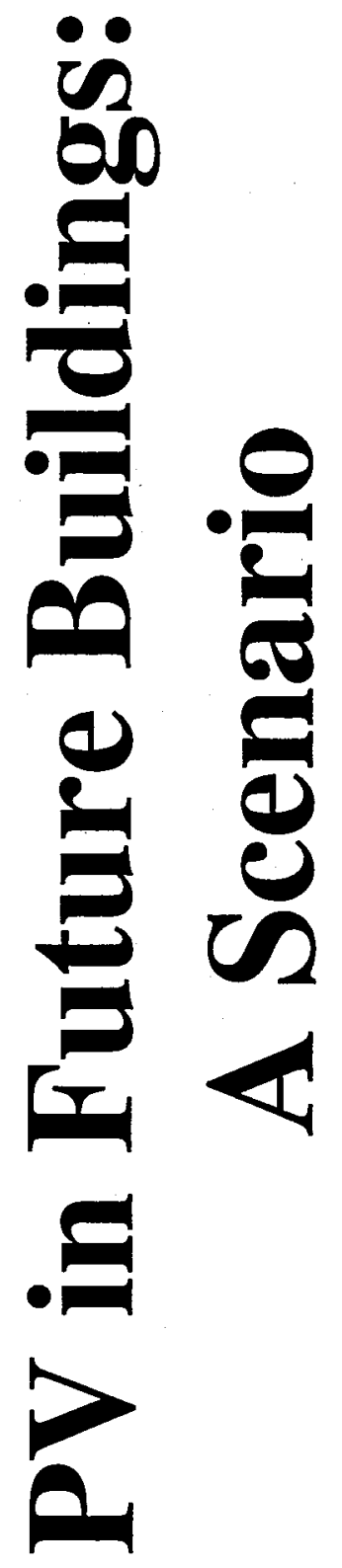




\section{The Future of Buildings}

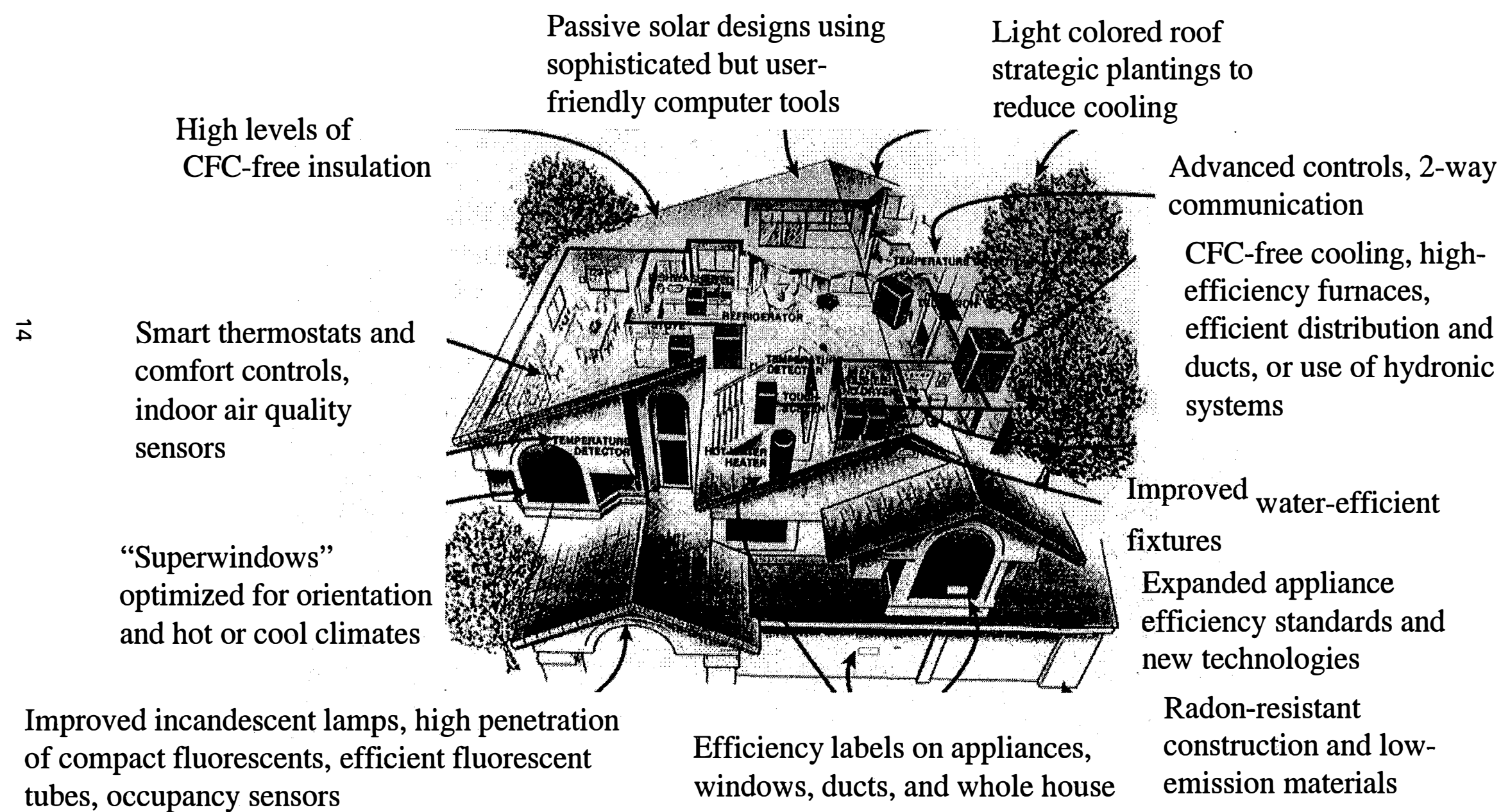

Lawrence Berkeley Laboratory, From the Lab to the Marketplace, 1995 


\section{PV Potential}

$\vec{v}$

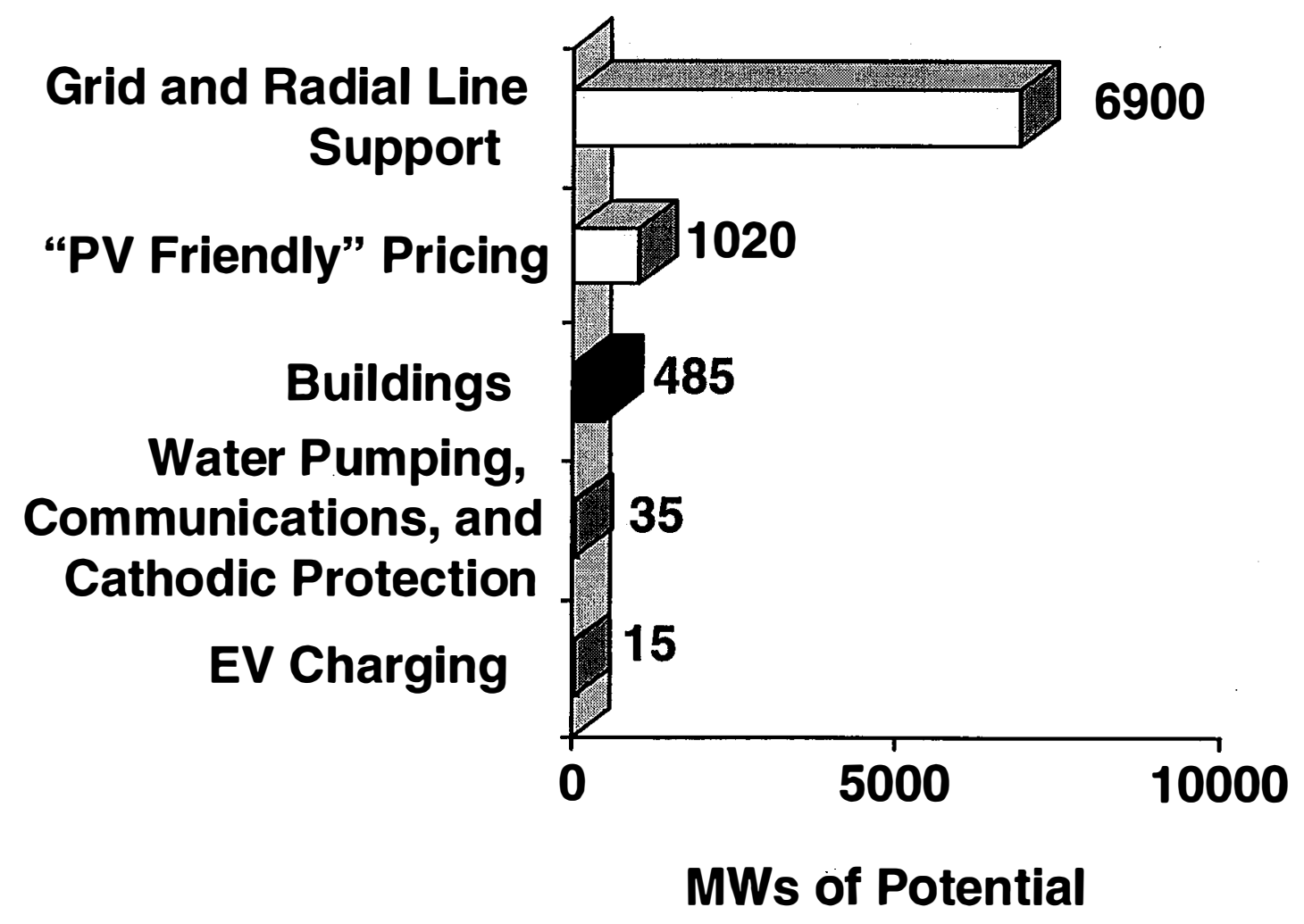




\section{Potential BIPV Market Penetration, with IRP Benefits}
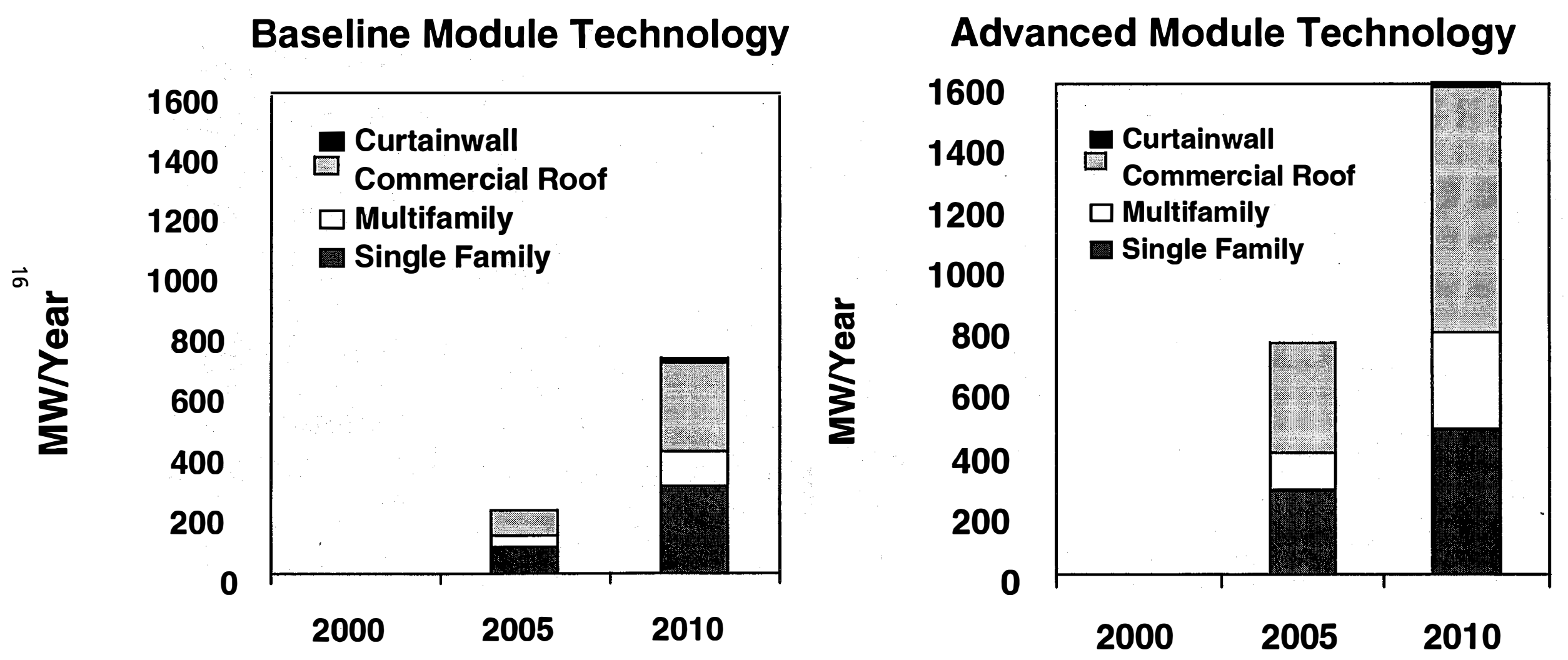

Source: AD Little BIPV Analysis and U.S. Market Potential, 1995 


\section{Niche Markets for BIPV}

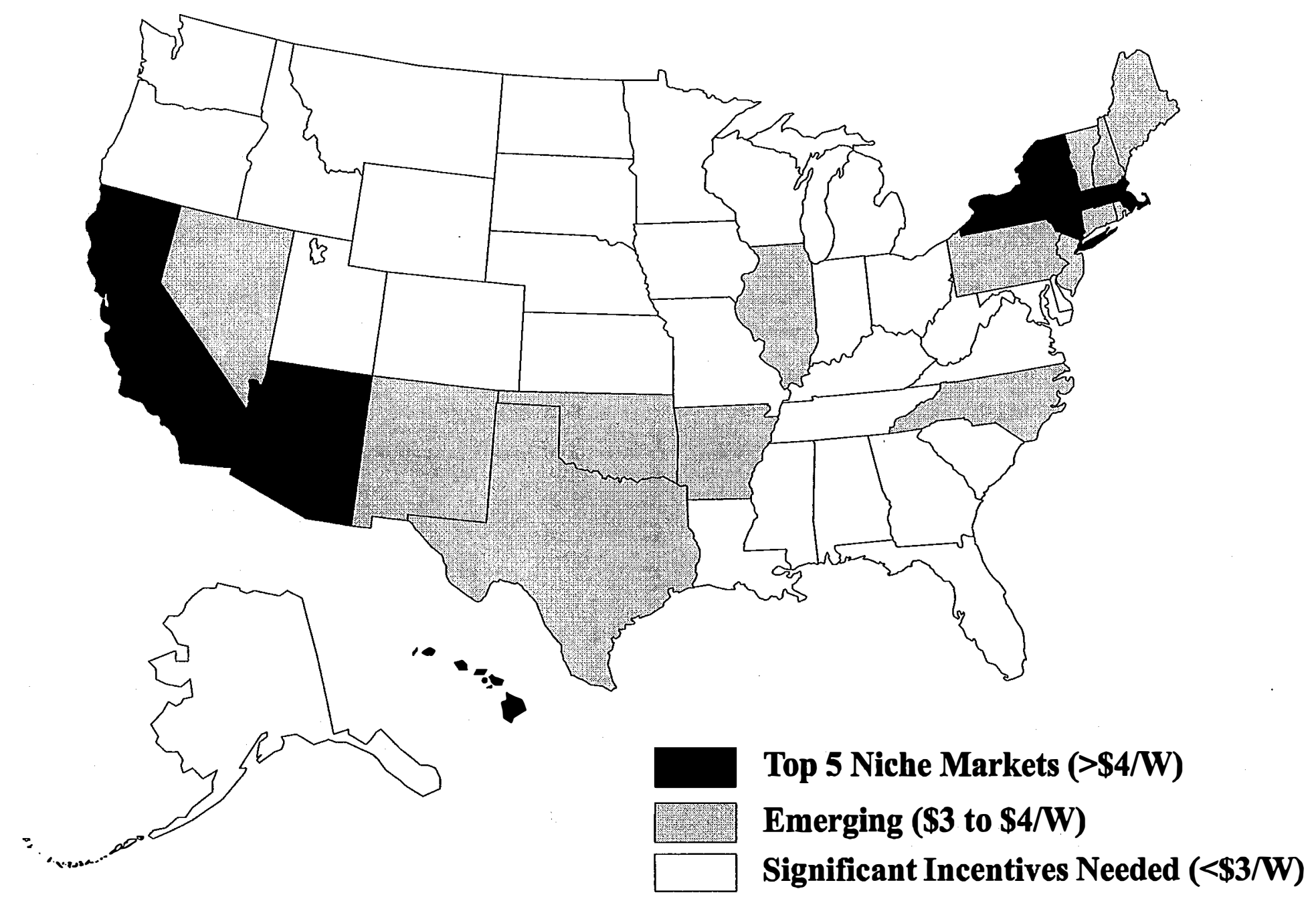

"Niche Markets for Grid-Connected PV," Wenger, Herig, Taylor, Eiffert, Perez, IEE PV Specialists Conference , April 1996 


\section{Utility PV System Cost History and States by Breakeven PV Price}

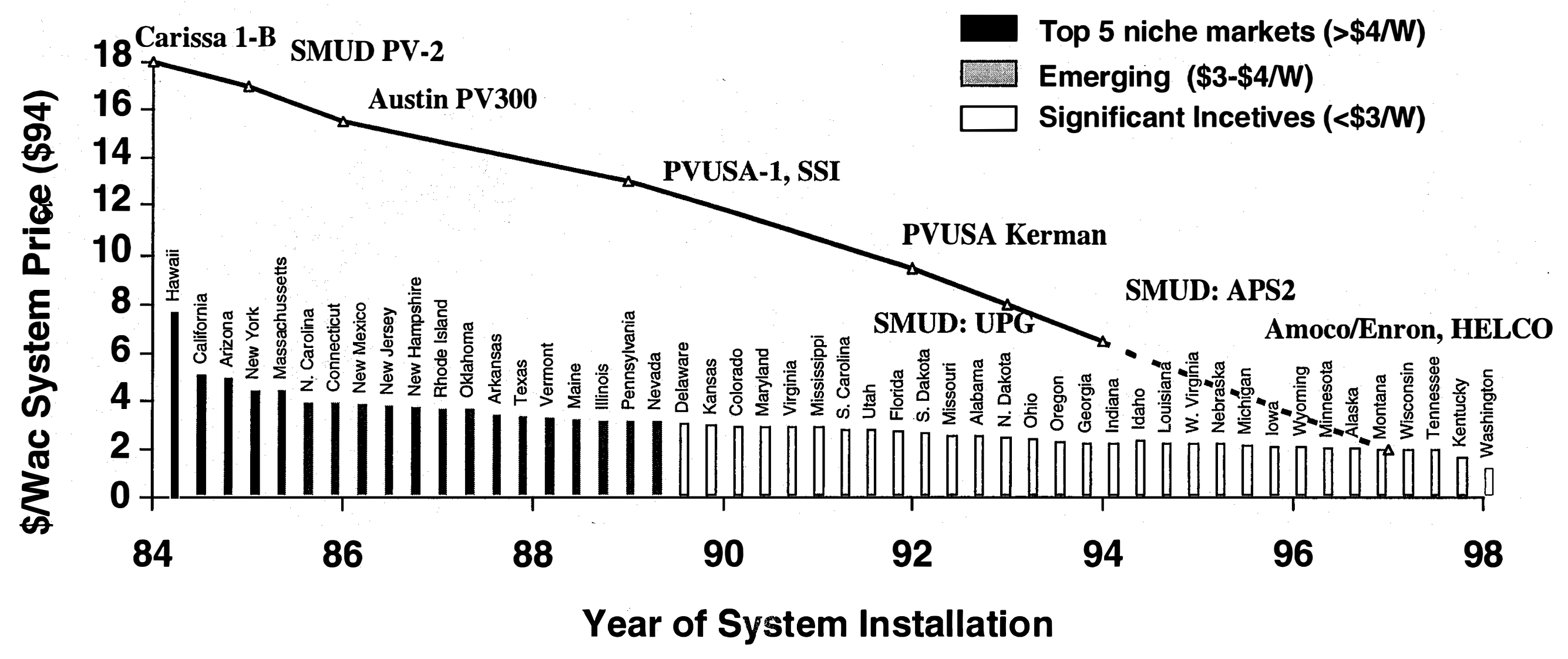

"Niche Markets for Grid-Connected PV," Wenger, Herig, Taylor, Eiffert, Perez, IEE PV Specialists Conference , April 1996 Dan Shugar and UPVG for system costs. 


\section{Technology Development: PVMaT}

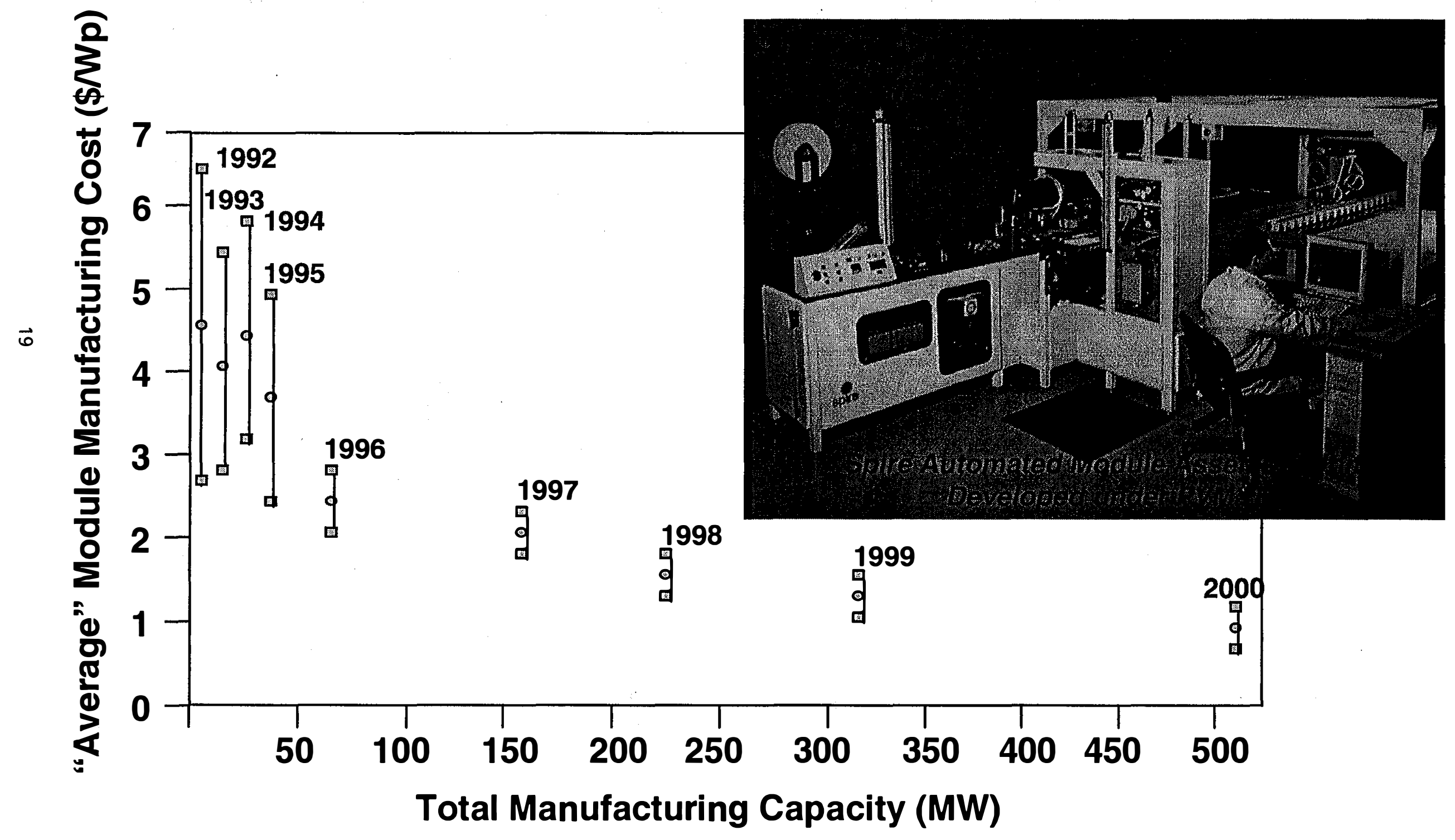




\section{A 100,000 Roof PV Scenario}

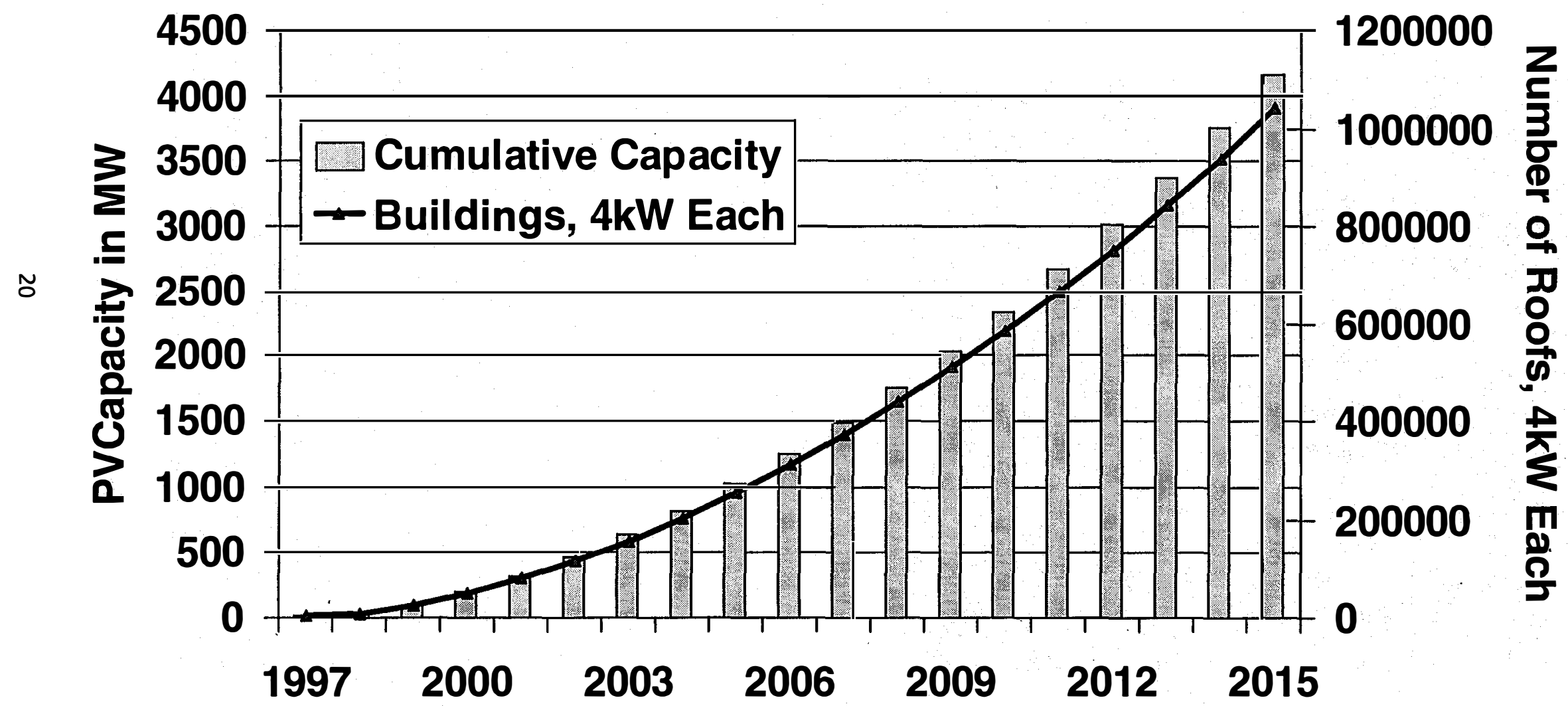




\section{Georgetown University}

Georgetown University Intercultural Center $337 \mathrm{kWp}$, Solarex Modules, 1983

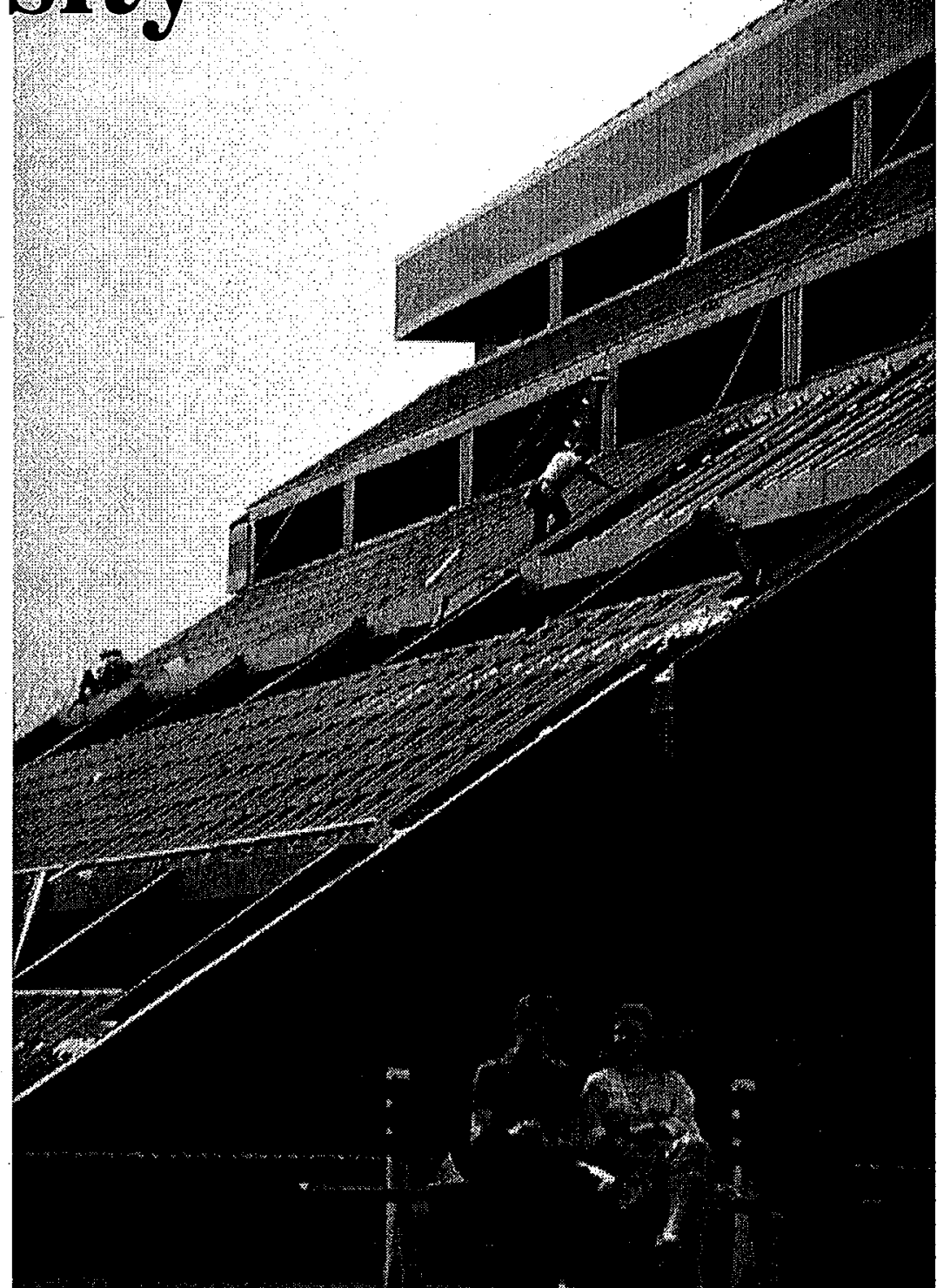




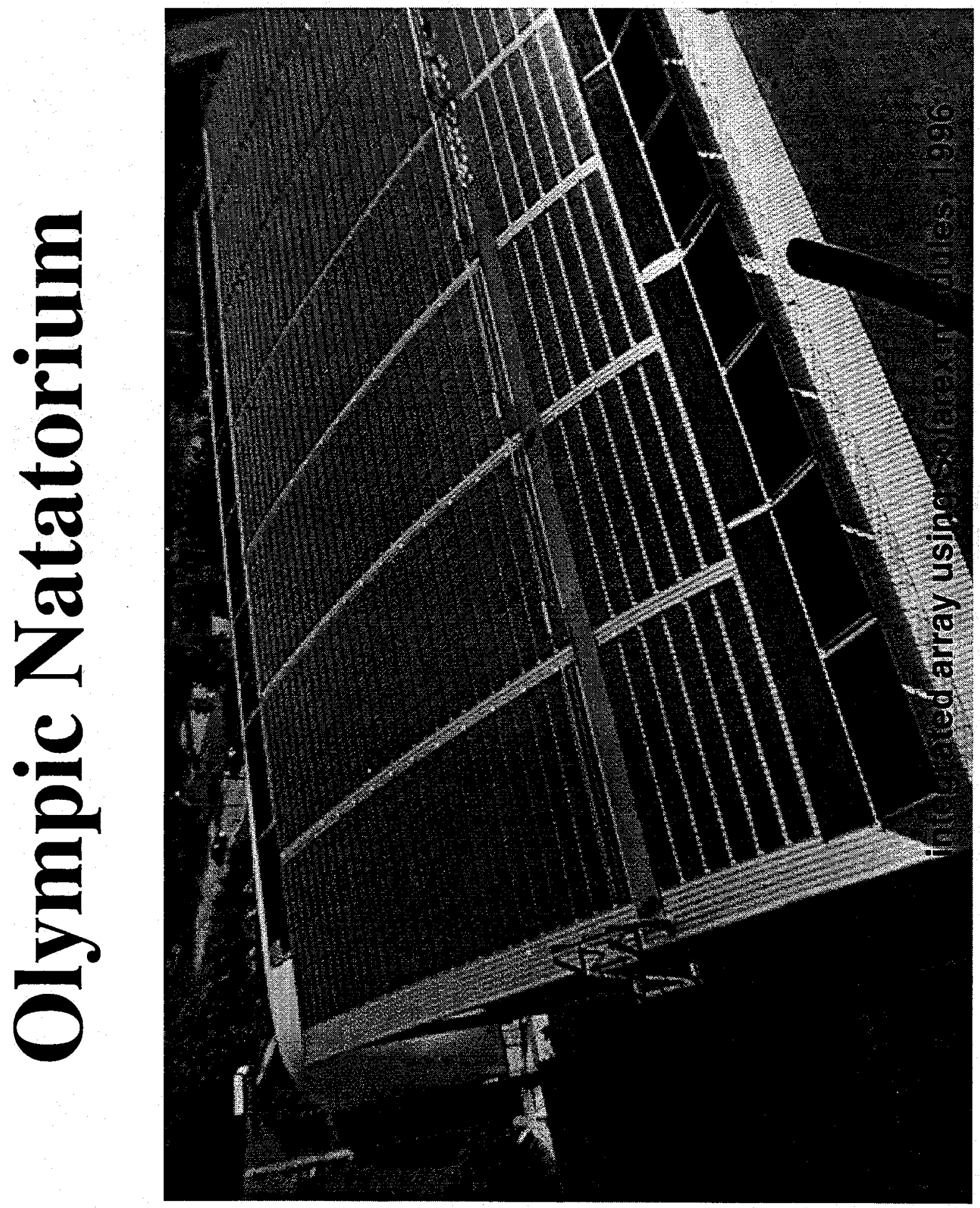




\section{Natatorium Walkway}

$\tilde{\omega}$

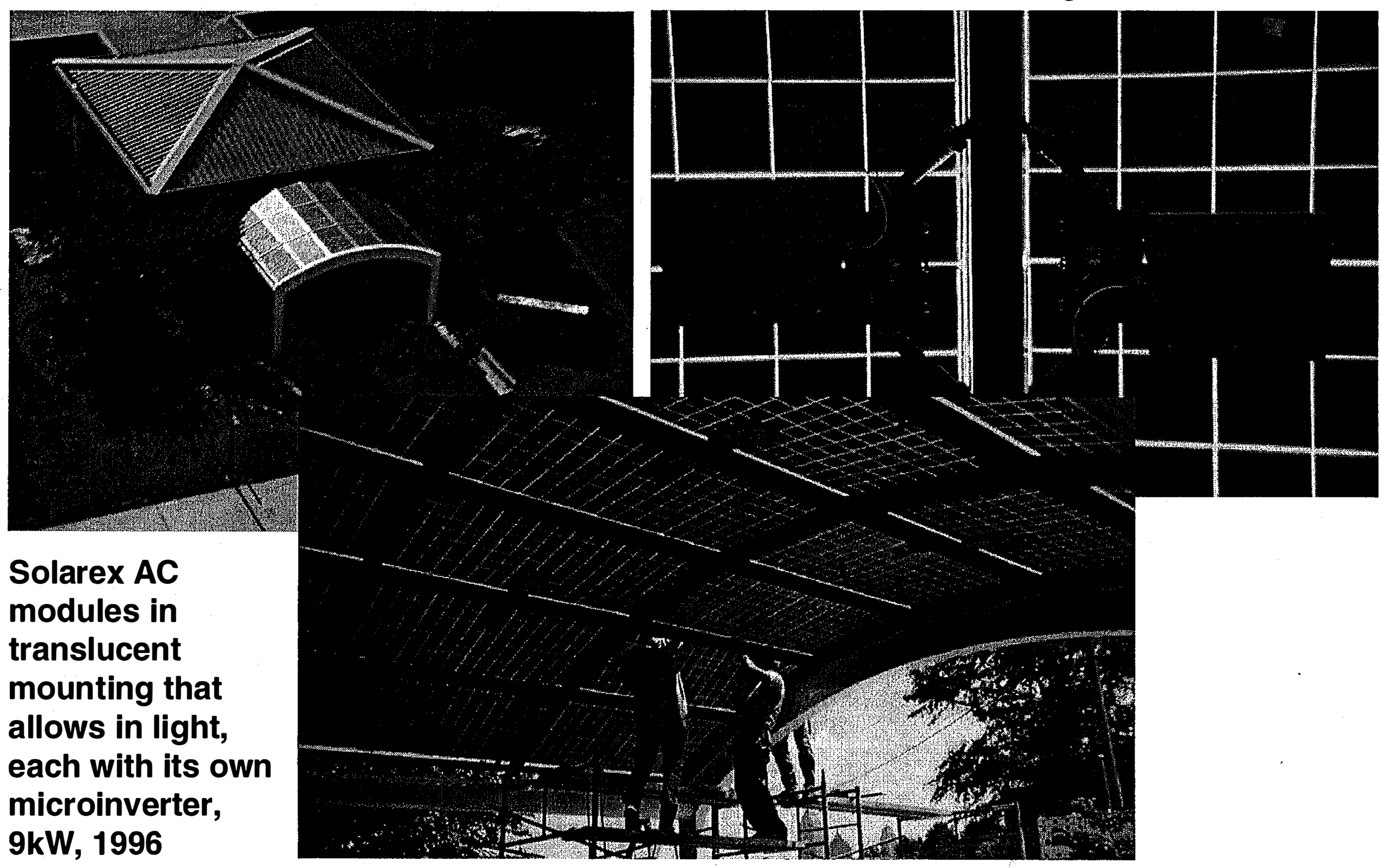



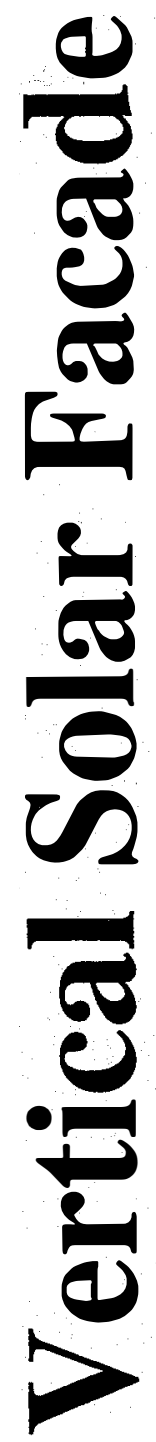

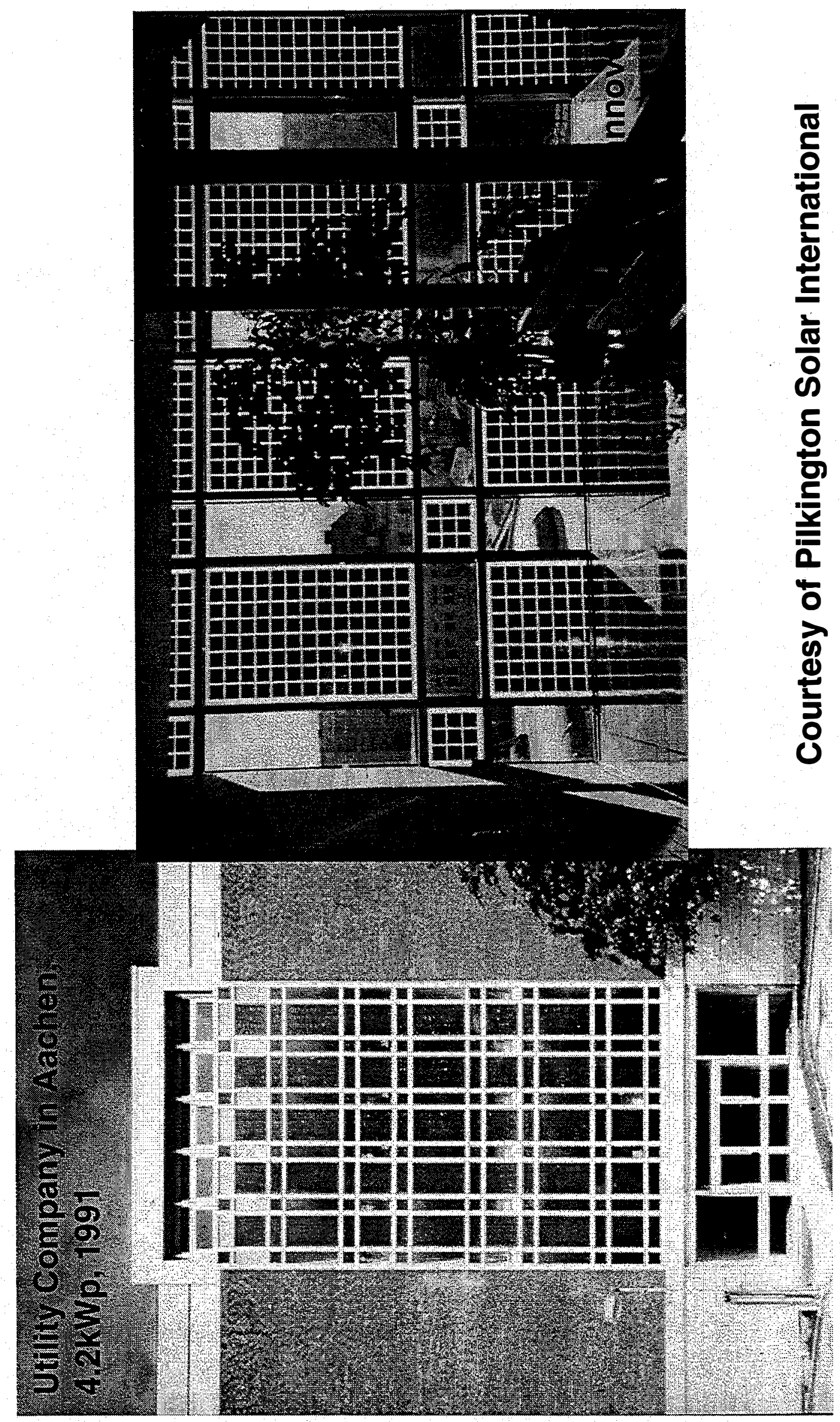




\section{Tilted Solar Facade}

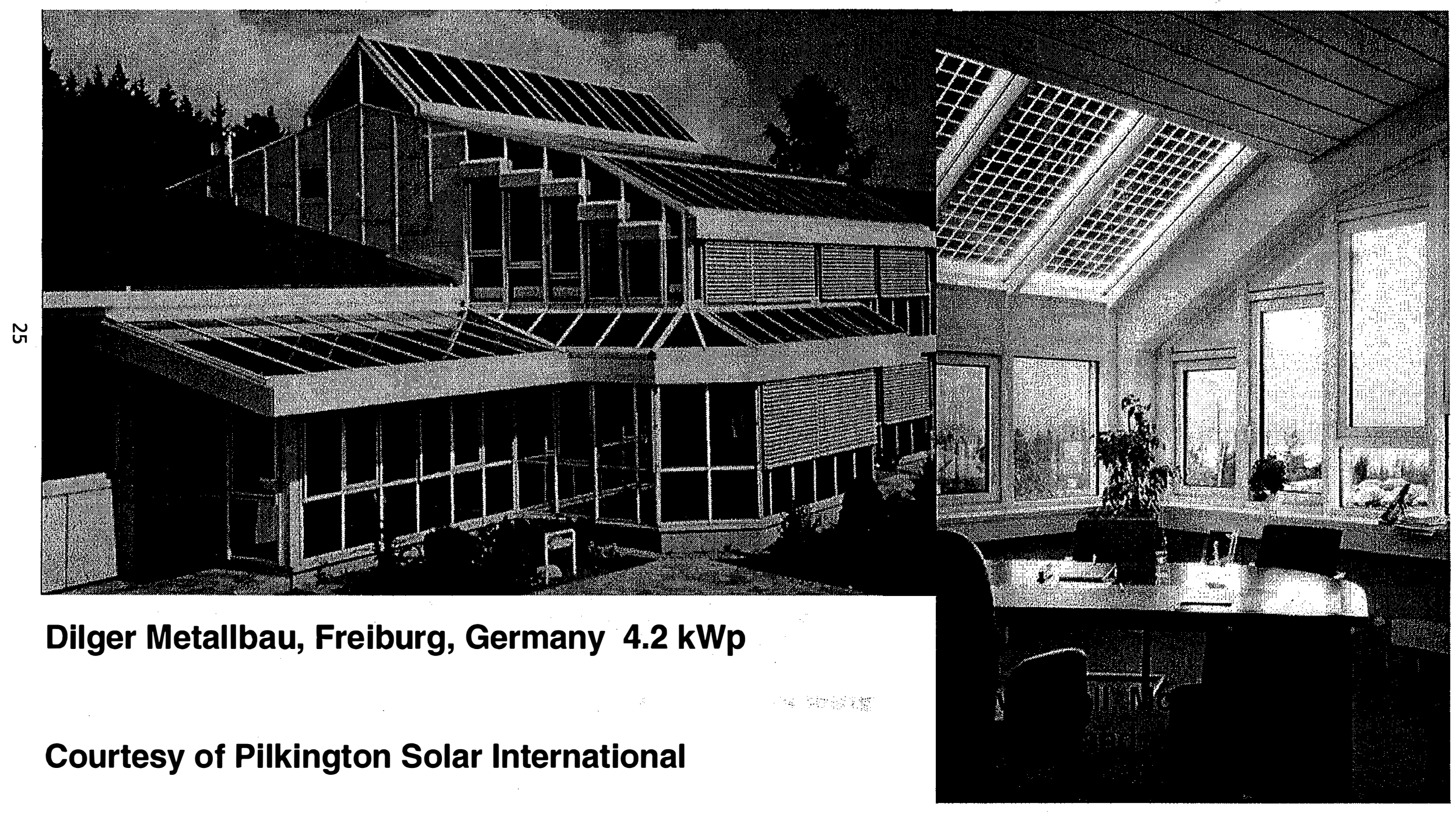




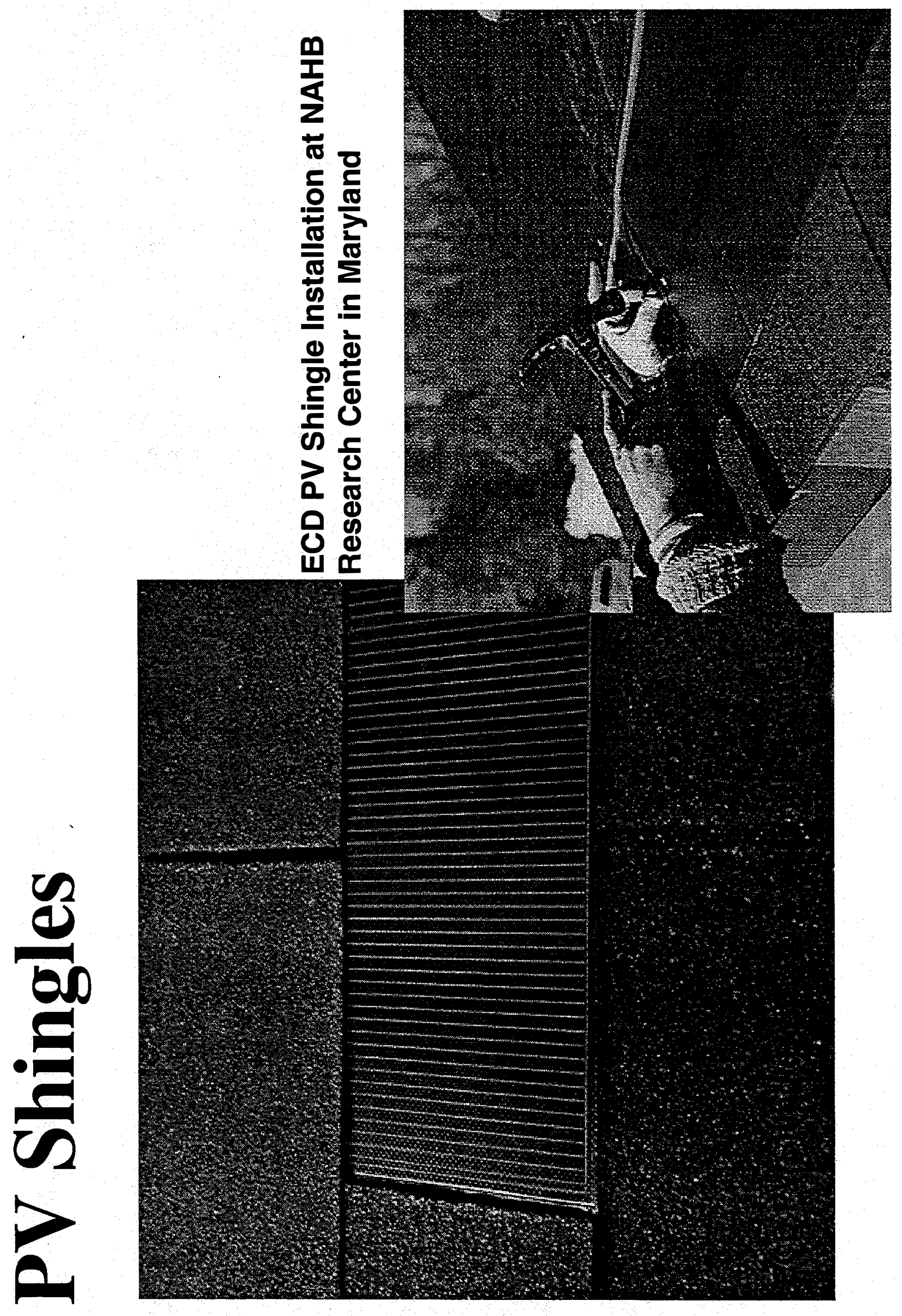



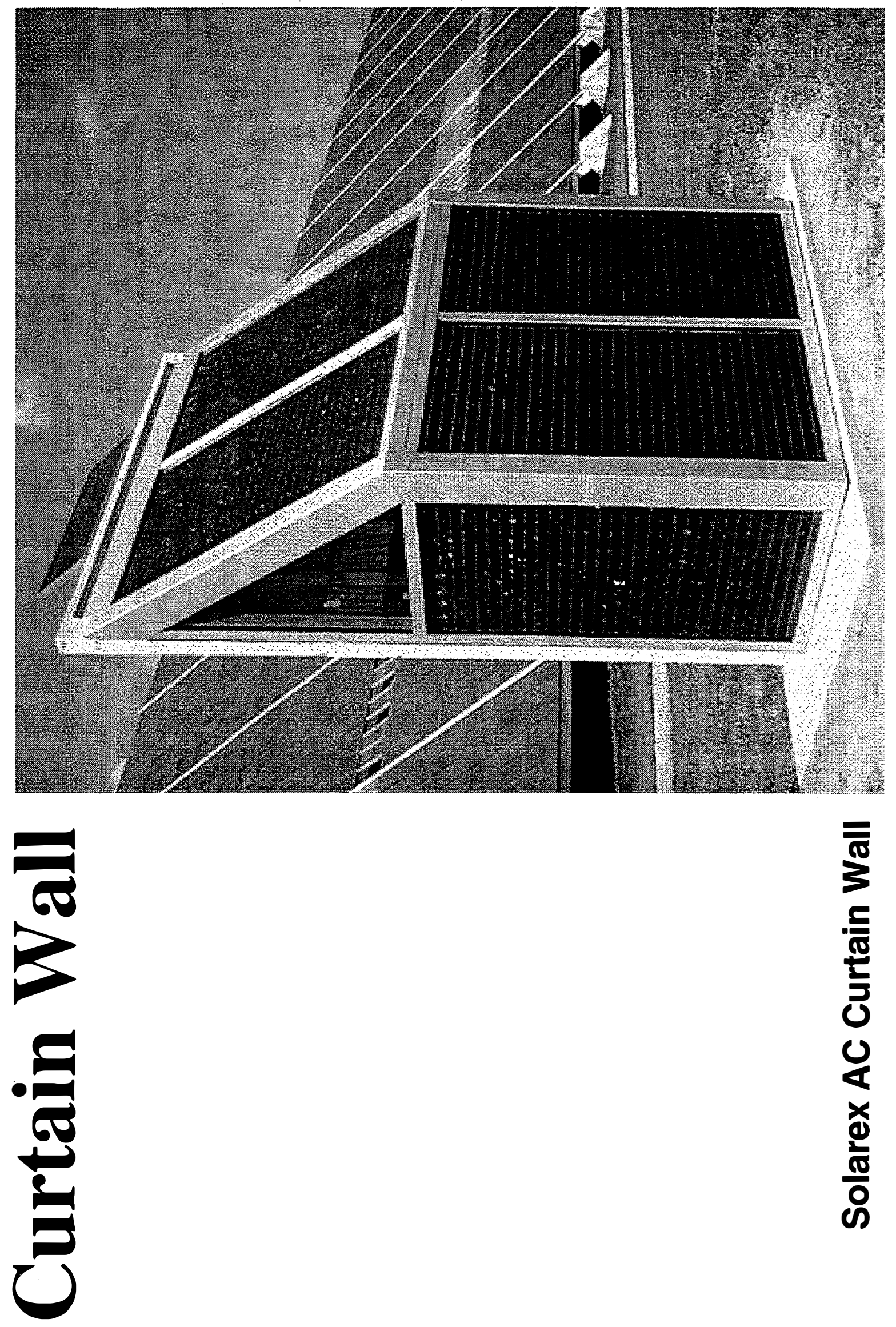


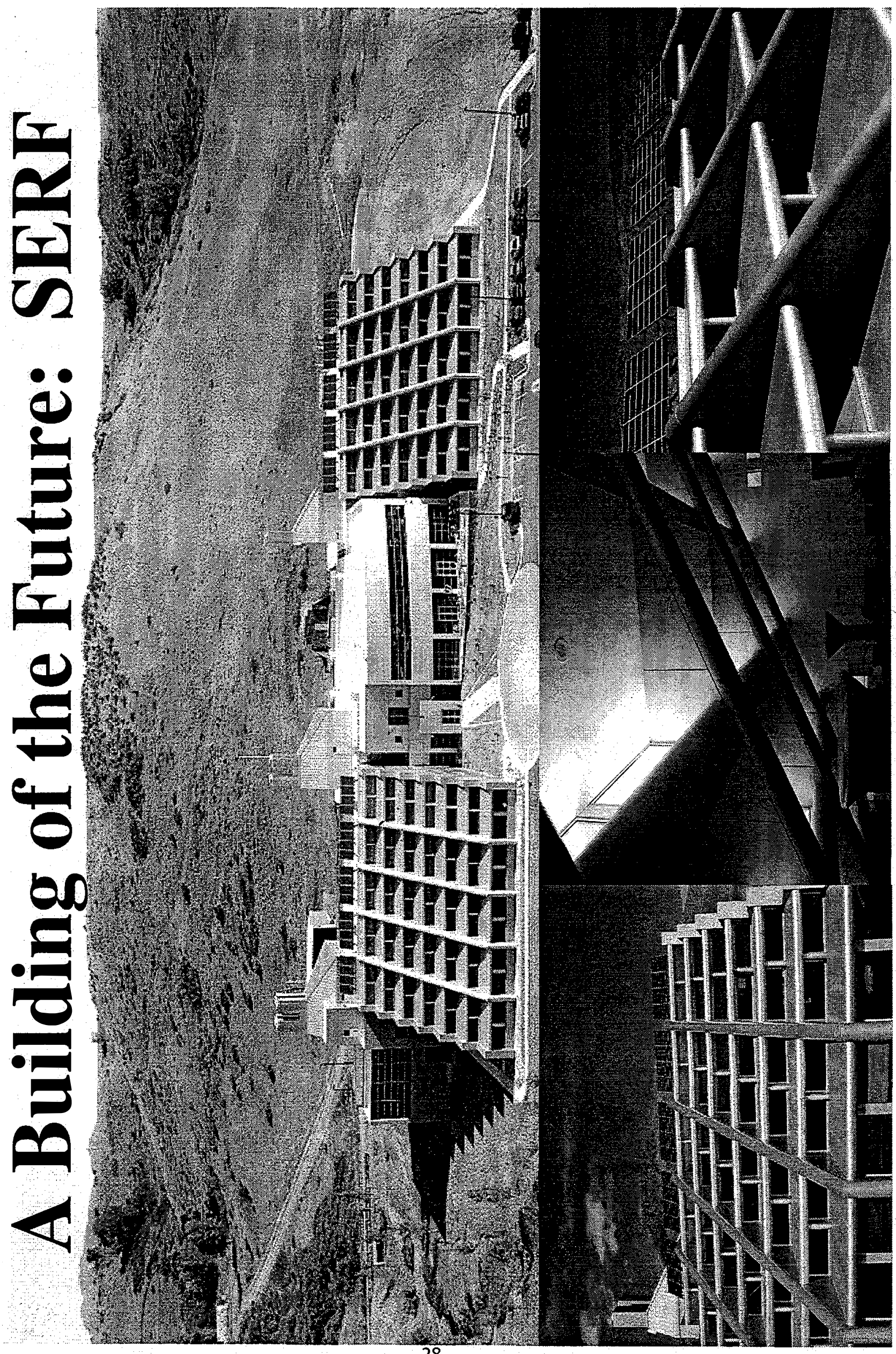




\title{
SUMMARY: "OVERVIEW OF CURRENT ISSUES: PV CELL AND MODULE PERFORMANCE AND RELIABILITY"
}

\author{
A. W. Czanderna \\ Center for Performance Engineering and Reliability \\ National Renewable Energy Laboratory \\ Golden, CO 80401-3393
}

The organizing committee asked I place in context and summarize the papers at this workshop dealing with PV cell and module performance and reliability (CMPAR). The presentation (Fig. 1) was divided into three parts: (1) overview of the interrelationship between performance and reliability, (2) a summary of the talks presented about CMPAR, and (3) the current status of reliability issues in cell and module materials and components. The overheads I used are attached as Figs. $1-24$, except those I used for (2) are redundant with materials provided by the authors elsewhere in these proceedings. For further reading, I will refer extensively to a recent article [1] entitled "Encapsulation of PV Modules Using Ethylene Vinyl Acetate Copolymer as a Pottant: A Critical Review," including figures or sections in this reference, e.g., [1, Fig. 1] means see Fig. 1 in ref. 1 in which more written detail is given.

The overall goals of CMPAR R\&D are to measure the performance with time and to learn how to eliminate the causes of performance losses (Fig. 2). Improving the stability of systems and arrays can be included by suitable word changes as given in the third bullet. The crucial importance of module stability is illustrated in Fig. 3 in which an arbitrarily chosen 50 watt module is used to illustrate the consequences of performance degradation for all reasons, including those in a system of operating modules. The least amount of system losses is $1 \% / y r$, the average of more than a dozen systems reported is $2.5 \% / \mathrm{yr}$, and the most extreme case at Carrisa Plains is $70 \%$ in 7 years (not plotted) [1, Section 2]. The dashed lines show linear and other possible extrapolations to 30 years. No accurate projections can be made with what we know today. Yet, a projection of power delivered vs time must be made if the life-cycle cost (Fig. 4) is to be determined. Who can imagine anyone making a multibillion dollar investment decision to produce electricity from PV without having a dependable service lifetime prediction? We use the words performance, reliability, stability, and durability when in reality we want to use service life or service lifetime prediction (Fig. 4). ASTM definitions for several key words important to CMPAR are listed in Fig. 5 in which it is clear that more than durability is needed. The major elements for service lifetime prediction (SLP) of devices like PV cells, modules, etc. are well known (Fig. 6); details about SLP [1, Section 6; 2,3] and how it can be applied for improved or new pottant materials [4] are available.

Although about a cumulative $500 \mathrm{MW}$ of PV modules have been deployed, who among us can assure the first bullet in Fig. 6 has been satisfied? Referring to Fig. 7 [1, Section 1.2.1], we note for contemporary crystalline $\mathrm{Si}$ modules (both pc and single crystalline) that choices are also available for superstrates (glass with and without $\mathrm{Ce}$ as well as polymers), pottants (A9918 EVA, 15295 EVA, 4 experimental EVA-based formulations being tested by Springborn, and an even greater number of experimental EVA-based formulations developed and being tested at NREL), AR coatings with and without metalization in contact with the pottant, etc. We are aware of the tremendous challenges for collecting solar energy that is economically competitive (Fig. 8) with other sources of power. Furthermore, we are obliged to expose the multilayered stacks for solar energy conversion systems to accelerated weathering environments (Fig. 6, second bullet) as summarized in Fig. 9. We know the interfaces are not stable (Fig. 10), so the concern is kinetics, which means the Arrhenius equation or a variant of it must be used properly [4] for the predominant degradative reaction (Fig. 6, 4th and 5th bullets). The quantified mechanisms are essential for choosing the correct models in bullet 5 of Fig. 6 . The absolutely crucial issue for reducing the cost of the R\&D for making a SLP is to identify a very sensitive parameter related to the performance loss. As K. Emery discussed at the meeting, the I-V measurement may be limited 
to $\pm 1 \%$, but that other measured parameters may be directly related to a performance loss. Sensitive measures of (or parameters relatable to) performance losses are essential for validating (Fig. 6, 7th bullet) the life distribution models for a SLP.

The current status of EVA (Fig. 11) has been summarized thoroughly [1]. As required by a SLP methodology (Fig. 6 bullet 4), the mechanisms of EVA degradation are known [1] and efforts have been completed at NREL to improve the stability of EVA [Fig. 6, 4th bullet]. Both NREL's formulations [5] as well as those being tested by Springborn [6] show a negligible rate of yellowing for the time tested. Caution must be exercised about becoming overoptimistic that EVA is now "fixed" because the absence of discoloration does not guarantee an absence of EVA degradation [1]; many other properties of EVA are important including its low conductivity that enables modules to pass the wet-hi-pot qualification test. At the least, however, the EVAbrowning crisis of 1990 has been postponed until more data are gathered about the true stability of the improved EVA formulations $[5,6]$. Some resources can and should be directed to the manifold other potential problems in cells and modules [Fig. 7 plus interconnects between the cells in a module], as I have repeatedly stated beginning with the PV Performance and Reliability Workshop in 1990 (Fig. 12). John Pern and I are repeatedly asked about proof that performance losses result from EVA browning, so I have included Fig. 13 from work originally presented in 1992 [7], and which is also discussed in our recent paper [1, Section 4.5]. As is seen, accelerated testing at 85 $\pm 2^{\circ} \mathrm{C}$ for 198 days under an RS-4 UV lamp produced a yellow-brown EVA and a loss in the efficiency of this single PV cell of $19 \%$. In this study, the loss in efficiency became progressively larger as the discoloration progressed from light yellow, to yellow, dark yellow, and yellow brown. The study [7] was terminated before a dark-brown EVA similar to that at Carissa Plains was obtained. Future studies of different encapsulation materials and designs should be (and will be at NREL) towards increasing the stability of individual encapsulated operating PV cells after exposures to accelerated degradation in WeatherOmeters, DSET chambers, and solar simulations, all with xenon light sources. A summary of what is and is not known about EVA degradation, originally presented at the 1993 Workshop, has been updated [1, Section 8]; in addition, conclusions and future prospects about EVA as the pottant have been given [1, Section 9].

Based on submitted abstracts, I then summarized the essential content of the presentations by $\mathrm{K}$. Emery, A. Delahoy, I. Eisgruber, T. Townsend, T. Strand, G. Jorgensen, P. Myers, M. Quintana, R. Spotts, R. Hammond, and C. Whitaker and indicated the important issues each would address about cell and module performance and reliability. This was part 2 of my talk, but no figures are included because all authors were asked to include summaries of their talks.

For the third part, Fig. 14 was used to focus attention sequentially on the major materials/components of a pc- or c-Si multilayer stack because they constitute over $90 \%$ of all deployed PV systems. Figures 15 through 20 summarize the current issues in encapsulation R\&D. In Fig. 15, the lack of any R\&D to mitigate soiling losses (4 to $10 \%$ net loss in efficiency) in PV modules is noteworthy. Permeable components to enhance photobleaching of EVA, which mitigates performance losses from yellowing but furthers the actual oxidative degradation of EVA, have only been addressed at low levels of effort. The UV filtering glasses [1, Fig. 38(a)] that successfully retard the rate of yellowing $[5,6]$ have been reported "to solarize," i.e., they lose their "UV-block" of $50 \%$ transmittance at $350 \mathrm{~nm}$ and $\mathrm{Fe}^{+3}$ state, which also means their transmittance in the visible and near IR is reduced. No R\&D is underway to verify these reports; if true, the EVA-discoloration problem may only be postponed for a few years before it will return with a vengeance. In Fig. 17, a broad summary of the present status of pottant R\&D is given; as far as is known, no one is seeking an advanced pottant (next to last bullet). The non-EVA-based pottant used by ASE Americas is not considered the ultimate pottant for encapsulating PV cells and modules [8]. In Fig. 18, other issues have been minimally or not addressed, even though most of the issues have been noted as concerns for long-term PV module reliability. Most importantly, for a SLP (last bullet, Fig. 18), a definition of "failure" (Fig. 19) must eventually be considered by the 
PV community, and this is not a trivial exercise. Clearly, PV modules that have lost $80 \%$ of their original rating but still pumps water will be viewed quite differently by someone at a remote site consisting of a few modules than by a utility executive who has made a multibillion dollar investment decision. In Fig. 20, the essential philosophy for an accelerated lifetime testing program for PV cells, minimodules, and modules and the sequence of work is summarized sequentially (Fig. 20); a technical approach for working with cells and minimodule based on Fig. 20 is given in Fig. 21. In conducting any of the work in Figs. 15-21, it is crucial to learn (Fig. 22) from prior researchers who conducted their work with limited success because of their technical approach could have been better $[1,4]$. The protocol for future studies that can be used to address most of the issues raised in Fig. 7 and Figs. 15-18 is summarized in Figs. 23 and 24. If appropriate resources are provided for PV module encapsulation R\&D, we can anticipate reaching a goal of predicting PV module service lifetimes by 2005 to 2010.

References (All NREL CPs or TPs are available, National Renewable Energy Laboratory, Golden, CO, 80401)

1. A. W. Czanderna and F. J. Pern, Solar Energy Materials and Solar Cells, 43 (1996) In Press for September 1996.

2. R. M. Fischer, et al., "Accelerated Life Testing of Devices with S/S, S/L, and S/G Interfaces," in A.W. Czanderna and A.R. Landgrebe, Guest Eds., Crit. Rev. Surface Chem., 2 (1993) 331 and NREL/CP-412-5007, September, 1992, Chapter 25.

3. H-M. Kim, G. J. Jorgensen, D. E. King, and A. W. Czanderna, "Development of a Methodology for Service Lifetime Prediction of Renewable Energy Devices," in R. J. Herling, Ed., Durability Testing of Nonmetallic Materials, ASTM, W. Conshohocken, PA, 1996, pp. 173-189.

4. A. W. Czanderna and F. J. Pern, Ibid, pp. 204-225.

5. F. J. Pern, S. H. Glick, A. W. Czanderna, and R. DeBlasio, in AIP Conference Proceedings, H. S. Ullal and C. E. Witt, Eds., Vol. 353, 13th NREL Photovoltaics Program Review, Amer. Inst. Physics, NY, 1995, pp. 569-580.

6. W. Holley, et al., Ibid, pp. 636-642.

7. F. J. Pern, "A Comparative Study of Solar Cell Performance Under Thermal and Photothermal Tests," in L. Mrig, Proc. PV Performance and Reliability Workshop, NREL/CP-411-5148, Sept. 1992, pp. 327-344.

8. J. Hanoka, private communication. 


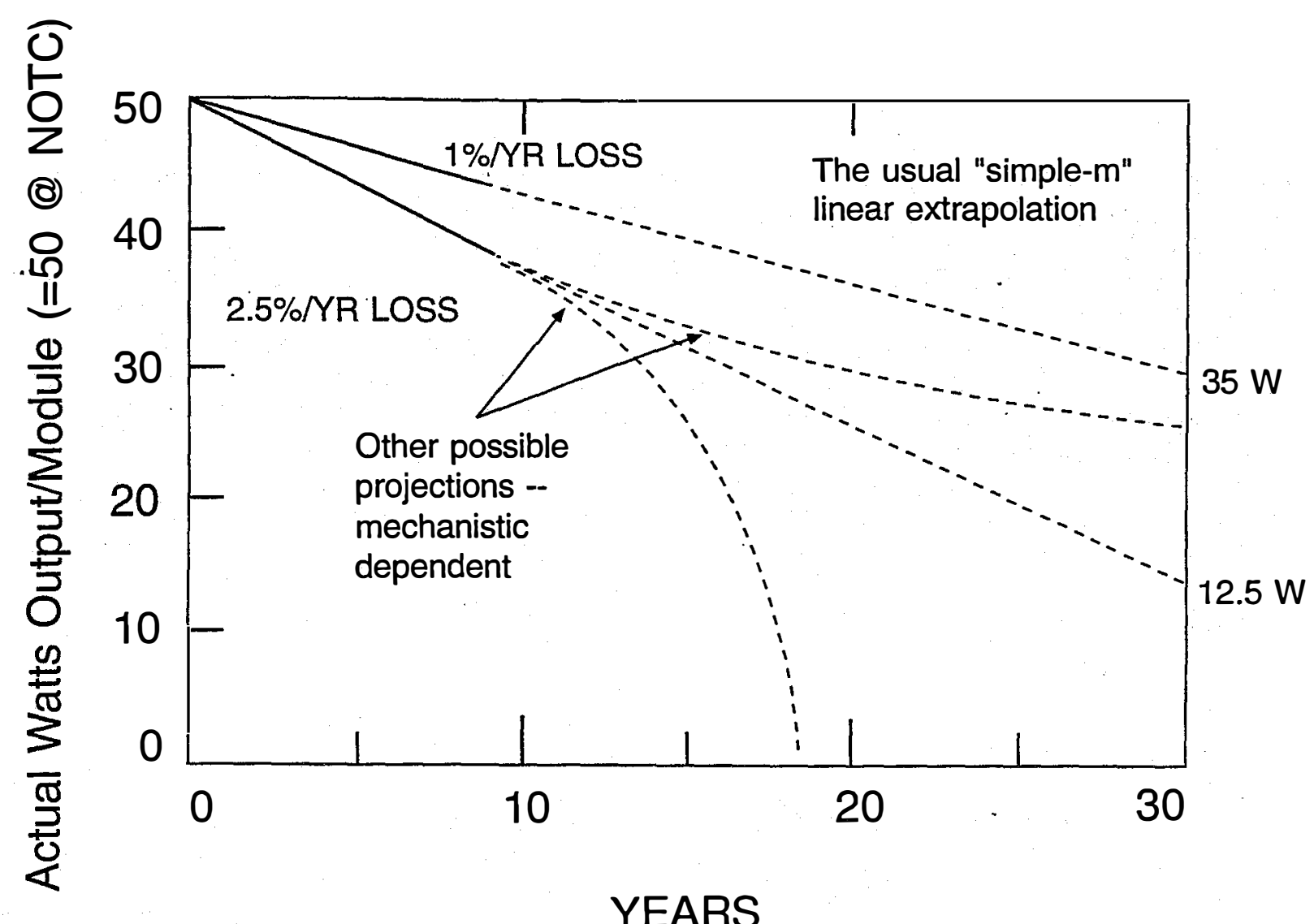

Fig: 3

\section{TECHNOLOGICAL DEVICES}

- $\operatorname{COST}$

- PERFORMANCE

- DURABILITY (RELIABILITY) --Service Lifetime is intended The Actual or Correctly Predicted Service Life is Required to Determine THE LIFE CYCLE COST. The latter involves

- Establishing durability is EXPENSIVE--if done correctly

- Using Accelerated Life Testing (ALT)/Real-time Weathering (RTW)

- Determining Mechanisms that cause performance loss

- Developing Models/Correlating ALT with RTW 


\begin{abstract}
ASTM Definitions
Durability - the capacity of maintaining the serviceability of a product, component, assembly or construction over a specified time.

Serviceability - the capability of a product, component, assembly or construction to perform the function(s) for which it was designed and constructed.

Service life (of a component or material) - the period of time after installation during which all properties exceed the minimum acceptable values when routinely maintained.
\end{abstract}

Accelerated aging test - an aging test in which the degradation of components or materials is intentionally accelerated over that expected in service.

Fig. 5

Improved Stability..PV Cells/Modules

Czanderna, Pern, King, Glick

\title{
Service Lifetime Prediction: Major Elements
}

- Need final design/materials of multilayer stack

- Identify and quantify "stresses" in real-time and accelerated weathering environments (AWE)

- Conduct reliability and durability testing in real-time and AWE and measure the most sensitive parameters possible for performance loss

- Identify/understand degradation of materials/at interfaces including quantifying the mechanisms (mitigate causes if degradation is fast)

- Develop models for correlating AWE and real-time tests (svrl sites)

- Establish stress and materials response data bases including those at different sites

- Develop predictive service lifetime models (for different sites) from above, using statistical approaches and life distribution methods 
Glass or Polynner

Superstrate

(UV Screcn - optional)

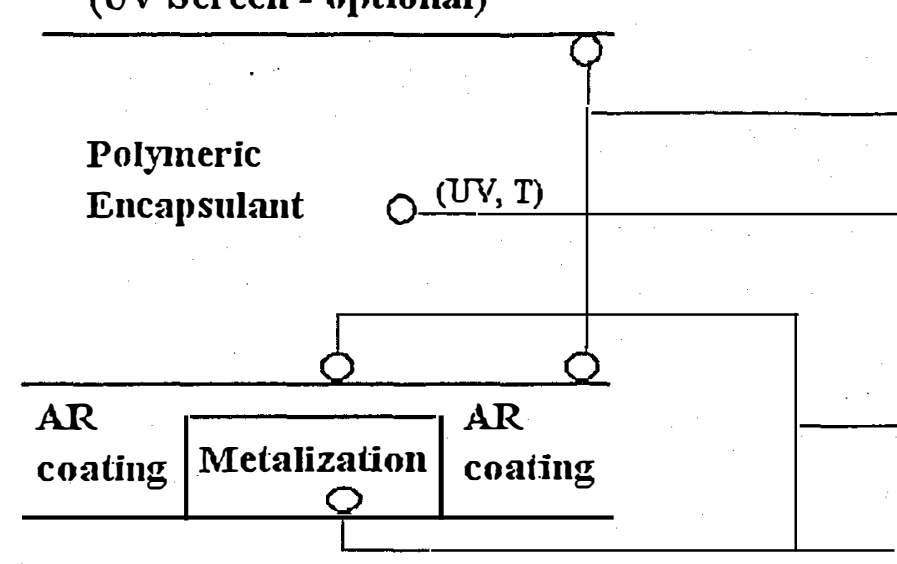

Cations/Anions

Interdiffusion into Polymer

Adhesion/Delamination

$\mathrm{O}_{2}, \mathrm{H}_{2} \mathrm{O}$ Inward Diffusion

Photothermal Oxidative

Degradation Reactions

Oxidation, Corrosion

M/M ion-catalyzed Reactions

E Field-induced Migration

Contact Rèsistance

Solar Cell Material

Polymeric Encapsulant

Substrate

Fig. 7

PV Encapsulant Lifetimes

Czanderna/Pem

\section{Solar Environment and Collecting Solar Energy}

- Major problem in solar energy technologies is not discovering how to collect the radiant flux, but how to collect it cheaply. Thus,

- EVA was chosen versus more expensive polymers/better properties and noting that

- Incident solar power is typically 500 to $1000 \mathrm{~W} / \mathrm{m}^{2}$

- Large collection areas are needed

- Materials used, production processes, operating and maintenance of the system-must be cheap

- Multilayered stacks of thin films are used 


\section{Stresses on Man-Made Solar Energy Conversion Systems}

- Alter collection device stability-hence, life cycle cost

- Stresses (as well as synergism among them) include

- UV radiation

- T and diurnal and annual cycles in T

- Relative humidity

- Other atmospheric gases and pollutants

- Other factors include rain, hail, dust, wind, thermal expansion mismatches, condensation/evaporation, of $\mathrm{H}_{2} \mathrm{O}$, etc.

- Need stable materials and interfaces

Fig. 9

\section{POTTANT/INTERFACES STABILITY}

- Thermodynamically unstable -- always in higher G state

- Always want a lower energy surface

- "Stability" depends on kinetic processes: composition

- At any $\mathrm{T}$ (or set of degradation parameters), ONE reaction usually predominates

- Typically, many reaction paths with different $\mathrm{E}_{\mathrm{A}}$. 
EVA DEGRADATION MECHANISMS THAT ARE KNOWN

- Deacetylation of vinyl acetate pendant group results from $\mathrm{T}$ or UV

- Photothermal (T and UV) produces acetic acid and polyenes --($\mathrm{C}=\mathrm{C}-)_{\mathrm{m}}-($ Higher $\mathrm{T}$, UV flux and more energetic UV gives yellow to dark brown)

- Increased [acetic acid] catalyzes the photothermal degradation

- Oxidation of polyenes produces keto-chromophores (photobleaching)

- Cyasorb UV 531 photodecomposes

- Degradation products are $\mathrm{HOAc}, \mathrm{CH}_{3} \mathrm{CHO}, \mathrm{CO}_{2}, \mathrm{CO}, \mathrm{CH}_{4}$, $\mathrm{H}_{2} \mathrm{O}$, etc.

Fig. 11

\title{
Module Durability of $\mathbf{3 0}$ years or More
}

\section{is Obviously Much More Complex}

\author{
than
}

\section{a Pottant Stability Issue}




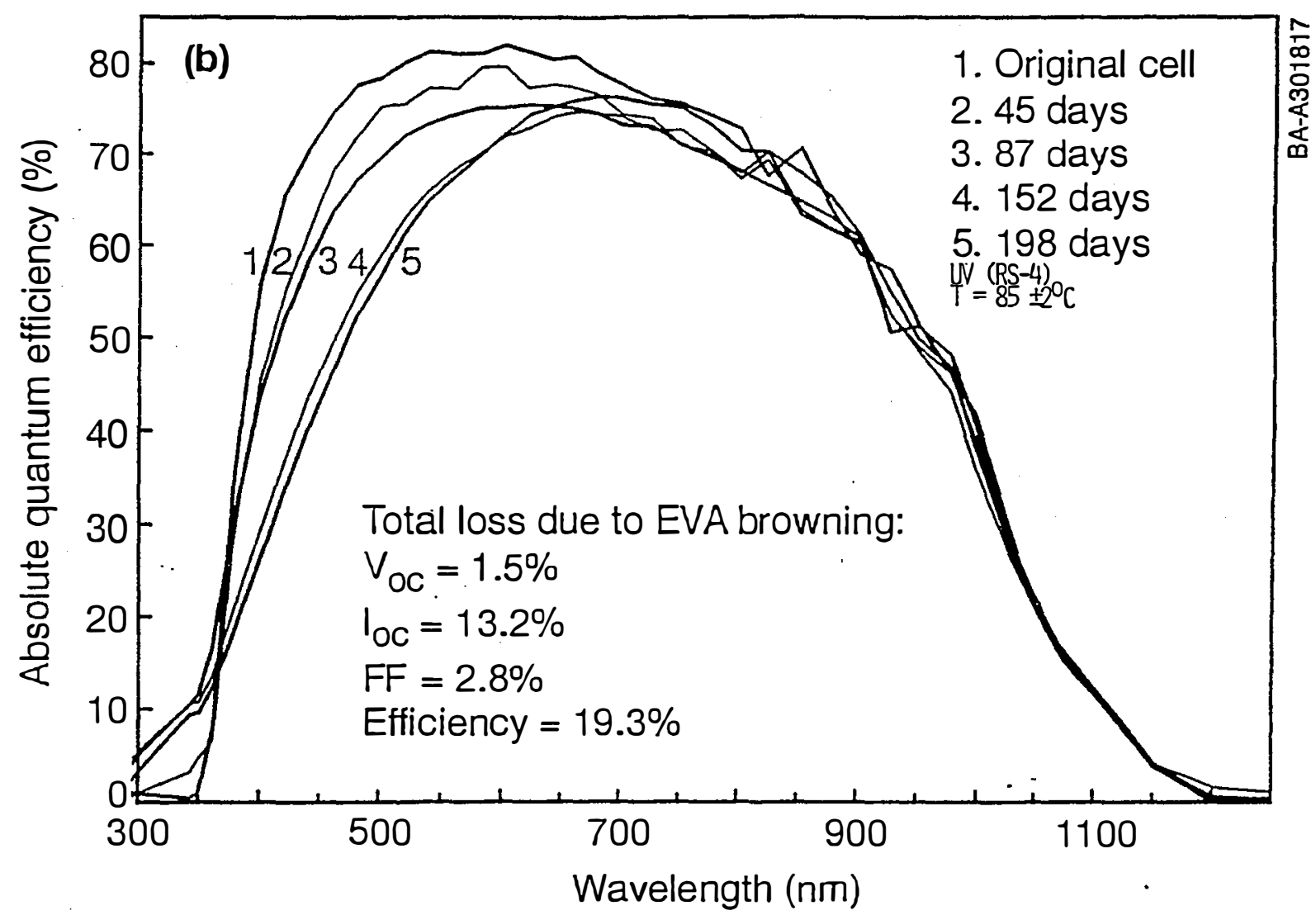

Fig. 13

PV Encapsulant Lifetimes

Cendioma/Pern

\section{Contemporary Multilayer PV Cell}

- Glass cover plate with or without UV screen

- Pottant with or without primer

- c-Si with metalization, AR coating, and base contact

- Pottant

- Supporting substrate.

Comment on cells, modules, arrays, and systems and a need to emphasize cell stability. 


\section{Status-Encapsulation R\&D-Superstrate}

- Antisoiling glasses, no R\&D in progress

- Permeable super- or substrate to enhance photobleaching of EVA

- How well do they perform?

- Does the photo-oxidized polymer retain adequate properties to perform its service function?

Fig. 15

Reliability Sci. PV Cells/Modules

Czanderna, Pern, Glick

\section{Status-Encapsulation R\&D-Superstrate}

- UV filtering glasses, AFG and PPG

- Corning glass recommended to industry in 1991 (Czanderna)

' Retard rate of yellowing (NREL, SLI), 1994

'Do they prolong the service life? 199x or 200x.

'Do they solarize and/or become ineffective?

- Are there cheaper alternatives? 


\section{Status-Encapsulation R\&D at NREL-Pottant}

- EVA is photothermally unstable and should be replaced

- A9918 (slow cure) degrades faster than 15295 (fast cure)

- 15295 recommended to industry; better near-term option, 9/94.

- Optimized (UV Absorber, UV Stabilizer, Ai tioxidant) EVA

- Technology transfered in September, 1995; slower yellowing.

- Modified EVA (new stabilization ingredients)-September, 1995

。 even slower yellowing verified, May, 1996

- Advanced Pottant, will be ready in $x$ years; $x(\$$ cap. eq.; FTE, etc.)

- Critical Review: Solar Energy Materials/Solar Cells 43(1996) pp. 101-183 by Czanderna and Pern

Fig. 17

Reliability Sci. PV Cells/Modules

Czanderna, Pern, Glick

\section{Status-Encapsulation R\&D-Other issues}

- Corrosion (metalization where applicable)

- Hot-spot formation, cell mismatch

- Loss of electrical isolation from pottant degradation

- Electromigration or field-induced degradiation

- Impurity diffusion into pottants

- M-ion catalyzed degradation

- Interconnect stability and contacts with solar cells

- Se vice lifetime prediction 
- What loss in efficiency is tolerable?

- Over what period of time in years?

\section{ESSENTIAL PHILOSOPHY FOR DURABILITY TESTING OF PHOTOVOLTAIC CELLS/MODULES}

1. Test full-size specimens, whenever possible

2. Use accelerated life testing (ALT) stresses for screening different configurations

3. Test complete cells/modules, whenever prssible

4. ALT variables (UV, T, RH, Pollutants, ...)

5. Use multiple ALT stresses

6. Deduce failure mechanisms from diagnostic analyses (e.g., SERI/TP-255-3537, July, 1990)

7. Mitigate causes of degradation, make new specimens, go to 2 for further screening of different materials, designs, etc. 
Technical Approach

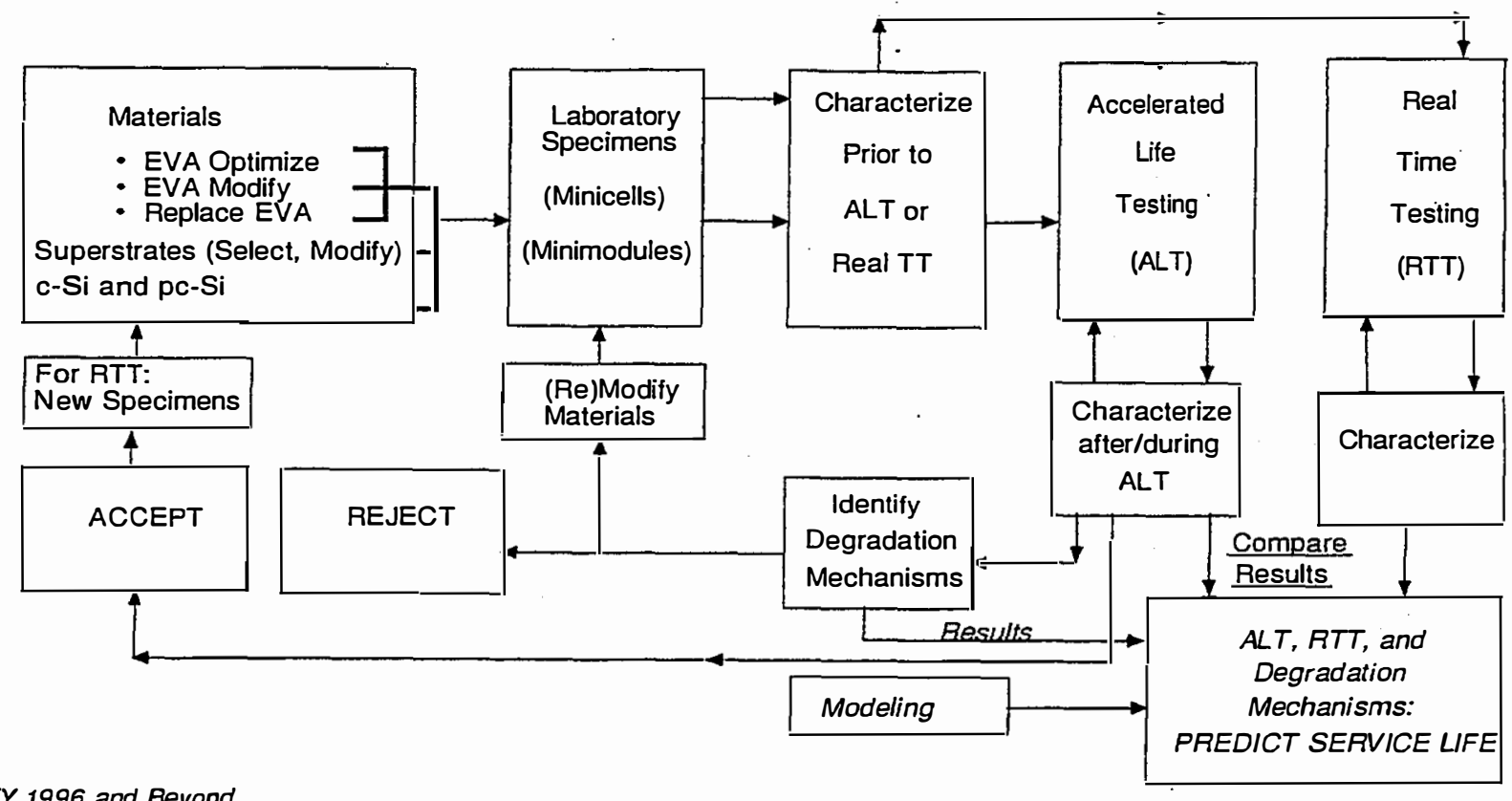

FY 1996 and Beyond

Fig. 21

\section{Valid Technical Approach for Improving Materials/Design/Lifetime Includes}

- Simulating the reality of module design and materials confinement in cell/minimodule specimens during ALT

- Permiting polymer degradation products to accumulate unless a non-hermetic design is employed

- Using a test matrix that accounts for the synergistic AWE influences of degradation in UV, $T, R H$, etc. during $A L T$

- Operating the cell in the encapsulated device during ALT

- Using actual activation energies in the Arrhenius equation (rather than the doubling/10 K "Rule of Thumb") for calculating rates of controlling degradative reactions

ALT=Accelerated Lifetime Testing; $\mathrm{RH}=$ Relative Humidity 


\section{Protocol for Future Studies}

- Extrude candidate pottants

- Choose combinations of superstrates, substrates, and pottants for c-Si minimodules

- Use laminating and curing combinations that simulate industrial practice

- Characterize before exposure as needed (I-V, FA, YI, etc.)

- Use Xenon filtered UV, T, \% RH on operating cells

- Measure I-V curves periodically plus other (e.g., FA)

Fig. 23

\section{Protocol for Future Studies (continued)}

- Conduct post mortem analyses to understand causes in efficiency losses

- Go back to the first bullet, repeat until lifetime potential appears favorable

- Make 20-50 identical samples of candidate combinations for ALT, distribution analysis, etc. and study at 3 or more Ts for $E_{A}$ determination, statistical analysis, and significance

- Proceed as discussed in the paper by Kim, et al. in ASTM 1294, R. Herling, ed., 1996 (In Press) 


\section{Photovoltaic Systems Performance and Reliability: Myths, Facts, and Concerns -- A 1996 Perspective}

by

Mike Thomas and Hal Post

Photovoltaic Systems Assistance Center

Sandia National Laboratories

\section{Introduction}

The total production of photovoltaic modules over the past year exceeded 80 megawatts. Of this, between 65 and 70 megawatts were used for terrestrial systems throughout the world. The going price in the U.S. for standard systems starts at about $\$ 7.00 / \mathrm{W}$ and up depending upon the application. Much of the market is for remote, stand-alone systems, but there is some small growth in subsidized programs for ac grid-connected applications. The potential for the photovoltaic technology appears to be excellent especially for the export market, but there are some technical and economic issues that require improvements.

This presentation was constructed to identify issues related to the current and future markets and needed system development for photovoltaics. Many of this issues take us back to questioning assumptions about system design that may be 10 years old. Most of the topics will be discussed in detail by a presenter in one of the two system sessions. A follow-on introductory talk will discuss more of the detail on fielded system issues like ratings, interconnections, long-term degradation, etc. An attempt is made to place the issues in the context of relative importance, industry directions, current markets, and the $\mathrm{R} \& \mathrm{D}$ community involvement.

\section{System Prices and Financing}

The relationship between system pricing and module advances is not widely understood. For the grid-tied system with no energy storage and no interconnection hardware costs, the PV modules represent as much as $50 \%$ of the overall costs. (ref. SMUD) This is a shift from about $70 \%$ presented just two years ago by the author at this same Workshop. A decrease in the price of the module impacts up to $50 \%$ of the system cost. In the marketplace of today, remote stand-alone and hybrid power systems are not driven by module prices. For these systems that include energy storage, modules represent no more than $25-30 \%$ of the total system price. Batteries, controls, and field balance of system represent the majority of the overall prices. Thus, a decrease of $50 \%$ in module cost may represent only a $50 \%$ X $25 \%=12.5 \%$ reduction in total price. An increase of module efficiency from $13 \%$ to $14 \%$ without any change in manufacturing costs, would represent 
less than a $1-2 \%$ reduction in price, at most. (The effect on area related costs would be small in this example.) Even for the grid-tied system, we would only be looking at a 3$4 \%$ effect from this efficiency increase. Thus the type of developmental changes in modules we have seen in recent years to improve performance represent only small incremental price changes at the system level; the promise of thin-films have yet to have an impact on the system marketplace. Many PV integrators and installers are in agreement that focusing on the "high" prices of modules misleads many potential customers today, actually hurts sales, and is not the dominant factor it is portrayed to be. Sustainable, volume sales are important to the industry and will free up the investment capital to build more capacity which will result in lower system price tags.

A major obstacle, not only to the industry's need to build capacity, is the availability of financing. Several U.S. PV companies are now seriously contemplating their ability to provide customers with some form of financial assistance. This should represent a major step forward.

In lieu of industry financing, some utility companies and their contractors have provided incentives to customers over the past years that have resulted in increased interest. Idaho Power was probably the first to offer such an approach, but their early attempts were limited to the high-end market. The Photovoltaic Services Network is a recent twist on this concept. In the absence of other funding, DOE/FEMP focus for innovative financing schemes has been on energy savings contracting, but there have been no renewable projects that have been successfully identified or implemented under this aegis. Why is this? This concept works well for conservation and energy efficiency, but it is not applicable to PV in today's marketplace. In fact, the ESPC concept for most renewables is so questionable that a proposed system at the Yuma Proving Grounds where modules and batteries would be furnished by the government at no cost to the project, still resulted in a 7-year payback cost for the remainder of the system of $\$ 0.40 / \mathrm{kWh}$. (ref. DOD PV Review Committee) Among other things, a simple lack of information on the life-cycle costs of PV systems is an issue with any project justification.

\section{System Reliability and Performance}

A recent limited survey of the PV system integrators of SEIA indicated that performance and reliability issues were things that needed improvement, but that there were no "showstoppers". This honestly reflects that the industry is busy selling and installing systems. The issues that will be discussed further in the Workshop, that are identified here, must be placed in that context. From the systems perspective, what we need is improved manufacturing for components from modules to power processing. For designs, we need well manufactured interchangeable parts rather than the one-of-a-kind, unique hardware we currently have, and we need to be able to predict the performance. 
A number of examples shows where we are. Published results from the study of a half a dozen hybrid PV-engine systems indicate that the PV array utilization ranges from 65$90 \%$. This means that in the worst case, $35 \%$ of the energy available from a PV array is not obtained because of operational or control strategies. Unlike the benchmark for the hybrid application which is the dc telecommunication systems that utilize engines and standard battery charging, these systems are ac, with custom PV-specific hardware. Analysis has also shown that the benefits from increased array utilization may be of very small incremental value, as will be presented in an upcoming paper in the Workshop. Likewise, system efficiencies run as low as $50 \%$ for these same systems because of losses in the inverters, batteries, and voltage drops. (IEEE PVSC- SWTDI) It could be argued that for many systems, most of the energy produced by the renewables never makes it to the load. There are still benefits from reduced run hours for the engine and lower fuel consumption, but the associated economic justifications that have been used for the systems are largely unrealized. Large, centralized, PV hybrids can be justified for environmental reasons and potential reductions in staff time for power system operation, but savings in fuel and engine maintenance represent relatively small contributions to the overall analysis. Unfortunately, many current designs, except by the most experienced members of the PV community, are being driven by fuel and engine run-time arguments.

Batteries are the largest source of uncertainty in the PV systems of today, both in performance and recurring costs; i.e., reliability. Not understanding how to use batteries is the biggest source of problems. While battery lifetimes are well characterized in many float applications, such as UPSs, this is not the case with PV systems. Battery operation as required by PV systems is very different from what they were designed for. Valve-regulated batteries, for example, have become popular especially in some of the larger applications because they are easy to handle. A particular type is the GNB Absolyte IIP. These batteries are quite expensive and are difficult to charge with PV according to the manufacturer's recommendations. (ref. GNB Manual, 5/95). A recent paper at the IEEE PVSC indicates that improper charging of these batteries in communication systems operated by the U.S. Coast Guard resulted in complete loss of electrolyte. (ref. Slagle \& Durand)

New issues are arising continually about high voltages required of battery banks (flooded or VRLA) in PV systems that are required to match the input voltages of the inverters. This results because the inverter design is driving the system design, not vice-versa. A potential reliability area that is unique (and possibly unnecessary) to the current designs of $\mathrm{PV}$ systems is the use of large capacity batteries in conductive containers at voltages between 350 and 500 volts. These battery cases are grounded to meet NEC requirements for equipment grounding. Arcing and fires have been observed at two major installations because of shorting from the cells to the cases. There are another 5 systems to be installed this calendar year that will incorporate this same battery configuration, adding considerable concem to the overall issues of system reliability and safety. We clearly have a dilemma. Battery manufacturers recommend that the cases not be grounded, but equipment grounding requirement interpretations of the NEC appear to 
require grounding. Grounded systems may arc; ungrounded systems possibly present a shock hazard.

In general, battery replacements in the field, from all causes, are required at roughly twice the frequency as predicted. For those systems with battery storage, the life-cycle costs are increased by an average of $35 \%$ because of the increased rate of replacement. (ref. Post)

Power processing technology is the second largest source of uncertainty in performance and reliability. Published results from PVUSA and EPRI indicate that inverters represent the weak link in PV systems in terms of reliability - grid-tied, stand alone and hybrid. A moderately successful approach has been employed in Australia, where government resources have been focused on one company and manufacturing of today's product. In the U.S., the PVMat activity in BOS has made multiple awards for design and performance improvements that are potentially manufacturable, but at about $1 / 3$ the investment made in the Australian program. The focus of these PV Mat contracts is generally toward long term $R \& D$, rather than manufacturablity, lower costs, and reliability improvements of existing products.

Not all inverters are unreliable. For example, two systems that have employed Toshiba inverters in grid-tied systems for more than 10 years have had virtually no inverter maintenance. (ref. Solar One Homeowners Association) This triggers two questions-1. How do we obtain similar reliability in today's hardware?; and 2. Are our current development contracts achieving advances in reliability that PV systems need?

\section{System Degradation and Maintenance}

There has been a great deal of reluctance to discuss system degradation, but it is essential to bring this issue to the surface in this type of Workshop. The issues here are really ones of maintenance and warranties. System warranty periods are usually no more than two years. Power conditioners, controllers, and other electronic devices are offered with warranties of 90 days or less. Switchgear, safety devices, and other BOS components may have little if any warranties at all. Modules may come with 5, 10,12 or 20 year performance warranties that warrant no more than $10 \%$ degradation in ten years. Batteries have pro-rated warranties, but are null and void unless the manufacturers' procedures for charging and temperature regulation have been followed. So what do we observe in the field for degradation?

First, in our experience, the chance that power conditioners and controllers will not work initially varies between 10 and $30 \%$. Most manufacturers will replace at no cost their products at this point. Mean time between failures cannot be accurately evaluated because many products change so rapidly. Modules are unquestionably the most reliable component in the system, but many are over-rated by 10 to $15 \%$ to begin with. (ref. PG\&E/PVUSA and others) Standard rates of degradation for modules over the first 
ten years of operation are typically $1-2 \%$ per year; i.e. greater than allowed by the warranties. (ref. Thomas and PVUSA) Since the performance of most systems is not measured accurately enough or, most likely, not at all, warranty claims for decreased performance are minimal.

Maintenance costs have been documented only on a few one-of a-kind systems, and then only after infant-mortality and other problems have been eliminated, and on the basis that no degradation occurred. Experience indicates that most stand-alone systems with energy storage, even the large ones, cost about $8 \%$ of the initial price per year to keep at a constant performance. Water pumping systems and other direct drive applications appear to be the exception to this rule, unless overly sophisticated controls are included. Consider the information in the literature. Large grid-tied systems have documented O\&M costs on the order of $\$ 0.01 / \mathrm{kWh}$. (ref. EPRI) One must consider that these same systems that have documented O\&M costs have been degrading at $1-2 \%$ per year for ten years or more and are now producing at $80 \%$ power or less of their original output. When degradation is figured into the system energy cost (through the continuing loss in energy production), the levelized energy cost of these systems are increased by $\$ 0.04-\$ 0.08 / \mathrm{kWh}$. (The cost to bring the system back to the original power output.)

Two results of these questionable analyses of total system maintenance have been to divert attention from the need to establish required preventive maintenance activities, and to significantly overestimate the value of the energy production.

\section{System Design and Value}

Photovoltaic system designs exist for many applications, but questions exist about many applications and few designs have integrated newly developing components and controls. For example, much of the renewable community has pushed for "Net" metering, which has certain advantages to the small group of owners today. This allows two way flow, to and from the utility, through the revenue meter for grid-ied applications. A number of states have adopted this position. Yet net metering drives the design towards a certain type of system configuration and does not recognize the potential benefits of energy storage; i.e., all energy is of equal value regardless of when it is produced and how much is needed. Time-of-day demand and energy rates, a less subsidized approach to maximizing value, could provide system owners and the utilities with additional benefits, but would usually require energy storage. (ref. Brooks) Salt River Project is evaluating some of these concepts for residential systems at their Chandler House, and PVUSA has been involved in the evaluation of the concept for commercial buildings.

Another example that pervades all of system design of ac systems, especially gridconnected, is the monolithic approach to power processing. By this we mean that a single unit is used independently of the size of the array field. The system is reverse engineered/designed based upon the requirements of the power conditioning 
hardware. Historically, the issue here has been referred to as system segmentation. The primary problem is that these systems incorporate low volume production, one-of-a-kind inverters. The poor reliability of power processing hardware has resulted in a whole new approach which is the ac module, sort of the infinite amount of segmentation, or redundancy.

A specific example of what appears to work for larger systems is the new hybrid at Pinnacles National Monument. The National Park Service installed this system using 6 Trace Engineering $4 \mathrm{~kW}$ units to meet a $20 \mathrm{~kW}$ load. A significant design step was to segment the load prior to design, so that the design did not see a single $20 \mathrm{~kW}$ load. In fact, one circuit serves a maintenance area and another circuit serves the remaining facility. In addition, 4 of the units are connected 2 in series and 2 in parallel to meet the remainder of the loads. The engine at this site has not run since the system began to operate at steady state, and the system is meeting the original design and economic goals.

Another major design issue is that the size of power conditioners is chosen to meet the instantaneous loads rather than continuous loads. As a consequence, oversized inverters are in place in many systems. (ref. Durand, et.al.) Typically, a $1 \mathrm{~kW}$ continuous baseload may be supplied by a $10 \mathrm{~kW}$ inverter. The efficiencies at these low loadings may be only $50-60 \%$ for two out of three of the inverter approaches that have been evaluated. (ref. Bonn) This problem is the rule rather than the exception, and results in reducing the energy produced by as much as half; i.e., doubling the price paid. One possible solution would be staged inverters so that the system operates at high efficiency over the full operational range.

\section{Systems Safety and Testing}

The National Electrical Code is being followed for many designs and installations. More and more hardware is in compliance with the NEC and much is UL Listed. Compliance with codes and standards is beginning to have a very positive effect on reducing field problems, and there appears to be little additional cost associated with this compliance. (ref. Wiles) However, some associated issues still exist. At best, customers receive a complete, as-built, drawing package and few receive anything but block diagrams prior to installation. This must be changed. Installation and maintenance manuals for the system owner are always helpful, but infrequently available. Many of the remaining problems after installation could be avoided if drawings and manuals were available. Many items, like complete drawings, grounding requirements, minimum allowable battery state of charge upon installation, acceptance test plan, and others should be specifically called out in the specification/purchase agreement so that there is no confusion between the buyer and seller.

Acceptance testing of systems came into vogue through the PVUSA Project where a considerable amount of experimental hardware was being installed. These acceptance 
tests were a part of the safety and performance information that PG\&E required prior to payment. Since none of the systems gracefully passed on their initial inspections, they were absolutely needed. Acceptance testing is still being performed at many of the larger sites. The cost of this testing is not linear with size and is almost prohibitive for any but the largest installations. In the last two large hybrid installations, Superior Valley (China Lake), and Dangling Rope (Glen Canyon NRA), the cost for acceptance testing including wet high pot, battery capacity, and array rating exceeded $\$ 40,000$ per site. The good news is that very few problems were identified which brings into question the continued need for this effort and cost. The point is that paying attention to specifications, codes and standards, and construction inspections is the least cost approach for the industry; this approach avoids problems rather than having to identify and fix them after installation.

The PV community may indeed start all over again with these issues as new technologies and building and home integrated systems become more popular. How would one fix a shingle module? How does one access a failed ac module? Will the new thin films have similar reliability problems as their predecessors? Will our current grounding practices and the NEC actually protect occupants from possible fires and electrical shock, especially if the systems include energy storage?

If the fundamental issue of system safety is not addressed, we will continue to iterate on safety in the field for each new technology or piece of hardware as it is introduced.

\section{Summary}

Issues facing PV systems have been presented in five categories:

- System Pricing and Financing
- System Reliability and Performance
- System Degradation and Maintenance
- System Design and Value
- System Safety and Testing

These categories are not all inclusive but do represent much of what a PV system is. Papers in the two systems sessions of this workshop will provide some detail on all of these issues, and the information in the two component sessions will make more sense when placed in the context of these systems perspectives. None of these issues is overwhelming. The markets for PV systems are expanding rapidly. It will be our challenge to address these issues quickly, which will require somewhat of a change in the community. More emphasis will have to be placed on resolving the issues of today so that the markets of tomorrow will grow unimpeded. It is clear that all of the PV community can contribute to the solutions in synergistic ways now that some of the 
fundamental issues have been identified and described. However, there is significant momentum oriented towards business as usual which may leave many of these issues unresolved for some time. From a systems perspective, continuing to follow the approach of the past, which is focused on individual components, will encourage improvements in components that may be of minimal benefit to today's marketplace. Without making improvements that benefit the systems of today and tomorrow, investment in component improvements may be of little value, market expansion will be slowed, and U.S. industry may be eclipsed by foreign competition. 


\title{
Photovoltaic System Costs for Stand-Alone Systems With Battery Storage as of 1996
}

Fact Sheet

\section{Prepared by Hal Post and Mike Thomas, PV Systems Assistance Center Sandia National Laboratories, May 15, 1996}

\begin{abstract}
This fact sheet addresses the current cost of stand-alone PV systems with battery storage. A companion fact sheet was developed for grid-tied systems and delivered to DOE on May 1, 1996. The companion document referenced costs for 3-4 kW grid-tied systems procured in quantity by SMUD at \$6.90, or \$0.20/kWh (ref., Osborn, 1996 ASES Conference). The additional information, presented here, was based upon a SAC analysis of all of the current information on stand-alone systems.
\end{abstract}

The Photovoltaic Services Network (PSN) offers a catalog of PV systems and prices for its 45 member utilities. Only water pumping and off-grid residential systems are offered through this vehicle at this time. The systems also come with customer and procurement support as well as warranties.

Only one set of off-grid residential systems offered today is comparable to the multi-home grid-tied effort at SMUD. The systems were developed by the U.S. PV industry according to a PSN/SAC specification and were designed to meet an $8 \mathrm{kWh}$ winter load. The largest PV system proposed (Photocomm, Inc.) includes a $3740 \mathrm{~W}$ array @ STC (12 year warranty on the modules), about 6 days of battery storage with an estimated lifetime of 5-7 years (50 $\mathrm{kWh}$ of flooded lead-acid batteries), a Trace Engineering 4048 full sine-wave inverter, and the required BOS for complete installation. The retail price for this system is about $\$ 12 / \mathrm{W}$. For all of the residential systems offered through the PSN, the retail costs range from a low of about $\$ 12 / \mathrm{W}$ (3740 W system) to a high of about $\$ 20 / \mathrm{W}$ (300 W system).

The costs are significantly higher for the stand-alone systems for a number of reasons:

1. Battery storage must be added to many of the systems.

2. Prices accurately reflect allowable costs in a significant and growing market.

3. The effective use of the electricity generated is reduced in stand-alone systems. This occurs due to the mismatch between the load, battery storage capacity and the available solar resource at times throughout the year.

Battery storage has a significant impact on the cost and efficiency of PV systems. These include:

- Batteries increase the present cost of a stand-alone PV system by approximately $\$ 2 / W ;$

- Batteries increase maintenance; over a 20-year period, battery replacement will add $\$ 3.50 / \mathrm{W}$ to the system present value cost; and

- Batteries decrease system efficiency by as much as $20 \%$ during charge and discharge. 
These observations assume 3 days of useable energy storage (6 days of total rated capacity), a maximum $50 \%$ depth of discharge, battery cost of $\$ 100 / \mathrm{kWh}$ of rated capacity, and a battery lifetime of 7 years.

These additions alone would increase the $\$ 6.90 / \mathrm{W}$ cost at SMUD by :

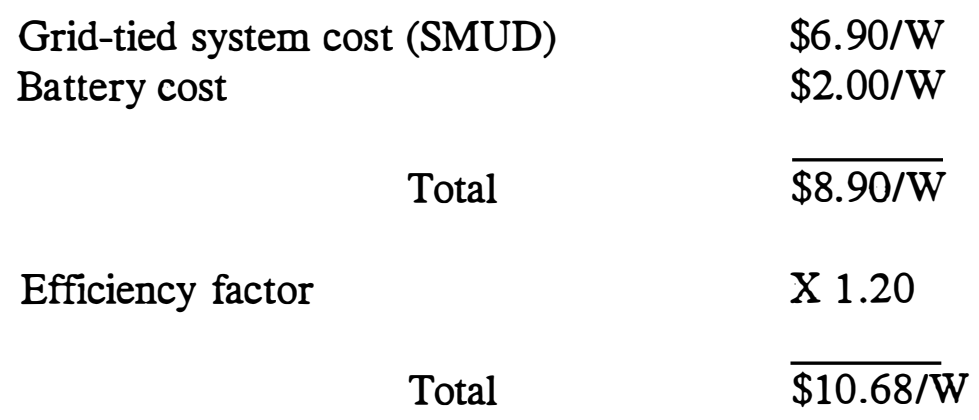

Clearly, $\$ 10.68 / \mathrm{W}$ compares favorably with the $\$ 12 / \mathrm{W}$ price of the largest PV system offered through the PSN for residential systems, especially since the SMUD costs represent a multiunit procurement and the Photocomm price is for a single system.

Recent procurements for large stand-alone systems for different applications support these prices as reported in Table 1, see below:

Table 1. Cost Summary for Recently Installed Stand-Alone Systems

System Size $(\mathrm{kW}) \quad$ Installed Cost $(\$) \quad$ Cost $(\$ / \mathrm{W})$

$\begin{array}{llll}\text { REWS } & 93.6 & 1,375,000 & 14.69\end{array}$

San Clemente Island
4-in-1
576
$6,355,978$
11.03

China Lake

Superior Valley

343.7

$3,600,000$

10.47

China Lake

Dangling Rope

115.2

$1,356,000$

Glen Canyon NRA

APS Carol Spring

25.6

463,420

18.10

Mtn.

Notes: (1) PV size is aggregate module power at STC.

(2) Installed cost is turn-key system contract price to system owner. 


\title{
Photovoltaic System Costs for Utility Interconnected Systems Without Storage as of 1996
}

Fact Sheet

\author{
Prepared by Mike Thomas and Hal Post, PV Systems Assistance Center \\ Sandia National Laboratories, May 1, 1996
}

This fact sheet addresses the referenced price of $\$ 0.20 / \mathrm{kWh}$ for grid-tied PV systems. Included here are the assumptions and a brief description of the how the numbers were developed. This comes exclusively from SMUD publications and personal communication with Don Osborn on April 30, 1996 and only applies to their specific set of conditions. Also included is information about the relevance of these SMUD installed costs when applied to other utilities in areas of high solar resource, Table 1 attached. See the attached paper referenced below and pay particular attention to the projected costs for systems and components presented at the end, including the $\$ 3.15 / \mathrm{W}-\mathrm{dc}$ at STC for crystalline silicon modules today. The out-year projections in Table 1 were developed based upon the SMUD data in the reference.

In 1996, SMUD published that it had achieved costs of $\$ 0.18 / \mathrm{kWh}$ for PV systems (Osborn and Collier, National Solar Energy Conference, ASES Solar 96, Asheville, NC, April 1996) in their northern California service territory. Installed costs for these systems include about $\$ 6.00 / \mathrm{W}$ system costs (hardware and labor) and about $\$ 0.90 / \mathrm{W}$ costs to SMUD for site preparation, metering, overheads, administration and interconnection, etc. Using their fixed charge rates and capacity factors ranging from $25 \%$ to $21 \%$ for tracking and fixed orientations respectively ( $2190 \mathrm{kWh}$ to $1840 \mathrm{kWh}$ ), SMUD has realized electricity costs of $\$ 0.18$ $\$ 0.20 / \mathrm{kWh}$ in constant year dollars. Note that these are not prices for the service, but costs to the utility.

The cost of $P V$ generated electricity is sensitive to several variables. The most important are:

Available energy at the site (capacity factors vary by a factor of 1.9, from $14 \%$ to $26 \%$, throughout the continental U.S.)

The fixed charge rate which varies from utility to utility from about $8 \%$ to $16 \%$ from rural coops and municipals to investor owned (varies by a factor of 2)

The SMUD example represents one of the best possible scenarios for lowering PV system costs. They have a low cost of money, a relatively good solar insolation, and they use a relatively steep learning curve to justify lowered costs. SMUD estimates that system costs can be reduced to $\$ 2.99$ by the year 2000 for an electricity cost of $\$ 0.08-\$ 0.09 / \mathrm{kWh}$ with cumulative utility industry purchases of over 200 megawatts. For example, SMUD paid only $\$ 3.15 / \mathrm{W}$-dc for crystalline silicon modules in a 1996 procurement and estimates that the price will be at $\$ 1.50 / \mathrm{W}$-dc by the year 2000. A decrease in price of this magnitude would normally require a ten fold increase in the manufacturing capacity over the same time period which appears to be a factor of $2 \mathrm{X}$ or $3 \mathrm{X}$ higher than current estimates. These module prices also represent $50 \%$ of the overall installed system cost in 1995 and 2000, which assumes that the other system costs will be reduced by a factor of $2 \mathrm{X}$ as well. 
Table 1. Levelized Energy Cost (Constant 1993 \$/kWh)

\begin{tabular}{lllllll} 
UTILITY & ECB & 1993 & 1995 & 2000 & $\underline{2005}$ & 2010 \\
\hline SMUD & - & 0.23 & 0.18 & 0.09 & 0.05 & 0.04 \\
Plains & $8.8 \%$ & 0.41 & 0.32 & 0.16 & 0.09 & 0.07 \\
APS & $15 \%$ & 0.70 & 0.55 & 0.27 & 0.15 & 0.12 \\
PG\&E & $11 \%$ & 0.51 & 0.40 & 0.20 & 0.11 & 0.09 \\
Austin & $13 \%$ & 0.61 & 0.48 & 0.24 & 0.13 & 0.11 \\
SRP & $12 \%$ & 0.54 & 0.42 & 0.21 & 0.12 & 0.09
\end{tabular}

Notes:

1. Costs of generation based on SMUD's published (1996) installed system costs for grid-tied PV systems w/o storage

2. Utility types include: Municipals - SMUD, Austin, SRP Investor Owned - PG\&E, APS Rural Coop - Plains Electric

3. All examples are located in high insolation areas of southwestern and western US

4. Fixed charge rates are taken from Sandia's Quickscreen database

5. $\$ / \mathrm{kWh}=$ (Fixed Charge Rate) $\times$ (Installed System Costs $) /(\mathrm{kWh} / \mathrm{yr}) \times(0.8)$

6. O\&M is assumed negligible 


\section{Cell, Module, and System Performance}




\section{UNCERTAINTIES IN PV PERFORMANCE INDICATORS FOR SERVICE LIFE PREDICTION K. Emery \\ National Renewable Energy Laboratory 1617 Cole Blvd. \\ Golden, CO 80401-3393 \\ USA}

PV cells and modules are often rated in terms of a set of standard reporting conditions defined by a temperature, spectral, and total irradiance. The change in the maximum electrical power or efficiency with respect to standard reporting conditions over a given time period is often used as the indicator of a PV technology's stability. This talk summarizes the state-of-the-art in the random and non-random uncertainties for various current versus voltage measurement procedures and equipment. The change in efficiency with time as a service life predictor directly predicts the power output after extended periods of time in the field. The problem with efficiency as a service life predictor is that it is sensitive to all things that affect the power output and hence is insensitive to which mechanism(s) caused a reduction in the power. Some degradation mechanisms such as impurity drift in the material will not be apparent in the efficiency until the space-charge region is shorted out. Examining the dark-current and shunt resistance will identify this effect long before it can be measured as a change in the efficiency. Other indicators that are sensitive to small changes in the perfromance include; dark I-V, quantum efficiency, series and shunt resistance, photo-response mapping, IR thermographs showing localized heating, and other methods.

This work is performed under Contract No. DE-AC36-83CH10093 to the U.S. Department of Energy. 


\section{Peak Power is the Key PV Performance Indicator}

Efficiency under Standard Conditions

Normalized Power under Prevailing Conditions

๑ Regression to Project Test Conditions ....

Degradation in efficiency can be from many causes that often can not be identified from light $\mathrm{I}-\mathrm{V}$ measurements alone. 
Uncertainties In I-V Measurements Are Composed Of Random And
Nonrandom Sources

$U_{95}=B+t_{95} \cdot S$

$B \equiv$ nonrandom error, bias limit $\equiv \sqrt{\sum\left(\Theta_{i} \cdot b_{i}\right)^{2}}$

$S \equiv$ random error, precision index $\equiv \sqrt{\sum\left(\Theta_{i} \cdot s_{i}\right)^{2}}$

$t_{95} \equiv$ student' $\mathrm{s} t$ for $95 \%$ confidence $\approx 2$

Different measurement systems and procedures have different random $\left(s_{i}\right)$ and nonrandom $\left(b_{i}\right)$ elemental error sources. 


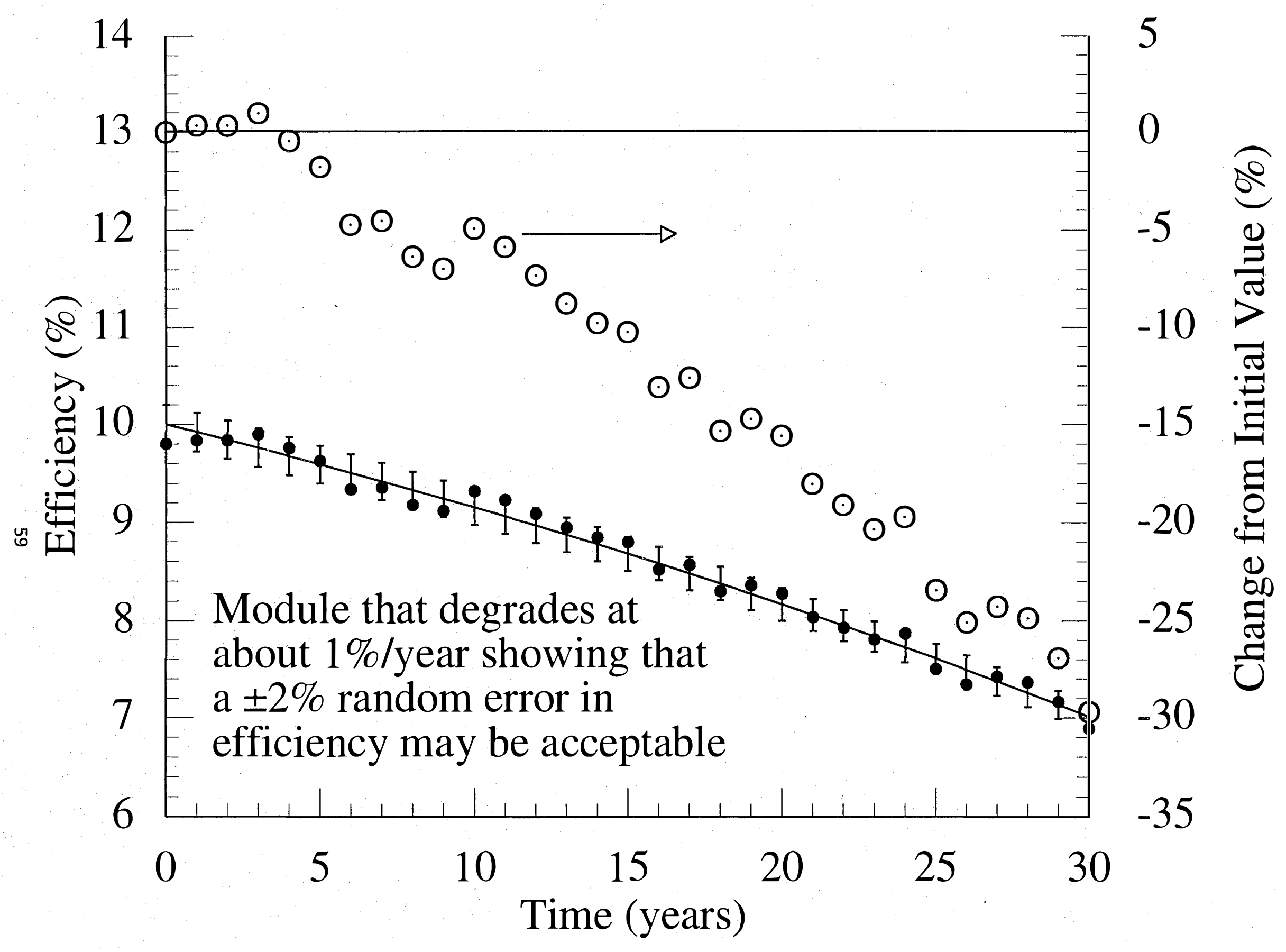




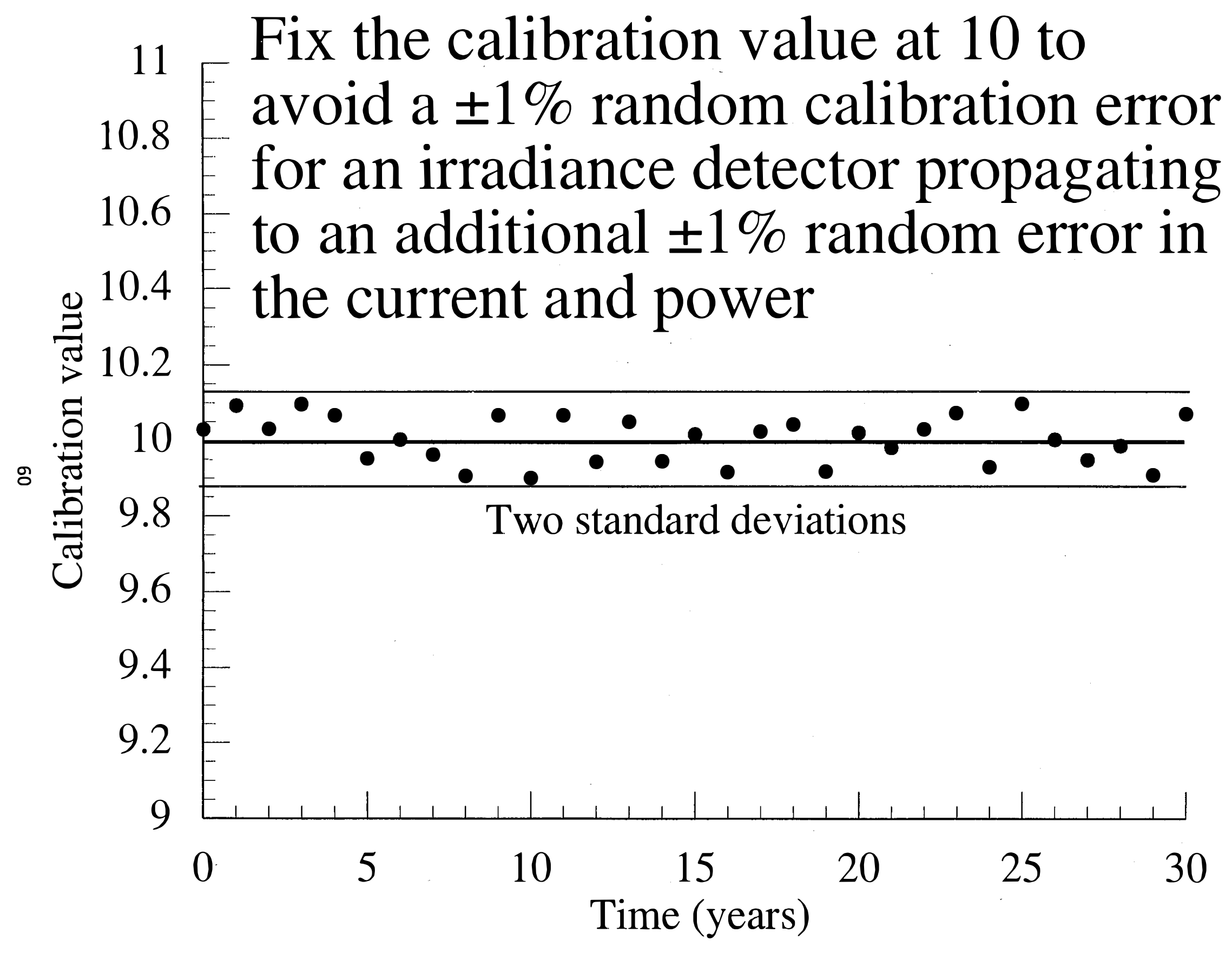




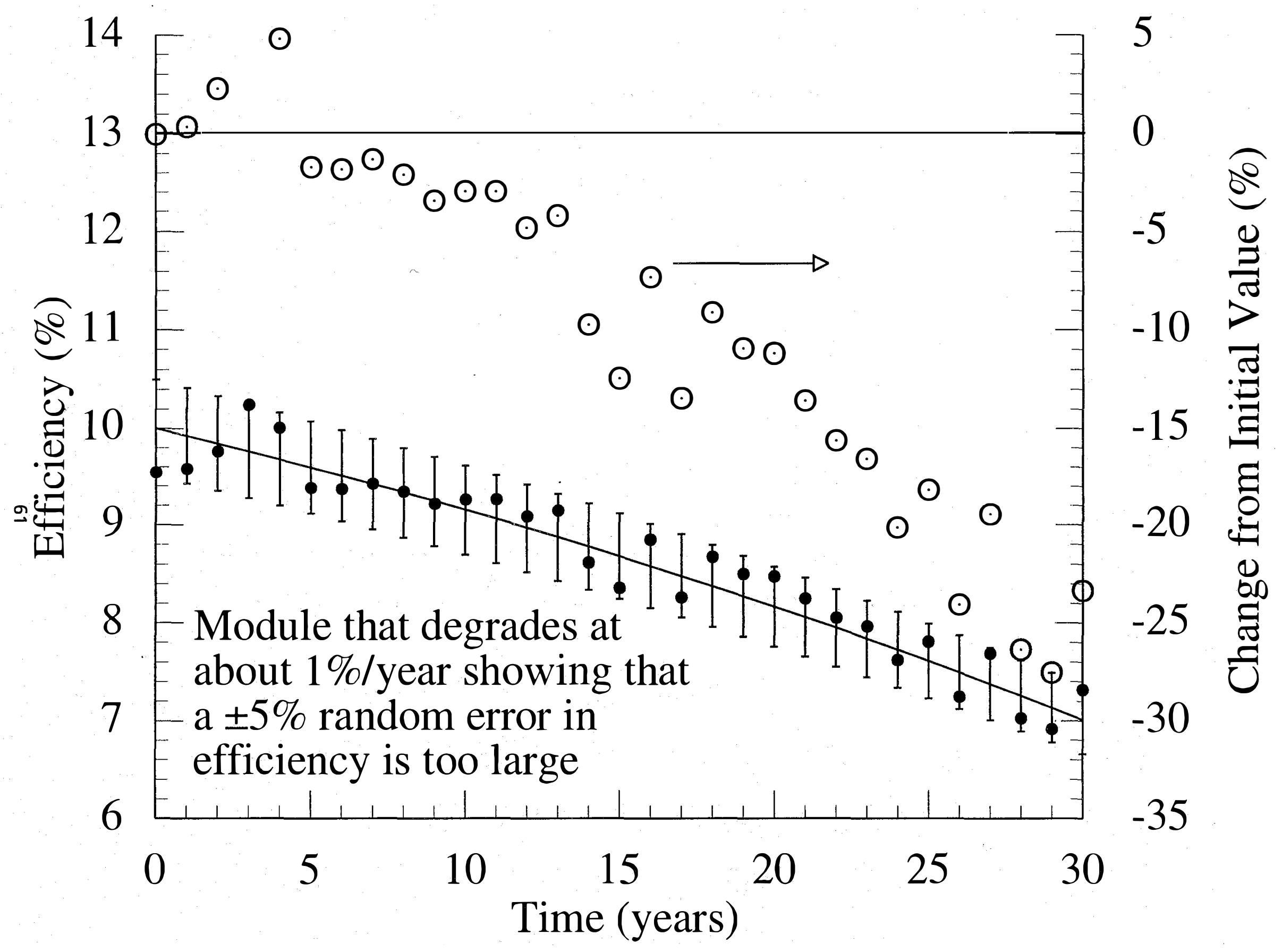


All Random Error Sources Must Be Minimized or Fossilized to

Measure Small Efficiency Changes

Ways of minimizing random errors

- $\quad$ Average repeated measurements

$\therefore \quad$ Do not change procedures, test beds or operators

- $\quad$ Perform the measurement under solar simulators where the spectrum, and temperature can be fixed.

- $\quad$ Permanently attach electrical contacts and temperature sensor 


\section{Ways of Fossilizing Random Errors}

- fix calibrations, when the random error in the calibration process is significant

- $\quad$ Ensure same area, temperature, 4-terminal contacting method and light level is achieved each time

Minimize changes in the efficiency because of random changes in the light level or spatial uniformity by dividing the maximum power by the short-circuit current instead of the irradiance. 


\section{Methods Used With The Spire}

240A To Minimize Random Errors In Module I-V Measurements

Solder voltage and current leads together and leave attached to the module to minimize variations if $F F$ from changing contact resistance

Fix the calibration value for the reference cell mounted in the Spire (calibrate once at start of series) 


\section{Methods Used With The Spire 240A To Minimize Random Errors}

Make sure the elevation of the monitor compared with the module is the same each time

Orient and locate the module the same way each time.

Note that over half of the change in $P_{\text {max }}$ from measurement to measurement is correlated with random changes in $I_{s c}$ 


\section{Alternative Performance Indicators Dark I-V}

The equation for the current as a function of voltage for a module can be written as a series / parallel combination of cells

ร

The simplified diode equation for a single cell can be written as

$$
\begin{aligned}
& I=I_{0}\left(e^{(q \cdot V /(n \cdot k \cdot T))}-1\right)-I_{s c}+V / R_{s h} \\
& V=V-I \cdot R_{s}
\end{aligned}
$$


Changes in the values of $R_{S}, R_{s h}, n$ and $I_{0}$ are greater than changes in the efficiency and are often measurable before changes in the efficiency can be detected.

- $\quad$ Random errors associated with light level fluctuations and spectral variations are eliminated

- $\quad$ Temperature related error sources (gradients, nonuniformities) are minimized.

- $\quad$ High accuracy instruments can be used. 


\section{Alternative Performance Indicators}

Photo-response mapping of individual cells in a module is very sensitive to variations in the photo-current, shunt resistance, and dark current and can provide a useful baseline indicator.

Measuring the shunt and series resistance of individual cells in a module at baseline and after the study will help identify the location and cause of any changes 


\section{Alternative Performance Indicators}

Fluorescence analysis of the encapsulant material is a sensitive method to determine changes in the encapsulant properties

\& Thermographs showing current mismatch, interconnect failure, hot spots

Relative quantum efficiency is more sensitive than $I_{s c}$ to intrinsic changes that affect the photo-current 


\section{Summary}

- Random errors in efficiency measurements can be minimized by fossilizing them.

- Comprehensive baseline testing of modules that will be subjected to longterm exposure testing is time consuming but essential to sorting out the contributions of various degradation mechanisms 


\title{
DETERMINATION OF THE INTERNAL SERIES RESISTANCE OF PHOTOVOLTAIC
} CELLS

\author{
Alan E. Delahoy \\ Energy Photovoltaics, Inc., Princeton, NJ 08543 \\ T.J. McMahon \\ National Renewable Energy Laboratory, Golden, CO 80401
}

\begin{abstract}
A new method is described to determine the internal series resistance (vertical rather than lateral components) of thin film solar cells[1]. The method involves illumination of a small area of the cell with light sufficiently intense to make the internal resistance easily observable. It works particularly well on $\mathrm{CIS}$ and $\mathrm{Cl}(\mathrm{G}) \mathrm{S}$ cells with small internal series resistance values with RA products between $10^{-1}$ and $10^{-4} \mathrm{ohm} \mathrm{cm}^{2}$. These values would be difficult to measure with standard techniques. We expect this technique to be especially valuable for spotting small changes in back contact resistance during accelerated stress testing and in identifying the source of any increased series resistance. Data measured on CdTe cells are presented and show a large drop in photogenerated current with decreasing spot diameters that was not seen with $\mathrm{CIS}$ and $\mathrm{CIGS}$ cells. A PSPICE circuit simulator program is applied to a number of non-ideal diode behaviors as well.

The effect of sheet resistance on thin film cell and module performance can be calculated and is well understood [2]. However, series resistance internal to the cell structure is not easily quantified, and a lumped series resistance deduced from cell measurements cannot differentiate between internal, sheet resistance or grid contributions. Possible sources of internal resistance are the semiconductor/back contact interface (the resistance may be ohmic or junction-like), and the bulk resistance of the films neutral region or the CdS (photoconductivity can make these resistances light-dependent).
\end{abstract}

\section{METHOD AND APPARATUS}

A small region of the cell is illuminated by a chopped and focused HeNe laser beam, and the ac current in the external circuit is recorded as a function of cell bias for both forward and reverse polarities. The optical and electrical set-ups are depicted in Figs. 1a and 1b. A single element lens (laser singlet) specifically optimized for focusing HeNe beams is utilized. The lens is mounted on a micrometer-driven translation stage that allows the diameter of the laser spot falling on the cell to be varied,

while maintaining constant total optical flux. The cell is mounted on an $x-y$ stage that can be translated by stepper motors. Electrical bias is applied to the cell using a Kepco bipolar supply. The DC voltage bias on the cell is measured directly at the cell terminals. The value of the current-sensing resistor $R_{C}$ is 10 ohms. The modulated (ac) component of the voltage across $R_{C}$ is measured with a lock-in amplifier synchronized to the chopper.

Four devices are analyzed in this paper: a $1.2 \mathrm{~cm}^{2}$ CulnSe2 (CIS) cell prepared by selenization of metallic precursors [3], a $0.41 \mathrm{~cm}^{2}$ CIGS cell prepared by a 3-stage (In,Ga) $2 \mathrm{Se}_{3}$ precursor process [4], a $0.12 \mathrm{~cm}^{2}$ CIGS concentrator cell prepared using a 2-stage process with an initial 200nm CuGaSe2 layer(overall device structure is glass/Mo/CIGS/CdS/ZnO) [5], and a $1.1 \mathrm{~cm}^{2}$ CdTe cell[6].

Fig. 1c shows the device equivalent circuit used for the analysis of the experimental data, a typical set of data for an EPV $1 \mathrm{~cm}^{2} \mathrm{CIS}$ cell being shown in Fig. 2. Analysis of the set of curves obtained by varying the laser spot diameter allows a determination of the internal resistance of the cell, as explained below.

For large beam diameters the photocurrent generated by the cell is fully collected for all values of reverse bias applied to the cell, thereby accounting for the saturated signal. As the test 
cell is placed under forward bias, some of the photocurrent is shunted by the forward-biased diode (mostly by the large area of the cell that is unilluminated) and this reduces the collected current by a factor $\left(1+J_{F} R_{C q} / n k T\right)^{-1}$ [7], where $J_{F}$ is the $D C$ forward current through the cell and $n$ is the ideality factor, thereby accounting for the observed fall-off in collected current. (By collected current, we mean that fraction of the photogenerated current i $L$ that passes through RC.) For a given test cell, all beam diameters larger than a certain value yield identical curves of collected current versus cell voltage.

For a beam diameter of 6 mils, the photon flux at the cell surface is approximately 240 suns equivalent. If the specific internal resistance is $r \mathrm{ohm} \mathrm{cm}^{2}$, and the illuminated area of the cell is $A$, then the numerical value of the cell internal resistance for the illuminated portion of the cell is $R_{i}=r / A$ ohms. Note that $R_{i}$ is controlled by the beam area. If the light-generated current $i_{L}$ is fully collected it must pass through $R_{\mathbf{i}}$, leading to a voltage drop ${ }_{i} R_{\mathbf{i}}$. (It can be shown that, because of the low photocurrent involved, about $1.4 \mathrm{~mA}$, the lateral voltage drop in a standard ZnO:Al transparent conductor can be neglected[1].) However, if the external cell reverse voltage plus $i_{L} R_{i}$ is sufficient to drive the illuminated diode into forward bias, the lightgenerated current will be partially shunted by the diode, and the measured photocurrent will be reduced.

From Fig. 2, for the case of a 6 mil diameter beam, it can be seen that the photocurrent starts to fall at an applied cell bias of $-0.35 \mathrm{~V}$, from which we immediately deduce that the voltage across the internal series resistance $R_{\boldsymbol{i}}$ must be larger than $0.35 \mathrm{~V}$, and to account for a $1-2 \%$ reduction in photocurrent must in fact be about $0.8 \mathrm{~V}$ (estimated using values of the diode parameters $n$ and JO appropriate for low light levels, as a first approximation, where JO is the reverse saturation current). From this we calculate an internal resistance $R_{i}$ of about 500 ohms, and a specific internal resistance $A R_{i}$ of $0.09 \mathrm{ohm} \mathrm{cm}^{2}$. Similar numbers for the specific internal resistance are deduced through analysis of the remaining curves for different beam diameters.

Measurements of the beam diameter were conducted by placing the cell under reverse bias and stepping the cell back and forth such that a scribed edge of the cell passed underneath the beam. The beam diameter was taken to be the distance over which the collected current varied between $85 \%$ and $15 \%$ of its maximum value. To measure beam diameters the cell was translated normal to the cell boundary. For the apparatus shown, the spot diameter could be varied between 22 mils and a minimum of 0.4 mils, as determined by the above method.

Pspice 6.0 for Windows (educational version) was used to model the circuit shown in Fig. $1 \mathrm{c}$ in order to extract a best fit internal resistance for the collected current versus voltage curve at each beam intensity. The specific modelling parameters for each set of curves were obtained in the following fashion. From the dark I-V curves of the cells, the diode ideality factor and the saturation current ( $\mathrm{N}$ and IS in Spice) were determined. The parameters that were varied to fit the data using the model were the illuminated diode internal resistance, its saturation current, and its ideality factor in that order. As base parameters, the dark diode characteristics were used. For the CIS cell the ideality factor of the dark diode well characterized the cell for the entire range of beam focussing; however, for both CIGS cells, the most focussed beam caused the ideality factor to increase substantially beyond 2 . The ensuing modelled curves were not as accurate as those for which $\mathrm{N}$ remained a constant throughout. From the modeled curves, we extracted values for the internal series resistance pertaining to the illuminated portion of the cell.

Figures $3 a, b$, and $c$ show the results of the curve fitting procedure described above as applied to the experimental data on the CIS, CIGS, and CIGS concentrator cells. The associated internal resistances are summarized in Table 1. The general trends seen from the data presented in Table 1 are clear. With decreasing beam diameter, the internal resistance $R_{j}$ of the illuminated portion of the cell increases, as anticipated. Despite large changes in $R_{\mathfrak{i}}$, the product $R_{i} A$ is roughly constant, and is identified as the specific internal resistance $r$. 
Table 1. Values of internal resistance ( $R_{\mathbf{i}}$, illuminated area only) and specific internal resistance (r) as deduced from the curve fitting procedure for the three cells.

\begin{tabular}{|c|c|c|c|c|}
\hline Cell & $\begin{array}{l}\text { Beam } \\
\text { diam. } \\
\text { (mil) }\end{array}$ & $\begin{array}{l}\text { Beam } \\
\text { area A } \\
\left(\mathrm{cm}^{2}\right)\end{array}$ & $\begin{array}{l}\mathrm{Ri} \\
\text { (ohm) }\end{array}$ & $\begin{array}{l}r=\operatorname{Ri~A} \\
\left(o_{m c m}^{2}\right)\end{array}$ \\
\hline $\mathrm{CIS}$ & $\begin{array}{l}22 \\
6 \\
4 \\
2\end{array}$ & $\begin{array}{l}2.4 \mathrm{E}-3 \\
1.8 \mathrm{E}-4 \\
8.1 \mathrm{E}-5 \\
2.0 \mathrm{E}-5\end{array}$ & $\begin{array}{l}- \\
4000 \\
600 \\
1700\end{array}$ & $\begin{array}{l}0.073 \\
0.048 \\
0.034\end{array}$ \\
\hline CIGS & $\begin{array}{l}17 \\
2.1 \\
0.4\end{array}$ & $\begin{array}{l}1.5 \mathrm{E}-3 \\
2.2 \mathrm{E}-5 \\
8.1 \mathrm{E}-7\end{array}$ & $\begin{array}{l}- \\
40 \\
450\end{array}$ & $\begin{array}{l}- \\
8.9 E-4 \\
3.6 E-4\end{array}$ \\
\hline $\begin{array}{l}\text { CIGS } \\
\text { concentrator }\end{array}$ & $\begin{array}{l}4 \\
0.4\end{array}$ & $\begin{array}{l}8.1 \mathrm{E}-5 \\
8.1 \mathrm{E}-7\end{array}$ & $\begin{array}{l}3 \\
330\end{array}$ & $\begin{array}{l}2.4 \mathrm{E}-4 \\
2.6 \mathrm{E}-4\end{array}$ \\
\hline
\end{tabular}

The same data collection methods were attempted on CdTe cells. Fig 4 a and b show the DC and AC currents vs bias voltage with varying spot size. This cell was $1.1 \mathrm{~cm}^{2}$ and had a fill factor of $64 \%$. It is clear that the assumption of constant photocurrent with decreasing spot size (total number of photons fixed) is no longer valid; Higher current densities and flatter bands result in more recombination and less current to the external circuit.

It is concluded that the method of cell preparation can influence the specific internal resistance of CIGS cells. Remarkably low values of the internal resistance were found, consistent with the recent successful development of CIGS concentrator cells. For the three cells examined (CIS, CIGS, and CIGS concentrator), the $r$ values obtained were about $0.05,0.0005$, and 0.00025 ohm $\mathrm{cm}^{2}$. The advantages of the method are that a) it clearly separates internal resistance from sheet resistance effects, b) it can be applied to monolithically interconnected modules, and $c$ ) it can probe selected areas of a cell with a resolution of better than $1 \times 10^{-4} \mathrm{~mm}^{2}$. The method should prove useful for the optimization of terrestrial, space and concentrator CIGS devices, and for the evaluation of alternative back contact schemes. The results measured on the CdTe cell will require more careful analysis to provide useful device information.

\section{ACKNOWLEDGMENTS}

This work was partially funded by the U.S. Department of Energy through Subcontract No. ZAF-5-14142-04 to EPV Inc. from NREL under the Thin Film Partnership Program. The authors would like to thank Dr. Jeff Britt for fabrication of CIS and CIGS cells, Dr. Rommel Noufi (NREL) for providing a CIGS and CIGS concentrator cell, Dr. Rick Powell (Solar Cells, Inc.) for providing a CdTe cell, and Professor Sigurd Wagner for discussions.

\section{REFERENCES}

[1] A.E. Delahoy and Adam M. Payne, "Determination of the Internal Series Resistance of CIS and CIGS Photovolaic Cell Structures", 25th IEEE PV Spec. Conf., Washington, DC, May 1996.

[2] A.E. Delahoy "Energy Delivery for Various PV Technologies Based on Realistic Irradiance and 
Temperature Distributions: Implications for Module and System Design", 13th European PVSEC (H.S. Stephens Associates, UK, 1995) pp. 1474 - 1478.

[3] A.E. Delahoy, J. Britt, F. Faras, F. Ziobro, A. Sizemore, G. Butler and Z. Kiss, "Progress in CulnSe2 and Culn(Se,S)2 Module Development," AIP Conf. Proc. Vol. 306, (1993) pp. 370-381.

[4] A.M. Gabor, J.R. Tuttle, D.S. Albin, M.A. Contreras, R. Noufi, and A.M. Hermann, "Highefficiency CulnXGa1-XSe2 solar cells made from (InX, Ga1-X)2 $\mathrm{Se}_{3}$ precursor films," Appl. Phys. Lett. 65, 1994, pp. 198-200.

[5] J.R. Tuttle, J.S. Ward, A. Duda, T.A. Berens, M.A. Contreras, K.R. Ramanathan, A.L. Tennant, J. Keane, E.D. Cole, K. Emery, and R. Noufi, "The Performance of Cu(In,Ga) Se2 Based Solar Cells in Conventional and Concentrator Applications", MRS Spring Meeting, San Francisco, 1996 (to be published).

[6] Supplied by Solar Cells, Inc

[7] J.R. Sites, H. Tavakolian, and R.A. Sasala, "The Analysis of Apparent Quantum Efficiency", Solar Cells 29, 1990, pp. 39-48.

\section{FIGURE CAPTIONS:}

Fig. 1. Experimental set up and equivalent circuit a) Optical arrangement

b) External electrical circuit ( $R_{C}$ is a current sensing resistor) c) Device equivalent circuit (within dotted box)

Fig. 2. AC current in the external circuit versus DC bias as measured across the test cell (CIS), for various laser spot diameters, and for two different total beam fluxes (solid symbols are measurements taken at a reduced beam flux, with AC signal multiplied by 10 for plotting purposes). Measured beam diameters: open circles - 22 mils; open triangles - 6 mils; open squares - 4 mils; open inverted triangles - 2 mils.

Fig. 3. Fits of modeled curves (lines) to experimental data (points) for the following cells: a) CIS; b) CIGS; and c) CIGS concentrator.

Fig. 4. Current vs bias voltage on a CdTe cell: a) DC dark and photocurrent with spot size as noted in microns; and b) AC photocurrent with spot size as noted in microns. 


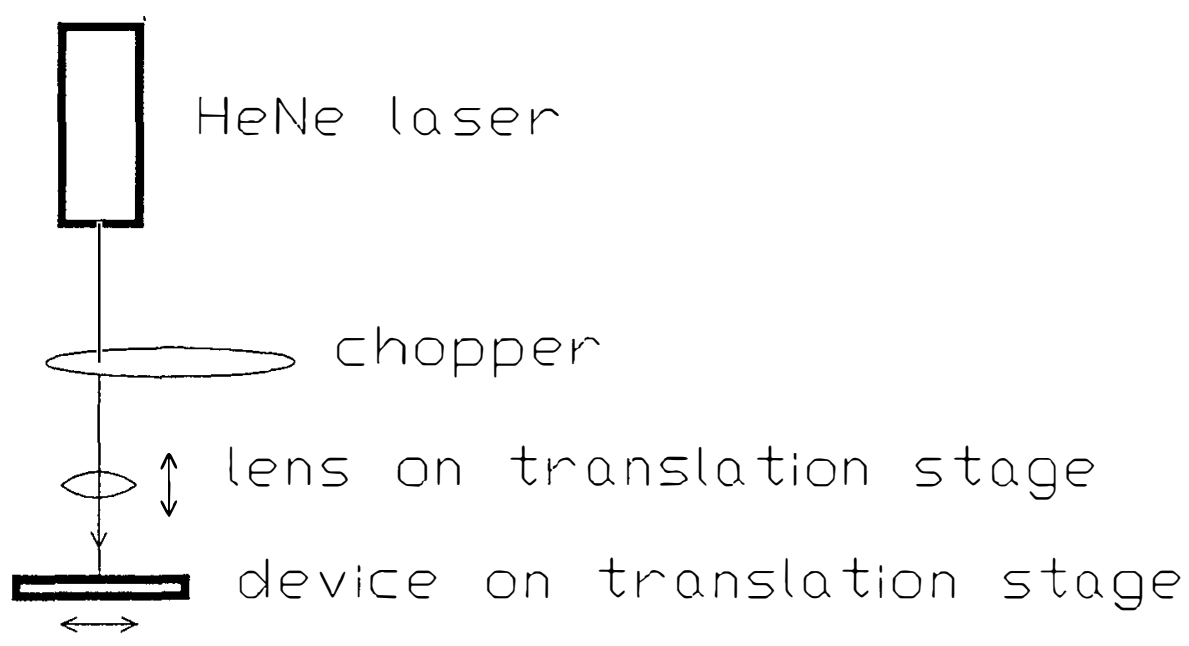
b.
chopped light

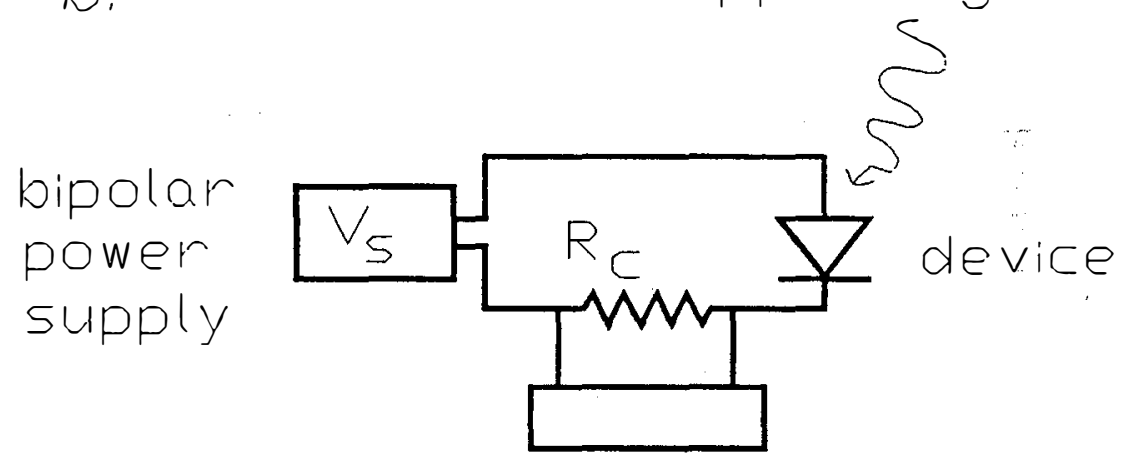

lock-in amplifier

$\subset$.

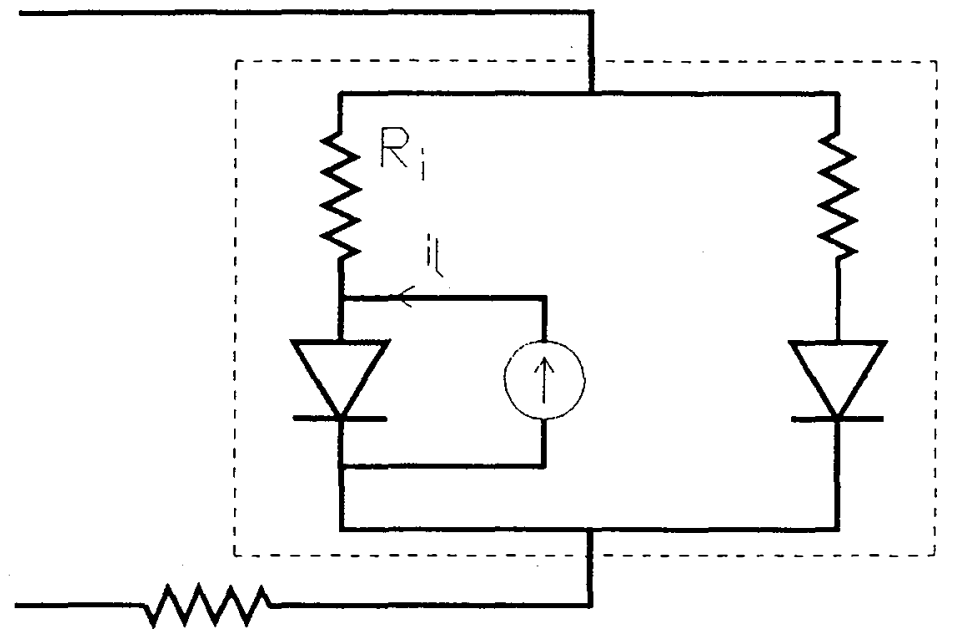

$R_{C}$ 


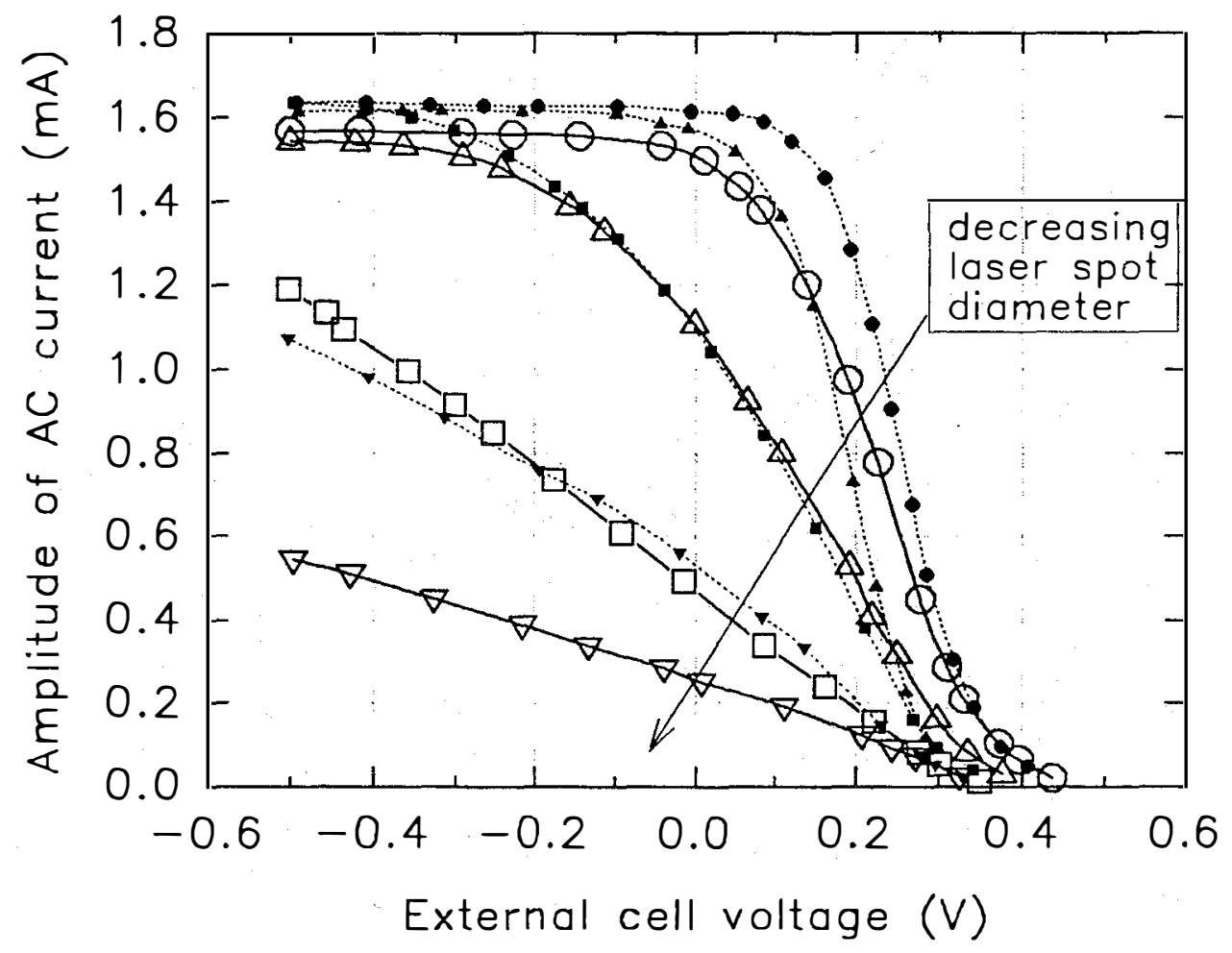

FIGL 
FIGJa CIS Cell

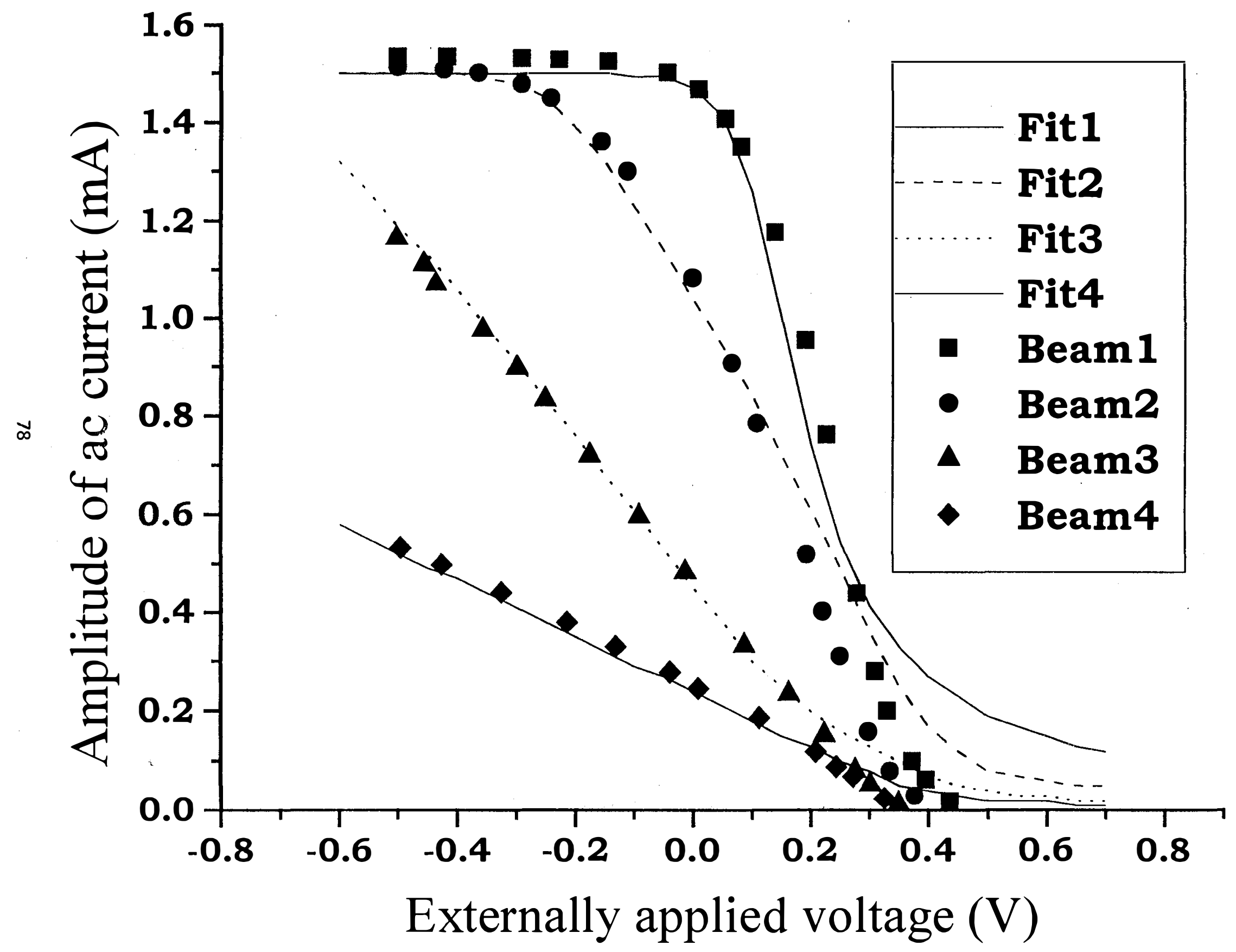


FIG 3b. CIGS Cell 1 (9 May 1996)

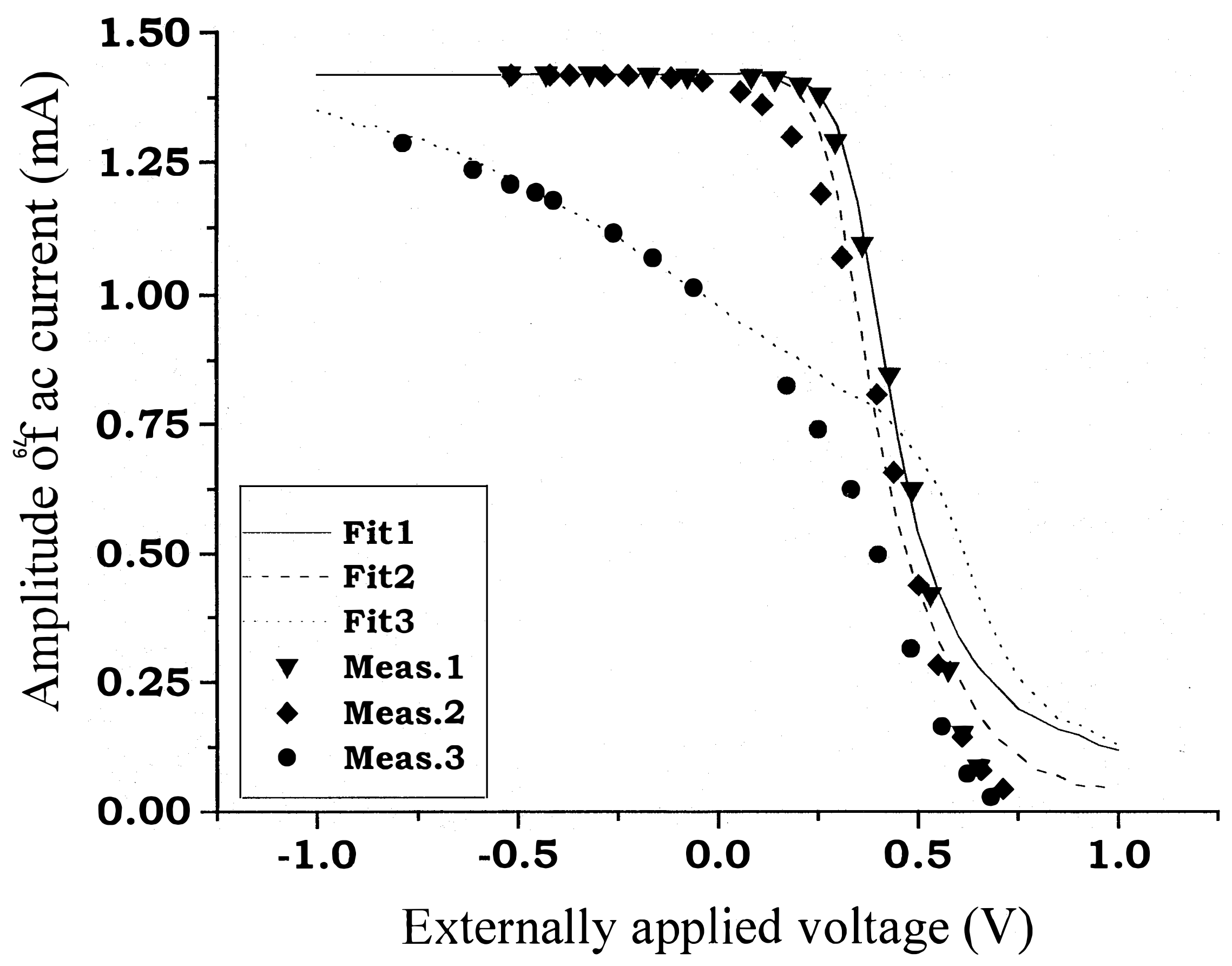


FIG 3C CIGS concentrator Cell

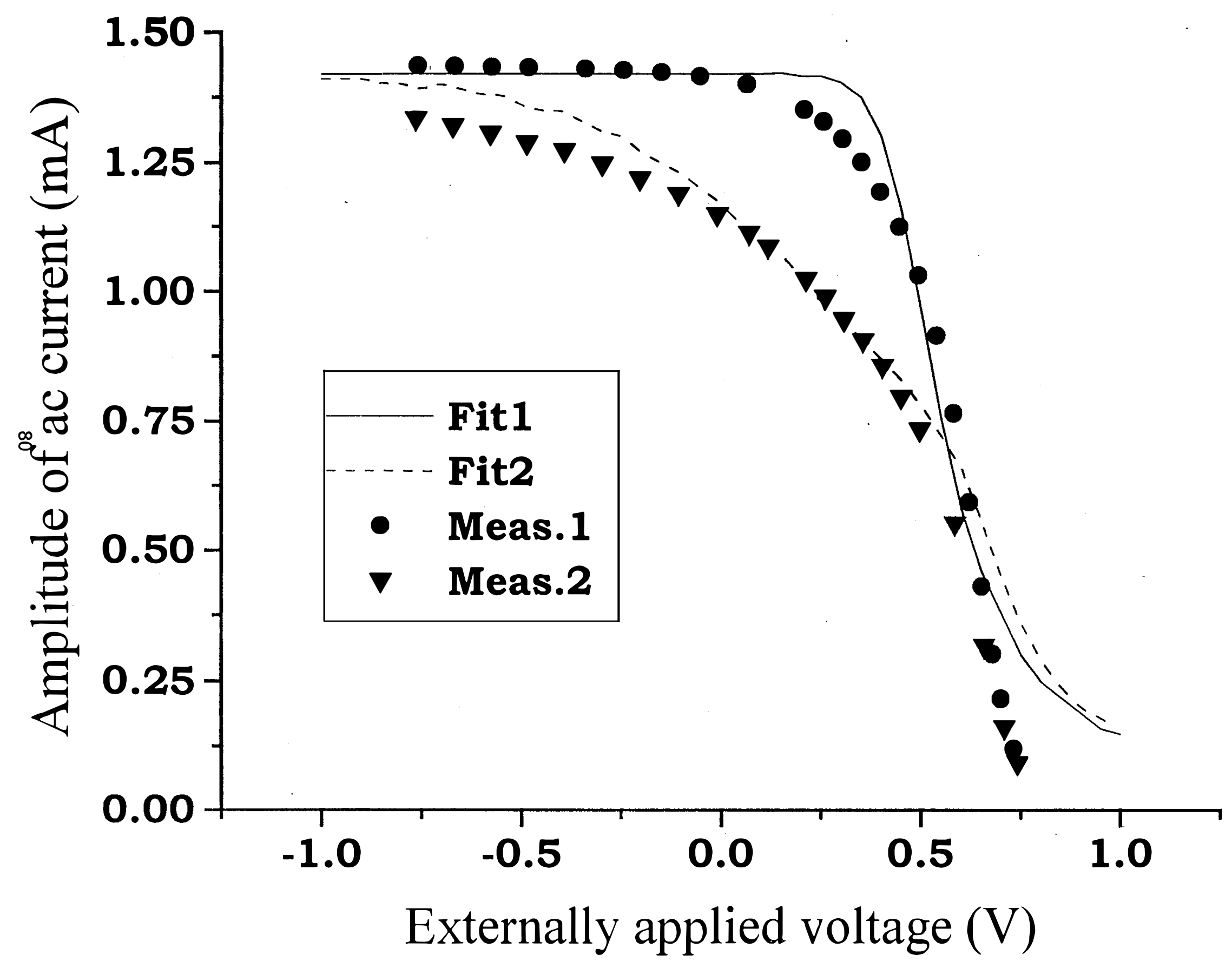




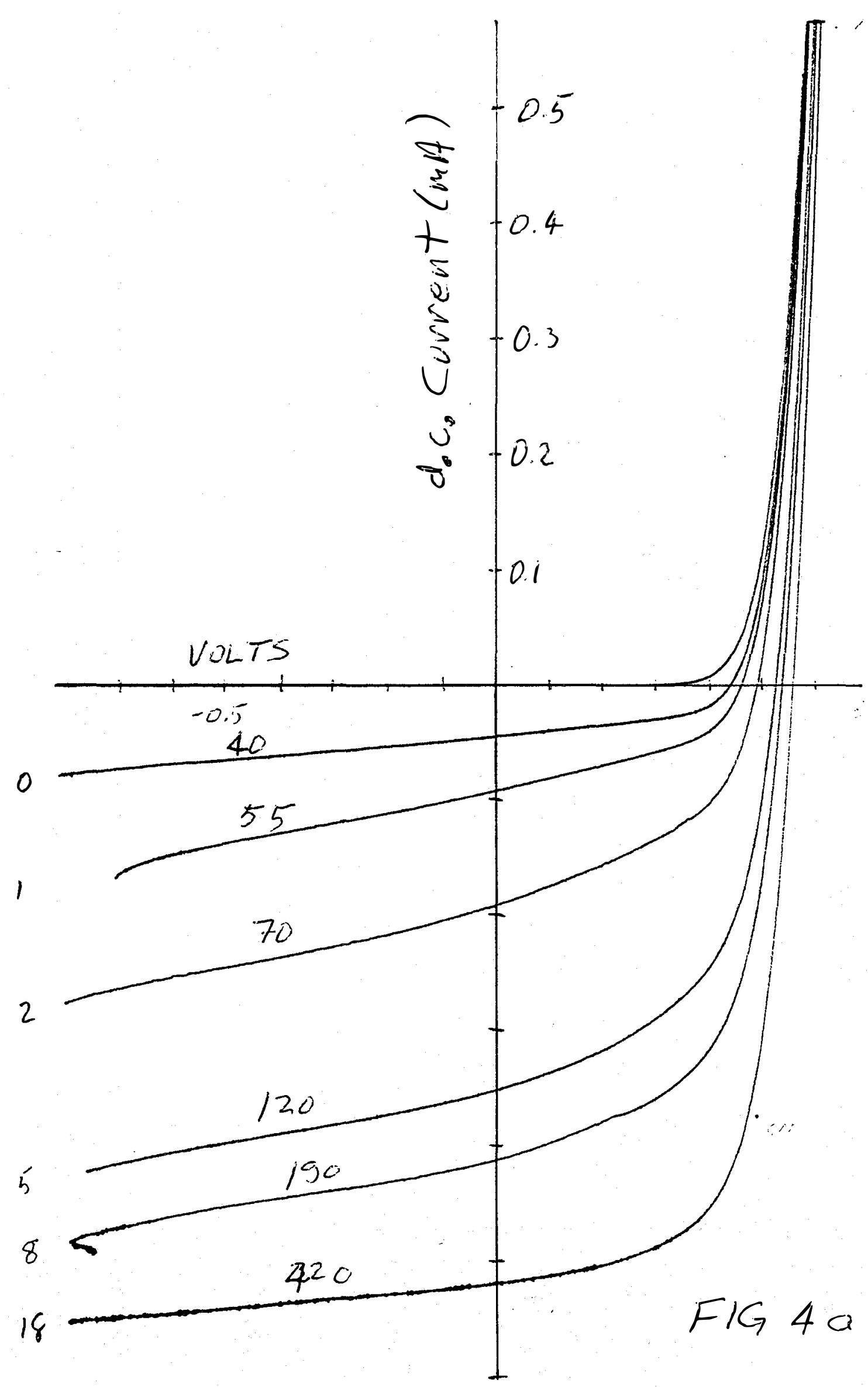

81 


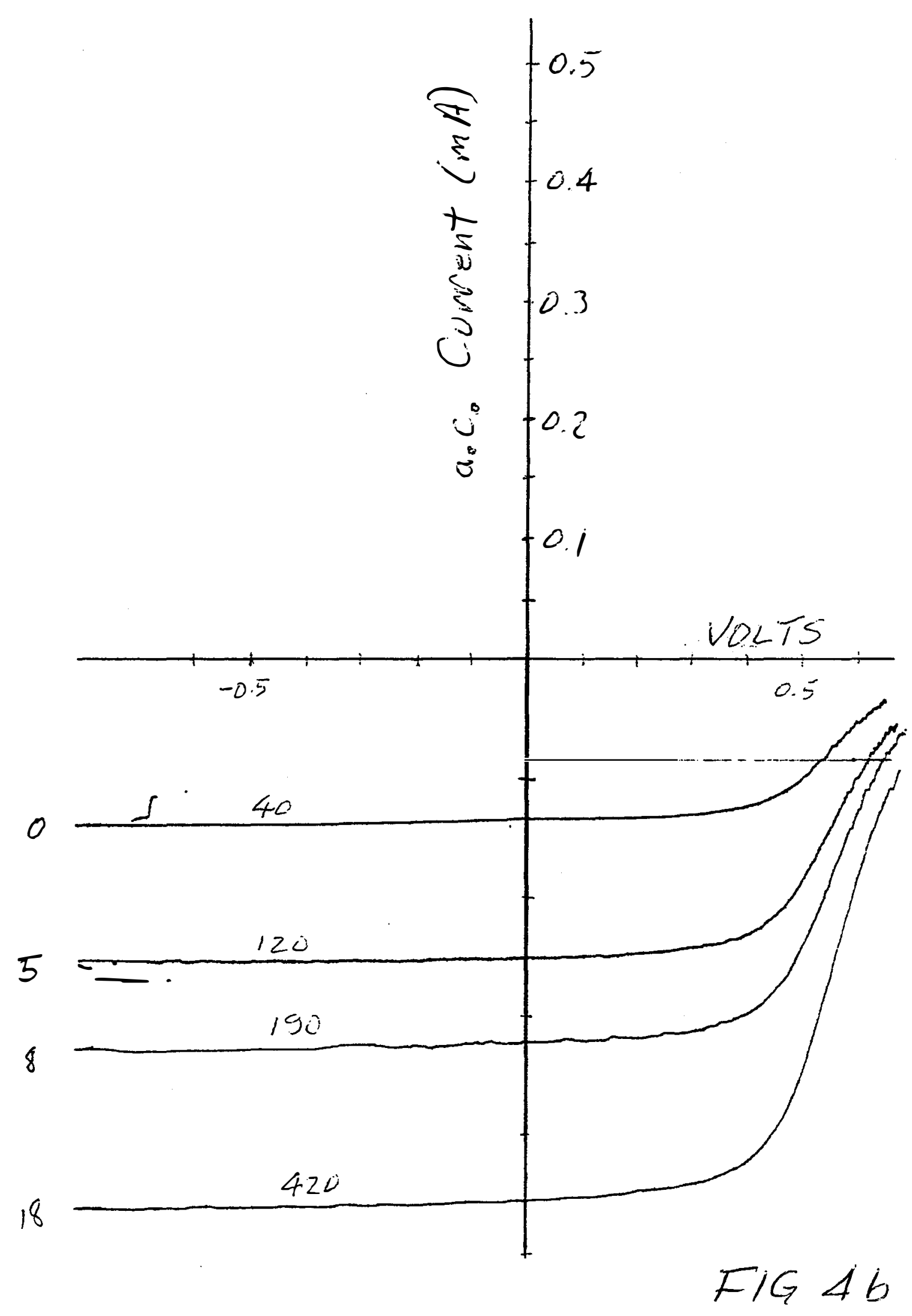

82 


\section{THIN FILM MODULE CHARACTERIZATION Ingrid Eisgruber Materials Research Group}

$\Rightarrow$ What differences between thin film and single-crystal modules are important to characterization of thin film modules?

$\Rightarrow$ What artifacts may be apparent if these factors are ignored?

- Current-Voltage

- Quantum Efficiency

- Selective Illumination

This research was funded by NREL subcontract to Colorado State University. 


\section{THIN FILM MODULE GEOMETRY}
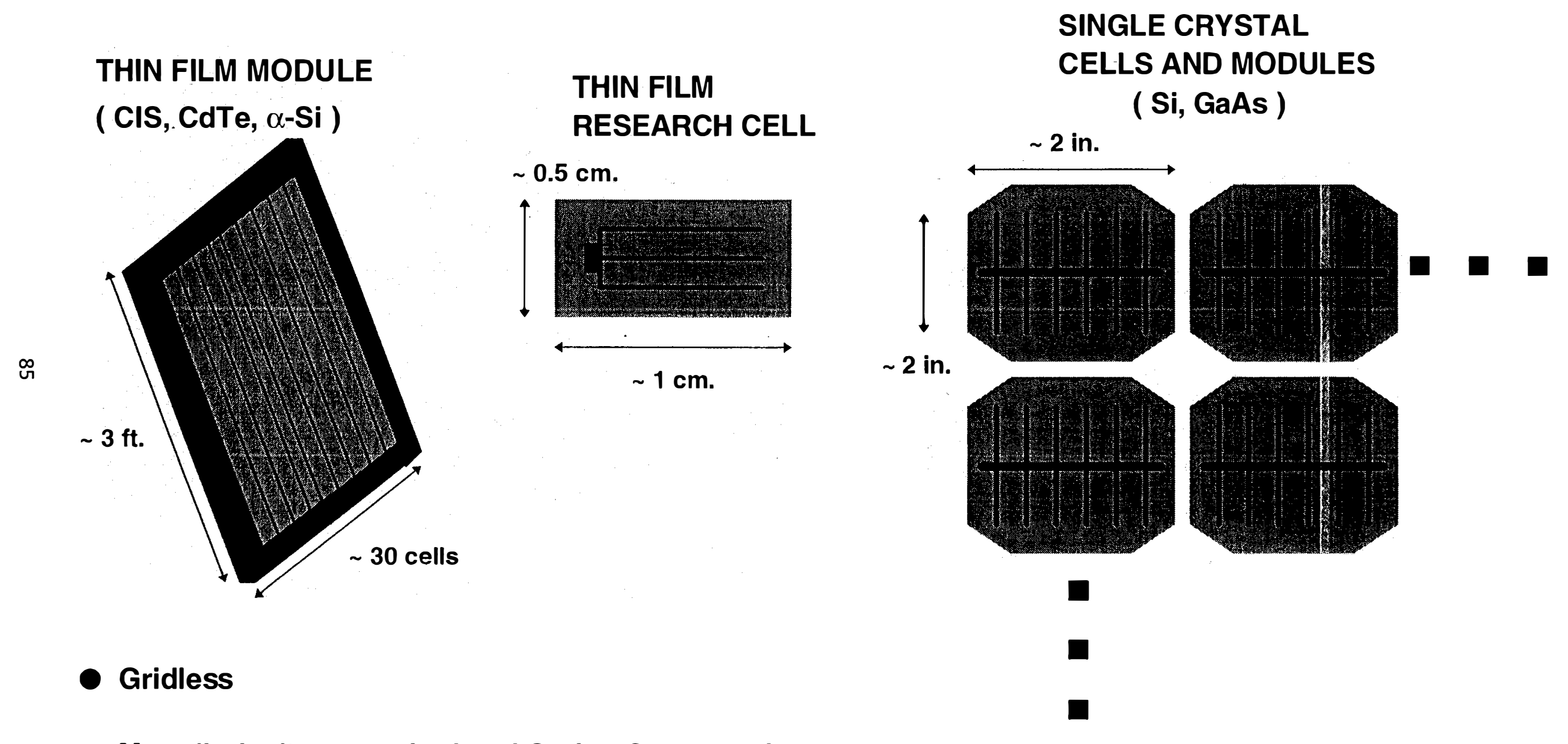

- Gridless

Monolithically Deposited and Series-Connected

- Cell Lengths Around 1 to $3 \mathrm{ft}$.

- Different Material Properties 


\section{CURRENT-VOLTAGE}

2 - POINT CONFIGURATION

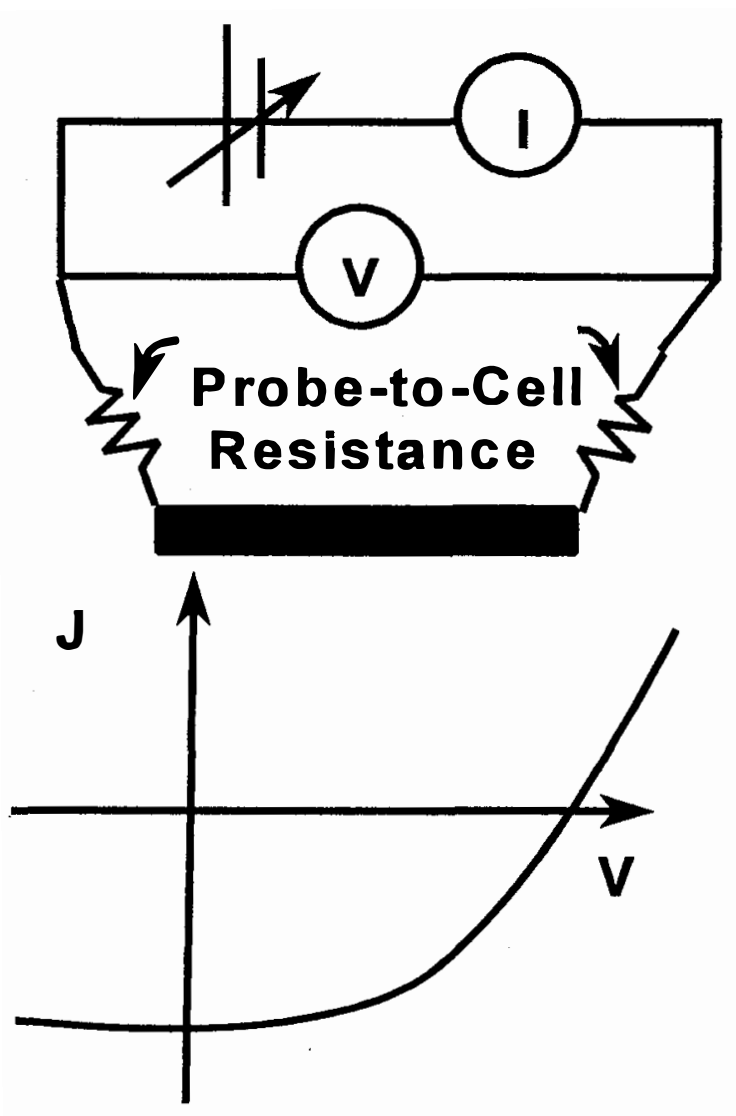

\section{4 - POINT CONFIGURATION}

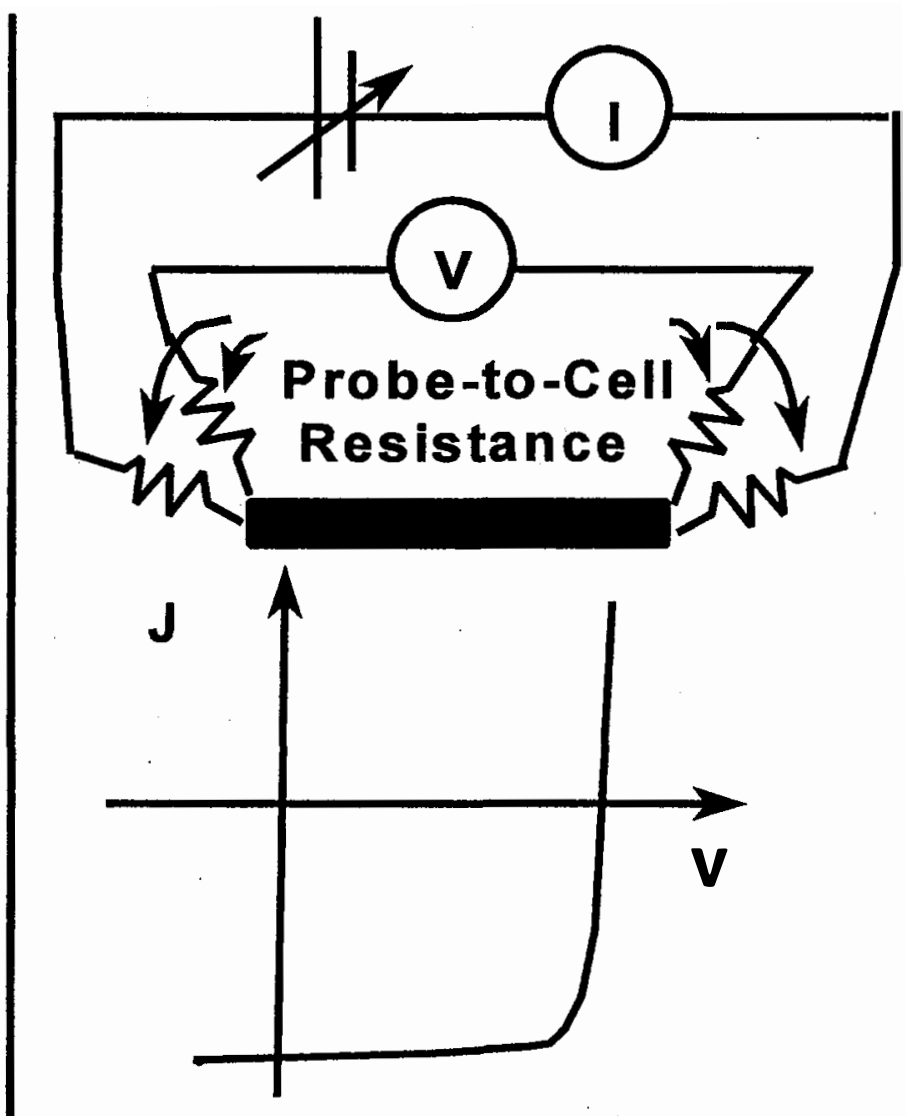

Excess Series Resistance / Artificially Low Fill Factor Most Important for: Large Cells Gridless Cells 

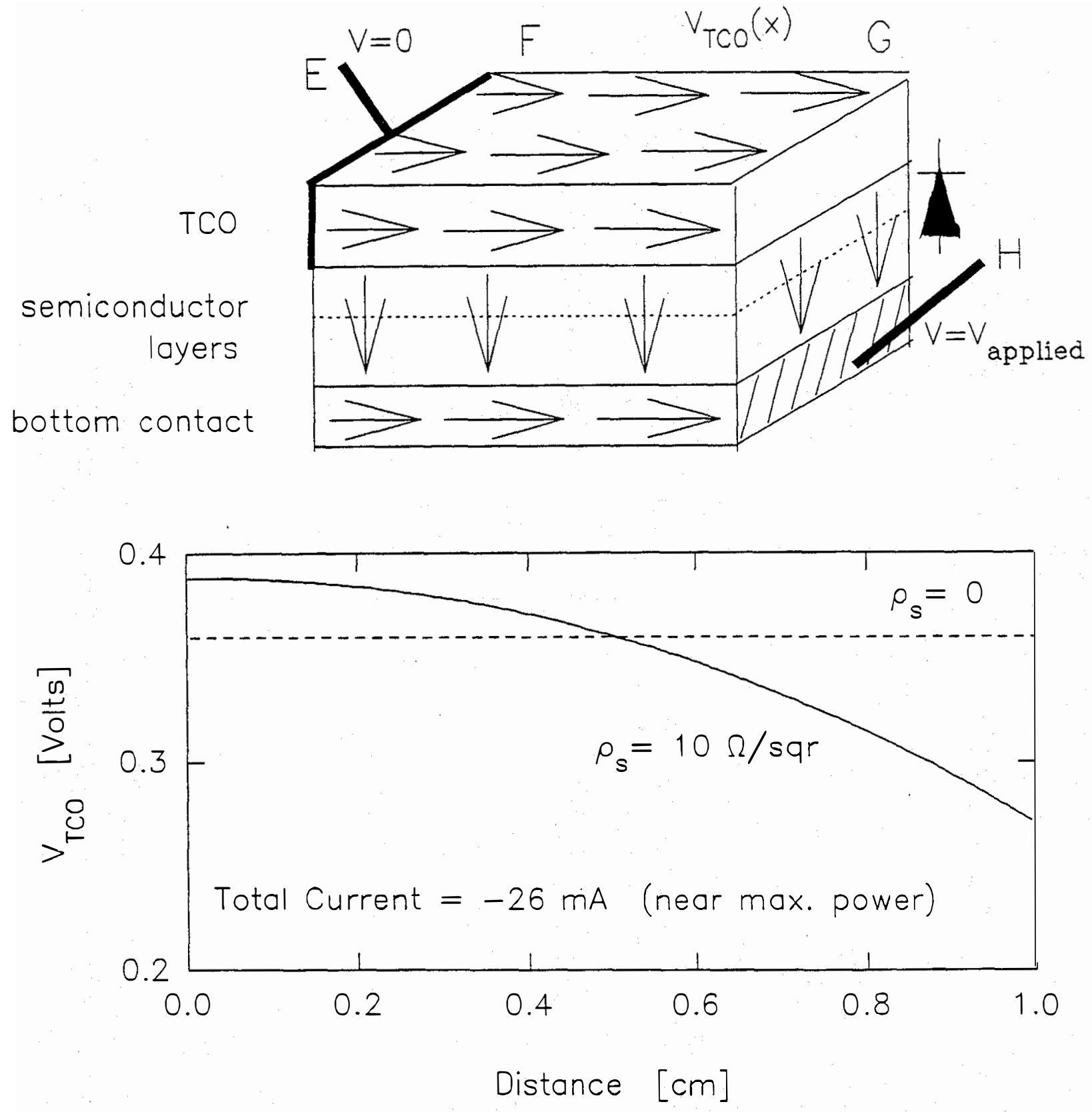

\section{VOLTAGE IN TRANSPARENT CONDUCTING OXIDE DEPENDS ON POSITION FOR LARGE GRIDLESS CELLS.}




\section{CURRENT-VOLTAGE PROBE PLACEMENT:}

Excess Series Resistance

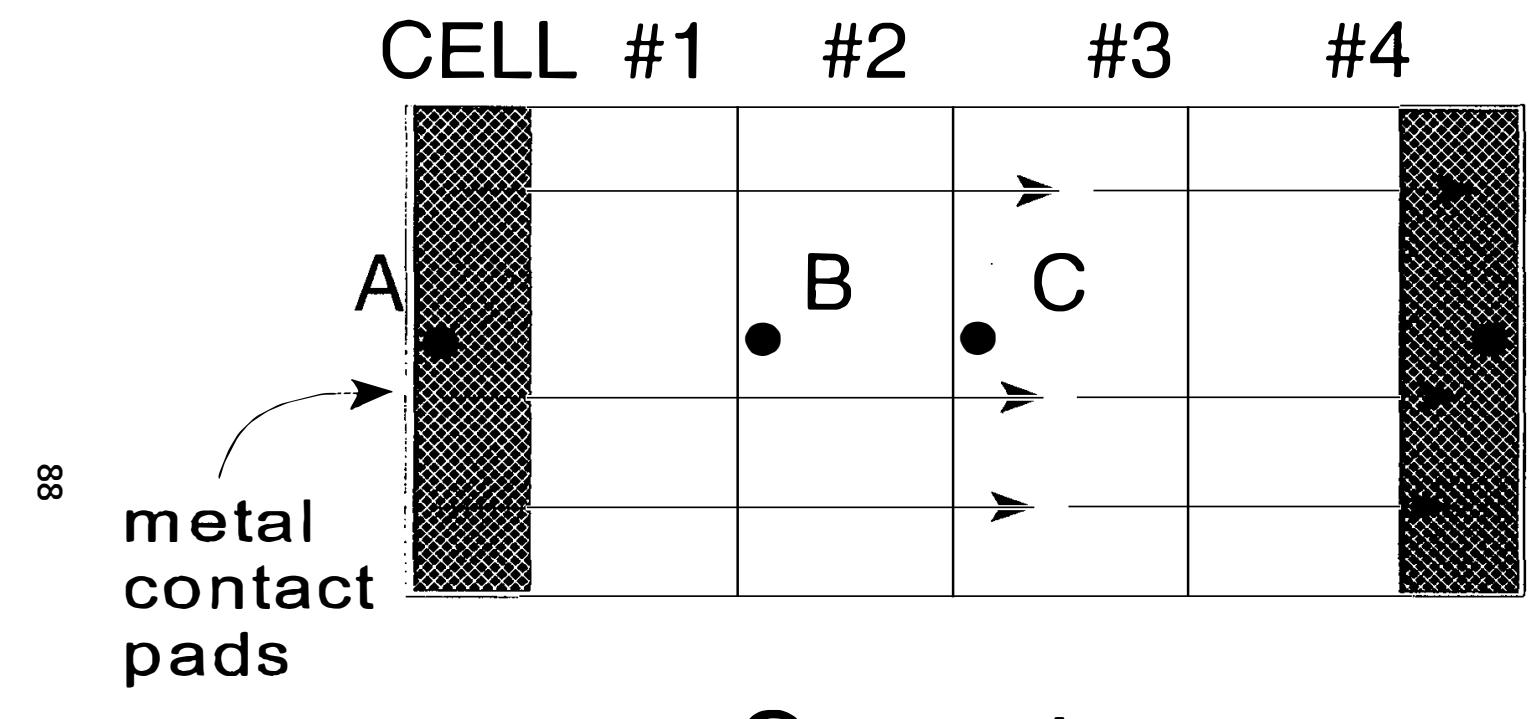

Correct

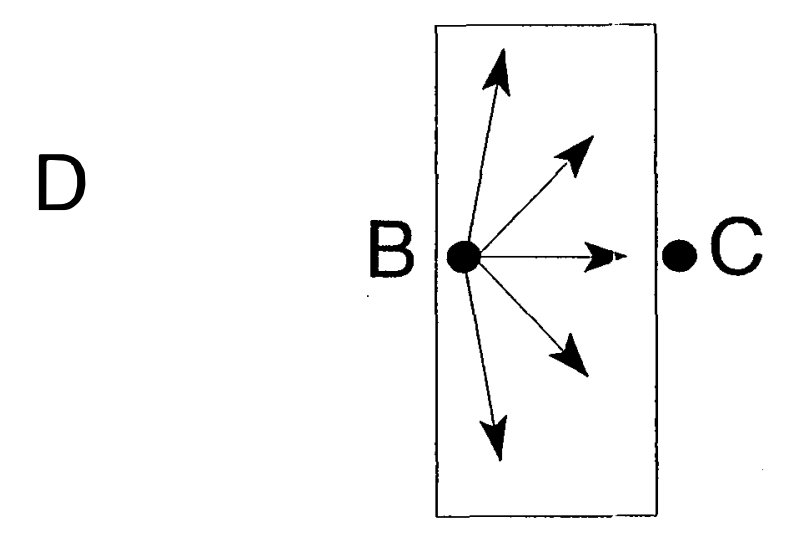

Incorrect

$$
\text { Excess Series Resistance } \approx \frac{1}{12} \rho_{s} L^{2} \quad\left[\Omega-\mathrm{cm}^{2}\right]
$$


CHOICES FOR VOLTAGE PROBE PLACEMENT

CURRENT PROBE, VOLTAGE PROBE

a) CURRENT PROBE

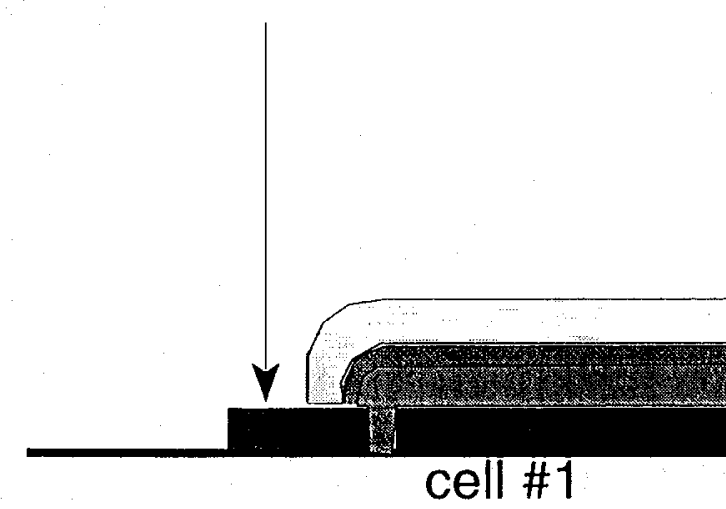

cell \#1

$\uparrow 4$ cell \#2

scribes

b)

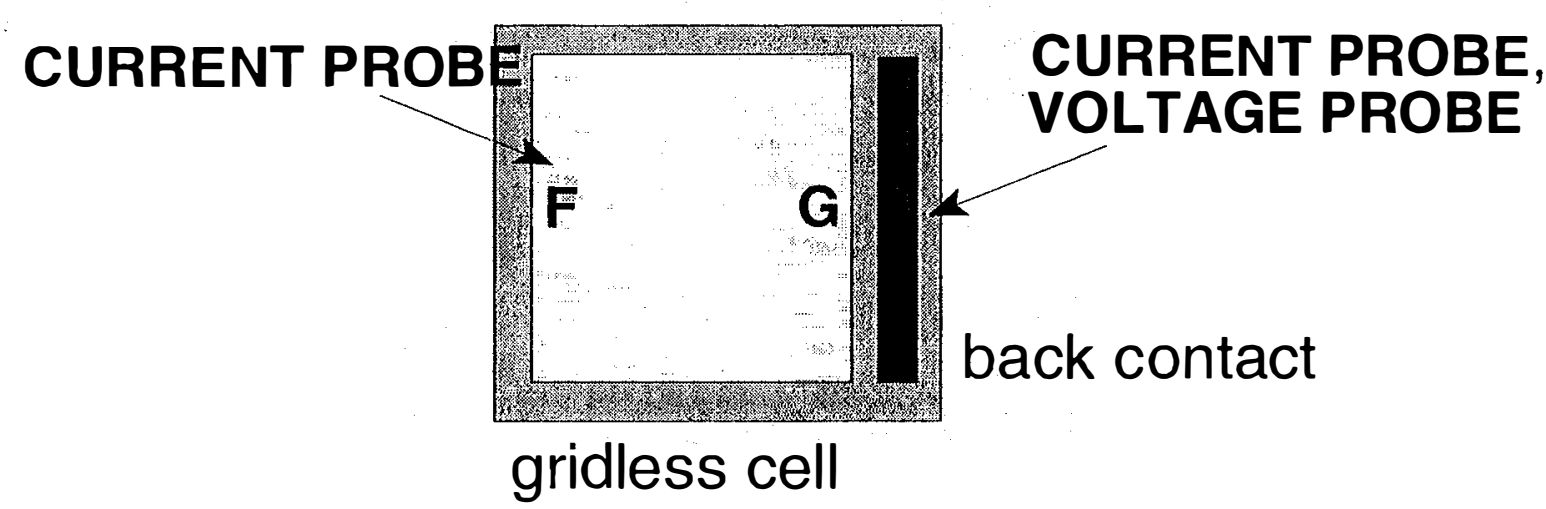




\section{CURRENT-VOLTAGE PROBE PLACEMENT: Hidden Series Resistance}

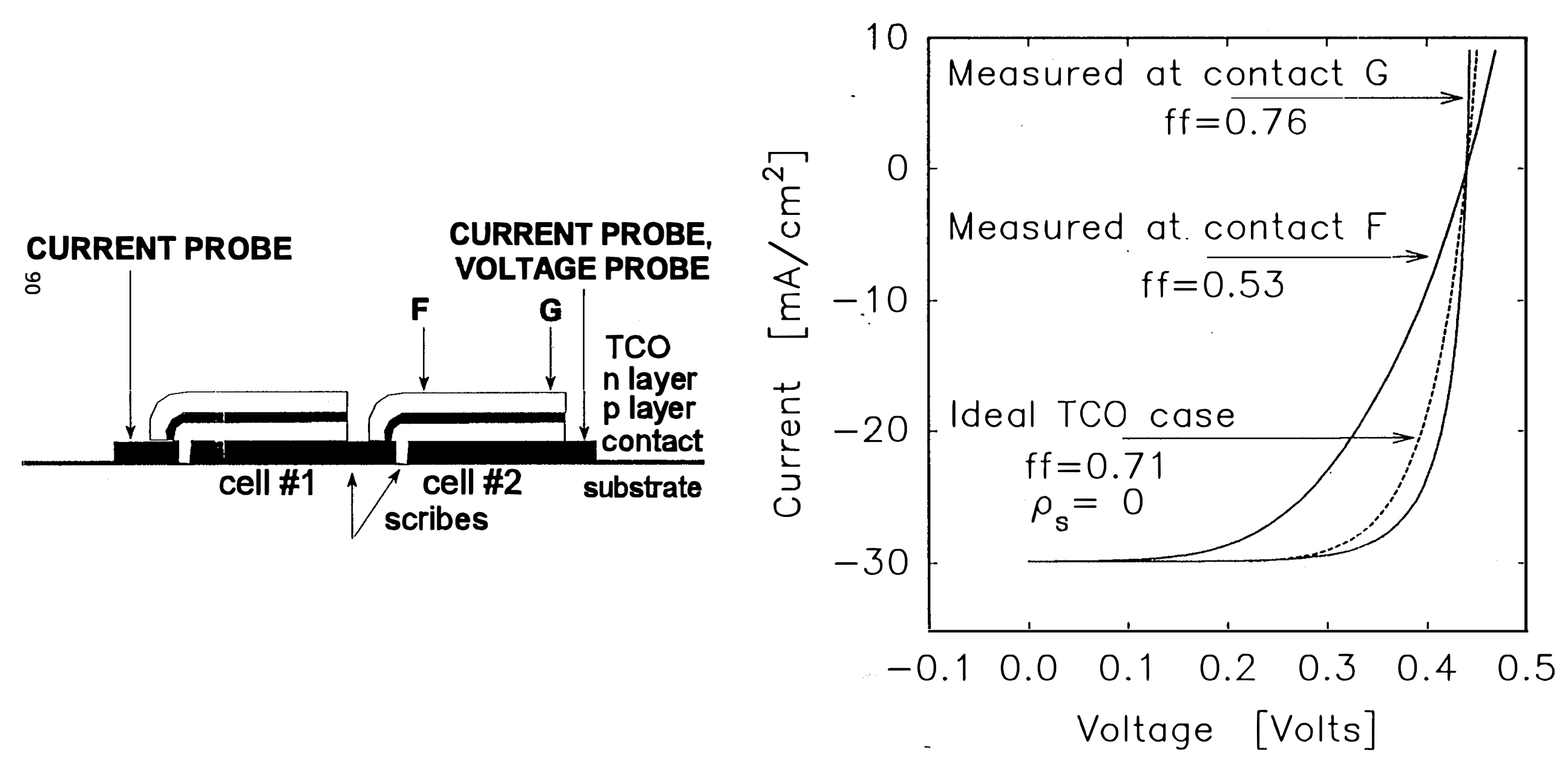




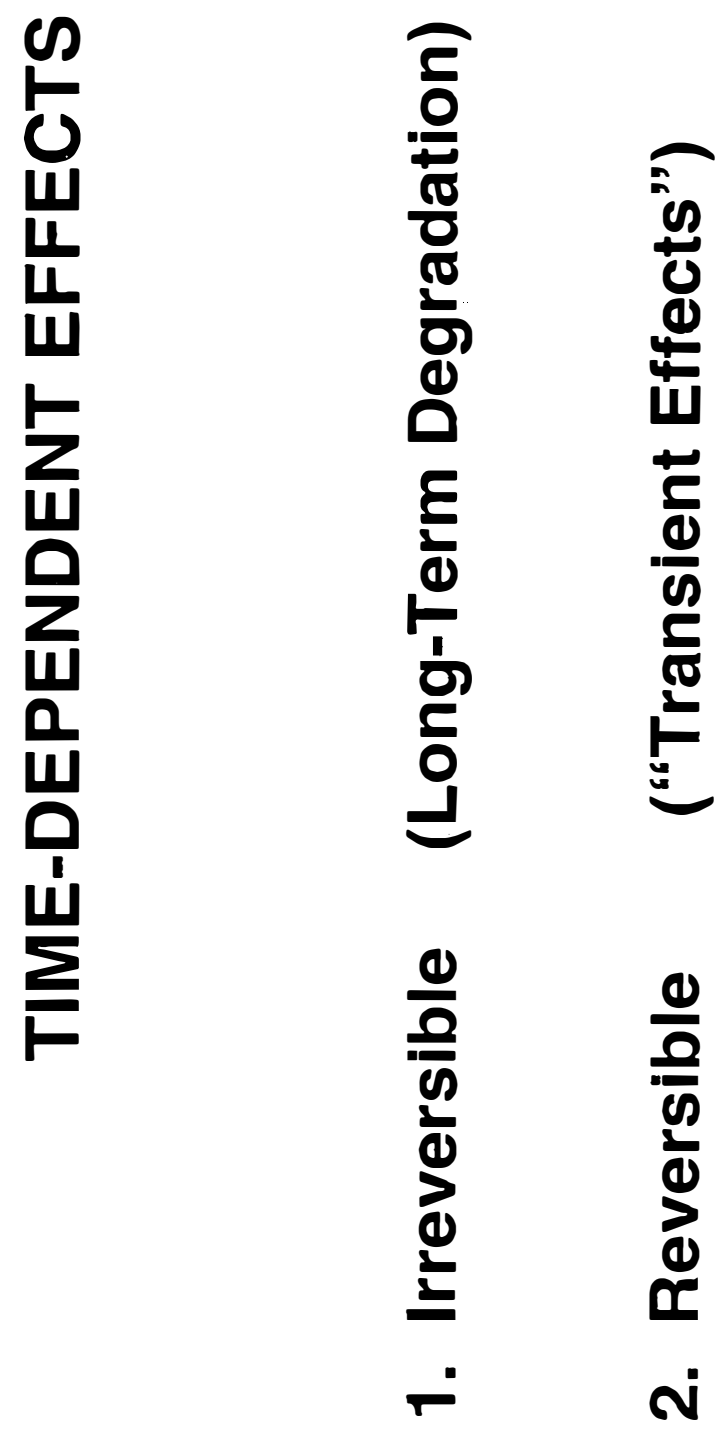




\section{TRANSIENT VOLTAGE EFFECTS}

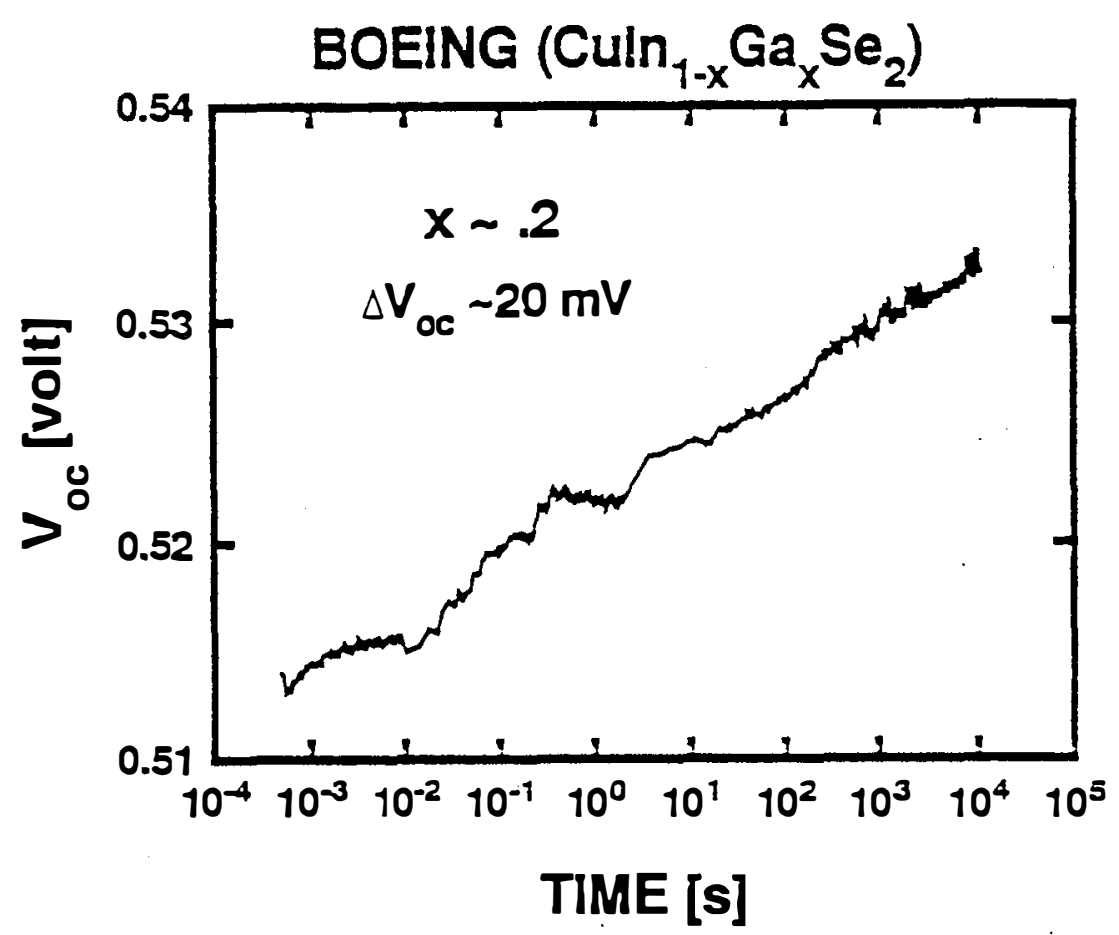

Typical transient voltage effect for polycrystalline cell."

\section{Identification:}

- voltage increases with time under forward bias

- effect is reversible

- voltage increase usually on the order of $5-40 \mathrm{mV}$

- effect is independent of temperature

** See R.A. Sasala, "Multi-Decade Time-Dependent Voltage of Polycrystalline Thin-Film Solar Cells", Ph.D. thesis, Colorado State University, 1993. 


\section{Origin:}

- Population of long-lived traps in and near depletion region changes.

- Champion cells tend to show smaller transient voltages.

Characterization:

- In comparing measurements, use consistent voltage pre-biases.

- Be aware of approximate size of voltage transients in your samples.

- Voltage pre-biased measurements most closely represent field operation. 


\section{LARGE SAMPLE CHARACTERIZATION}

- Simulator Intensity: Uniformity better than $\pm 4 \%$

$\Longrightarrow$ measured currents are within $1 \%$ of actual currents.

- Simulator Temperature: Uniformity better than $\pm 10^{\circ} \mathrm{C} \Rightarrow$ Measured voltages are within $\sim 2 \mathrm{mV}$ of actual voltages at average temperature.

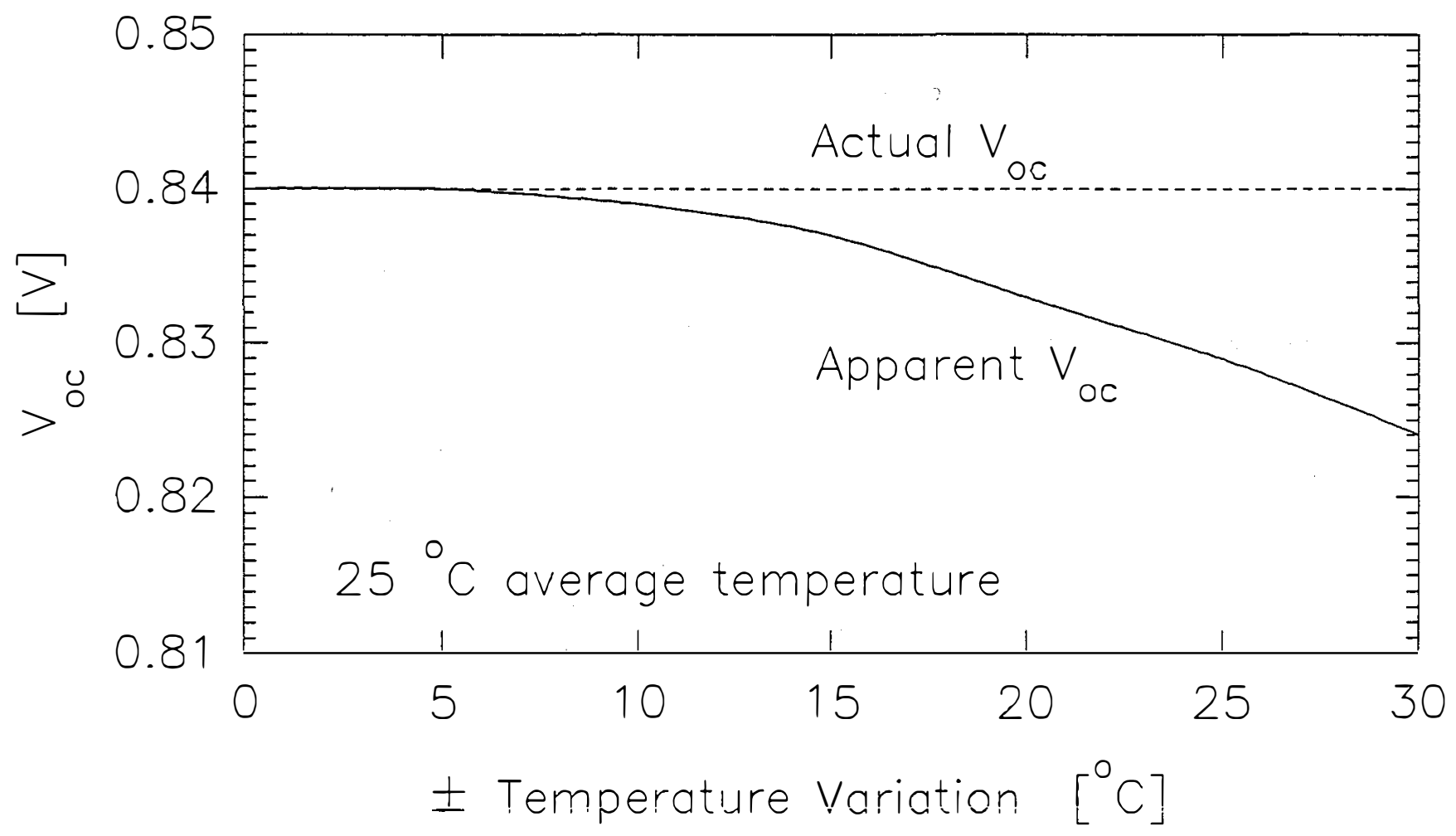




\section{QUANTUM EFFICIENCY}

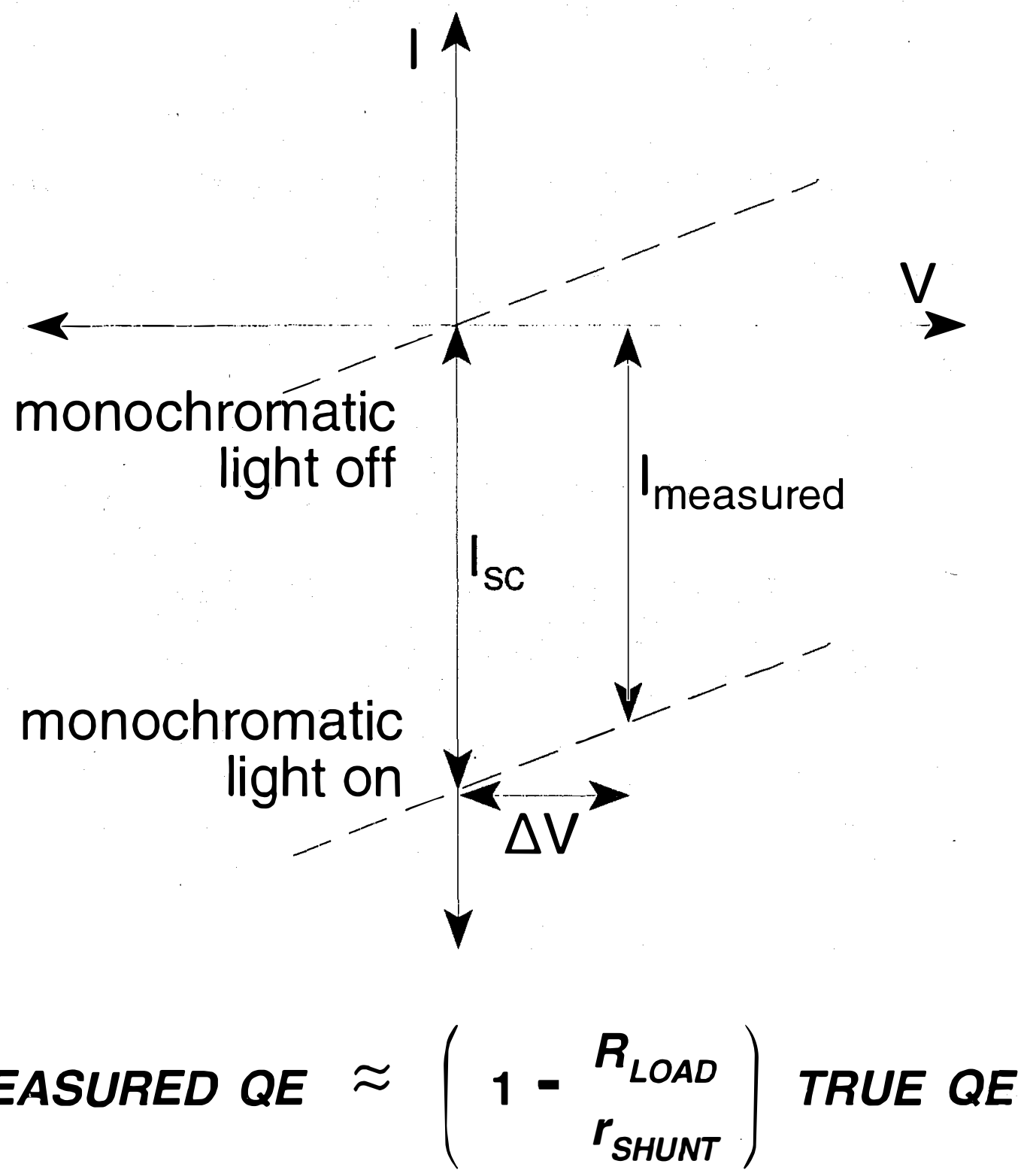

For small cell:

$\frac{R_{\text {LOAD }}}{r_{\text {SHUNT }}} \approx \frac{1 \Omega \text { circuit }+1 \Omega \text { contact resistance }}{1 \mathrm{k} \Omega-\mathrm{cm}^{2} \times 1 \mathrm{~cm}^{2}}=0.2 \%$

For large gridless cell:

$\frac{R_{L O A D}}{r_{\text {SHUNT }}} \approx \frac{1 \Omega \text { circuit }+10 \Omega \text { contact resistance }}{1 \mathrm{k} \Omega-\mathrm{cm}^{2} \times 25 \mathrm{~cm}^{2}}=25 \%$ 


\section{QUANTUM EFFICIENCY}

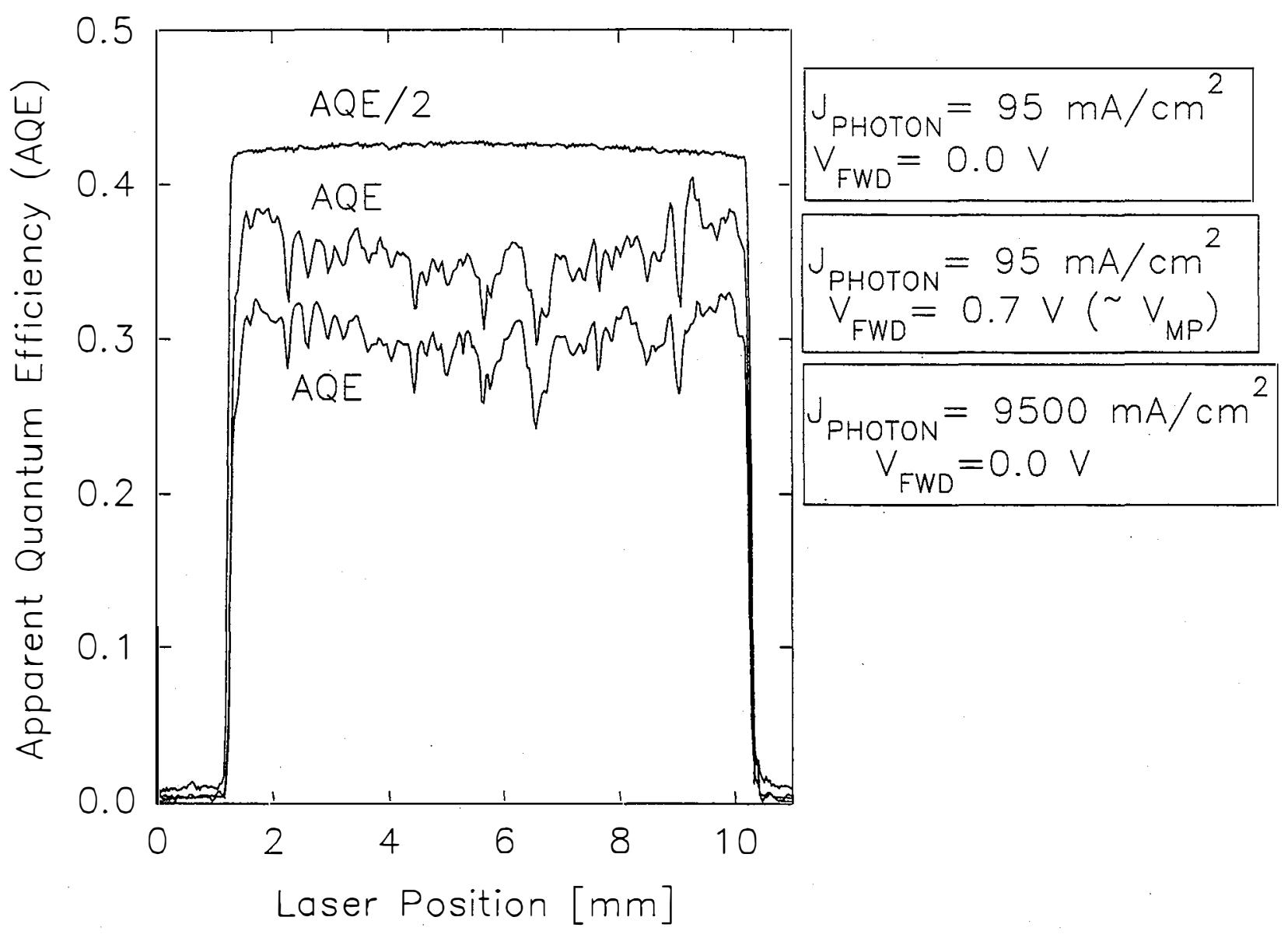

High intensities reflect forward bias behavior of cell, not short-circuit current.

Differences between high low intensity behavior is much more pronounced for thin films than for single-crystai celis. 


\section{SELECTIVE ILLUMINATION}

What information about individual cells in encapsulated modules can be extracted by selectively illuminating individual cells?

- INDIVIDUAL CELL SHUNT RESISTANCES

See T.J. McMahon, T.S. Basso, S.R. Rummel, "Cell Shunt Resistance and Photovoltaic Module Performance”, 25th IEEE Photovoltaics Specialists Conference, 1996.

- INDIVIDUAL CELL SHUNT RESISTANCES AND PHOTOCURRENTS

See I.L. Eisgruber, J.R. Sites, "Extraction of Individual-Cell Photocurrents and Shunt Resistances in Encapsulated Modules", Progress in Photovoltaics, Vol. 4, 1996.

- In general, current from any one cell depends on all cells in module - careful interpretation required! 
SELECTIVE ILLUMINATION: CELL-TO-CELL CURRENT COMPARISONS

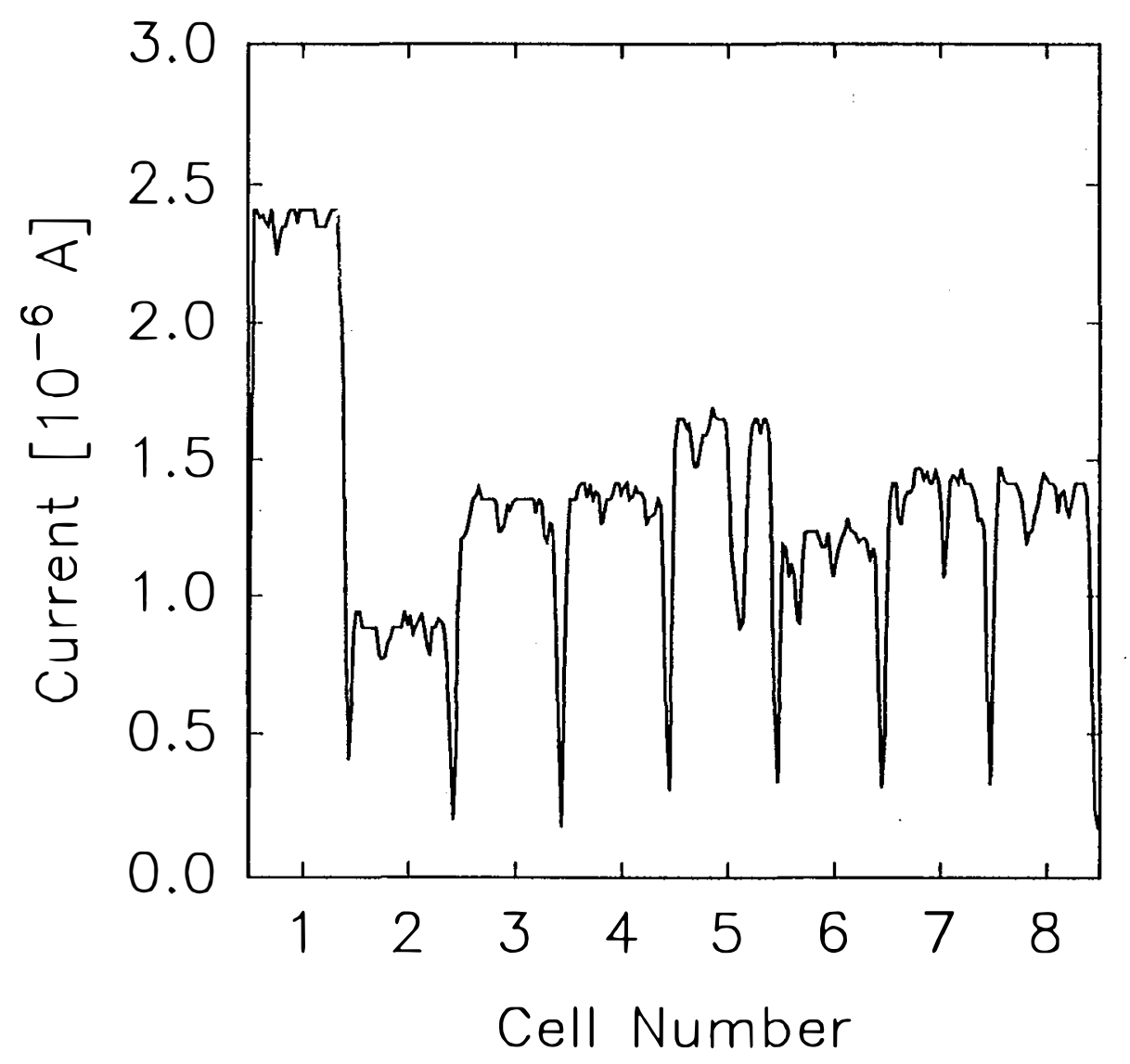

Identical Individual Cell Photocurrents 


\section{SELECTIVE ILLUMINATION: \\ CELL-TO-CELL CURRENT COMPARISONS}
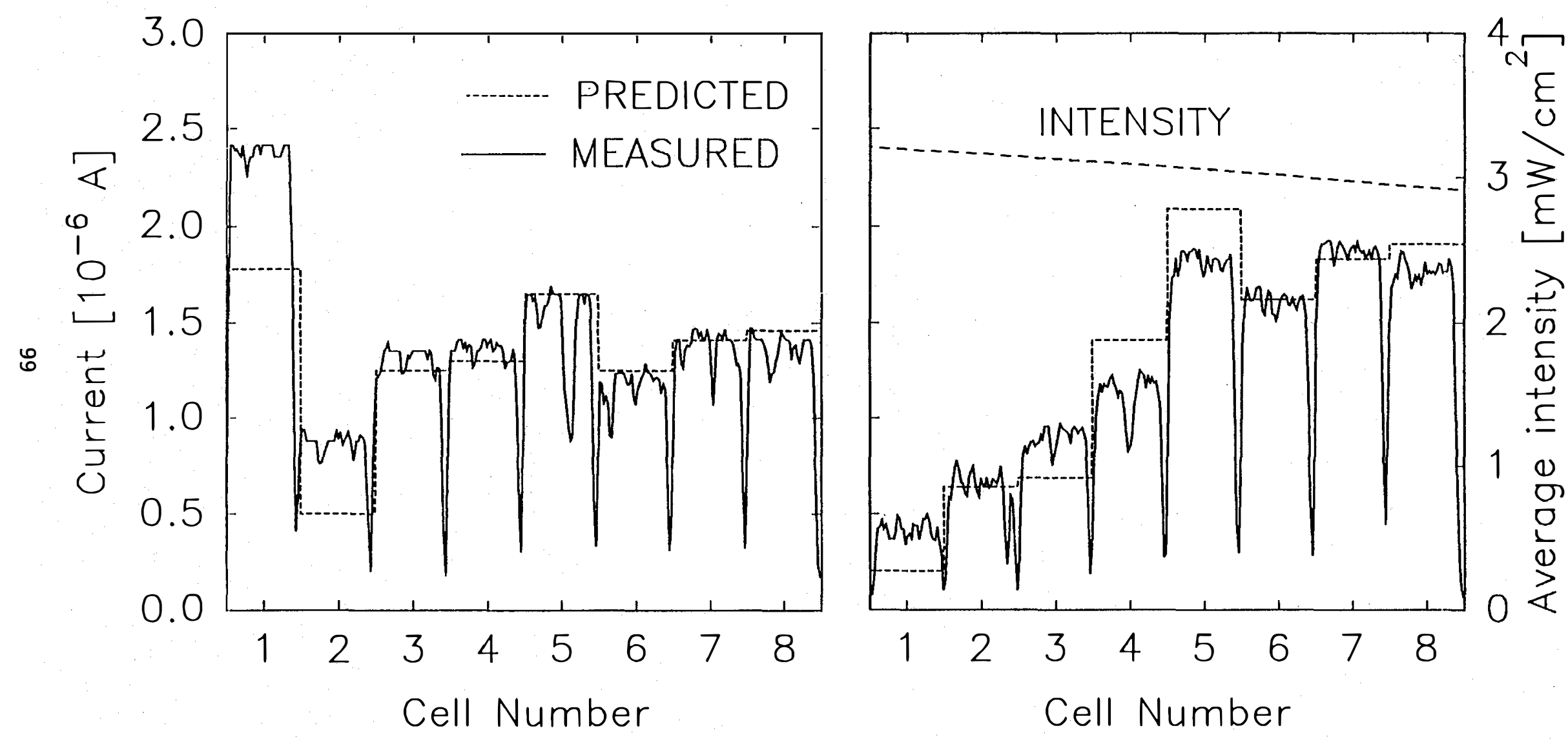

No background bias light With background bias light 


\section{OPEN-CIRCUIT VOLTAGE}

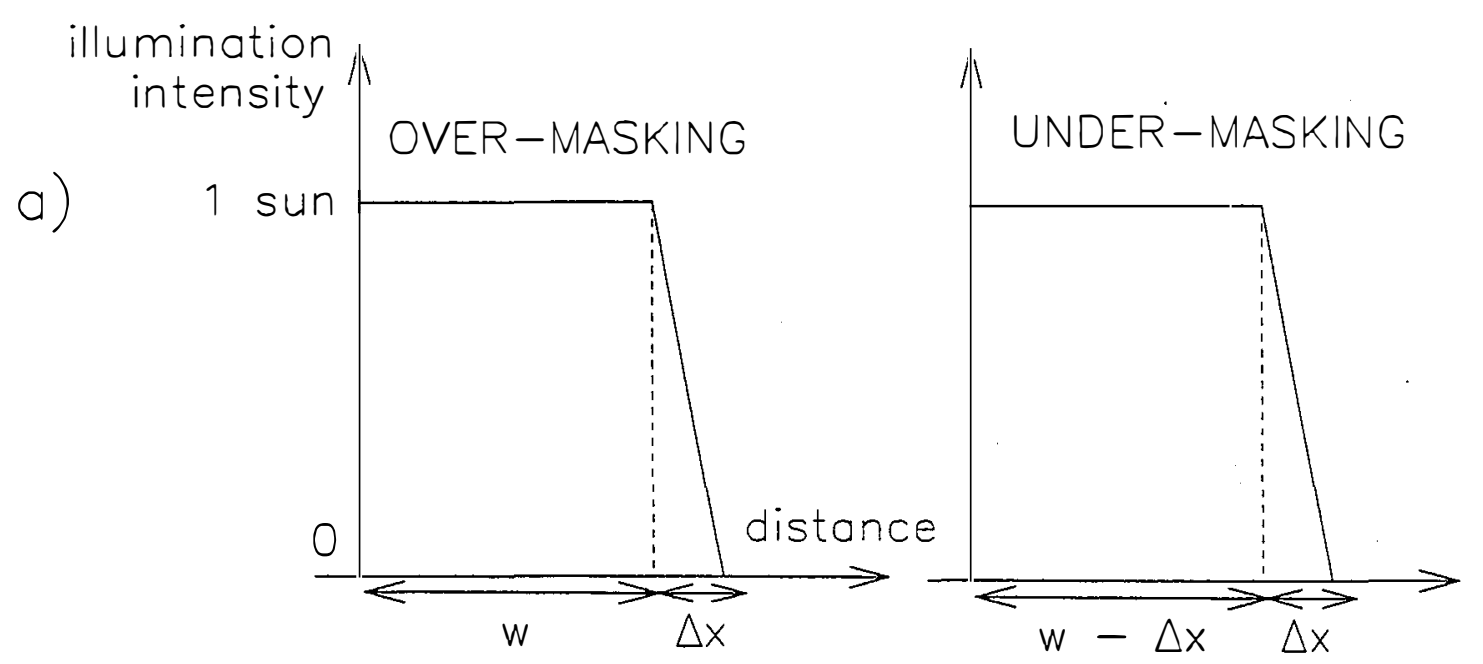

b)

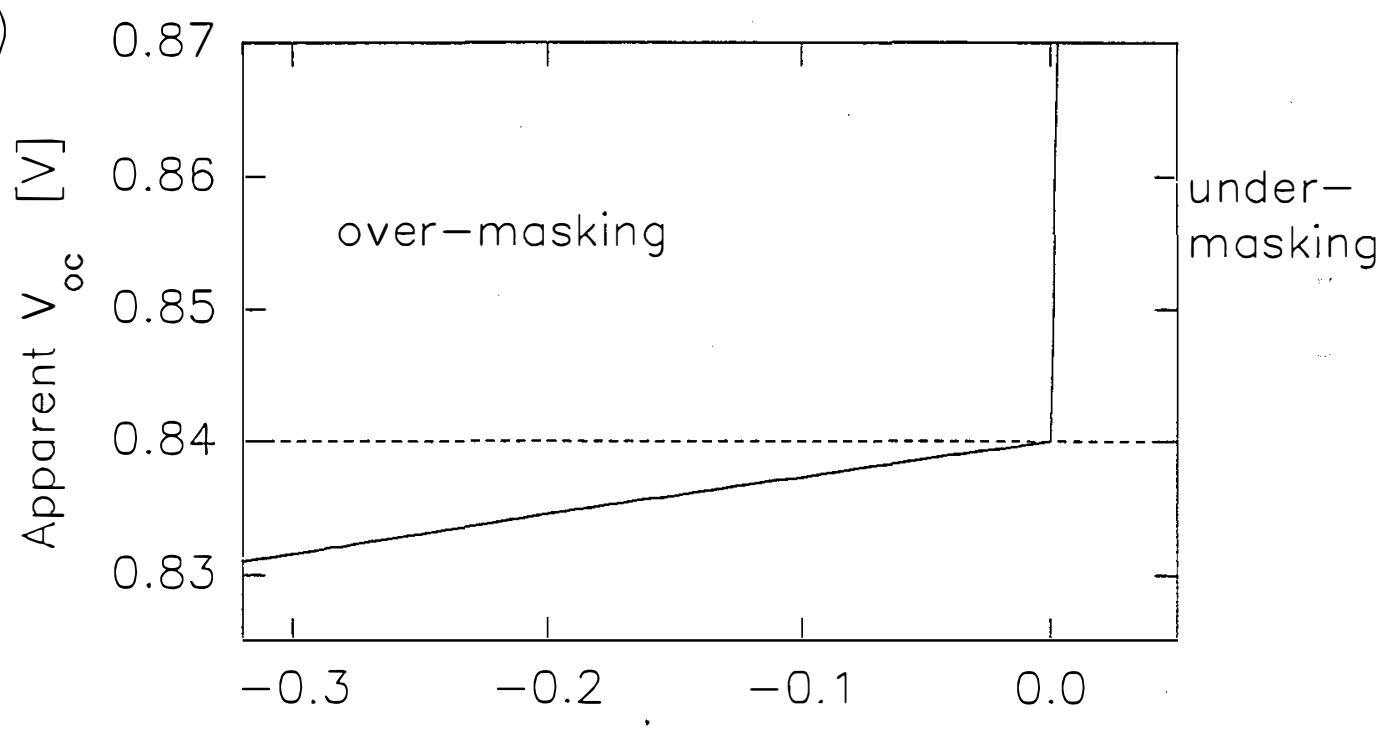

Illumination Distance From Cell Edge [cm]

\section{- For over-masking: $\Delta \mathrm{V}_{\text {oc }}=\mathrm{V}_{0} \ln (1-\Delta \mathrm{x} / 2 \mathrm{w})$ \\ - For under-masking: $\Delta \mathrm{V}_{\text {oc }}=\mathrm{J}_{\mathrm{L}} \mathrm{r}(\Delta \mathrm{x} / 2 \mathrm{w})$ \\ - Longer, thinner, cells make measuring open circuit voltage through selective illumination much less accurate for thin-film cells than for single-crystal cells.}




\section{CONCLUSIONS}

Meaningful characterization of thin film modules requires:

- correct placement of current-voltage probes to avoid artificially high or artificially low series resistances.

- consistent handling of voltage transients.

- low circuit impedance and reasonable intensity for measuring quantum

$\vec{\varrho}$ efficiency.

- uniform simulator intensity $( \pm 4 \%)$ and temperature $\left( \pm 10^{\circ} \mathrm{C}\right)$ to measure full currents and voltages.

- careful interpretation of selective illumination measurements.

- Currents depend on all cells in module. Information can be extracted by proven methods.

- Voltages are very sensitive to masking error, particularly in the thin-film geometry. 


\section{An Evaluation of Long-Term System Degradation at PVUSA}

NREL PV Performance and Reliability Workshop

Lakewood, CO

September 4, 1996

T. Townsend, Endecon Engineering 


\section{Introduction}

- Degradation: definition, mechanisms

- Two methods of calculating degradation rate

- Analysis of 11 PVUSA systems @ 5 sites

6 of these have over 5 years operation 


\section{Degradation}

\section{- Working definition:}

Irreversible change in PV system output

- Some possible mechanisms:

1. Surface deterioration and/or soiling

2. Cover material deterioration

3. Encapsulant deterioration

4. Sun-induced (other time-dependent?) cell degr.

5. Cell contact corrosion/increasing resistance

6. BOS/wiring corrosion, undetected failures

(wiring, fuses, diodes, MOVs)

7. PCU component aging 


\section{Limitations}

- Calibration accuracy, drift

- Modeling error

- The usual confounding factors:

1. Varying soiling

2. Varying spectrum

$\vec{i} \quad 3$. Varying incidence angle

4. Varying temperature

5. Varying irradiance

(Thank you Sandia's D. King for tackling these!) 


\section{Two Ways of Estimating Degradation}

- Track semi-annual monthly efficiency changes

Best-fit using series of screened April and October data scaled to $45^{\circ} \mathrm{C}$. (Screened for partial failures or operating problems.) These months usually have clean panels, enough clear days, and near-PTC operating temperatures, as well as similar spectrum and incidence angles. Done here for 6 systems [SSI, Solarex, Sovonics (2), UPG, ENTECH].

- Periodic rerate with regression model

Use model to translate screened power data to reference condition such as PTC (1 sun, $20^{\circ} \mathrm{C} \mathrm{T}_{\text {air, }} 1 \mathrm{~m} / \mathrm{s}$ )

$\mathrm{Pwr}=\mathrm{C}_{1}{ }^{*}\left|\mathrm{rr}+\mathrm{C}_{2}{ }^{*}\right| \mathrm{rr}^{2}+\mathrm{C}_{3}{ }^{*}\left|r r^{*} \mathrm{~T}_{\mathrm{air}}+\mathrm{C}_{4}{ }^{*}\right| r r^{*} \mathrm{WS}$

Done for 11 systems. 
PVUSA Systems with over 3 yrs. operation

\begin{tabular}{|l|l|l|}
\hline \multicolumn{1}{|c|}{ Name } & \multicolumn{1}{c|}{ Start vear } & Installed kW \\
\hline Siemens Davis & 1989 & $18.7 \mathrm{~kW}$ dc \\
\hline Sovonics Davis & 1989 & $17.3 \mathrm{~kW}$ dc \\
\hline UPG Davis & 1989 & $15.7 \mathrm{~kW}$ dc \\
\hline Sovonics Maui & 1989 & $18.5 \mathrm{~kW} \mathrm{dC}$ \\
\hline Solarex Davis & 1990 & $15.7 \mathrm{~kW}$ dc \\
\hline ENTECH Davis & 1991 & $16.5 \mathrm{~kW}$ dc \\
\hline IPC Austin (Mobil) & 1992 & $17.9 \mathrm{~kW}$ ac \\
\hline APS Davis & 1992 & $479 \mathrm{~kW}$ ac \\
\hline SSI Kerman & 1993 & $498 \mathrm{~kW}$ ac \\
\hline IPC Davis (Mobil) & 1993 & $196 \mathrm{~kW}$ ac \\
\hline IPC Maspeth (Uni-Solar) & 1993 & $17.9 \mathrm{~kW}$ ac \\
\hline IPC Farmingdale (Mobil) & 1993 & not accepted \\
\hline
\end{tabular}




\section{SSI EMT Array Semi-Annual Effic. Trend}

SSI EMT ARRAY DEGRADATION HISTORY

SEMI-ANNUAL EFFIC., SCALED TO 45 DEG. C

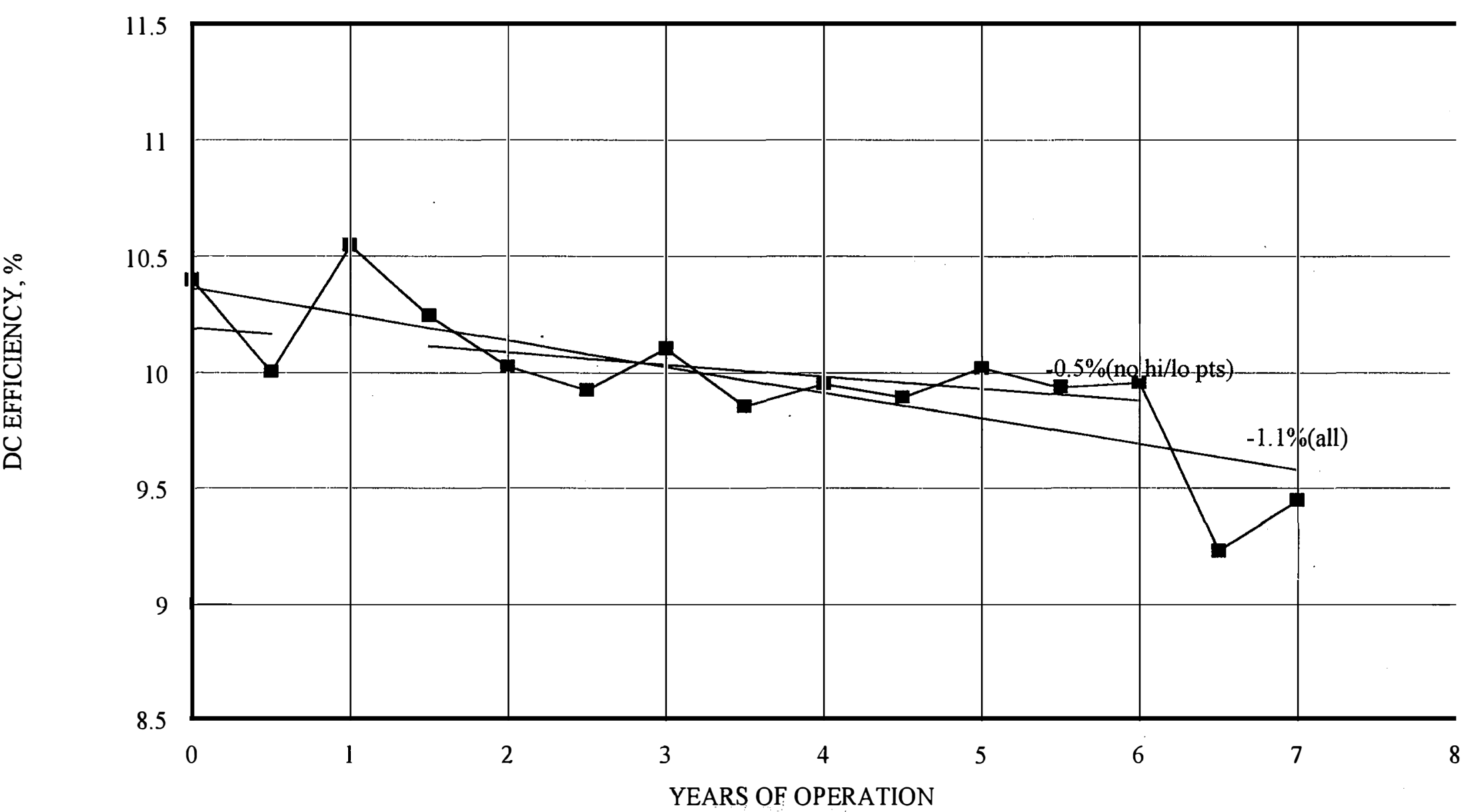

OVERALL DEGRADATION RATE $=-1.1 \% \tilde{\mathbf{n}} 0.5 \%$

r-squared $=0.60$ 


\section{Sovonics Davis EMT Array Effic. Trend}

SOVONICS EMT ARRAY DEGRADATION HISTORY

SEMI-ANNUAL EFFIC., SCALED TO 45 DEG. C

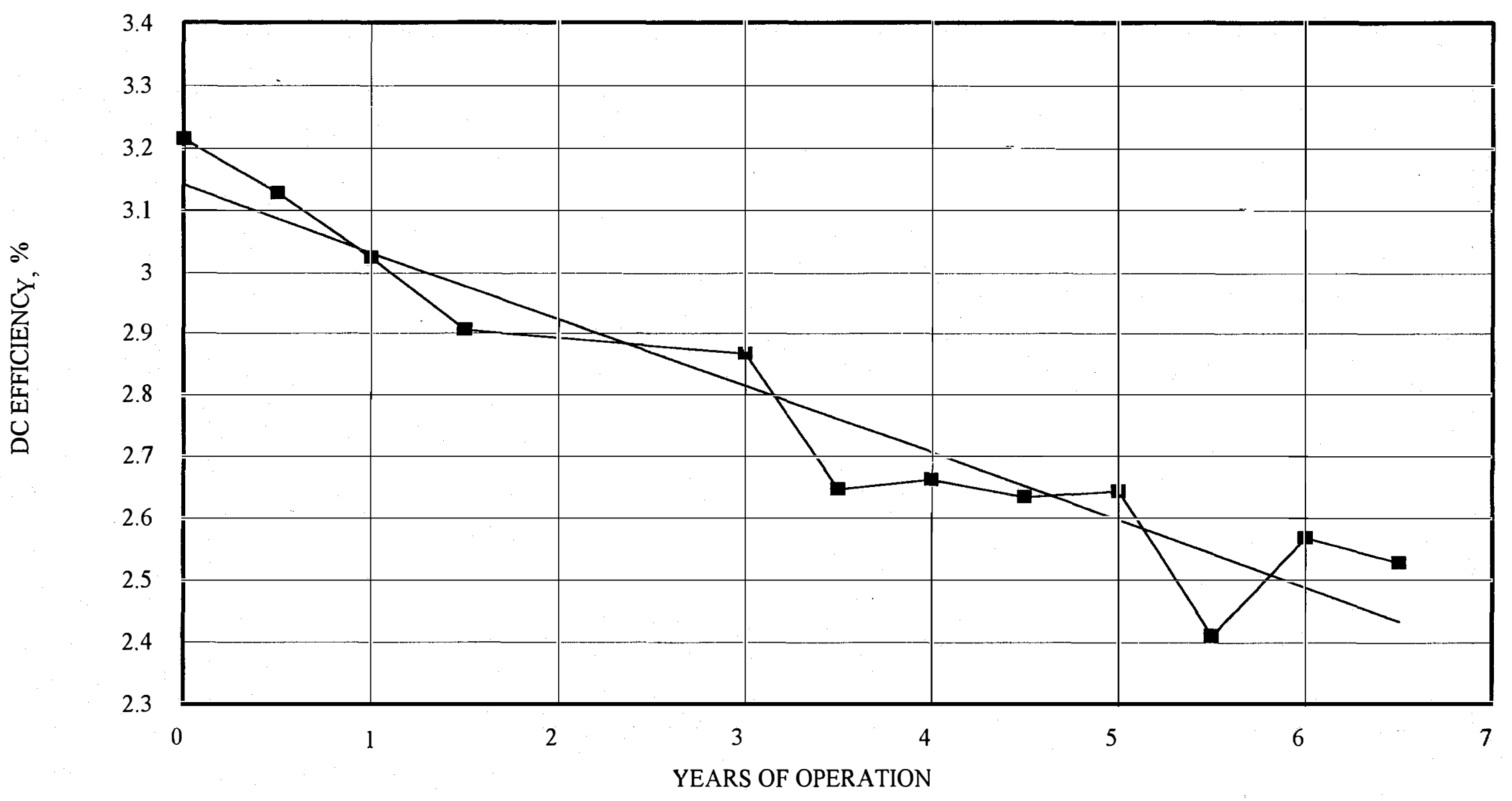

OVERALL DEGRADATION RATE $=-3.8 \%$ ñ $0.4 \%$ r-squared $=0.91$ 


\section{Sovonics Maui EMT Array Effic. Trend}

MAUI EMT ARRAY DEGRADATION HISTORY

SEMI-ANNUAL EFFIC., SCALED TO 45 DEG. C

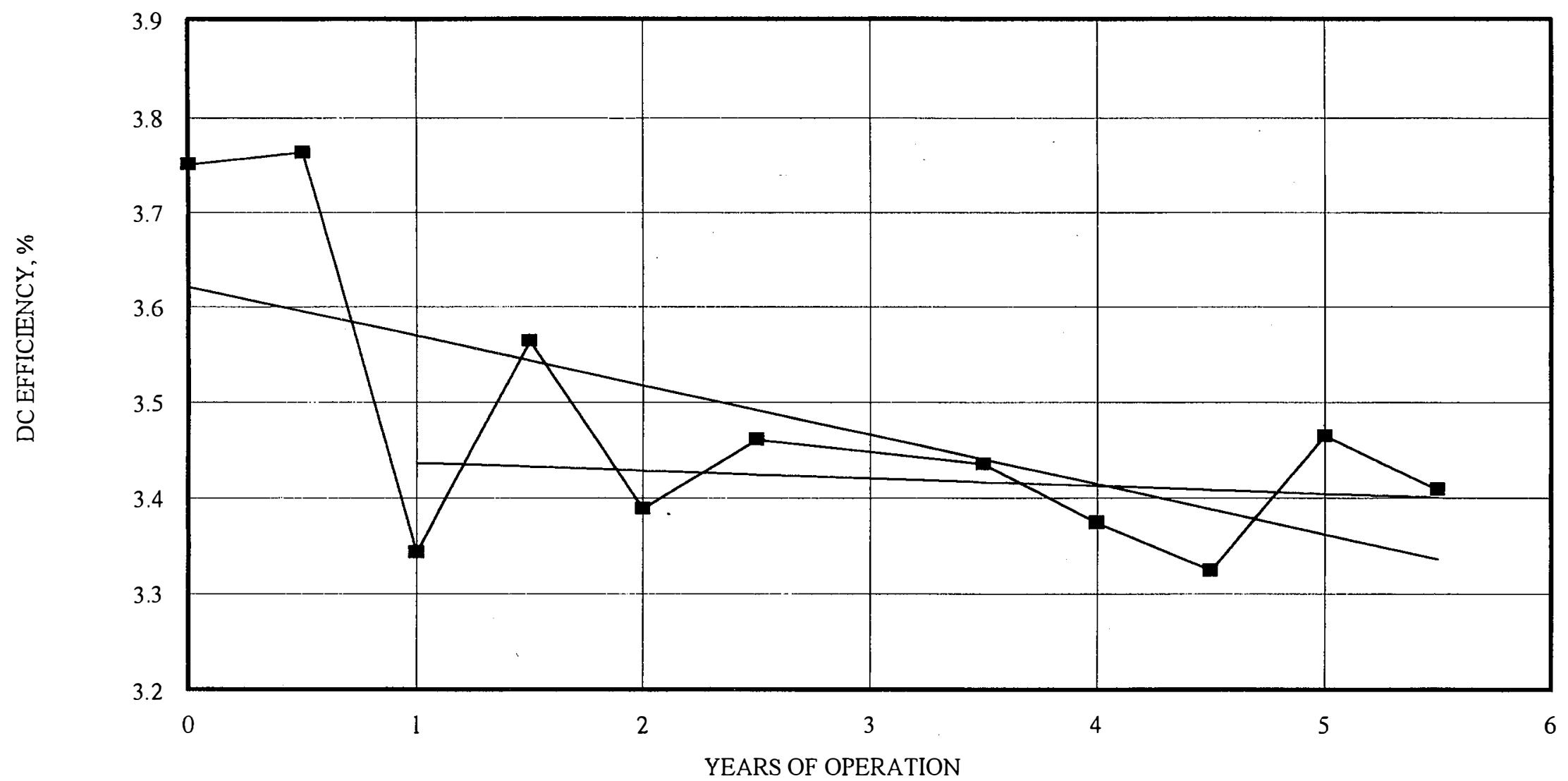

OVERALL DEGRADATION RATE $=-1.5$ ñ $1.2 \%$ (Zero $w / o$ lst yr)

r-squared $=0.41$ 


\section{Overall EMT Array Efficiency Trend Results}

EMT Array Long-Term Degradation

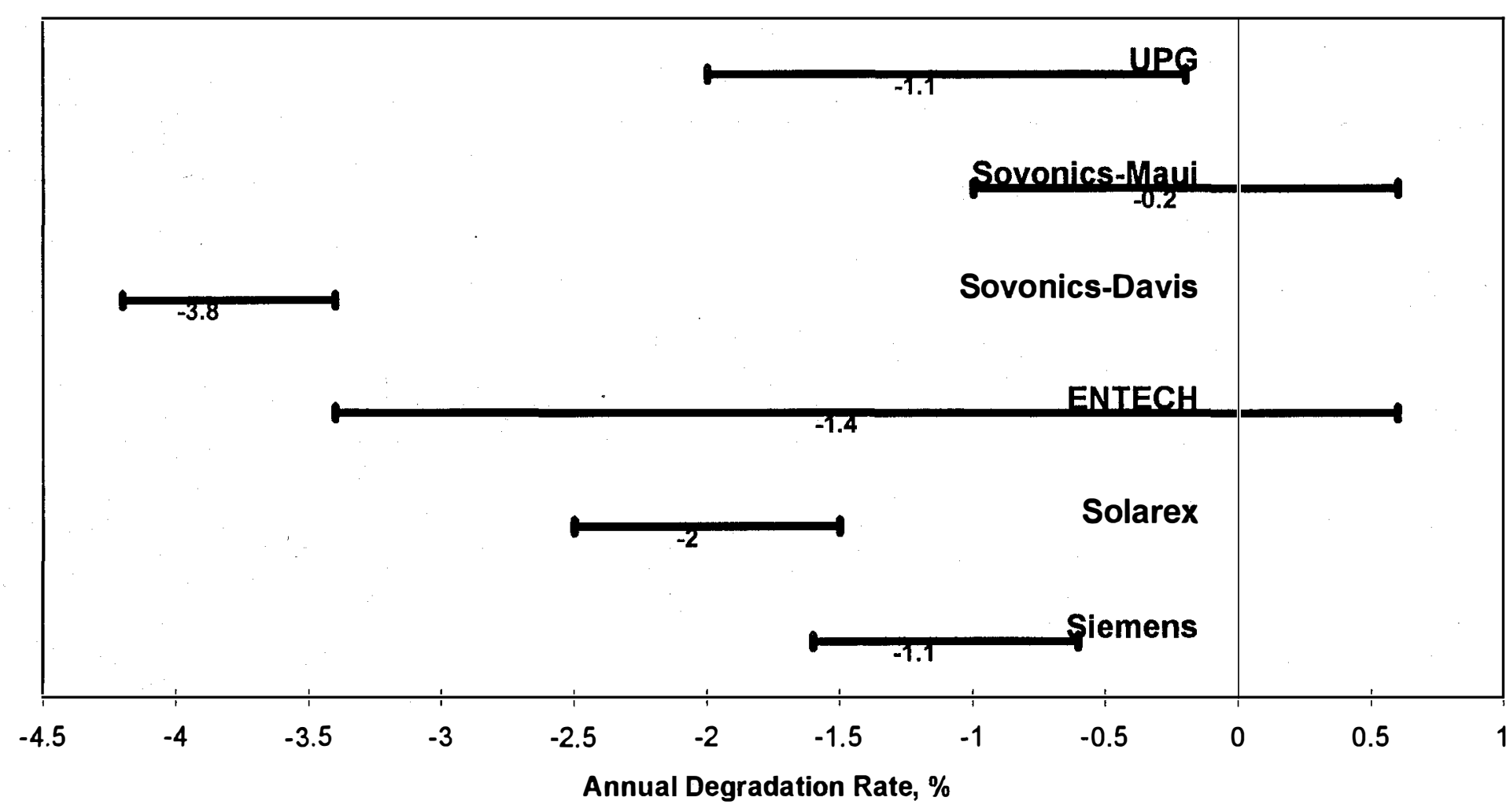


Regression Model Re-Rating

\begin{tabular}{|c|c|c|c|c|}
\hline Name & Orig. Rating & Re-Rated & $\begin{array}{l}\text { Yrs. elapsed } \\
\text { Y la }\end{array}$ & $\begin{array}{l}\text { Degr. Rate \% } \\
\text { De }\end{array}$ \\
\hline ssI & $18.7 \mathrm{~kW} d \mathrm{dc}$ & 16.5 Apr 96 & 7.2 & $-1.7(-1.1 \pm 0.5)$ \\
\hline Sovonics Davis & $17.3 \mathrm{~kW} \mathrm{dc}$ & 13.7 Apr 96 & 6.8 & $-3.4(-3.8 \pm 0.4)$ \\
\hline UPG & $15.7 \mathrm{~kW}$ dc & 13.2 Apr 96 & 6.3 & $-2.7(-1.6 \pm 1.0)$ \\
\hline Sovonics Maui & $18.5 \mathrm{~kW} \mathrm{dc}$ & 16.5 Oct 93 & 3.9 & $-2.9(-1.5 \pm 1.2)$ \\
\hline Solarex & $15.7 \mathrm{~kW} \mathrm{dc}$ & 13.7 Apr 96 & 5.5 & $-2.4(-2.0 \pm 0.5)$ \\
\hline ENTECH & $16.5 \mathrm{~kW} \mathrm{dc}$ & 17.0 Oct 93 & 2.5 & $+1.2(-1 \pm 2)$ \\
\hline IPC Austin & $17.9 \mathrm{~kW}$ ac & 16.1 Apr 96 & 3.0 & 3.5 \\
\hline APS & $479 \mathrm{~kW}$ ac & $\begin{array}{l}428 \text { Oct } 93 \\
378 \text { Apr } 96\end{array}$ & $\begin{array}{l}1.0 \\
2.5\end{array}$ & $\begin{array}{l}10.6 \\
4.8\end{array}$ \\
\hline SSI Kerman & $498 \mathrm{~kW}$ ac & 476 Apr 96 & 2.8 & 1.6 \\
\hline IPC Davis & $196 \mathrm{~kW} \mathrm{ac}$ & 191 May 96 & 2.9 & 0.9 \\
\hline IPC Maspeth & $17.9 \mathrm{~kW}$ ac & $\begin{array}{l}\text { 15.6 Aug } 94 \\
\text { 12.9 Jun } 95\end{array}$ & $\begin{array}{l}1.0 \\
0.8\end{array}$ & $\begin{array}{l}13 \\
20\end{array}$ \\
\hline
\end{tabular}




\section{Conclusions}

- Although the uncertainty is still large, system level degradation seems to be occurring for all system types except ENTECH's concentrator and it's due for a recheck.

- Degradation rates for a-Si systems skewed by initial stabilizing period, then range widely afterwards: Sovonics Maui and UPG nearly flat, APS and Sovonics Davis 4-5\%, and IPC/Uni-Solar Maspeth 20\%? There must be site-specific partial failures to cause this wide range.

- Two degradation calculation methods agree well. Both show strong seasonal influence, though.

- Typical PVUSA degradation rate of $2 \%$ consistent with literature and with PVUSA's earlier reports.

- If $2 \%$ or so is real, need to consider it up front in performance/economics. Not a show-stopper. 


\title{
ARRAY UTILIZATION IN HYBRID SYSTEMS
}

\author{
Rick Chapman \\ Photovoltaic System Assistance Center \\ Sandia National Laboratories \\ Albuquerque New Mexico
}

$\vec{A}$ What is definition of array utilization for a hybrid system ? 


\section{BENEFITS OF HYBRID TECHNOLOGY}

Generator alone - generator sized for peak load but runs mostly at low load

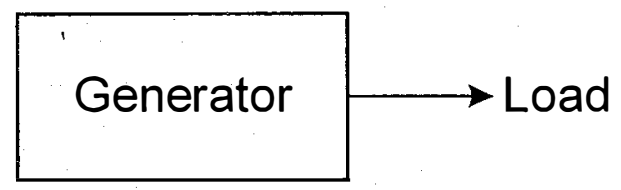

-runs 24 hours/day (8760 hours/year)

- low generator loading results in poor fuel efficiency

Generator with battery and power processing - generator runs at full load then shuts down

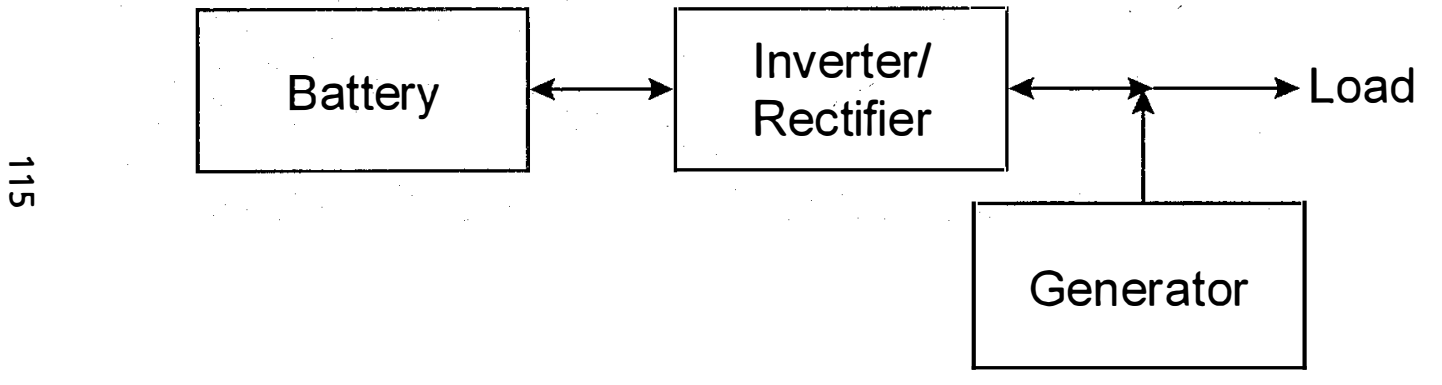

- generator must produce more energy to meet load plus losses but.....

-runs fewer hours (less maintenance) and

-uses less fuel (less fuel cost)

Add PV (hybrid) - PV energy displaces generator energy

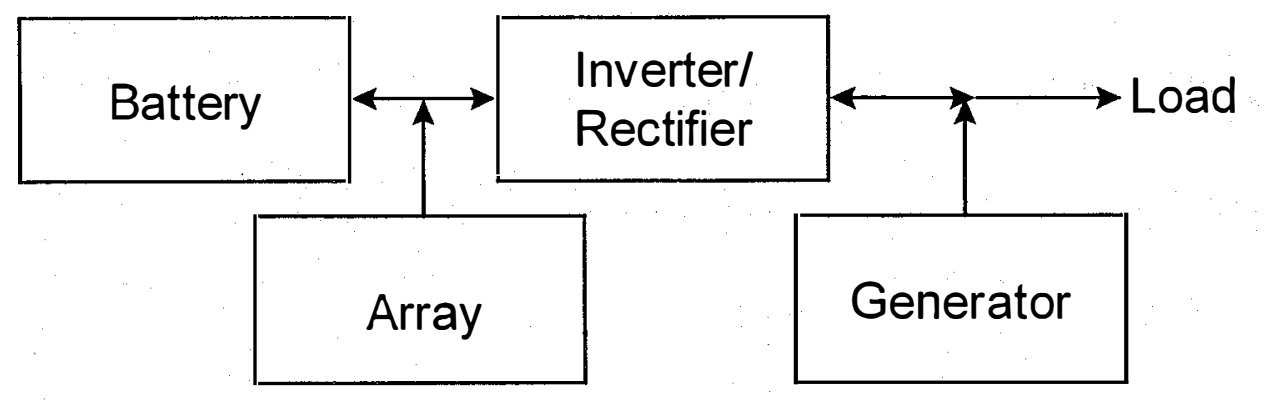

-runs fewer hours and

-uses less fuel 


\section{ARRAY UTILIZATION IN A HYBRID SYSTEM IS HOW WELL DOES ARRAY ENERGY DISPLACE GENERATOR ENERGY}

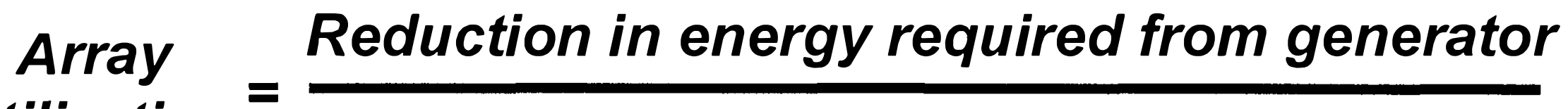 Utilization}

MEASURE OF RETURN ON INVESTMENT FROM ADDING PV 


\section{QUESTIONS}

-What is "good" array utilization?

-How to achieve good array utilization?

-How important is good array utilization?

\section{ANSWERS}

-Performance simulation analysis based on Grasmere Point Hybrid System (Mt Home AFB) 


\section{WHY GRASMERE POINT SYSTEM?}

-Rule-of-thumb" sizing says system should have good array utilization - limit PV size so all PV power is absorbed by load

- daily load - $1050 \mathrm{kWhac}$ (900-1300)

- daily PV - 320 kWhac (175 in Dec - 350 in July)

\section{however...}

- Generator run algorithm and balance of system sizing limit battery's ability to store and dispense PV power on an instantaneous basis

- load - 10-125 kWac; PV 77.6 kW peak

- PV power must go to battery when generator on

$$
\text { also... }
$$

-PV is direct-coupled to battery - no max power tracking 


\section{GRASMERE POINT HYBRID SYSTEM \\ Block Diagram}

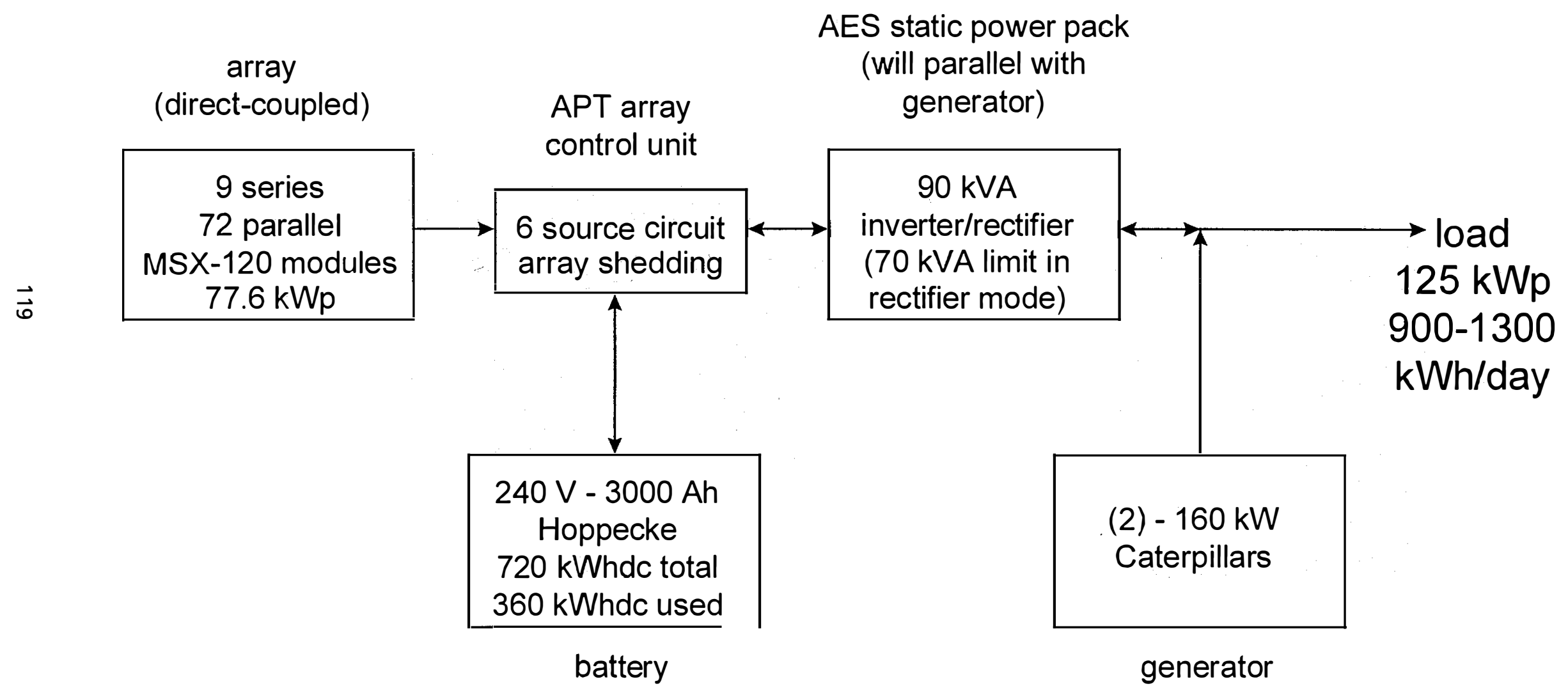




\section{FACTORS THAT MAY RESULT IN POOR ARRAY UTILIZATION}

Non-optimum capture of available PV energy

-No max power tracking

System limits battery's ability to store and dispense PV power

- Limited battery capacity

- Generator runs until battery fully charged every start

- note - generator provides equalization charge every 200 hours (10\% overcharge)

-Inverter cannot carry peak load - generator will start for peak load as well as low SOC 


\section{USE HYSIM MODEL TO ANALYZE EFFECT OF THESE FACTORS INDEPENDENTLY}

-Add max power tracking

-Increase battery capacity from 720-2400 kWh

-Decrease generator stop limit from 100-80\% SOC

- retain equalization every 200 hours

-Increase inverter capacity from 90-150 kVA 


\section{POWER TRACKING DOES NOT EFFECT ARRAY UTILIZATION}

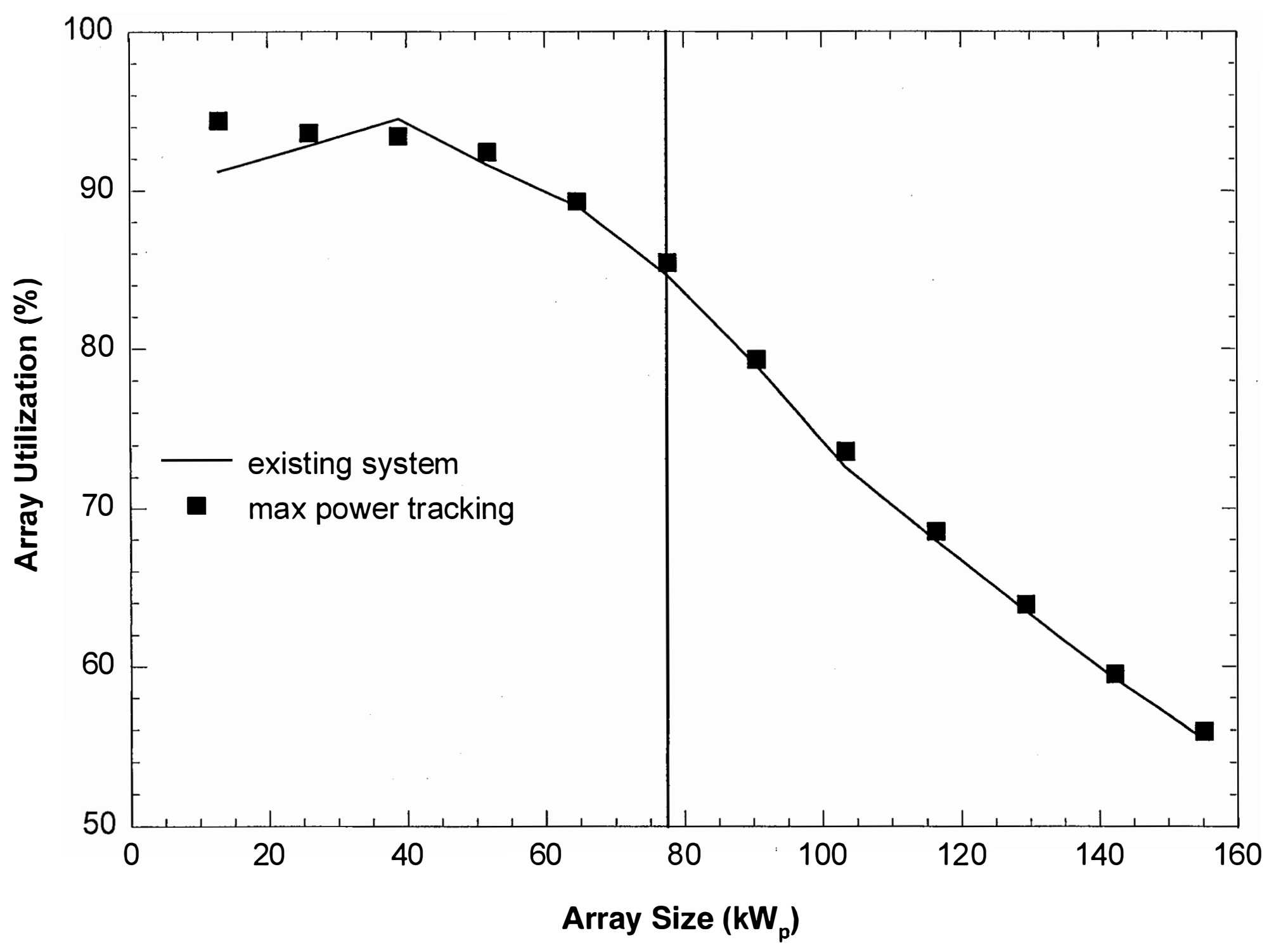




\section{RELY ON BATTERY TO USE ALL PV POWER}

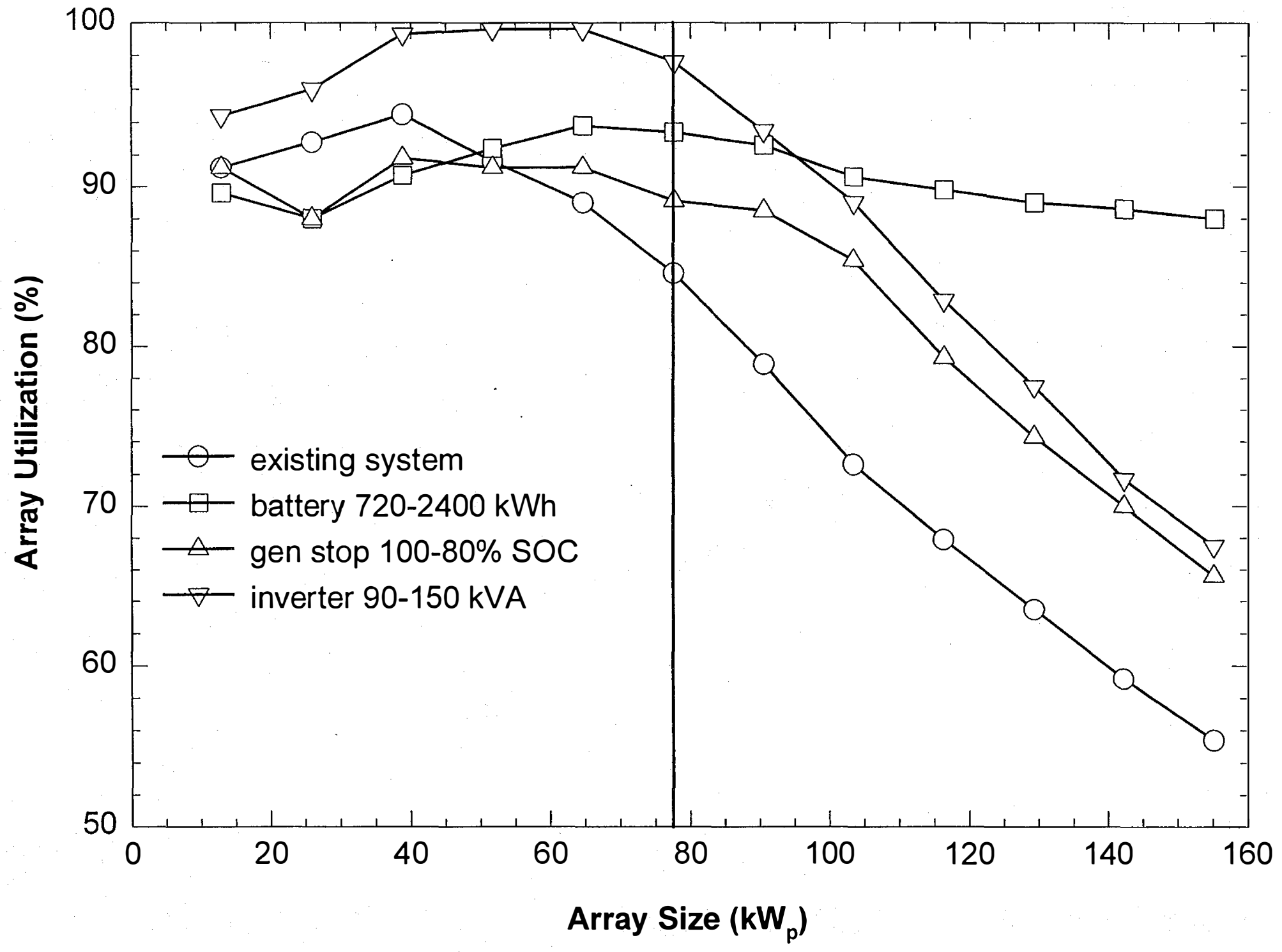


BATTERYIPOWER PROCESSING LOSSES ARE CRITICAL

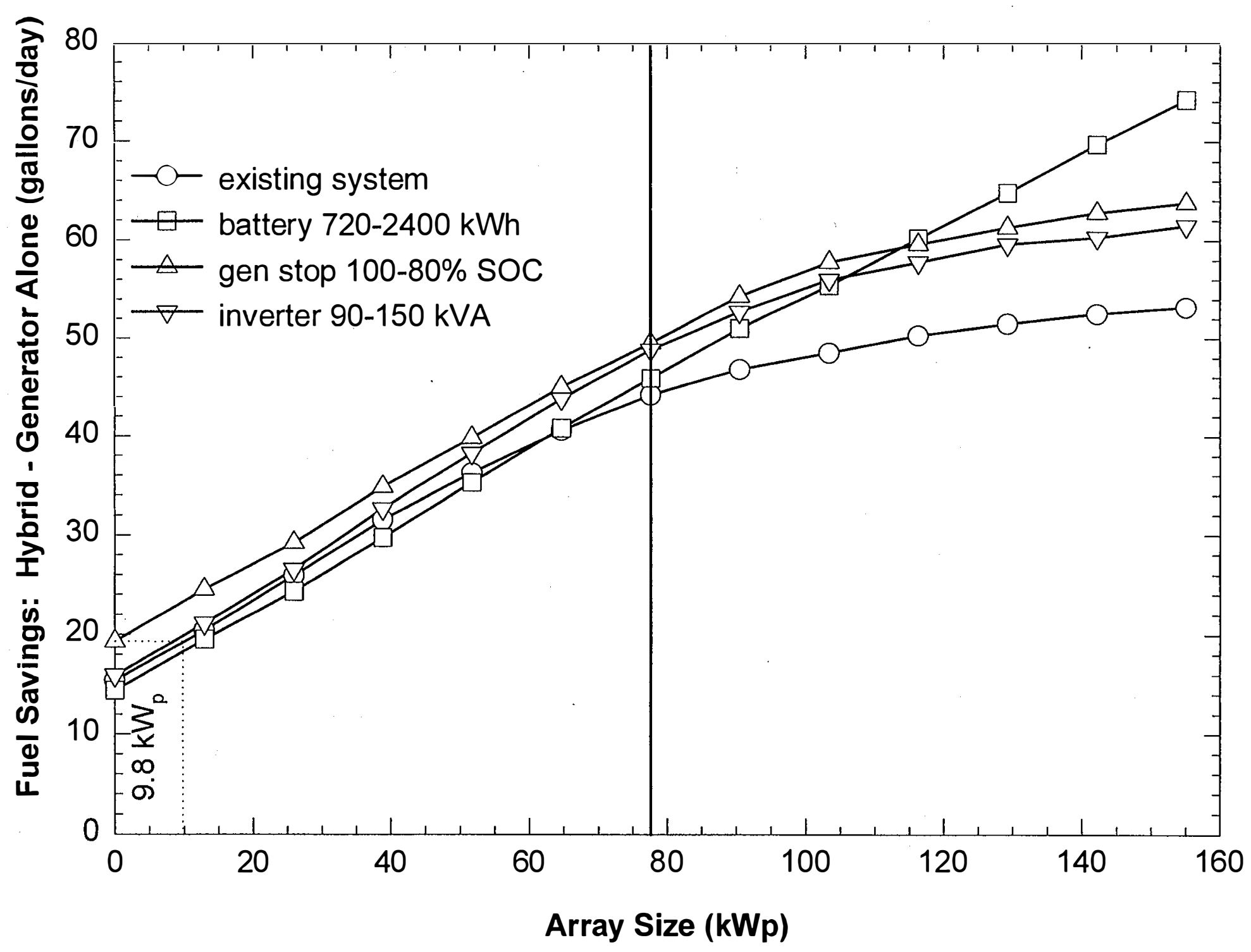




\section{BATTERY AND POWER PROCESSING LOSSES ARE CRITICAL}

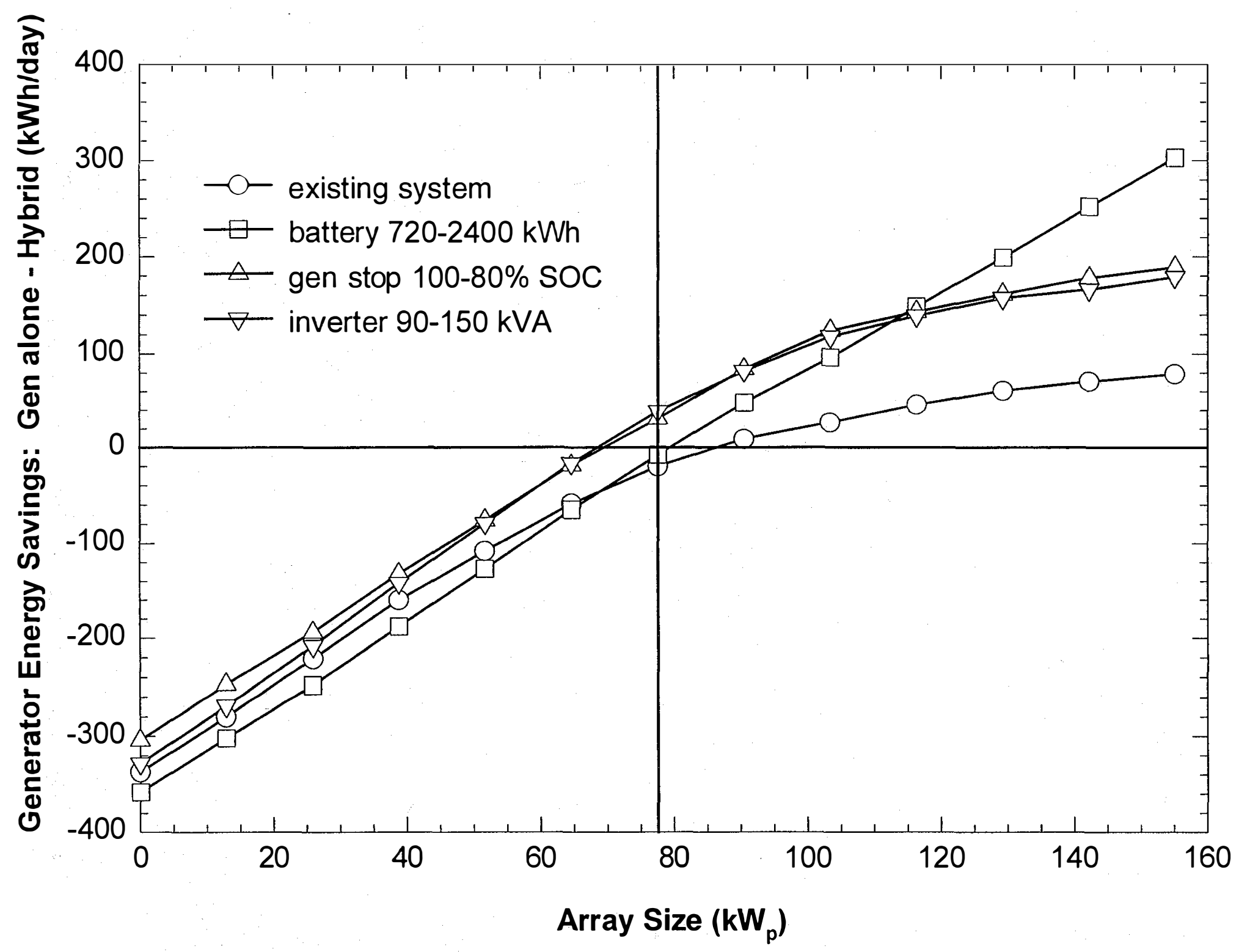




\section{EFFECTIVE ARRAY SIZE IS ARRAY UTILIZATION}

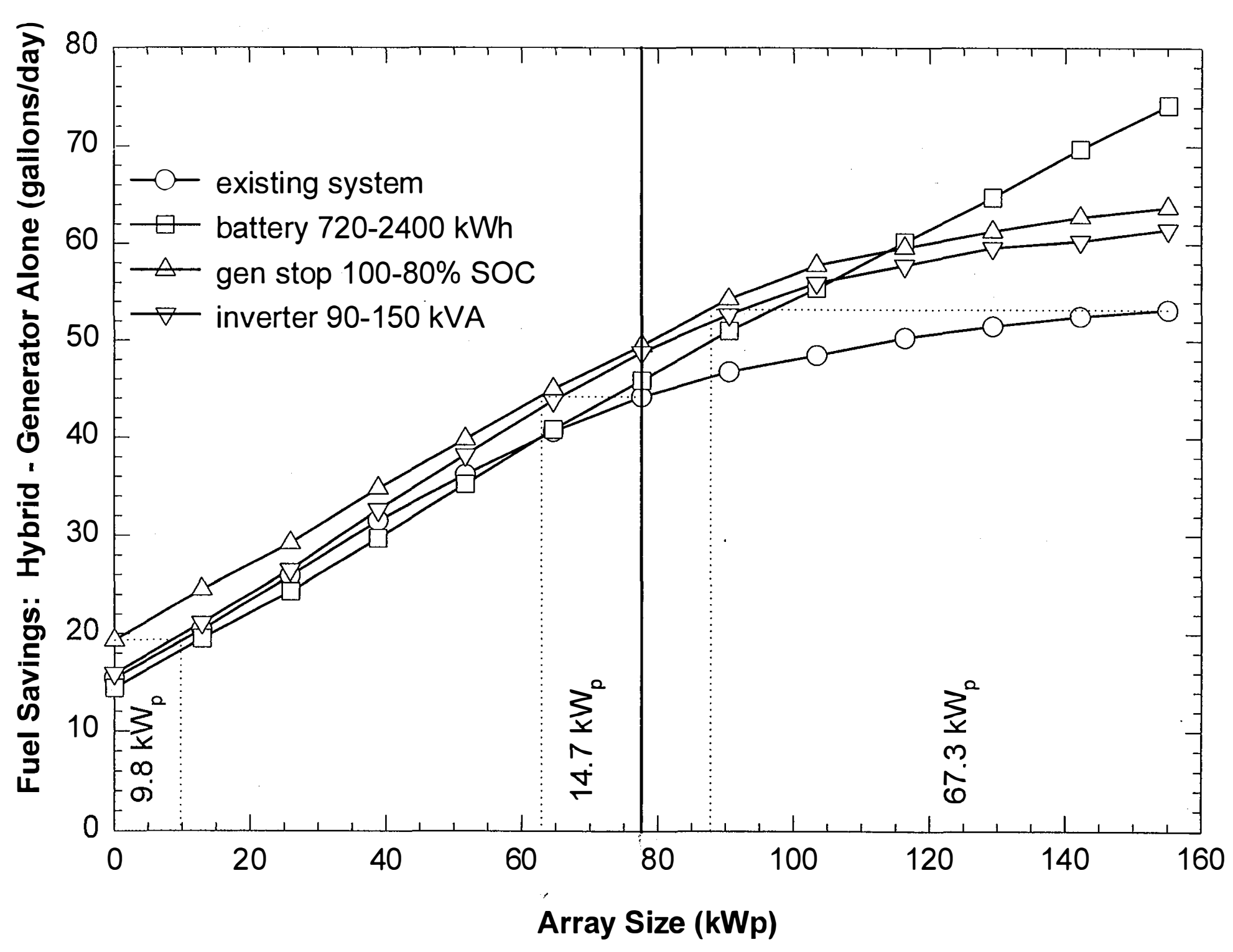




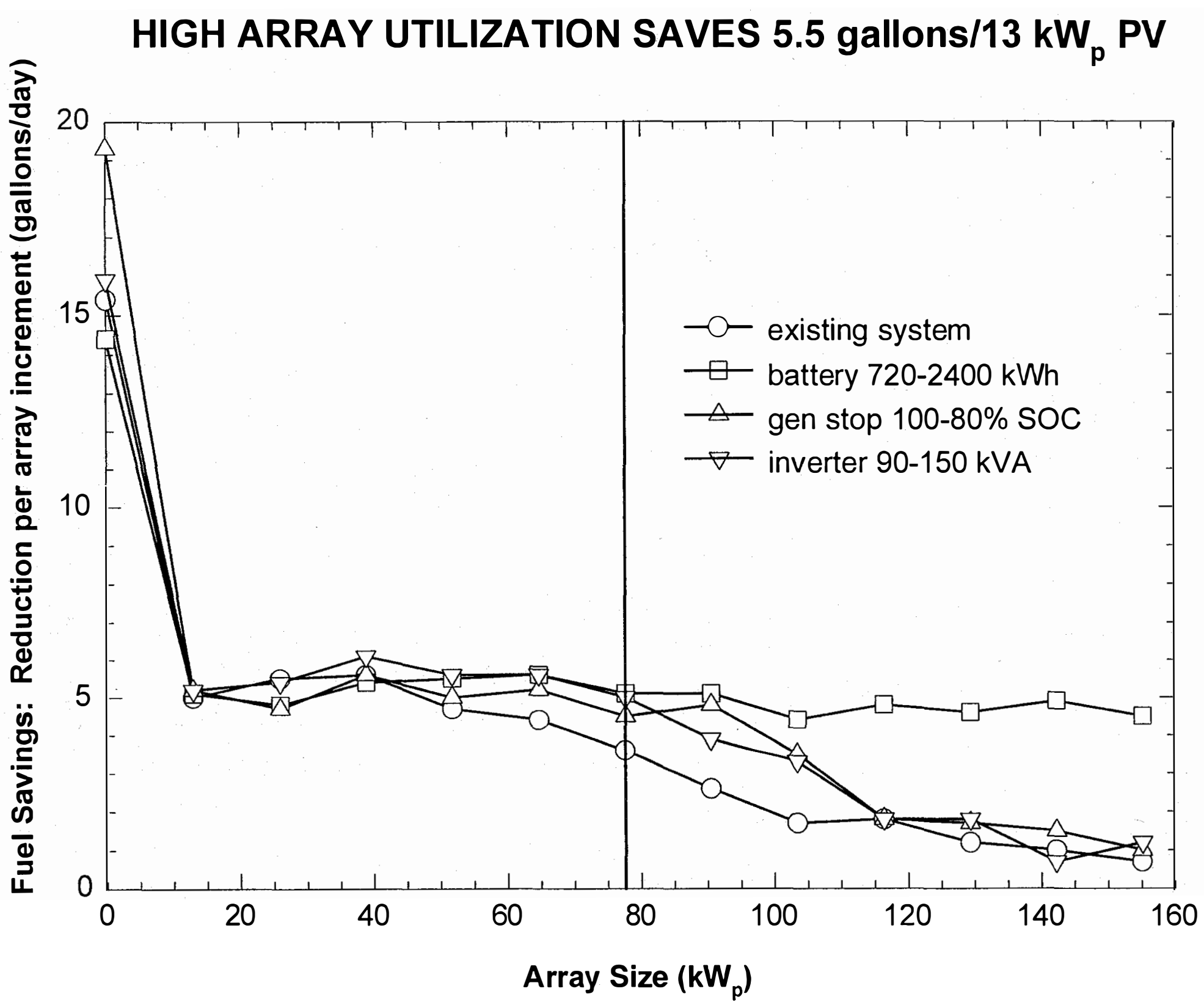


RUN-TIME SAVINGS HAVE SAME TRENDS AS FUEL

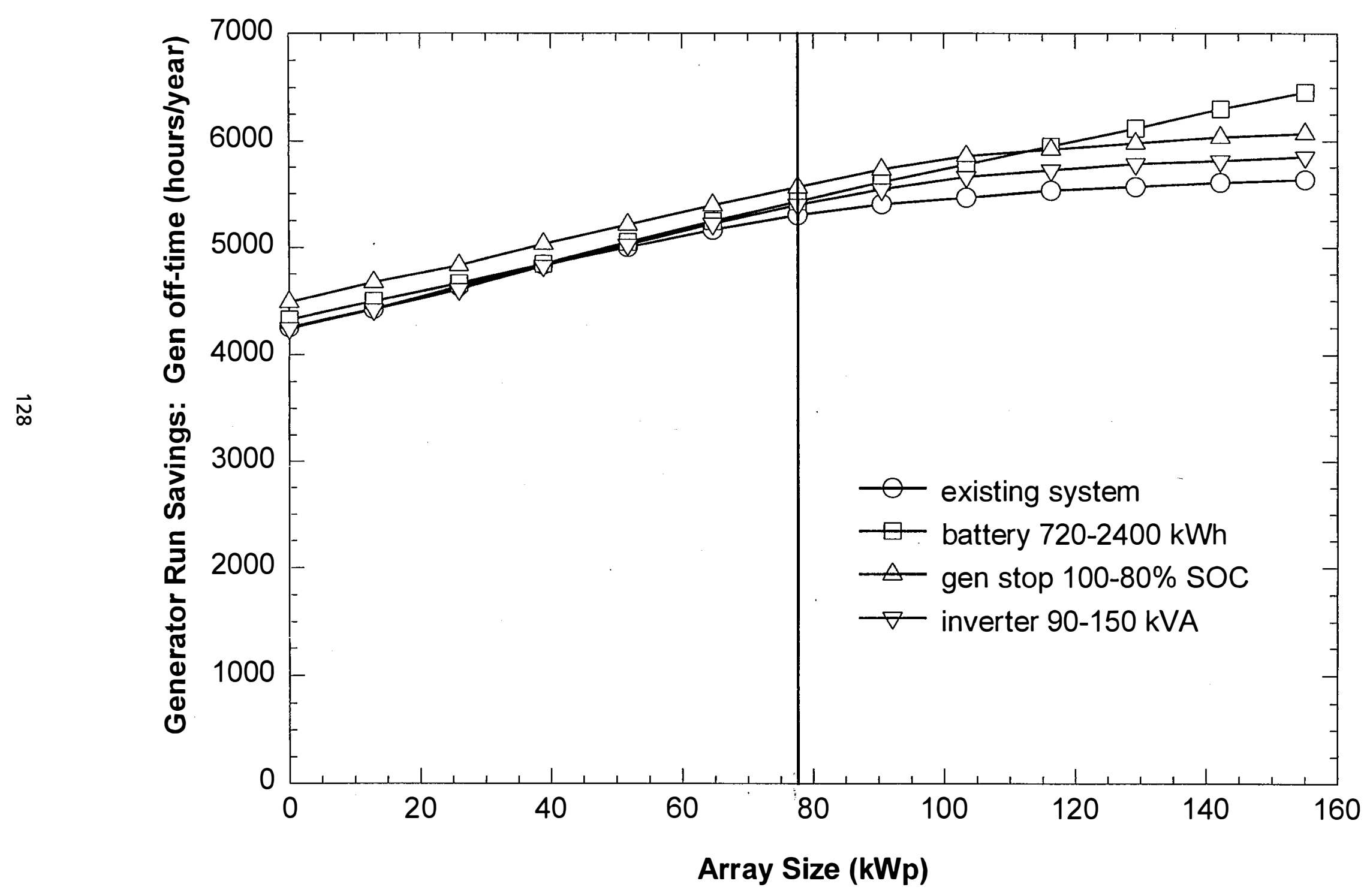




\section{ARRAY UTILIZATION IN HYBRID SYSTEMS CONCLUSIONS}

-Array utilization can and should be $90 \%$ and higher

-Can maintain good array utilization with proper operating strategy and balance of system design

- battery capacity must increase as array size increases

- max power tracking not required

-Battery/power processing losses are critical 


\title{
Comparison of Array Performance at NREL
}

\author{
Troy Strand and Robert Hansen \\ National Renewable Energy Laboratory \\ 1617 Cole Blvd. Golden, Colorado 80401
}

\section{Introduction:}

As part of the Technology Validation Task several utility-interconnect photovoltaic (PV) systems have been deployed at the National Renewable Energy Laboratory's (NREL) PV Outdoor Test Site. These systems include advanced thin-film PV technologies of dualjunction amorphous silicon (a-Si/a-Si), $\mathrm{Cu}(\mathrm{In}, \mathrm{Ga}) \mathrm{Se}_{2}$, and $\mathrm{CdS} / \mathrm{CdTe}$ as well as stateof-the-art single and multi crystalline. Each of these systems were deployed to conduct insitu technical validations of PV array performance and reliability. This presentation compares the normalized energy production (dimension-less) of each PV array by season. A further comparison of each system's annual normalized energy production (also dimension-less) in the early morning hours and about solar for July 15, 1996 is also made.

\section{Methodology:}

The problem of comparing each array's energy production on a level playing field is not a trivial matter. Balance-of-system component failure and system outages are random from one system to the next. Each system is slightly different in configuration. Array orientation is generally true south with the exception of one which is facing $15^{\circ}$ east of true south. The arrays are typically tilted at $40^{\circ}$ from horizontal with the exceptions of one that is at $45^{\circ}$ and another that is at $30^{\circ}$. Each array is operated at its max-power point and most are connected to bipolar inverters operating above \pm 200 volts, but one array is operating at about 50 volts and still another is operating at 32 volts. The percent loss in power output of each system is different and is largely influenced by PV module current mismatch, wire/dc losses, and the ability of the peak-power tracking hardware to locate and operate at the peak-power point. These issues all impact energy production and must be accounted for to ensure the fair comparison of each array's energy production.

To account for these differences, an annual power rating for each system is determined at $1000 \mathrm{~W} / \mathrm{m}^{2}$. This rating is calculated from the data collected through continuous monitoring of the time period from June 27, 1995 to June 27, 1996 where the irradiance is restricted between 900 and $1100 \mathrm{~W} / \mathrm{m}^{2}$. The date and time of all outages and failures by system is determined and the data collected on these dates and times is ignored for all systems. Each system's seasonal (summer, fall, winter, and spring) energy production is normalized its own power rating, thus accounting for all system losses Finally, differing array orientation and tilt angle is accounted for by additionally normalizing the energy production to the number of equivalent peak sun hours seen by the array.

\section{Results:}

The data is presented in bar graph format. The seasonal energy production normalized by the annual power rating and corresponding 
seasonal peak sun hours for each system are presented as one graph. A comparison of each system's energy production (also normalized by the power rating and corresponding peak sun hours) in the early morning and about solar noon is presented in a line graph.

\section{Conclusions:}

The narrower band-gap technologies were seen to exhibit a large seasonal swing in performance $\left(\mathrm{Si}-13 \%\right.$ and $\mathrm{Cu}(\mathrm{In}, \mathrm{Ga}) \mathrm{Se}_{2}-$ 14\%). a-Si/a-Si showed a $7 \%$ seasonal swing in performance and $\mathrm{CdS} / \mathrm{CdTe}$ showed only a $1 \%$ seasonal swing in performance. $\mathrm{CdS} / \mathrm{CdTe}$ and $\mathrm{Cu}(\mathrm{In}, \mathrm{Ga}) \mathrm{Se}_{2}$ appear to "turn on" earliest. CdS/CdTe and a/Si-a/Si both showed negligible decreases in performance due to rising temperature $\mathrm{Cu}(\mathrm{In}, \mathrm{Ga}) \mathrm{Se}_{2}$ and $\mathrm{X}-\mathrm{Si}$ showed noticeable decreases in performance due to rising temperature.

\section{Acknowledgments:}

The authors thank Roland Hulstrom and Richard DeBlasio for their support of the Engineering and Technology Validation Team. We also thank Ben Kroposki, Tom McMahon, and Carl Osterwald for their technical support. This work was supported by the United States Department of Energy under contract number DE-AC02$83 \mathrm{CH} 10093$. 


\section{Comparison of Array Performance at NREL}

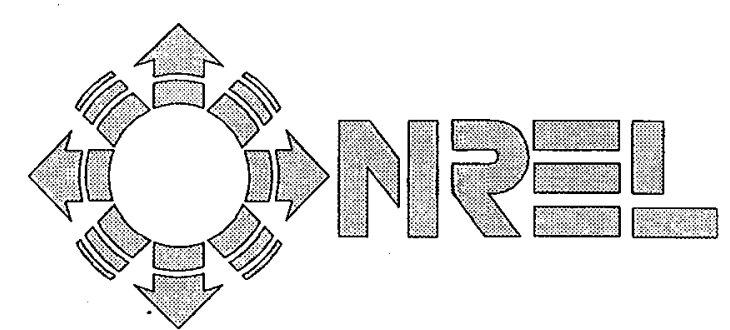

National Renewable Energy Laboratory

Troy Strand and Robert Hansen

Photovoltaic Performance and Reliability Workshop

September 4-6, 1996

Lakewood, Colorado 


\section{Acknowledgments}

- U.S. Department of Energy

Contract No. DOE-AC36-83CH10093

- Roland Hulstrom and Richard DeBlasio for their support of this work at NREL

- Ben Kroposki and Tom McMahon 


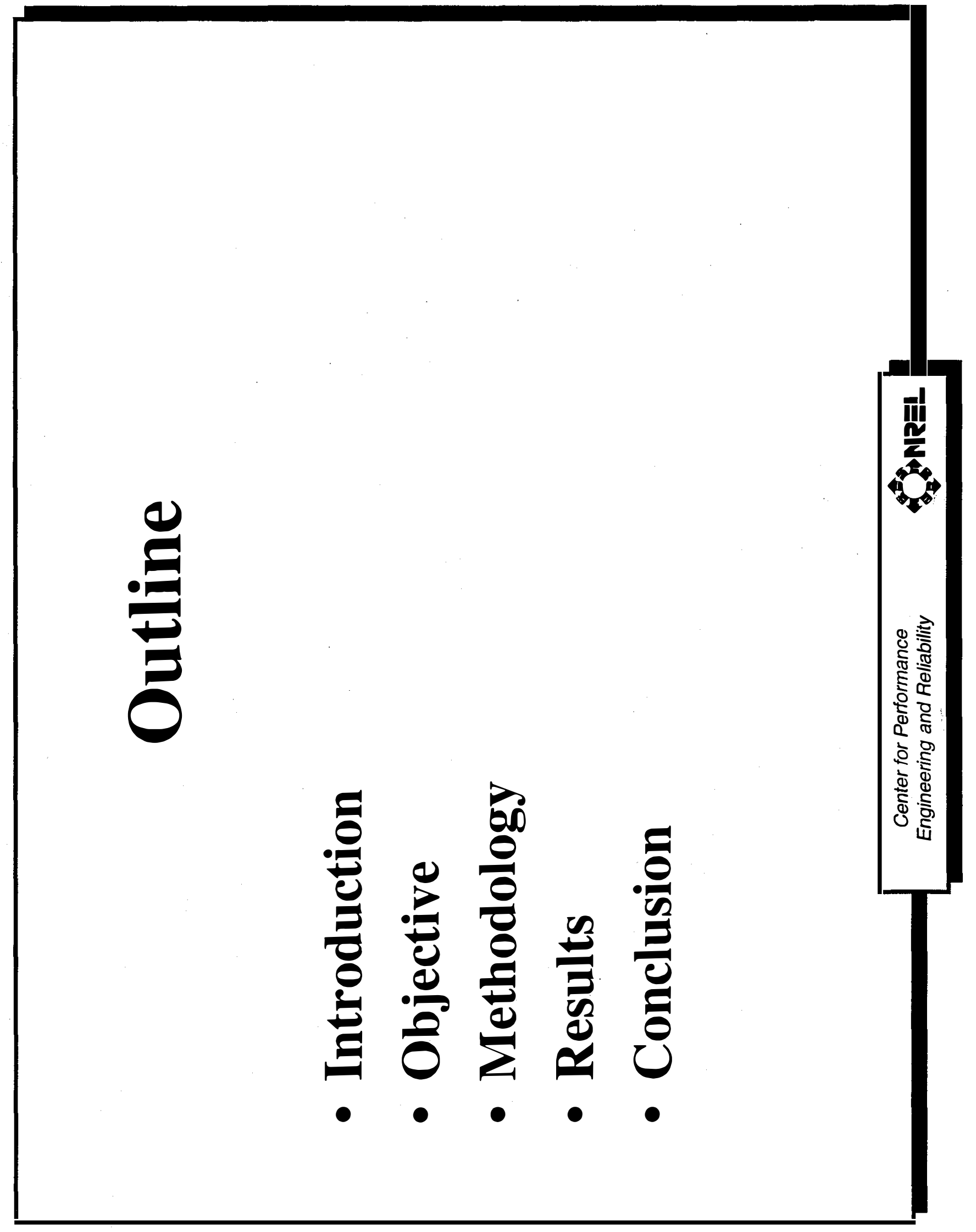




\section{Introduction}

- The Technology Validation Team has deployed several systems at the National Renewable Energy Laboratory's (NREL) PV Outdoor Test Site to conduct in-situ technical validations of PV array performance and reliability.

- These systems include advanced thin-film PV technologies of dual-junction amorphous silicon (a-Si/a-Si), $\mathrm{Cu}(\mathrm{In}, \mathrm{Ga}) \mathrm{Se}_{2}$, and $\mathrm{CdS} / \mathrm{CdTe}$ as well as state-of-the-art single and multi crystalline. 


\section{Objective}

- Compare the normalized energy production (dimension-less) of the technologies currently being evaluated at NREL

- Compare each technologies' normalized power output (dimension-less) in the early morning hours at low irradiance and at solar noon. 


\section{Methodology}

- Place each technology on a level playing field

- Account for Balance-of-system component failures and system outages

- Account for differing Array tilt angles and orientation

- Account for system losses: PV module current mismatch, wire/ dc losses, and the ability of the peak-power tracking hardware to locate and operate at the peak-power point. 


\section{Methodology}

- Account for all system losses:

- Determine an annual power rating for each system at $1000 \mathrm{~W} / \mathrm{m}^{2}$.

- This rating was calculated from the data collected through continuous monitoring of the time period from June 27, 1995 to June 27, 1996 where the POA irradiance was restricted between 900 and 1100 $\mathbf{W} / \mathbf{m}^{2}$. 


\section{Methodology}

- Determine date and time of all system outages and failures by system and ignore the data collected on these dates for all systems.

- Differing array orientation and tilt angle is accounted for by additionally normalizing the energy production to the number of equivalent sun hours seen by the array. 


\section{Methodology}

Normalized Energy

Production
Energy Produced (Wh)

$=$

System Rating (W) X Equivalent Sun Hours (h) 


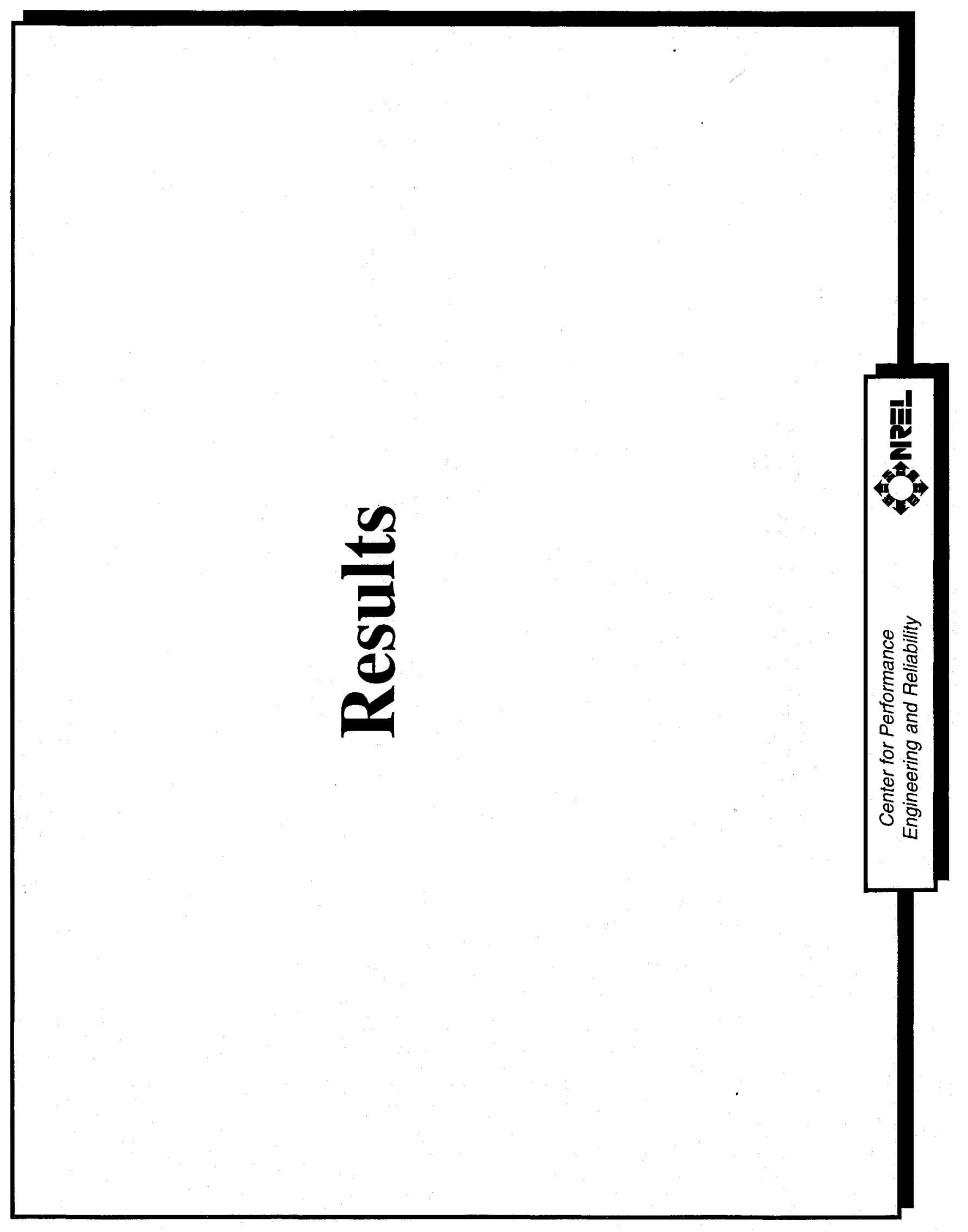




\section{Array Descriptions}

\begin{tabular}{|c|c|c|c|}
\hline$a / S i-a / S i$ & $\begin{array}{l}\text { Grid-Tied } \\
( \pm 250 \mathrm{Vpk})\end{array}$ & 64 & 1239Wpk \\
\hline CdS/CdTe & $\begin{array}{l}\text { Grid-Tied } \\
( \pm 260 \mathrm{Vpk})\end{array}$ & 24 & 1098Wpk \\
\hline $\mathrm{Cu}(\mathrm{In}, \mathrm{Ga}) \mathrm{Se} e_{2}$ & $\begin{array}{l}\text { Grid-Tied } \\
(+32 \mathrm{Vpk})\end{array}$ & 12 & 264Wpk \\
\hline$M-S I$ & $\begin{array}{l}\text { Grid-Tied } \\
(+50 \mathrm{Vpk})\end{array}$ & 5 & $1262 \mathrm{Wpk}$ \\
\hline$X-S i$ & $\begin{array}{l}\text { Grid-Tied } \\
( \pm 239 \mathrm{Vpk})\end{array}$ & 140 & $6216 \mathrm{Wpk}$ \\
\hline
\end{tabular}




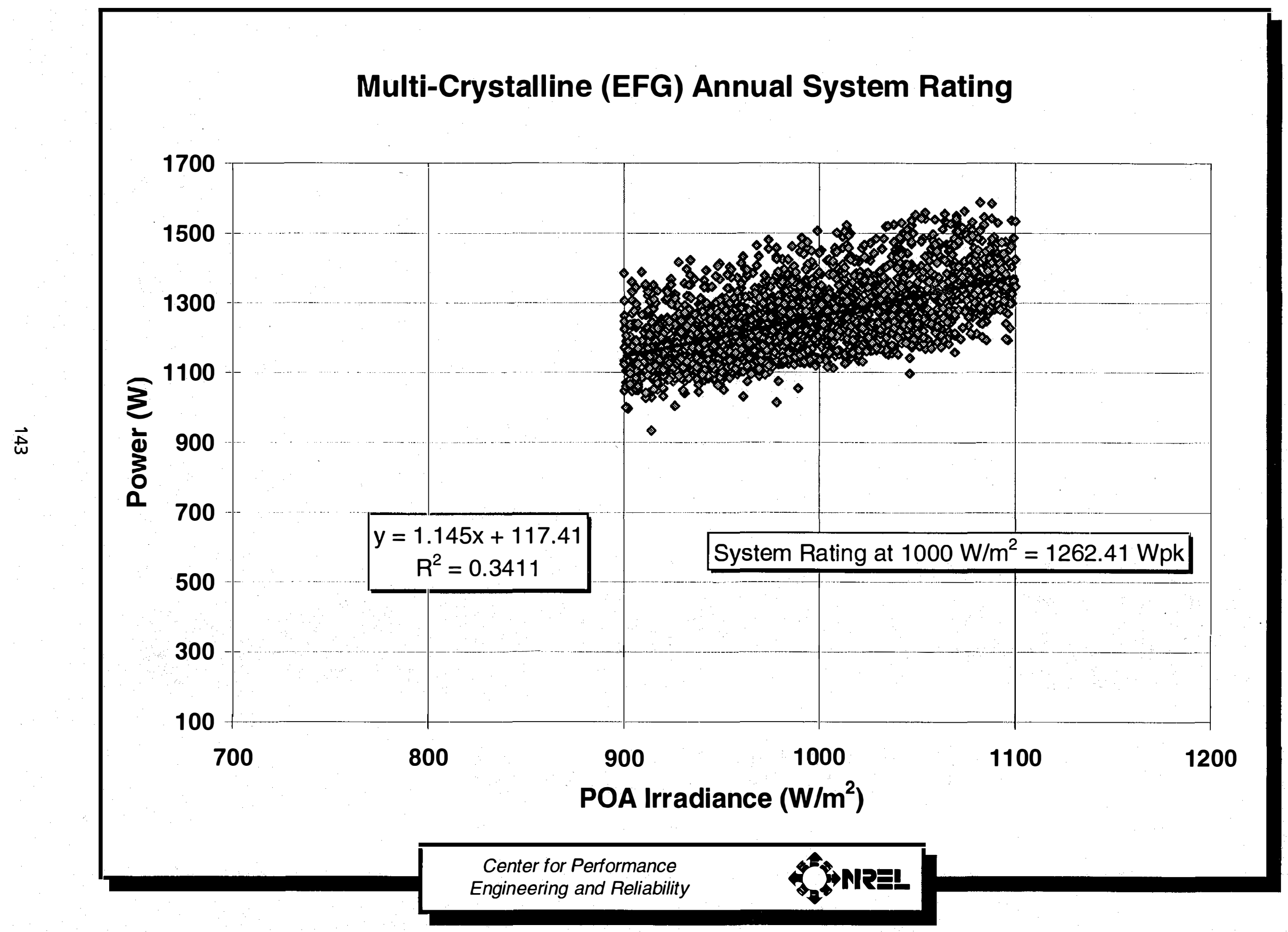




\section{Single-Crystalline Annual System Rating}

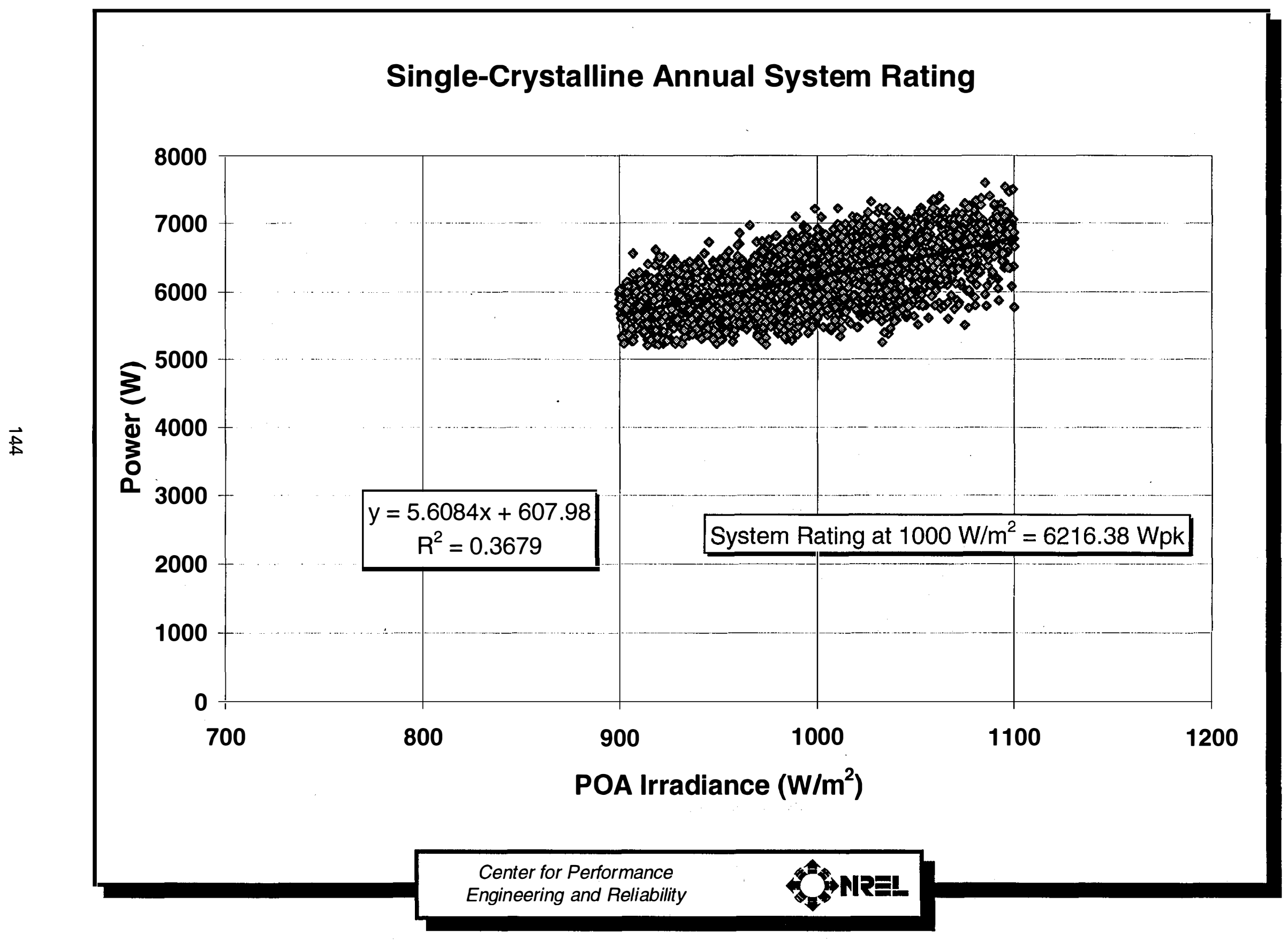




\section{$\mathrm{Cu}(\mathrm{In}, \mathrm{Ga}) \mathrm{Se}_{2}$ Annual System Rating}

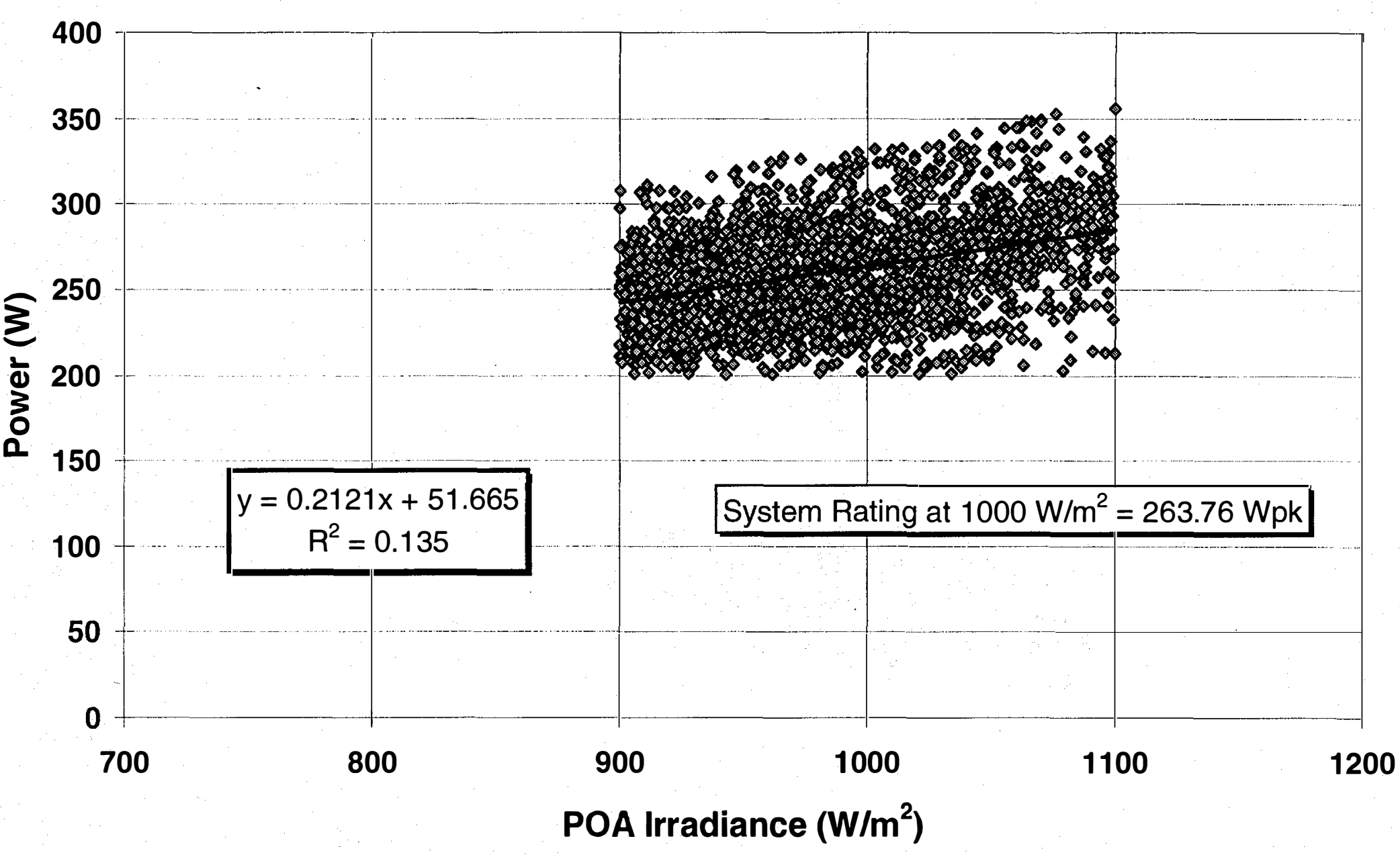




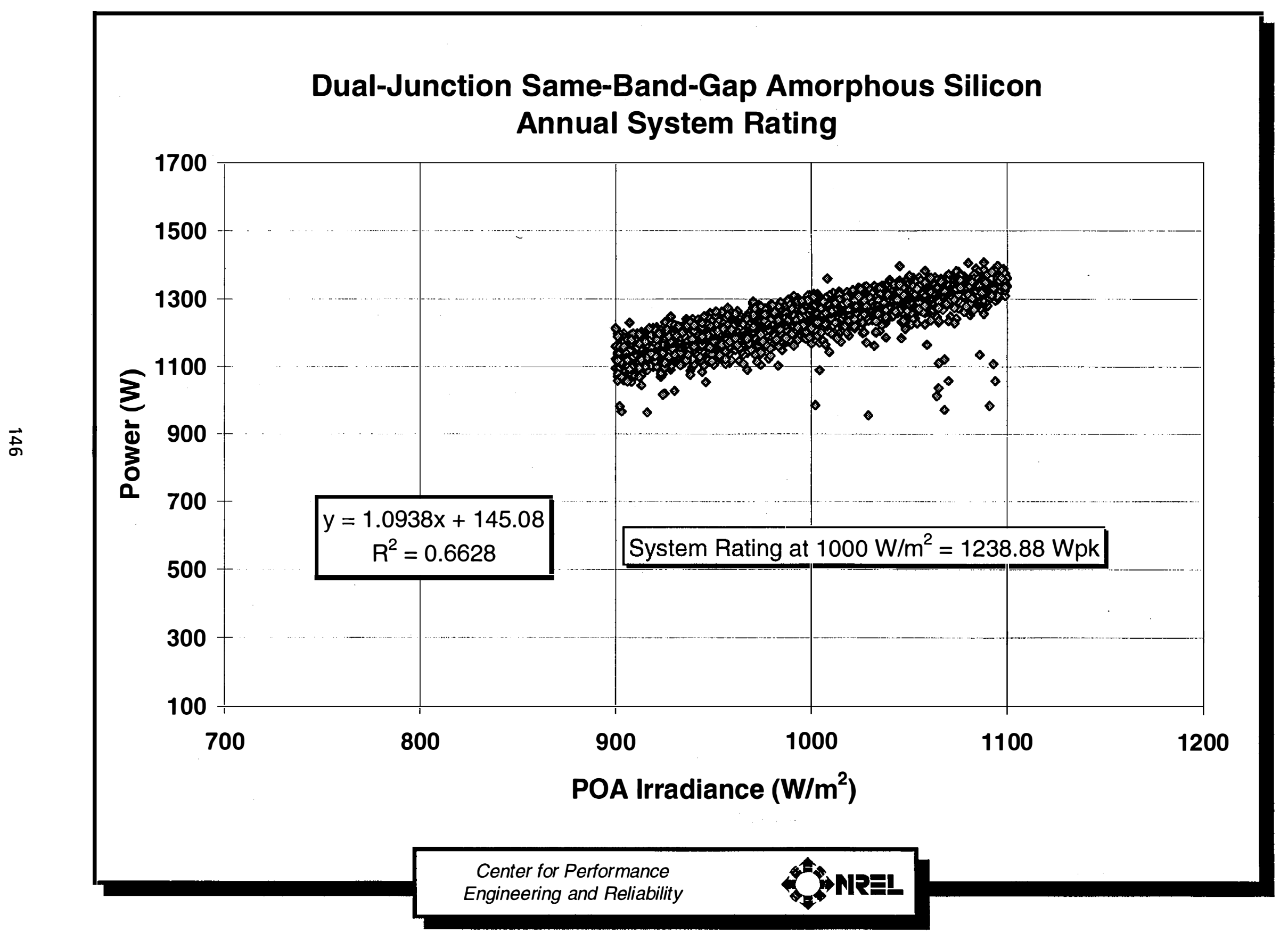




\section{CdS/CdTe Annual System Rating}

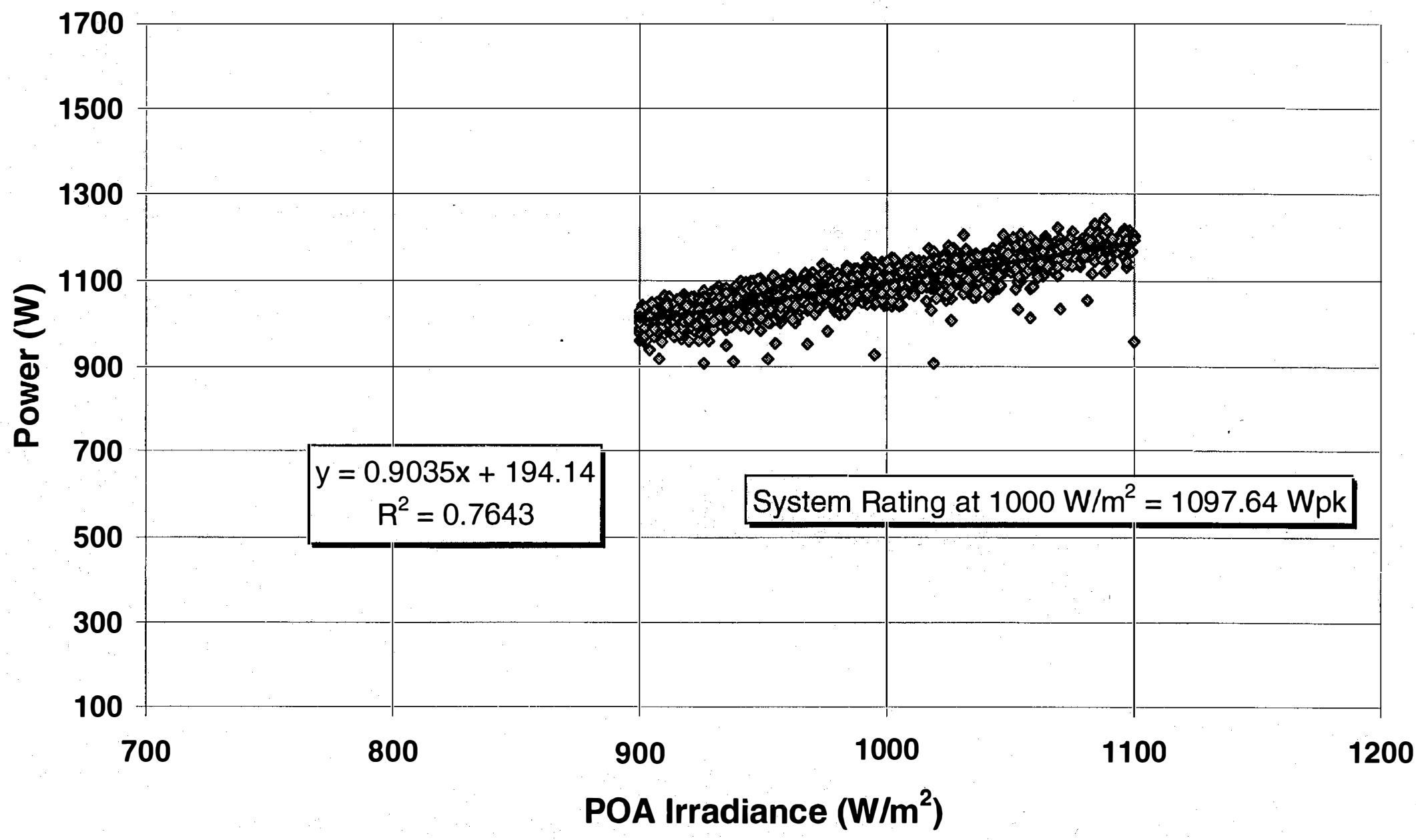




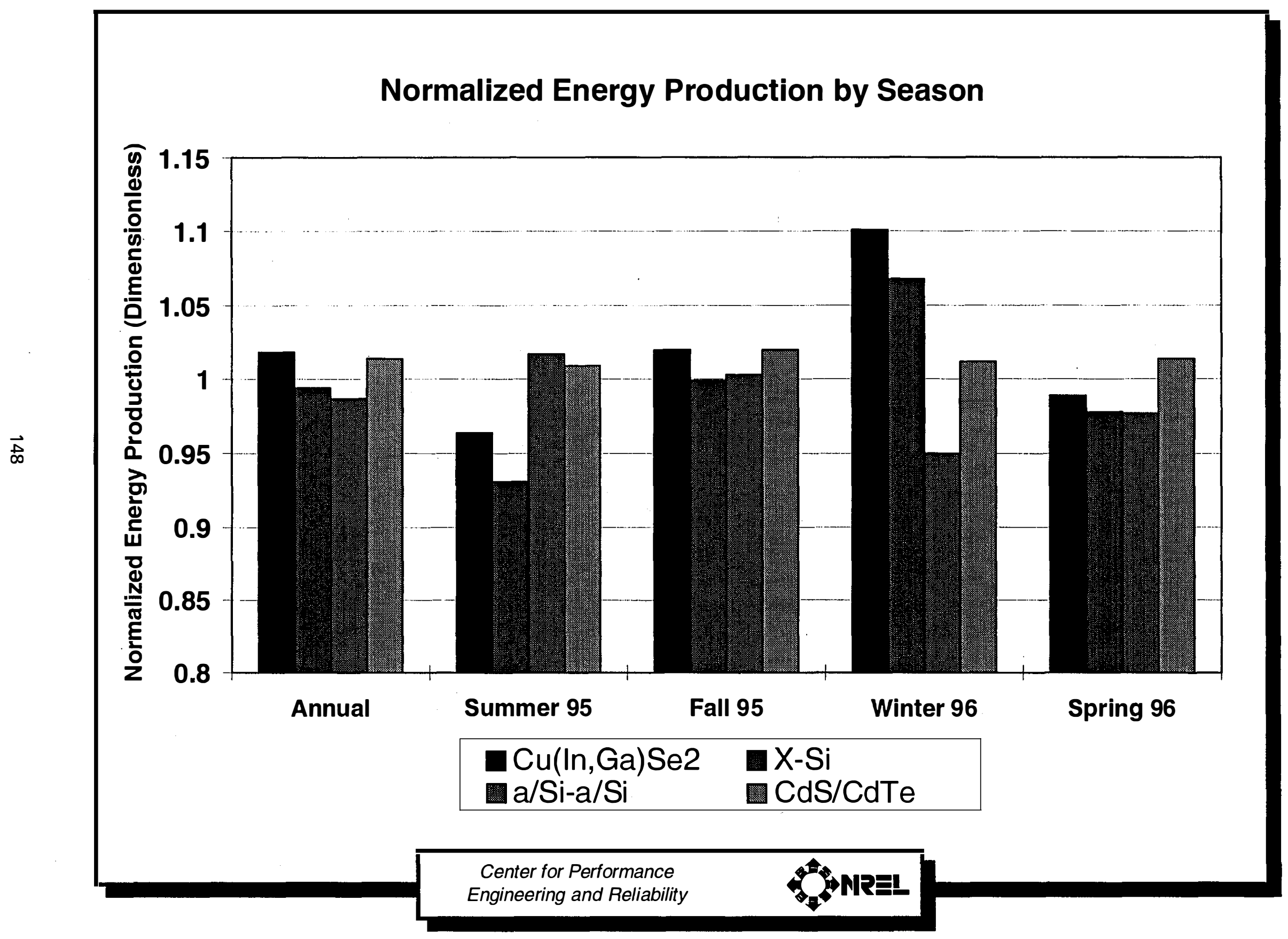




\section{Normalized Performance Profile for June 15, 1996}

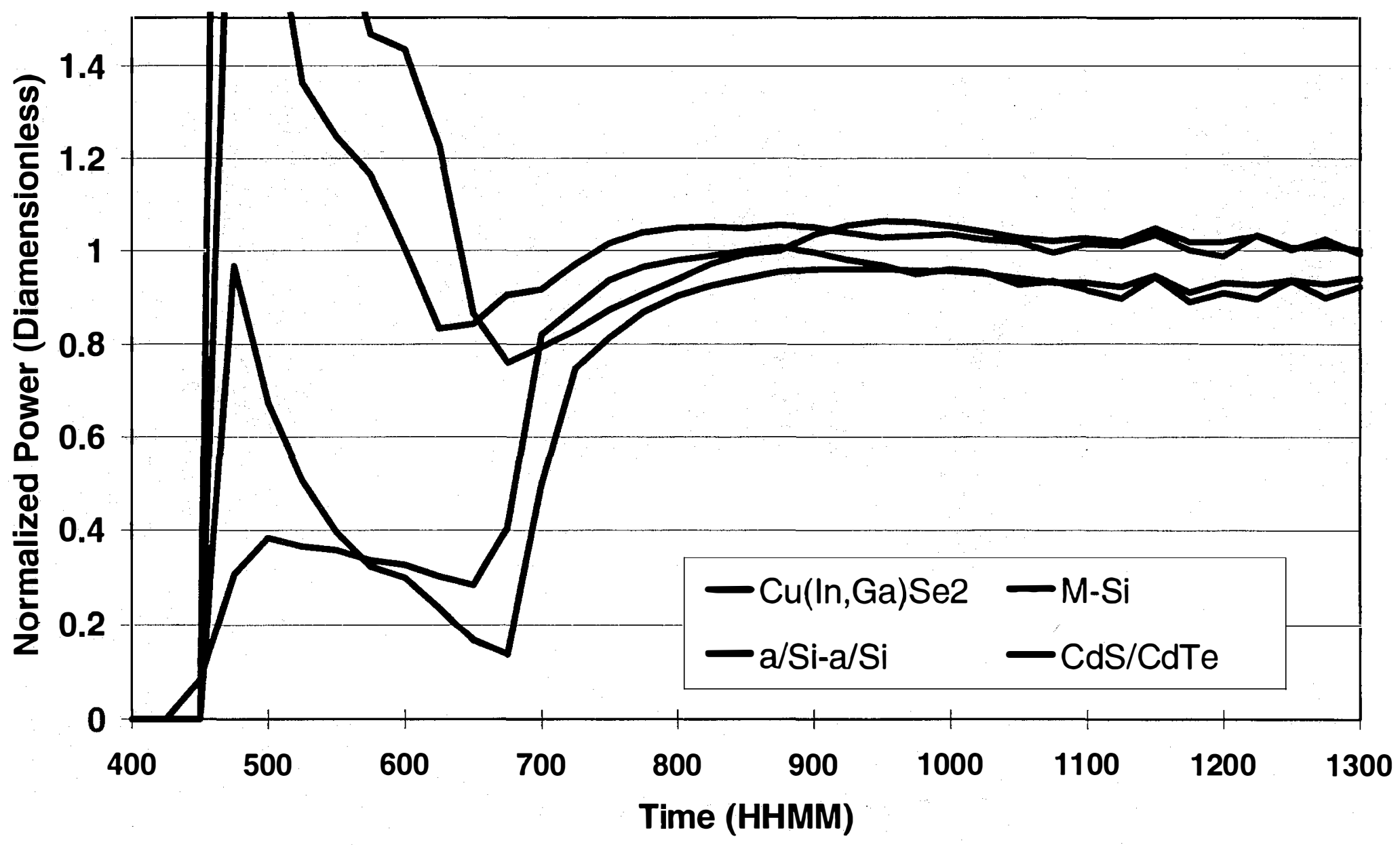




\section{Conclusions}

- Narrower band-gap technologies showed a large seasonal swing in performance (Si-13\% and $\left.\mathrm{Cu}(\mathrm{In}, \mathrm{Ga}) \mathrm{Se}_{2}-14 \%\right)$.

- Dual-junction same-band-gap Amorphous silicon showed a $7 \%$ seasonal swing in performance.

- CdS/CdTe showed only a 1\% seasonal swing in performance. 


\section{Conclusions}

- CdS/CdTe and $\mathrm{Cu}(\mathrm{In}, \mathrm{Ga}) \mathrm{Se}_{2}$ appear to "turn on" earliest

- CdS/CdTe and a/Si-a/Si showed negligible decreases in performance due to rising temperature

- $\mathrm{Cu}(\mathrm{In}, \mathrm{Ga}) \mathrm{Se}_{2}$ and $\mathrm{Si}$ showed noticeable decreases in performance due to rising temperature 


\section{The AC Photovoltaics Module 1}

\author{
Steven J. Strong \\ Solar Design Associates, Inc.
}

Dr. Robert Wills, P.E.

Advanced Energy Systems, Inc

Solar Design Associates, Advanced Energy Systems and Solarex Corporation have designed and developed a large-area photovoltaic module whose electrical output is $\mathrm{AC}$ power suitable for direct connection to the utility grid. The large-area AC PV module features a dedicated, integrally-mounted, high-efficiency DC-to-AC power inverter with a nominal output of 250 Watts (STC) at $120 \mathrm{VAC} 60 \mathrm{~Hz}$ that is fully compatible with utility power.

The module's output is connected directly to the building's conventional AC distribution system without need for any DC wiring, string combiners, DC ground-fault protection or additional power-conditioning equipment. We call this concept an AC Photovoltaic Module or, in context, simply an "AC Module". The AC Module concept is presented in the Figure below.

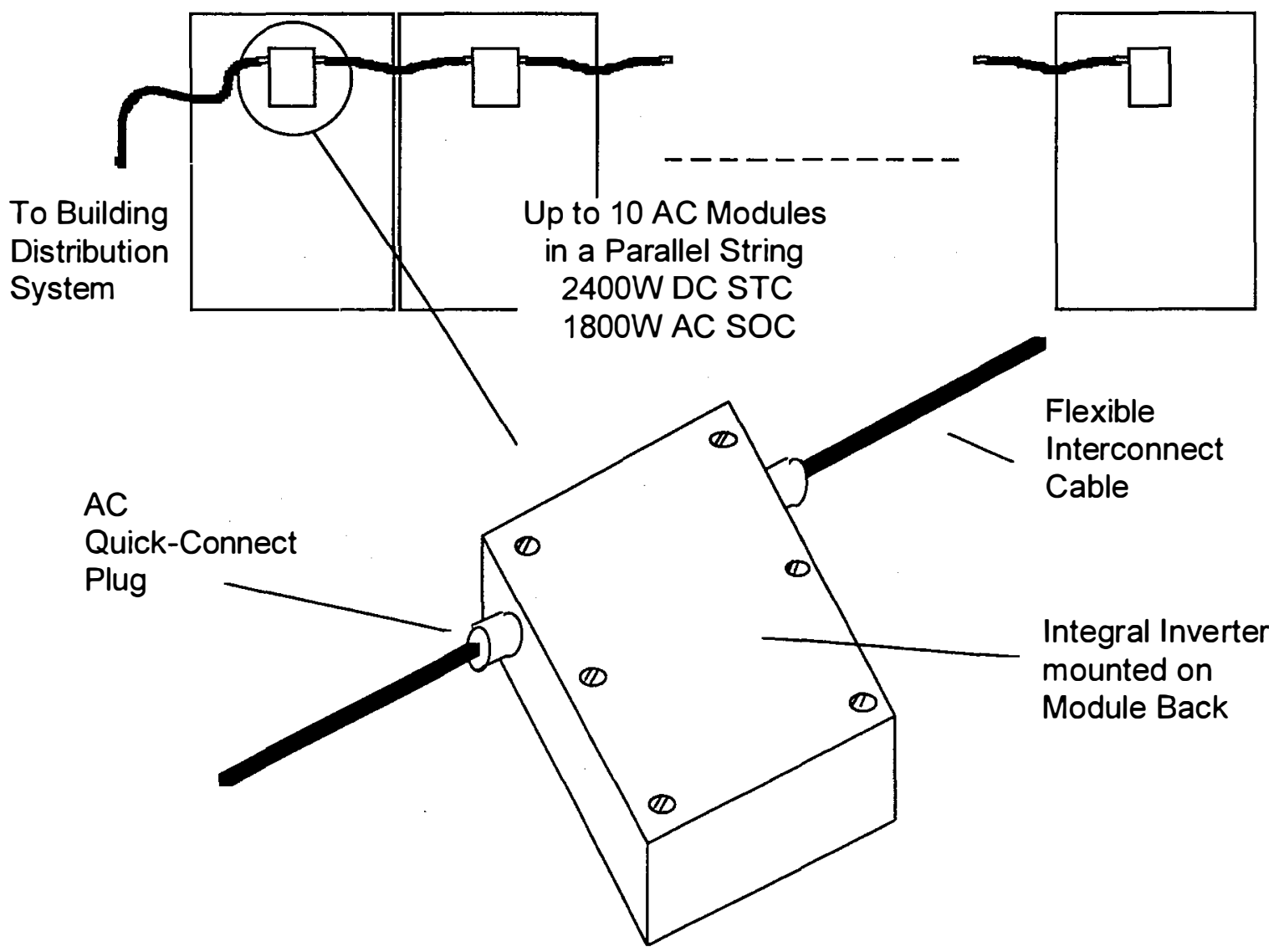

The AC PV Module 
The AC module is of glass-superstrate design, is nominally 24 square feet in size and currently employs crystalline silicon solar cells. Engineering design has been completed for the direct building integration of the $\mathrm{AC}$ module into the vertical facades and sloped-roof construction of residential, commercial and institutional buildings, replacing the traditional building skin. A framed version of the AC module is also being produced for the nonintegrated application of photovoltaics systems for buildings and in ground-mounted applications.

The AC module has the potential to become the first photovoltaic power "building product", as it can be marketed as a complete, packaged solution for the emerging residential rooftop and commercial demand-side management / supply markets. On-board two-way communications and data acquisition using power-line-carrier technology are standard features on each $\mathrm{AC}$ module.

AC modules can be sold with frames to be mounted on conventional support structures or, they can be sold without frames as glass laminates for direct building integration where the $\mathrm{PV}$ module displaces conventional building materials such as architectural glass in commercial buildings.

With the cost of displaced architectural glass and the labor to install it credited toward the cost of the PV system, building-integrated PV becomes very attractive. This is especially true with the AC module's ease of installation.

In addition, $\mathrm{AC}$ modules allow significant flexibility in system sizing. Systems as small as one module can be fielded and can then be added to in increments of one module. Orientation and shading of the array is not as much of a concern as with conventional systems and, since every $\mathrm{AC}$ module has its own maximum power point tracker, the mismatch losses common to series DC strings are eliminated.

With all these advantages, the $\mathrm{AC}$ photovoltaic module promises to become a universal building block for use in all utility-interactive PV systems.

Prototype systems incorporating the AC module were fielded in the spring of 1996 on the new natatorium complex at the Olympic village in Atlanta and on residential rooftops in the Sacramento Municipal Utility District's PV Pioneer Program with good results.

1 This work is sponsored in part by cost-shared agreement with the US Department of Energy, the National Renewable Energy Laboratory and Sandia National Laboratory. 


\title{
USE OF IRRADIANCE AND TEMPERATURE DATA TO PREDICT AC MODULE LIFETIME
}

\author{
Clayton Handleman and Dorothee Reinmuller* \\ Ascension Technology Inc., 235 Bear Hill Rd. Waltham MA 02154 \\ *University of Karlsruhe, Germany \\ September, 1996
}

\begin{abstract}
The thermal performance of the SunSine ${ }^{\mathrm{TM}} 300$ AC module inverter housing is being studied in order to assess inverter lifetime. Particular attention is being paid to electrolytic capacitor heating and degradation.

This paper discusses the measurement program currently underway which has two primary goals: 1) to optimize the enclosure design for minimization of electrolytic capacitor temperature rise, 2) develop a model which will allow us to use solar insolation and ambient temperature data to model electrolytic capacitor temperature. This model will predict electrolytic capacitor lifetime, presumed a significant factor in inverter reliability. Preliminary results and their implications are presented.
\end{abstract}

\section{INTRODUCTION}

Since the 1985 Gardner Massachusetts Photovoltaic demonstration project, momentum has been building in support of the concept of the distributed utility. The recent shift towards deregulation of the electric power industry has catalyzed the acceptance of this concept for photovoltaics and other small scale generation technologies.

In the Gardner model, small PV arrays of 2 to $18 \mathrm{~kW}$ are mounted on rooftops with DC wiring taken from the rooftop array to an inverter located inside a climate controlled building. With AC modules the electronics are located on the photovoltaic module outdoors with no exposed DC wiring. The electronics are exposed to a wide range of temperatures. The range of temperatures are highly dependent upon geographic region.

A significant amount of data has been accumulated on the life expectancy of inverters located in climate controlled areas or outdoors away from the excess heat of PV modules. However, because the AC module has only recently been introduced, little is known about its life expectancy, particularly in light of its placement close to the hot PV module.

Ascension Technology is introducing an AC PV module, the SunSine ${ }^{\mathrm{TM}} 300$. This product has been developed with funding from the National Renewable Energy Laboratory, Sandia National Laboratories, New England Electric System as well as support from ASE Americas and a number of early adopter utilities. Careful attention has been paid to enclosure design and component selection in an attempt to match the inverter lifetime to that of the PV module to which it is attached. In order to establish warrantee criteria and improve the design of the SunSine ${ }^{\mathrm{TM}} 300$, Ascension Technology has embarked upon a thermal evaluation of the 
SunSine $\mathrm{TM}_{300}$. Using this data, insolation and temperature data from our worldwide network of rotating shadowband pyronometers, and established failure prediction criteria for electrolytic capacitors, we are developing a model to estimate $\mathrm{AC}$ module lifetime. Results will also be used to direct design improvements to extend lifetime.

Electrolytic capacitors have a well understood failure mechanism which results from evaporation of the liquid electrolyte. They are generally considered to be significantly more likely to fail than other system components in a properly designed power converter. This is supported by Ascension Technology's many years of field experience. We have installed, monitored and maintained a large number of inverters produced by a variety of manufacturers. We have found that the majority of failures in well designed inverters arise either from infant mortality or electrolytic capacitor failure.

\section{THERMAL DESIGN}

The thermal design issues of an AC PV Module may be summarized as follows. Some assumptions will be made to facilitate an overview, more exact quantification follows.

$\begin{array}{lll} & \text { Assumption } & \text { Actual } \\ \text { Inverter efficiency } & 90 \% & \text { Varies from about } 88 \% \text { to } 92 \% \\ \text { Module efficiency } & 12.5 \% & \text { Typical } \\ \text { Module heat removal } & \text { Back }=\text { Front } & \text { Front reradiates more efficiently than back } \\ \text { Module reflectivity } & \text { None } & \text { Very low } \\ \text { Full Sun } & 1000 \mathrm{~W} / \mathrm{m}^{\wedge} 2 & \text { Can be higher } \\ \text { Module Rating } & 300 \mathrm{~W} & \text { About right at STC }\end{array}$

In full sunlight the module $\left(2.4 \mathrm{~m}^{\prime} 2\right)$ will produce $300 \mathrm{Wdc}$. At $90 \%$ efficiency, the power electronics will produce about $30 \mathrm{~W}$ of waste heat. The transformer produces half the heat while the Power semiconductors produce most of the rest. The power semiconductors are mounted to the enclosure and very effectively couple their heat, about $10 \mathrm{~W}$ to the exterior of the enclosure. This leaves about $20 \mathrm{~W}$ which heats the interior of the enclosure. Of this about $15 \mathrm{~W}$ is produced by the transformer. This can be partitioned off from the rest of the enclosure leaving about $5 \mathrm{~W}$ of heating from the rest of the system.

We expect the two major causes of capacitor heating to come from ESR heating of the electrolytic capacitors and enclosure heating as a result of module heat coupled into the inverter enclosure. ESR heating can be calculated and is easily incorporated into models. Therefore our attention has been on the coupling of module heat into the enclosure and exhaust of that heat.

The footprint of SunSine ${ }^{\mathrm{TM}} 300$ is about $12.5^{\prime \prime}$ square $\left(0.1 \mathrm{~m}^{\wedge} 2\right)$. This footprint leads to a significant amount of heat transfer from the module to the inverter enclosure. At $1000 \mathrm{~W} / \mathrm{m}^{\wedge} 2$ a simple calculation using the above assumptions suggests that as much as $88 \mathrm{~W}$ of heat is absorbed by the section of module covered by the enclosure. If half of that heat, $44 \mathrm{~W}$, gets out the back and couples effectively to the enclosure then it will have a significant impact on Electrolytic 
capacitor heating. This leaves a total heat input to the inverter package of $74 \mathrm{Watts}$ thermal at one full sun.

\section{INVERTER ENCLOSURE DESIGN}

Ascension Technology has developed an aluminum enclosure that is attached to the rear of the PV module. The enclosure consists of two parts. Adhesively attached to the module is a flat $1 / 4$ " aluminum mounting plate. Mounted to this plate is a flanged aluminum casting. Several variables are being studied empirically to see how they affect capacitor temperature. These include: thickness of the gap between the module glass and the mounting plate, variation of flange surface area in thermal contact with aluminum plate, effectiveness of fins for heat removal.

The aluminum plate can be mounted very close to the module glass or an air gap can be created using a spacer. Convection and conduction are affected by changing the gap. Convection cools both the module and the enclosure. Heat conducted from the module to the inverter package is reduced by increasing the gap size.

The casting was originally designed with fins around the edge to increase surface area and better couple heat to the surrounding air. It is thought that they also increase the cross sectional area of aluminum in contact with the flange. This would help move heat away from the plate keeping it cooler. It is desirable to determine whether cooling the plate at the expense of heating the enclosure walls would reduce the interior temperature. Fabrication of an enclosure without fins would reduce its cost. Therefore it is desirable to quantify their impact in order to evaluate trade-offs between production cost and reliability improvement.

The flange itself was originally designed with a machined gasket groove. The purpose was to permit hermetic sealing of the enclosure. We have since decided not to hermetically seal the unit. With this requirement lifted we sought to determine if thermal performance could be enhanced by machining the flange flat for maximum thermal contact between the plate and the casting.

\section{INVERTER LIFETIME CALCULATION}

Working under the assumption that lifetime of the electrolytic caps will govern the inverter lifetime we are developing a lifetime model. As long as electrolytic caps are operated within their electrical ratings, their lifetimes are well understood functions of operating temperature and to a lesser degree, operating voltage. Degradation occurs as a result of electrolyte evaporation through the capacitor end seals. The rate of evaporation is quantified by the equation below. After about $40 \%$ of the electrolyte evaporates, effective series resistance (ESR) rises sharply and capacitance drops rapidly. At this point the capacitor's operating parameters go out of specification and the likelihood of failure increases dramatically.

The industry standard model uses as a doubling constant of $10 \mathrm{C}$ where lifetime doubles for every $10 \mathrm{C}$ below the capacitor's maximum rated operating temperature. 


$$
\begin{gathered}
L_{x}=L_{o} 2^{\frac{T_{0}-T_{x}}{10}} \\
L_{x}=\text { Lifetime atactualoperating temperature } T_{x} \\
L_{o}=\text { Lifetime atmaximum ratedoperating temperature } \\
T_{o}=\text { Maximum rated operating temperature }{ }^{\circ} \mathrm{C} \\
T_{x}=\text { Actualoperating temperature }{ }^{\circ} \mathrm{C} \\
T_{x}=T_{A}+\Delta T \\
\Delta T=\text { Temperature rise, ripple current heating } \\
T_{A}=\text { Airtemperature inside theenclosure }
\end{gathered}
$$

A more conservative model is sometimes used that changes the doubling constant to $15 \mathrm{C}$ for the part of the temperature below $75 \mathrm{C}$, see equation below. We will use the more conservative model below.

$$
L_{x}=L_{o} 2^{\frac{T_{o}-75^{\circ} \mathrm{C}}{10}} \times 2^{\frac{75^{\circ} \mathrm{C}-T_{x}}{15}}
$$

Actual operating temperature, $T_{x}$ is estimated from two components, internal enclosure temperature and ESR (equivalent series resistance) heating. ESR is as a parasitic resistance which causes ohmic heating from ripple current in the capacitor. The resultant rise in temperature is due to ESR.

$$
\Delta T=\frac{I^{2} \times E S R}{K \times A}
$$

$I=$ Ripple current

$E S R=.075 M a x$, thisdrops at higher temperature operation .

$K=$ Thermal constant $=0.006$

$A=$ case surfacearea, about 9.8 inch $^{2}$ per capacitor 
It is approximated that with the SunSine ${ }^{\mathrm{TM}} 300$ topology:

$$
\begin{gathered}
I=\frac{I_{D C}}{2} \\
I_{D C}=P V \text { DC current output by the PVmodule }
\end{gathered}
$$

The SunSine ${ }^{\mathrm{TM}} 300$ has two capacitors in parallel, and for one of the two capacitors:

$$
\begin{aligned}
& \qquad I_{D C}=\frac{P O A \times M E \times A}{2 \times V_{m p}} \\
& P O A=\text { Plane of Array irradiance } \\
& M E=\text { Module efficiencywhich isabout } 12.5 \% \\
& A=\text { Module Area, } 2.4 m^{2} \\
& V_{m p}=\text { Maximumpowervoltage whichis typicallyabout } 50 \mathrm{~V}
\end{aligned}
$$

Under one full sun, the PV dc current would be $6.0 \mathrm{Amps}$, yielding an approximate ripple current of 1.5 Amps per capacitor. Using the above we are developing as a model of capacitor temperature as as a function of ambient temperature and insolation. Using this model and Ascension Technology's large temperature and insolation database, we will be able to make some useful predictions about AC module lifetime in a variety of geographic locations. It should be noted that we are not taking windspeed into account, this is as a conservative aspect of our model since wind will cool the modules, extending the life of the electrolytic capacitors.

At this time two modeling approaches are being studied for capacitor temperature prediction, table look-up and as a functional relationship. as a table would be developed by placing as a unit out in the field and accumulating operational data. Once as a sufficient data set is accumulated data from many locations could be run through the model for lifetime prediction. It is preferable to find as a well behaved functional relationship between ambient temperature, POA and capacitor temperature. This would permit model development using much less data and therefore as a smaller resource commitment.

In either case, clouds significantly complicate determination of capacitor temperature. Our simulations will assume cloudless days. This is as a conservative assumption since in most cases clouds will reduce POA, module temperature, and therefore capacitor temperature.

\section{ELECTROLYTIC CAPACITOR LIFETIME MODELS}

Since capacitor degradation is the result of an evaporative process, temperature cycling is not expected to have an accelerating effect over and above the degradation caused by operating at elevated temperature. Discussions with engineers at capacitor manufacturers supported this assumption. When operated well below their maximum rated operating voltage, voltage has little 
impact on lifetime. The capacitors in the SunSine 300 are operated at $1 / 2$ of their rating during normal operation.

Manufacturers generally give Electrolytic caps lifetime ratings of 1000, 2000, or 5000 hours. These ratings are usually bestowed upon an entire family of capacitors based upon certain aspects of manufacture that all capacitor models in a given family share. The lifetime rating is the number that the manufacturer guarantees. For each model in a family, manufacturers often do further testing to determine the lifetime of that specific model within the family. These numbers are often available from the manufacturer and can be considerably higher than the nominal value used for the family as as a whole. Typically the lower voltage capacitors will have longer lifetimes than higher voltage capacitors. In our case the manufacturer recommended that we use 5000 hours at $110 \mathrm{C}$ rather than the rated 2000 hours at $105 \mathrm{C}$ for calculating capacitor lifetime.

In our initial lifetime calculations we ignored enclosure heating from the inverter's operation. We did, however, include ESR heating of the capacitors. We then derated time based upon operating temperature. For example, a $105 \mathrm{C}$ rated 2000 hour capacitor would have a lifetime of 4000 hours if held at $95 \mathrm{C}$. If instead, you hold that electrolytic capacitor at $95 \mathrm{C}$ for 2000 hours, the question is how do you quantify its remaining life? One way is to convert the hours at $95 \mathrm{C}$ to equivalent hours at $105 \mathrm{C}$. Since, its lifetime at $95 \mathrm{C}$ is 4000 hours, half of its life would be expended. Half of its life at $105 \mathrm{C}$ is 1000 hours. So 2000 hours at $95 \mathrm{C}$ is equivalent to 1000 hours at $105 \mathrm{C}$. The following equation transforms time operating at an arbitrary temperature $\mathrm{x}$ to equivalent time of operation at maximum temperature.

$$
\begin{gathered}
t_{M a x E q}=\frac{t_{0}}{2^{\frac{75-T_{x}}{15} \times 2_{o}-75}} \\
t_{\text {MaxEq }}=\text { Equivalent time atmaximum ratedtemperature. } \\
t_{o}=\text { Time operatingat some temperature below } t_{\text {MaxE } q} \text {. }
\end{gathered}
$$

Ascension Technologies' database of temperature and POA radiation is stored in 10 minute bins. Using the above equation, we can take each of those bins and transform it to equivalent time. Summing over a year we can get the equivalent hours in a typical year. Dividing into the capacitor's rated lifetime we get the expected lifetime in years.

$$
\begin{aligned}
& \qquad L_{c}=\frac{L_{o}}{\sum t_{i}} \\
& t_{i}^{\prime}=\text { Equivalent timew wich } \text { thecapacitors remainat temperature i duringone year } \\
& L_{c}=\text { Calculated lifetime of the capacitor }
\end{aligned}
$$

At this point more work needs to be done to develop a functional relationship between capacitor temperature, POA and ambient temperature. Lifetime calculation is easily done once capacitor temperature is known. If a well behaved function is not found, a comprehensive look- 
up table will be compiled. Completion of the models and verification with field data is expected to occur over the next six months.

\section{TEST RESULTS}

A standard enclosure mounted $3.0 \mathrm{~mm}$ off of the module is the control configuration. This consisted of the SunSine ${ }^{\mathrm{TM}} 300$ with fins and a gasket groove machined in the flange.

Machining the flange of the inverter enclosure flat improved the performance, reducing the peak capacitor temperature by $2.0 \mathrm{C}$. Removal of the fins had less impact on enclosure performance. The peak capacitor temperature was about $0.5 \mathrm{C}$ hotter than the control configuration. The finless version, with a faced flange has not yet been tested. It is thought that this could impact internal temperature due to reduced cross sectional area of the aluminum reducing the amount of heat drawn out of the mounting plate into the casting.

Varying the air gap between the plate and the module had an impact on electrolytic capacitorand module hot spot temperature. At POA of $980 \mathrm{~W} / \mathrm{M}^{2}$, module temperature under the control enclosure was $61.0 \mathrm{C}$. With a $1.3 \mathrm{~mm}$ spacing between the mounting plate and the glass the module temperature was 58.7C. The capacitor temperature was $43.0 \mathrm{C}$ for the $1.3 \mathrm{~mm}$ spacing and 39.1C for the control enclosure with $3 \mathrm{~mm}$ spacing. Module temperature increases with increased gap thickness. This indicates that insulation rather than convective cooling is the dominant thermal effect caused by increasing the air gap. The enclosure with a $3 \mathrm{~mm}$ gap and machined flange had the best performance with peak capacitor temperature $5.3 \mathrm{C}$ less than the thin gapped mounting with the unmachined flange.

\begin{tabular}{|l|l|l|l|l|}
\hline $\begin{array}{l}\text { POA=980W/m² } \\
\text { Ambient Temp=27.6C }\end{array}$ & $\begin{array}{l}\text { Faced Flange, } \\
3.0 \mathrm{~mm} \text { gap }\end{array}$ & $\begin{array}{l}\text { Finless, } \\
3.0 \mathrm{~mm} \text { gap }\end{array}$ & $\begin{array}{l}\text { Control, } \\
3.0 \mathrm{~mm} \text { gap }\end{array}$ & $1.3 \mathrm{~mm}$ gap \\
\hline $\begin{array}{l}\text { Module Temp Under } \\
\text { Enclosure }\end{array}$ & 60.3 & 61.7 & 61.0 & 58.7 \\
\hline Capacitor Temp & 37.7 & 39.5 & 39.1 & 43.0 \\
\hline $\begin{array}{l}\text { Module temp away from } \\
\text { enclosure }\end{array}$ & 54.0 & 54.0 & 54.0 & 54.0 \\
\hline
\end{tabular}

In order to get a preliminary result for inverter lifetime we ran the numbers assuming that each day would be the same as August 201996 in Waltham Massachusetts. The maximum values of several parameters were as follows: ambient temperature $28.9 \mathrm{C}(84 \mathrm{~F})$, module temperature 53C, Plane of Array radiation 1023 Watts/square meter. Clearly this is conservative for New England since most days will be substantially cooler. It also may be optimistic for Fresno. There one could expect to see module temperatures around 70C. The preliminary lifetimes generated used the following assumptions: 


\begin{tabular}{|l|l|}
\hline \multicolumn{1}{|c|}{ OPTIMISTIC } & \multicolumn{1}{|c|}{ CONSERVATIVE } \\
\hline $\begin{array}{l}\text { Internal heating from the electronics is } \\
\text { ignored. Though we think module heating is } \\
\text { the largest factor, further testing is needed to } \\
\text { ascertain the impact of temperature rise due to } \\
\text { waste heat from the electronics. }\end{array}$ & $\begin{array}{l}\text { ESR remains constant. It actually decreases } \\
\text { as the capacitor temperature rises. So the } \\
\text { ripple current heating estimates are a little } \\
\text { high. }\end{array}$ \\
\hline & $\begin{array}{l}\text { A clear day was used as the representative } \\
\text { day. In the summer clouds reduce radiation } \\
\text { received by the module. In the winter } \\
\text { enhancement from snow and cloud cover } \\
\text { occurs, the temperature is low and the } \\
\text { increased temperature will have minimal } \\
\text { impact on lifetime. }\end{array}$ \\
\hline & $\begin{array}{l}\text { We used the 15C doubling constant below } \\
\text { 75C. Much of the manufacturers literature } \\
\text { suggests using the 10C doubling constant over } \\
\text { the entire temperature range. }\end{array}$ \\
\hline
\end{tabular}

We ran numbers for two enclosure configurations, one with data from an enclosure using $1.3 \mathrm{~mm}$ gap between the module and the enclosure and once with an enclosure with its flange machined flat and having a $3.0 \mathrm{~mm}$ gap between the enclosure and the module. The following results were obtained. The more optimistic numbers use the manufacturers suggested 5000 hour lifetime rather than the guaranteed 2000 lifetime. We did, however stick with the more conservative $105 \mathrm{C}$ rather than the $110 \mathrm{C}$ that they thought was correct for the part we are using.

\begin{tabular}{|l|l|l|}
\hline $\begin{array}{l}\text { Capacitor lifetime in } \\
\text { Years }\end{array}$ & $1.3 \mathrm{~mm}$ Gap & $\begin{array}{l}\text { Faced Flange, 3.0mm } \\
\text { Gap }\end{array}$ \\
\hline $2000 \mathrm{Hr} @ 105 \mathrm{C}$ & 14.9 & 17.5 \\
\hline $5000 \mathrm{Hr} @ 105 \mathrm{C}$ & 37.2 & 43.7 \\
\hline
\end{tabular}




\section{CONCLUSION}

Various enclosure modifications had measurable impacts on the temperature inside the SunSine ${ }^{\mathrm{TM}} 300$. The gap between the module and the inverter allowed the enclosure to cool more at the expense of creating a more severe module hot spot. This indicates that thermal conduction rather than convection is the dominant mechanism impacted by changing the gap size. Furthermore this suggests that a trade-off will need to be made between inverter lifetime and performance degradation due to localized module heating.

Initial indications are that removal of fins has as a minimal effect on internal enclosure temperature. This test was only carried out with an enclosure that had as a gasket groove in its flange. At the writing of this paper, the same test was being run with an enclosure that has as a solid machined flat flange. If the results are again favorable, we will be able to eliminate the fins from the casting reducing cost and weight.

Initial calculations showed that enclosure optimizations currently under investigation could extend SunSine ${ }^{\mathrm{TM}} 300$ lifetime by about $15 \%$.

Equations were developed to predict capacitor lifetime based upon temperature. A model to calculate capacitor temperature from POA and ambient temperature is under development. Initial data suggests that inverter lifetimes comparable to that of a PV module could be expected in many regions. This conclusion is, however, tentative.

\section{REFERENCES}

1. Lauber J. A. Aluminum Electrolytic Capacitors--Reliability, Expected Life, and Shelf Capability. Sprague Electric Co. (1985)

2. Beresk J. August 23, 1996 correspondence. Matsushita Electronic Components Corporation of America 


\title{
USE OF IRRADIANCE AND TEMPERATURE DATA TO PREDICT AC MODULE LIFETIME
}

\author{
Written By:
}

Clayton Handleman

Engineer

Ascension Technology, Inc.

\author{
Dorothee Reinmuller \\ Student Intern \\ University of Karlsruhe, Germany \\ Presented By: \\ Greg Kern \\ Manager, Research \& Development \\ Ascension Technology, Inc.
}




\section{SunSine $^{\mathrm{TM}} 300$ AC PV Module}

Nominal Ratings:

$\begin{array}{llll}\text { Voltage (Vac) } & 120 & 240 & 277 \\ \text { Current (Aac) } & 2.5 & 1.25 & 1.1 \\ \text { Power (Wac) } & 300 & 300 & 300\end{array}$

Our work on AC Module lifetime is specifically targeted to the SunSine ${ }^{\mathrm{TM}} 300$ AC PV Module. 


\section{SunSine $^{\mathrm{TM}} \mathbf{3 0 0}$}

\section{Development Funding and Support Provided By:}

National Renewable Energy Lab Sandia National Laboratories New England Electric System Many Early Adopter Utilities

ASE Americas ASE $300 \mathrm{~W} / 50 \mathrm{~V}$ 


\section{AC Module Lifetime}

\section{Causes of Failure}

1. Early Failures due to an incomplete design. Lab, Field, and Beta Unit testing should shake out these weaknesses

ज् and corrections incorporated into the design.

2. Component Infant Mortality. The manufacturing process should incorporate enough burn-in to catch the majority of infant mortality failures.

3. Component failure. Once the Design and Manufacturing process are mature, this should be the leading cause of failure of units in the field. 


\section{AC Module Component Failure Modes}

How do we know which components will be the least reliable in AC Modules?

We really don't know, because we don't have any historical data to show what the failure modes have been.

What's our best guess as to the one least reliable component?

\section{Electrolytic Capacitors}




\section{Failure Mode of Electrolytic Capacitors}

Degradation occurs as a result of electrolyte evaporation through the capacitor end seals. The rate of evaporation increases by about $2 \mathrm{x}$ for every 10 degree $\mathrm{C}$ rise in temperature. After about $40 \%$ of the electrolyte evaporates, $\vec{\triangleright}$ ESR rises sharply and capacitance drops leading to iminent component failure. 


\section{Goals of our Thermal Testing Program}

1.

Develope a model to predict Electrolytic Capacitor Lifetime in AC PV Modules.

2.

Optimize enclosure design to minimize Electrolytic Capacitor Temperature. 


\section{Thermal Design Assumptions}

Assumptions:

Inverter Efficiency $\quad 90 \%$

Module Efficiency $\quad 12.5 \%$

Module Heat Removal $\quad$ Back $=$ Front

$\vec{\jmath}$

Module Reflectivity. None

Other:

Module Rating

300 Watts

Module Area

$2.4 \mathrm{~m}^{\wedge} 2$

Inverter Footprint

$0.1 \mathrm{~m}^{\wedge} 2$ 


\section{Heat Balance at Full Sun (All Units in Watts)}

Solar Power hitting Module

2400

\author{
Converted to DC \\ Converted to AC \\ $\vec{s}$
}

300

270

30

1050

1050

Heat radiated out Front

Heat radiated out Back

Heat into AC Module

44

Into Air

1006 


\section{Capacitor Ratings}

Capacitor Family Rating: $\quad 2,000$ Hours at 105 C

Manufacturer's Suggestion $\quad 5,000$ Hours at $110 \mathrm{C}$

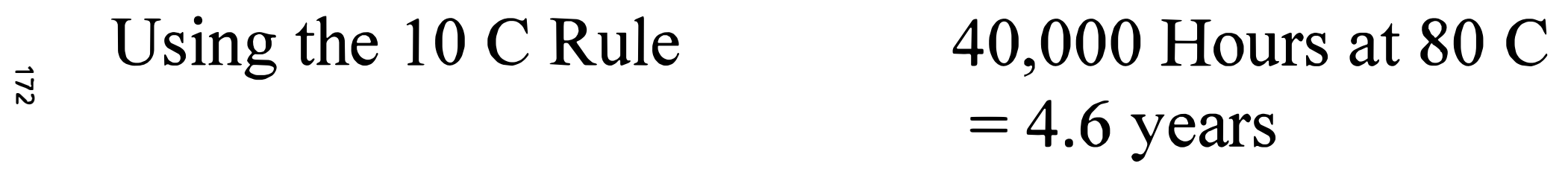




\section{Lifetime Model Equations}

$$
L_{x}=L_{o} 2^{\frac{T_{o}-T_{x}}{10}}
$$

$$
\begin{aligned}
& L_{x}=\text { Lifetime at actual operating temperature } T_{x} \\
& L_{o}=\text { Lifetime atmaximum ratedoperatingtemperature } \\
& T_{o}=\text { Maximum ratedoperating temperature }{ }^{\circ} \mathrm{C} \\
& T_{x}=\text { Actualoperating temperature }{ }^{\circ} \mathrm{C}
\end{aligned}
$$




$$
\begin{gathered}
T_{x}=T_{A}+\Delta T \\
\Delta T=\text { Temperature rise, ripple currentheating } \\
T_{A}=\text { Air temperature inside the enclosure }
\end{gathered}
$$

\section{A more conservative model:}

$$
L_{x}=L_{o} 2^{\frac{T_{o}-75^{\circ} \mathrm{C}}{10}} \times 2^{\frac{75^{\circ} \mathrm{C}-T_{x}}{15}}
$$




\section{Temperature Rise due to ESR:}

$$
\Delta T=\frac{I^{2} \times E S R}{K \times A}
$$

I=Ripplecurrent

$E S R=.075$ Max, this drops at higher temperature operation. $K=$ Thermal constant $=0.006$

$A=$ case surface area, about 9.8 inch $^{2}$ per capacitor 


\section{Time at Rated Temperature}

$$
t_{\text {MaxEq }}=\frac{t_{0}}{2^{\frac{75-T_{x}}{15}} \times 2^{\frac{T_{o}-75}{10}}}
$$

$t_{\text {MaxEq }}=$ Equivalent time at maximum rated temperature . $t_{o}=$ Time operating at some temperature below $t_{M a x E q^{*}}$ 


\section{Lifetime Calculation}

$$
\begin{aligned}
& \qquad L_{c}=\frac{L_{o}}{\sum t_{i}} \\
& t_{i}=\text { Equivalent time which the capacitors } \\
& \text { remainattemperature } i \text { during one year } \\
& L_{c}=\text { Calculated lifetime of the capacitor }
\end{aligned}
$$




\section{Enclosure Design}

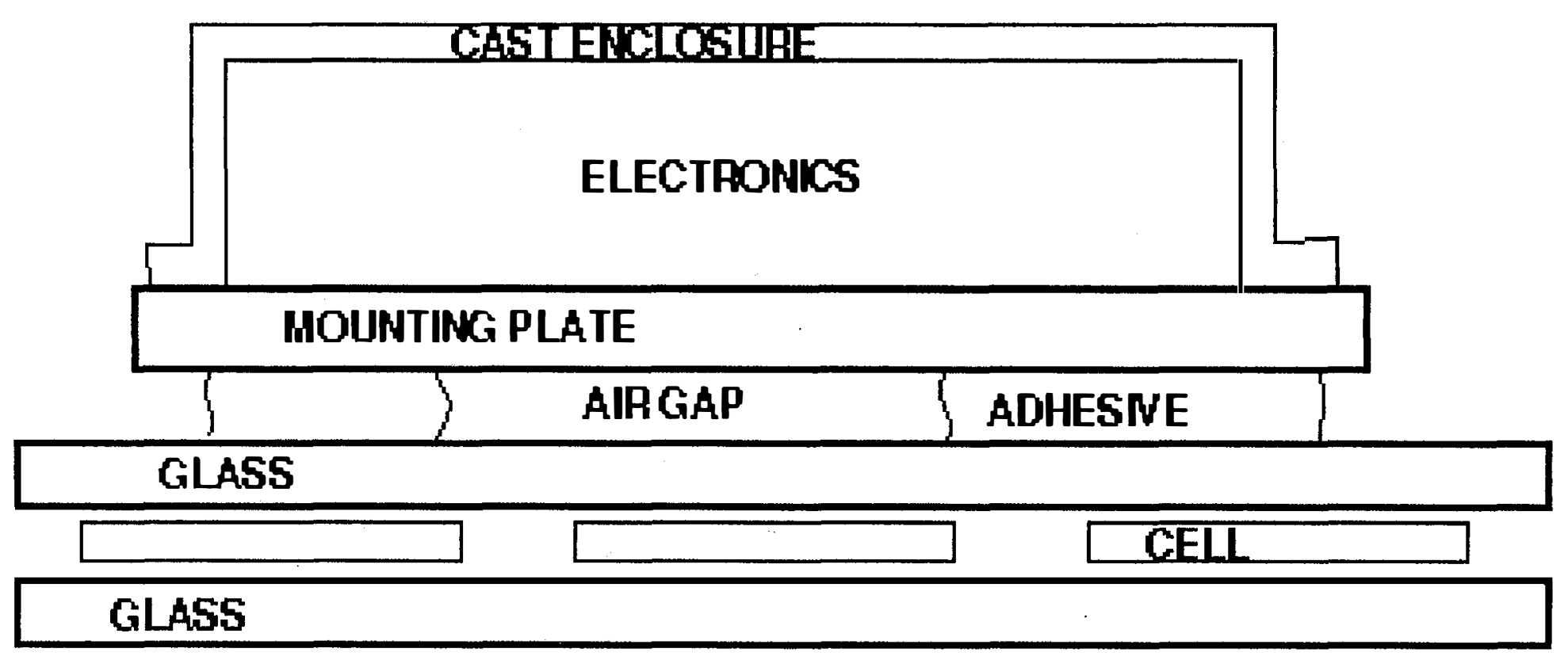




\section{Enclosure Design Variables}

1.Size of the Air Gap

2.Use of Radiating Fins

3.Thermal Attachment to Mounting Plate

4.Size, Footprint for now set at $0.1 \mathrm{~m}^{\wedge} 2$. 


\title{
Empirical Test Setup
}

Four units were mounted on modules and instrumented for:

\author{
Ambient Temperature \\ Module Back Surface Temperature \\ Module Temperature under Mounting Plate \\ Temperature Inside Enclosure \\ Capacitor Temperature
}




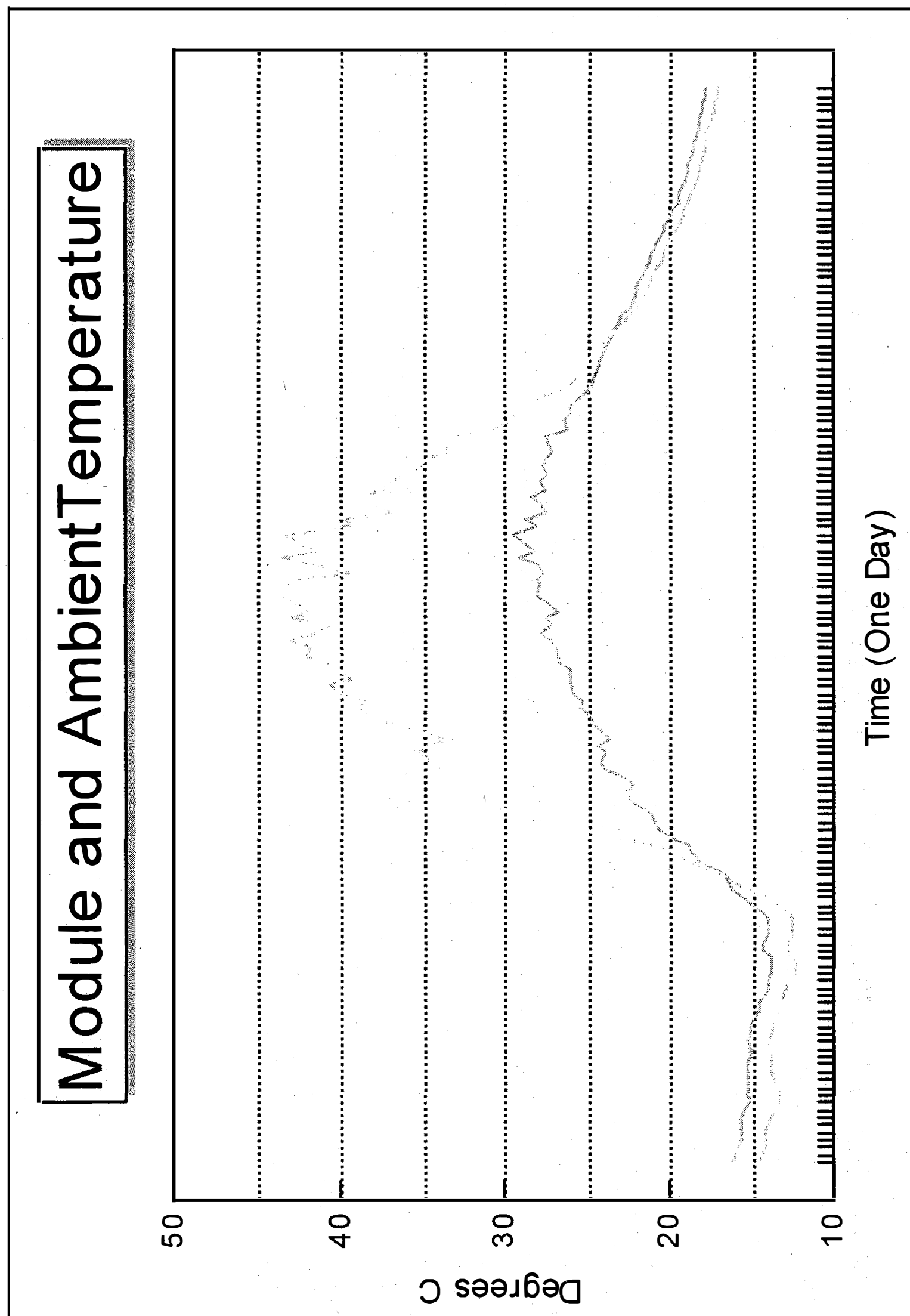

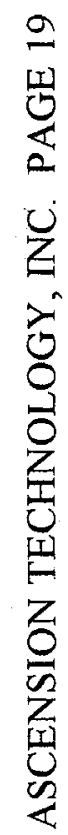




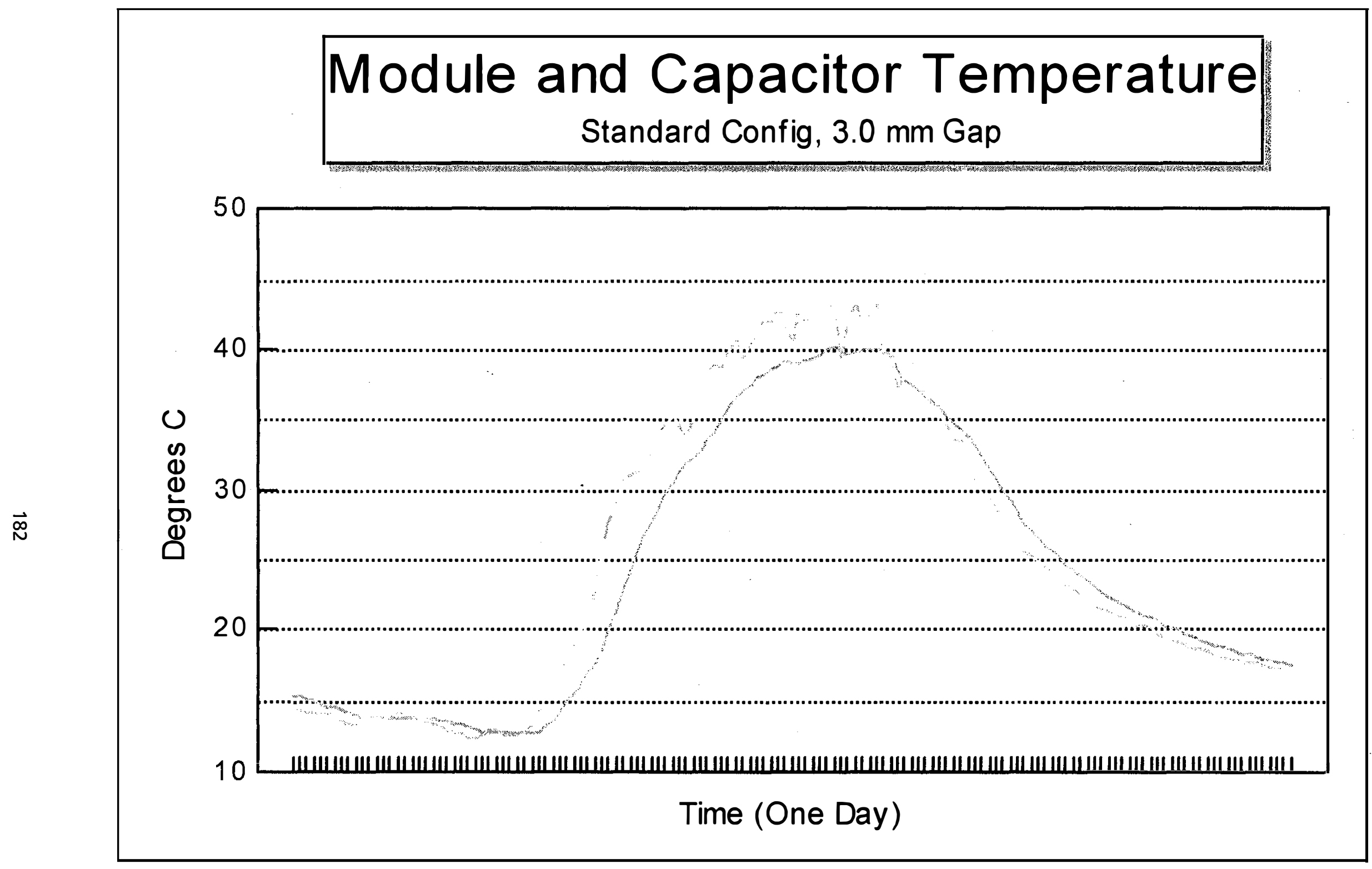

ASCENSION TECHNOLOGY, INC. PAGE 20 


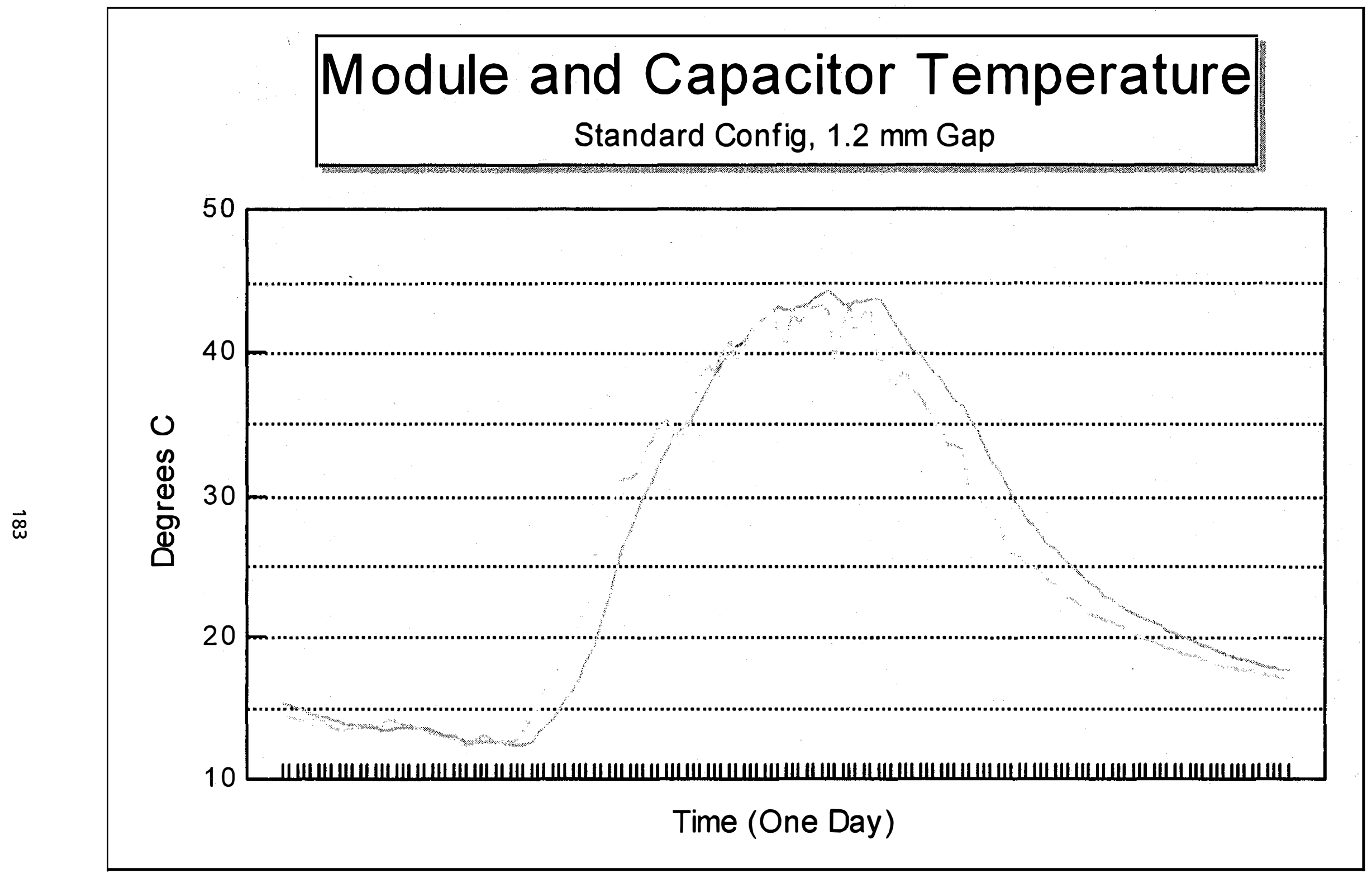




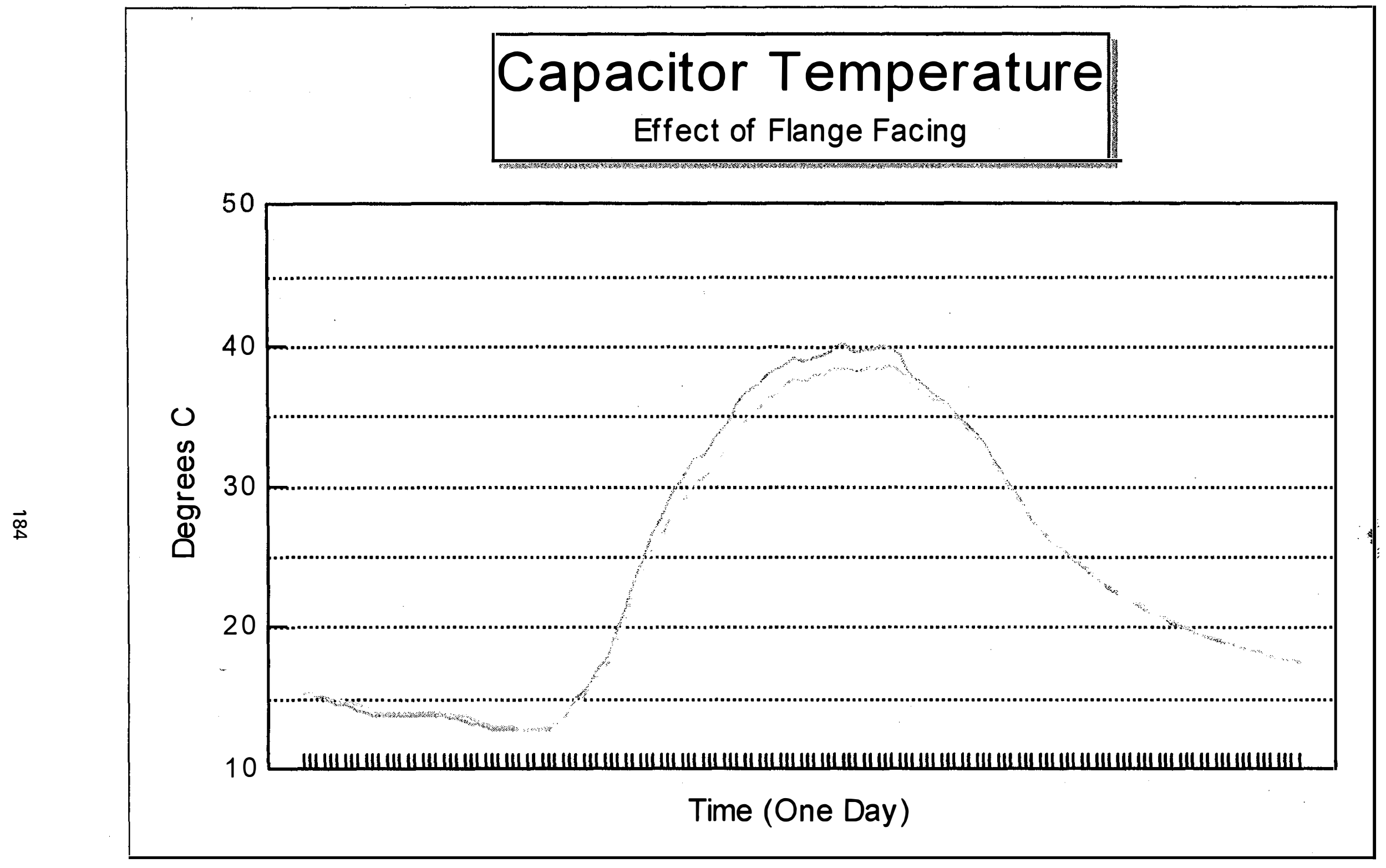

ASCENSION TECHNOLOGY, INC. PAGE 22 


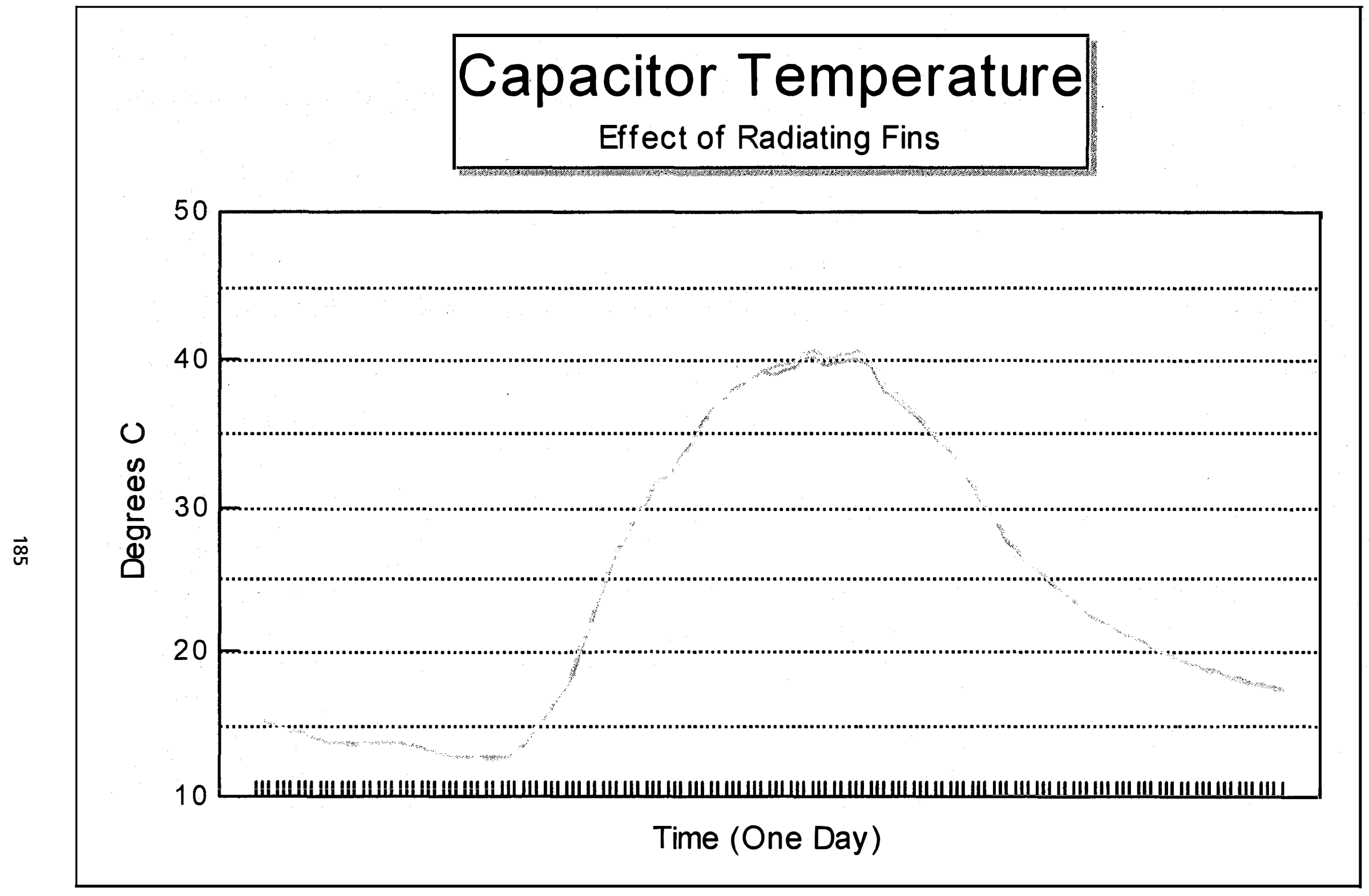

ASCENSION TECHNOLOGY, INC. PAGE 23 


\section{Test Results Summary}

\begin{tabular}{|l|l|l|l|l|}
\hline $\begin{array}{l}\text { POA=980W/m } \\
\text { Ambient } \\
\text { Temp=27.6C }\end{array}$ & $\begin{array}{l}\text { Faced } \\
\text { Flange, } \\
3.0 \mathrm{~mm} \\
\text { gap }\end{array}$ & $\begin{array}{l}\text { Finless, } \\
3.0 \mathrm{~mm} \\
\text { gap }\end{array}$ & $\begin{array}{l}\text { Control, } \\
3.0 \mathrm{~mm} \text { gap }\end{array}$ & $1.3 \mathrm{~mm}$ gap \\
\hline $\begin{array}{l}\text { Module Temp } \\
\text { Under Enclosure }\end{array}$ & 60.3 & 61.7 & 61.0 & 58.7 \\
\hline Capacitor Temp & 37.7 & 39.5 & 39.1 & 43.0 \\
\hline $\begin{array}{l}\text { Module temp } \\
\text { away from } \\
\text { enclosure }\end{array}$ & 54.0 & 54.0 & 54.0 & 54.0 \\
\hline
\end{tabular}




\section{Conclusions From Empirical Tests}

1. Increasing the Air Gap between the module and mounting plate reduces Capacitor temperature significantly.

2. Removal of the radiating fins does not have a

$\overrightarrow{\mathrm{\sigma}}$ significant impact on Capacitor temperature.

3. Increasing the thermal contact between the casting and mounting plate reduces Capacitor temperature. 


\section{Lifetime Calculation}

Based upon test data from one day, and assumes every day of operation has the same temperature profile.

\begin{tabular}{|l|l|l|}
\hline $\begin{array}{l}\text { Capacitor Lifetime } \\
\text { in Years: }\end{array}$ & $1.3 \mathrm{~mm}$ Gap & $\begin{array}{l}3.0 \mathrm{~mm} \text { Gap, with } \\
\text { Faced Flange }\end{array}$ \\
\hline $2000 \mathrm{Hr} @ 105 \mathrm{C}$ & 14.9 & 17.5 \\
\hline $5000 \mathrm{Hr} @ 105 \mathrm{C}$ & 37.2 & 43.7 \\
\hline
\end{tabular}




\section{Conclusions from Lifetime Calculation}

1. Calculated Lifetime result depends Greatly on the Capacitor Specification.

2. More work needs to be done to validate the models that we are using.

3. Obviously, the cooler the components operate, the longer the lifetime will be.

4. Lifetimes in excess of 10 years may very well be achievable. 


\section{What's Next?}

1. Continued Testing and Modeling at Ascension Technology.

2. Field Testing

2 Units at NREL (Delivered)

2 Units at Sandia

1 Unit at STAR Center

6 Beta Test Units at Customer Locations 


\section{Cell and Module Reliability}




\section{ACCELERATED ENVIRONMENTAL TESTING}

\section{for SCREENING and LIFETIME PREDICTION}

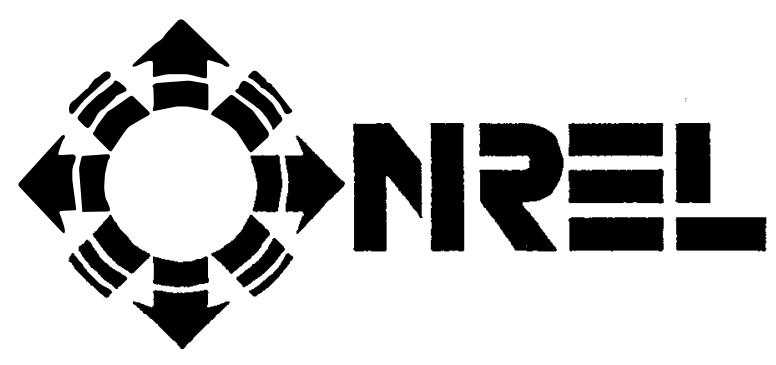

Gary Jorgensen

NATIONAL RENEWABLE ENERGY LABORATORY

September 5, 1996 


\section{OUTLINE}

- Objectives of Accelerated Environmental Testing (AET)

- Considerations for AET

- Reasons to Perform AET.

$\vec{\triangleright}$

- $\quad$ AET and Screening Tests

- AET and Service Lifetime Prediction (SLP)

- Application to PV Modules and Systems 


\section{OBJECTIVES Of ACCELERATED ENVIRONMENTAL TESTING}

- Obtain failure data

- Project failure rates

- Establish value of failure rate during the stable use period

- Determine time of onset of wearout failure period

- Allow prediction of service lifetime

- Monitor incoming lot reliability (accept or reject lot)

- Produce and remove early life failures 
CONSIDERATIONS for ACCELERATED ENVIRONMENTAL TESTS

- The failure mechanism must be the same for elevated stress conditions as that expected under normal use conditions

- Over the range of stresses (down to use stress) for which this holds, "true acceleration" occurs

- For practical reasons, choose linear acceleration factors:

$$
t_{u}=a_{i} \cdot t_{s}
$$

- Inferences typically involve extrapolation in both stress and time; tests should be planned to minimize the amount of extrapolation in both stress and time

- Models for extrapolation should have a basis in (be derived from) the physics and chemistry of the important failure mechanism(s)

- It is important to define "failure" 
Relationship Between Stress and Lifetime

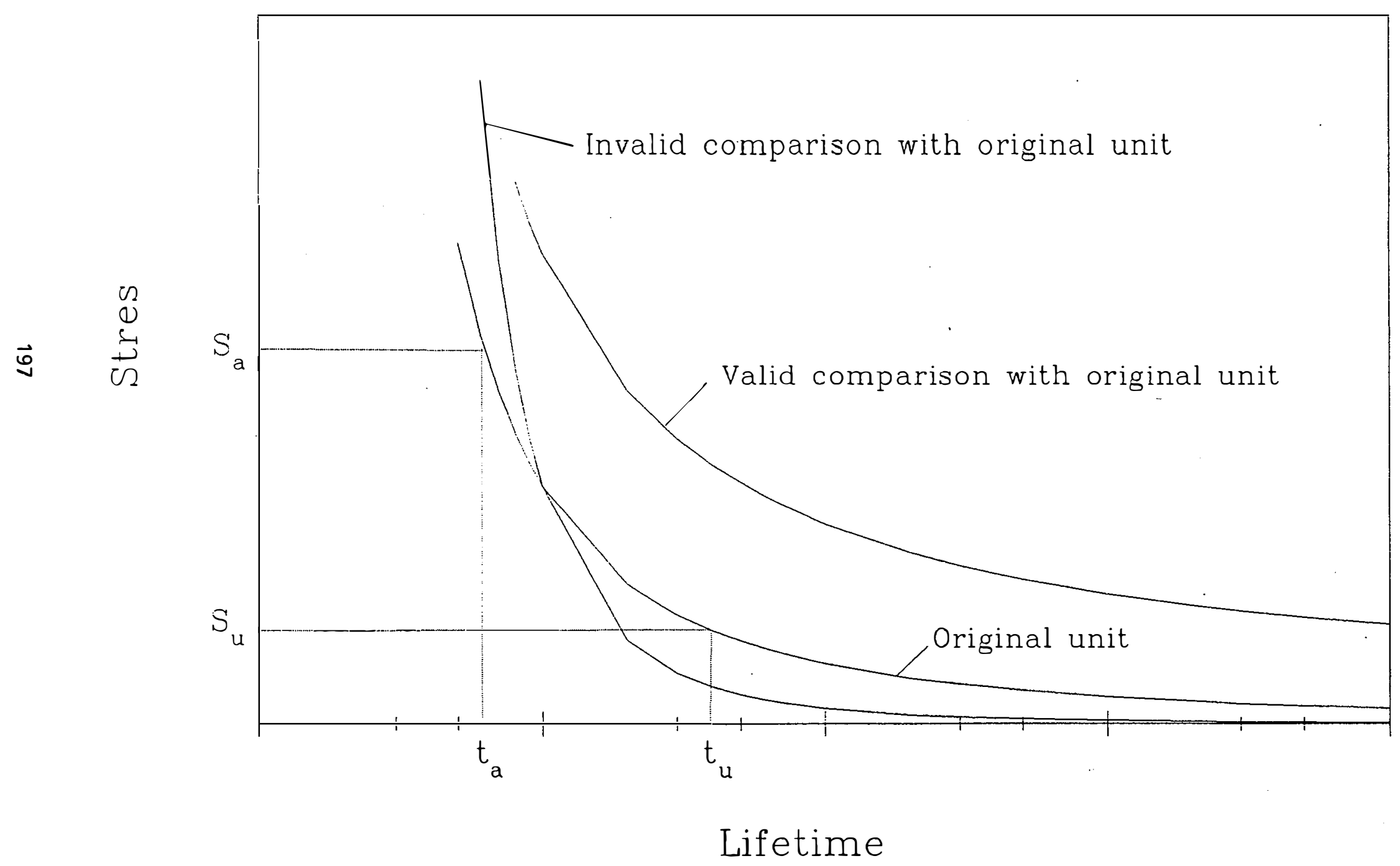




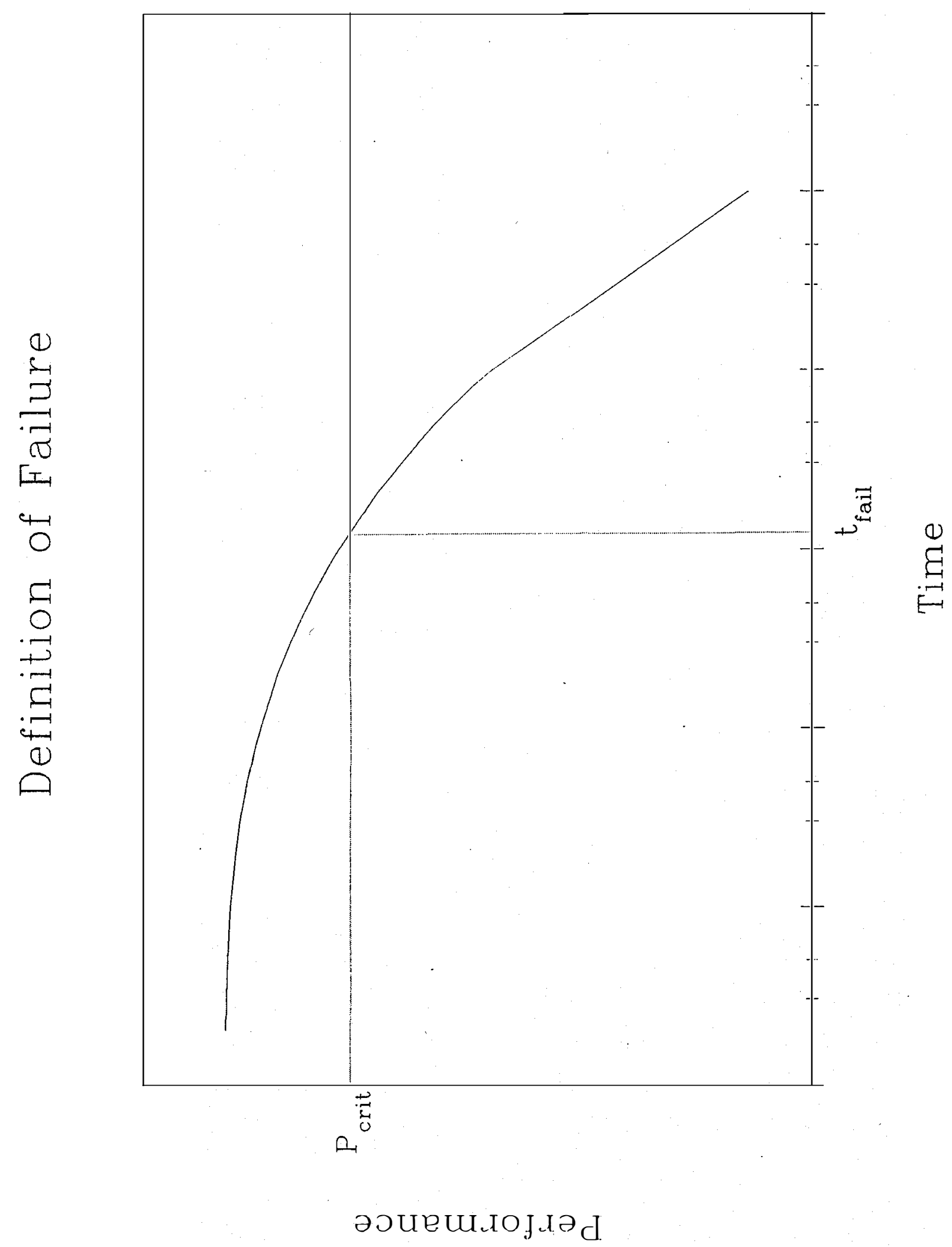




\section{COMPARATIVE CORRELATION TESTS [3]}

- Establish correlation between accelerated and real-world weathering results

- Can use nonparametric statistics, for example, Spearman rank correlation:

$$
r_{s}=\frac{\sum_{l=1}^{n} R\left(X_{i}\right) R\left(Y_{i}\right)-n\left(\frac{n+1}{2}\right)^{2}}{\sqrt{\sum_{l=1}^{n} R\left(X_{l}\right)^{2}-n\left(\frac{n+1}{2}\right)^{2}} \cdot \sqrt{\sum_{l=1}^{n} R\left(Y_{i}\right)^{2}-n\left(\frac{n+1}{2}\right)^{2}}}
$$

where:

$\mathrm{n}=$ number of pairs of values

$R\left(X_{i}\right), R\left(Y_{i}\right)=$ rank values for sample series $X$ and $Y$ where, for example, $X_{i}$ is a series of samples exposed in an accelerated chamber and $Y_{i}$ is the same series exposed outdoors

- For $r_{s}>\sim 0.9$ can then use accelerated test to rank new (interfamily) materials and (closely related) processes 


\section{TYPES of ACCELERATED ENVIRONMENTAL TESTS [5]}

- STRIFE (Stress Life) or "Elephant Tests" [6]

- Burn-In

- Environmental Stress Screening (ESS) or "Shake and Bake"

- Highly Accelerated Life Tests (HALT) 


\section{Elephant Tests}

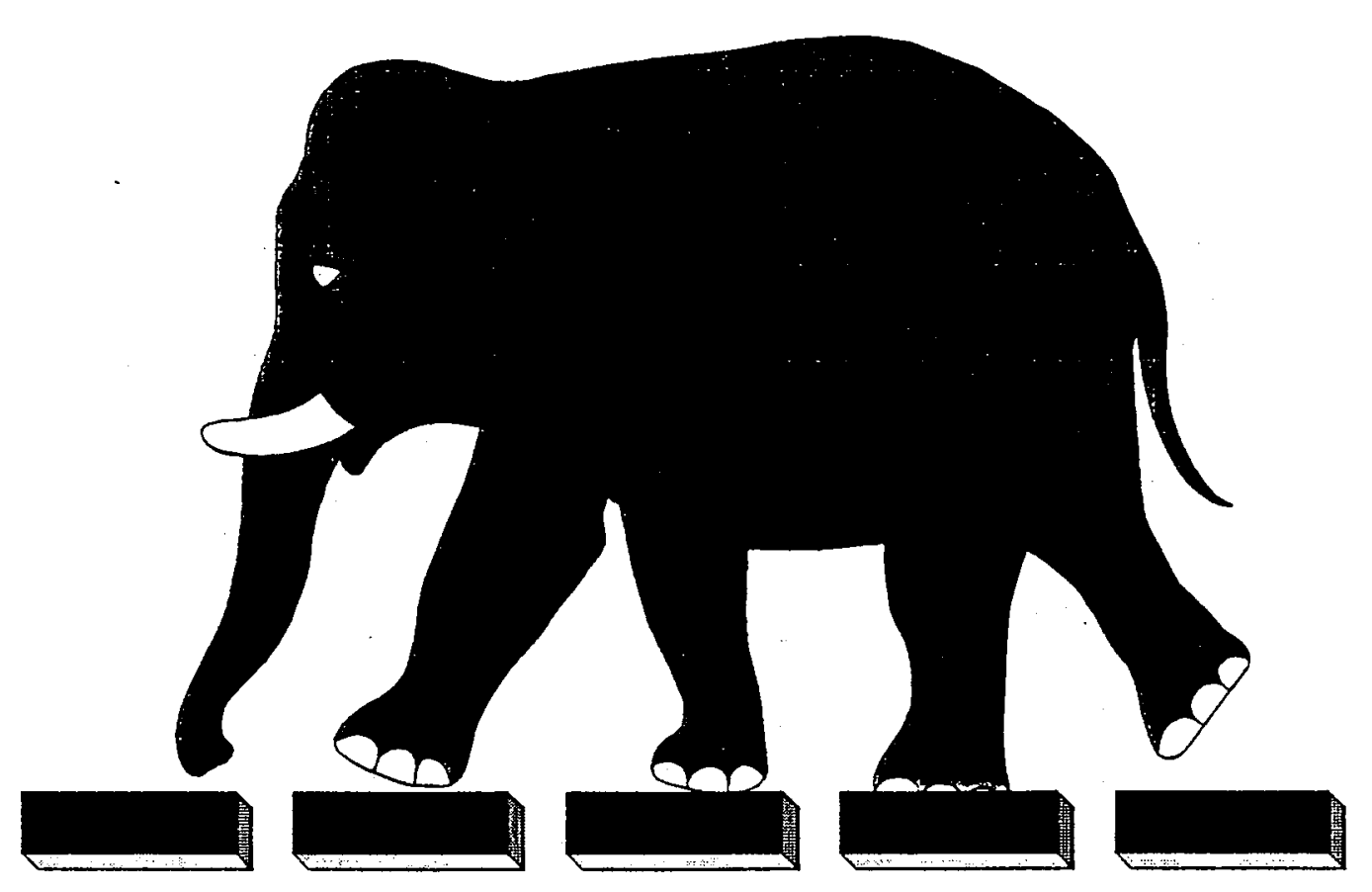

- Use aggressive stress to force failures of prototype units

- Resulting failures are due to product or process design flaws 


\section{Burn-In Tests}

- Eliminate "early failures" typically associated with manufacturing defects

ํ. Level of burn-in stress must not be high enough to damage the non-defective units

- Duration of burn-in traded off against expense

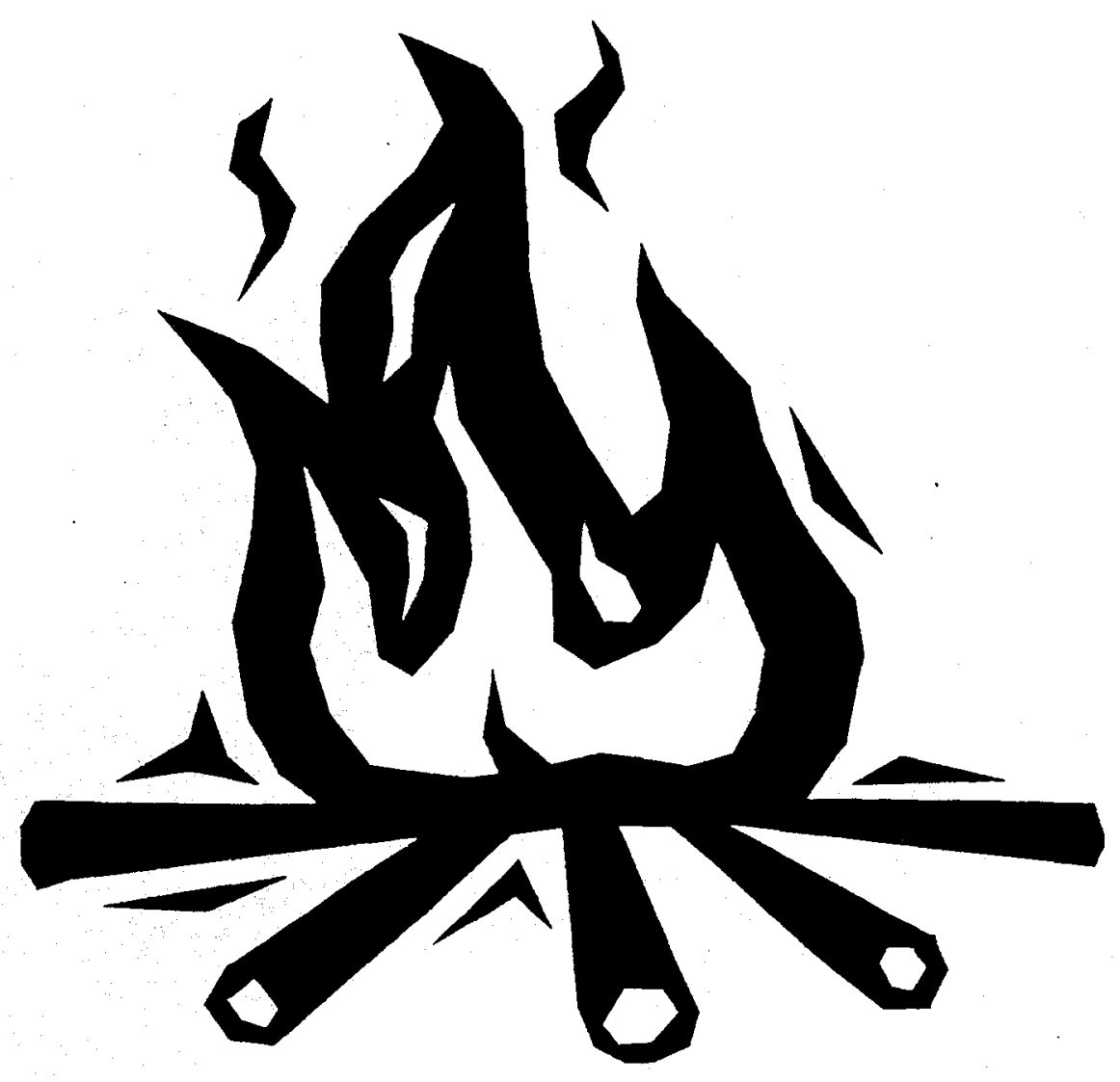




\section{Shake and Bake Tests}

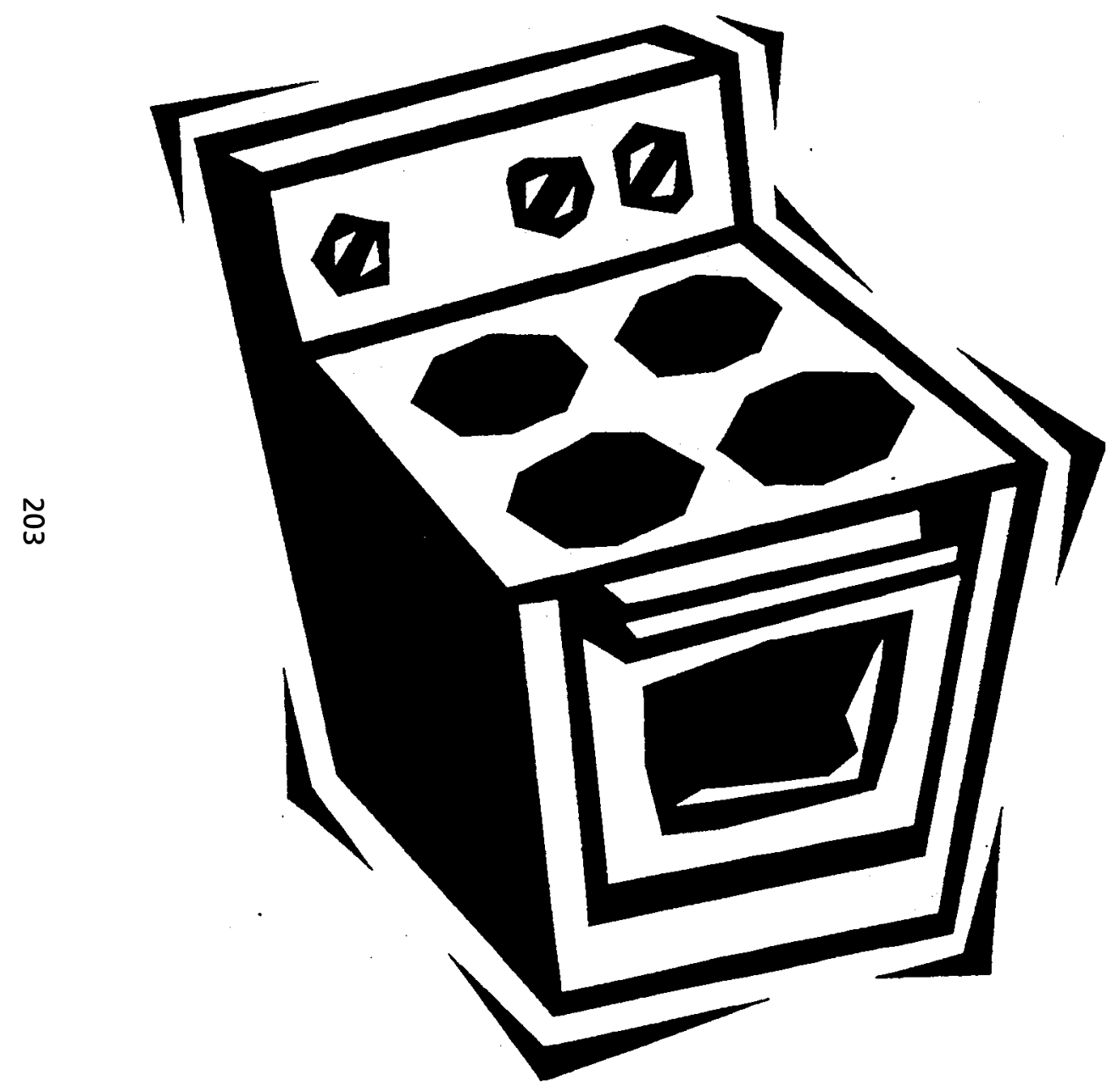

- Test units at system or subsystem level

- Use milder but more complicated stress regimen

- Screen out defective items without harming system 


\section{Highly Accelerated Life Tests}
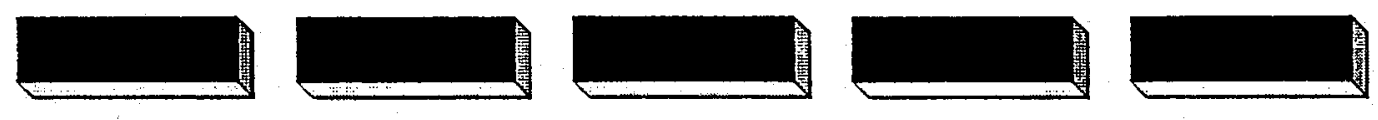

- Useful when inferences about life at use conditions are not needed ั

- Inspection sampling of new lots of materials/components

- Burn-in screening testing

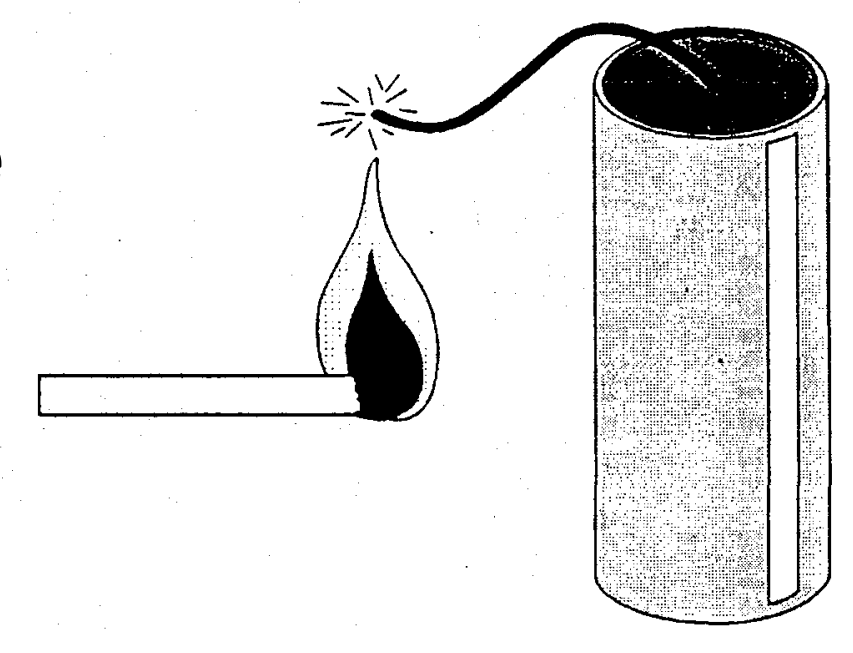

- Provide scoping information useful in planning more extensive ALT

- Explore relevance of failure modes discovered in STRIFE tests 


\section{The Bathtub Curve}
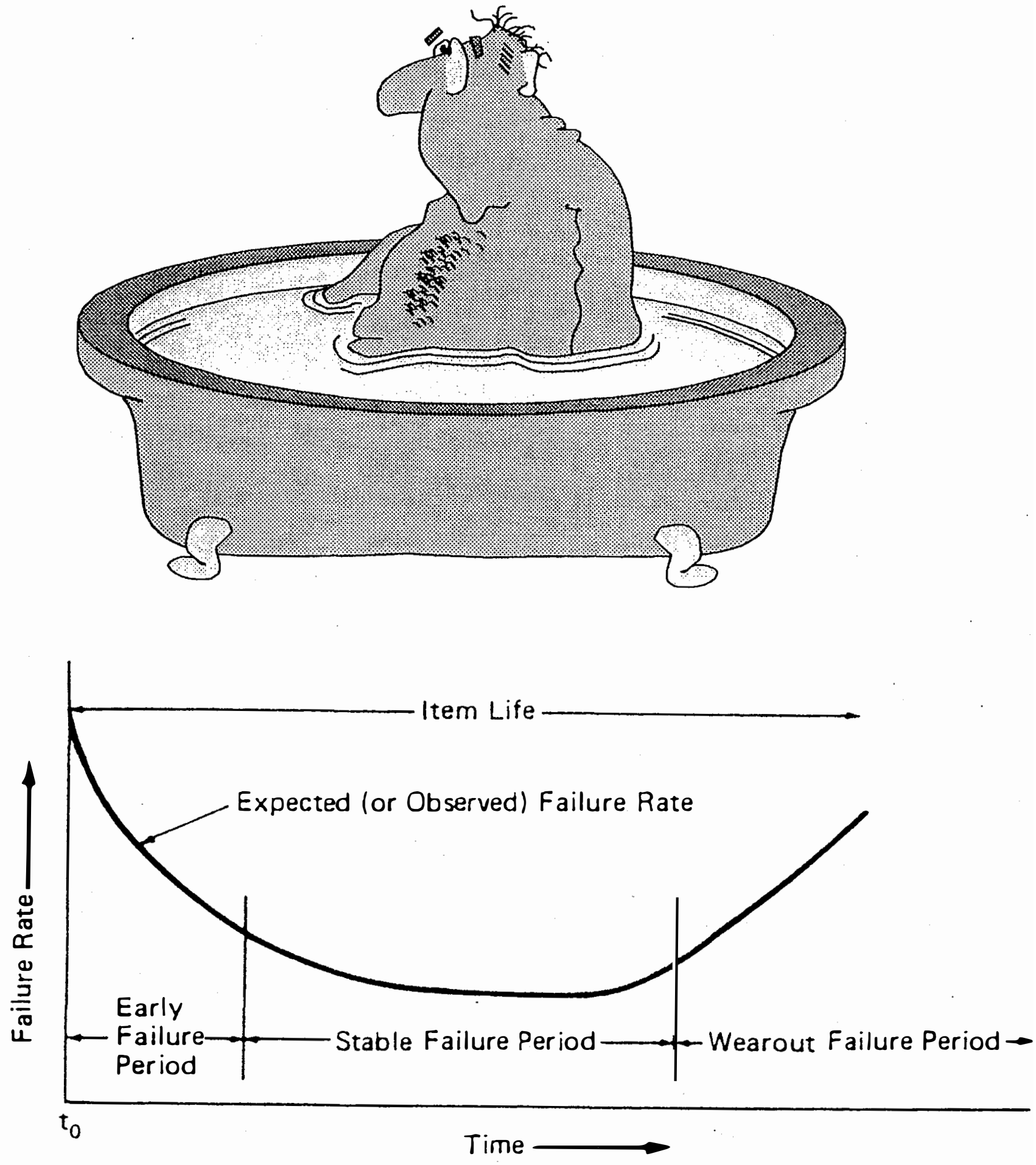

Bathtub Curve for Failure Rates [ 7$]$ 
SOME USEFUL DISTRIBUTIONS for LIFE TESTING

\begin{tabular}{|c|c|c|c|}
\hline \multirow[b]{2}{*}{ Quantity } & \multicolumn{3}{|c|}{ Distribution } \\
\hline & Exponential & Weibull & Log-Normal \\
\hline $\begin{array}{l}\text { Probability } \\
\text { Density } \\
\text { Function } \\
\text { (PDF), f(t) }\end{array}$ & $\lambda \exp (-\lambda t)$ & $\begin{array}{l}(m / t)(t / c)^{m} \cdot \\
\exp \left[-(t / c)^{m}\right]\end{array}$ & $\begin{array}{c}\left\{1 /\left[s t(2 \pi)^{1 / 2}\right]\right\} \bullet \\
\exp \left\{-\left[1 /\left(2 s^{2}\right)\right]\left[\ln (t)-\ln \left(t_{50}\right)\right]\right\}\end{array}$ \\
\hline $\begin{array}{l}\text { Cumulative } \\
\text { Distribution } \\
\text { Function } \\
\text { (CDF), F(t) } \\
\end{array}$ & $1-\exp (-\lambda t)$ & $1-\exp \left[-(t / c)^{m}\right]$ & $\int_{0}^{t} f(t) d t$ \\
\hline $\begin{array}{l}\text { Reliability } \\
\text { (survival) } \\
\text { function, R(t) }\end{array}$ & $\exp (-\lambda t)$ & $\exp \left[-(t / c)^{m}\right]$ & $1-F(t)$ \\
\hline $\begin{array}{l}\text { Failure } \\
\text { (hazard) rate, } \\
h(t)\end{array}$ & $\lambda$ & $(m / c)(t / c)^{m-1}$ & $f(t) / R(t)$ \\
\hline $\begin{array}{l}\text { Mean } \\
\text { expected life, } \\
E(t)\end{array}$ & $1 / \lambda$ & c $\Gamma(1+1 / m)$ & $t_{50} \exp \left(s^{2} / 2\right)$ \\
\hline
\end{tabular}




\section{EXPONENTIAL DISTRIBUTION}

- Exhibits constant failure rate

- Demonstrates "lack of memory" regarding length of operation

- Implies unit does not age, wear out, or degrade with use

- Usefulness

- Model long, flat part of bathtub failure rate curve

- Applicable to many systems or subassemblies

- Can approximate general failure rate curve by piece-wise sum of exponential parts

- Get equivalent information from testing 10 units for 20,000 hours as from testing 1000 units for 200 hours

- Closure property

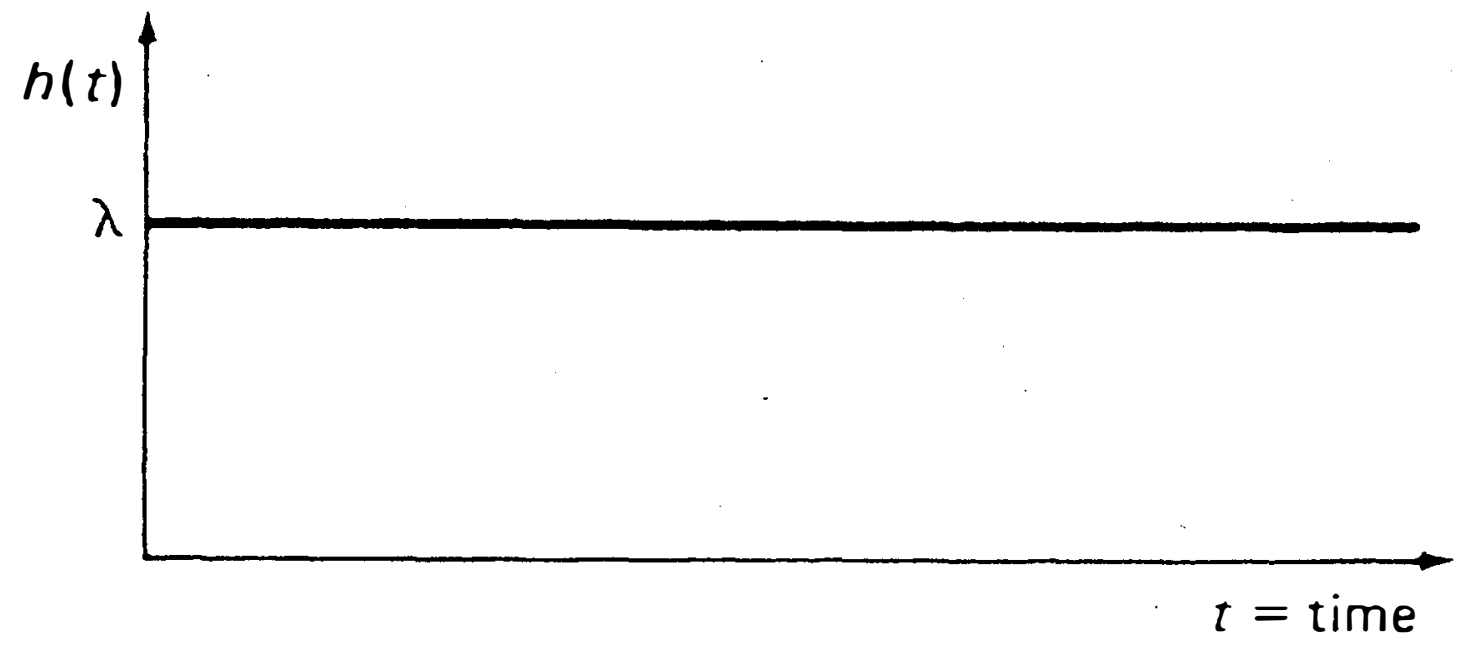

The Exponential Distribution Failure Rate $h(t) \quad[7]$ 


\section{WEIBULL DISTRIBUTION}

- Very flexible; wide variety of possible failure rate profiles

- Derivable from "extreme value" distribution applicable when failure is due to a "weakest link" of many possible failures

- Useful in modeling early failures due to manufacturing defects that escape discovery $(m<1)$

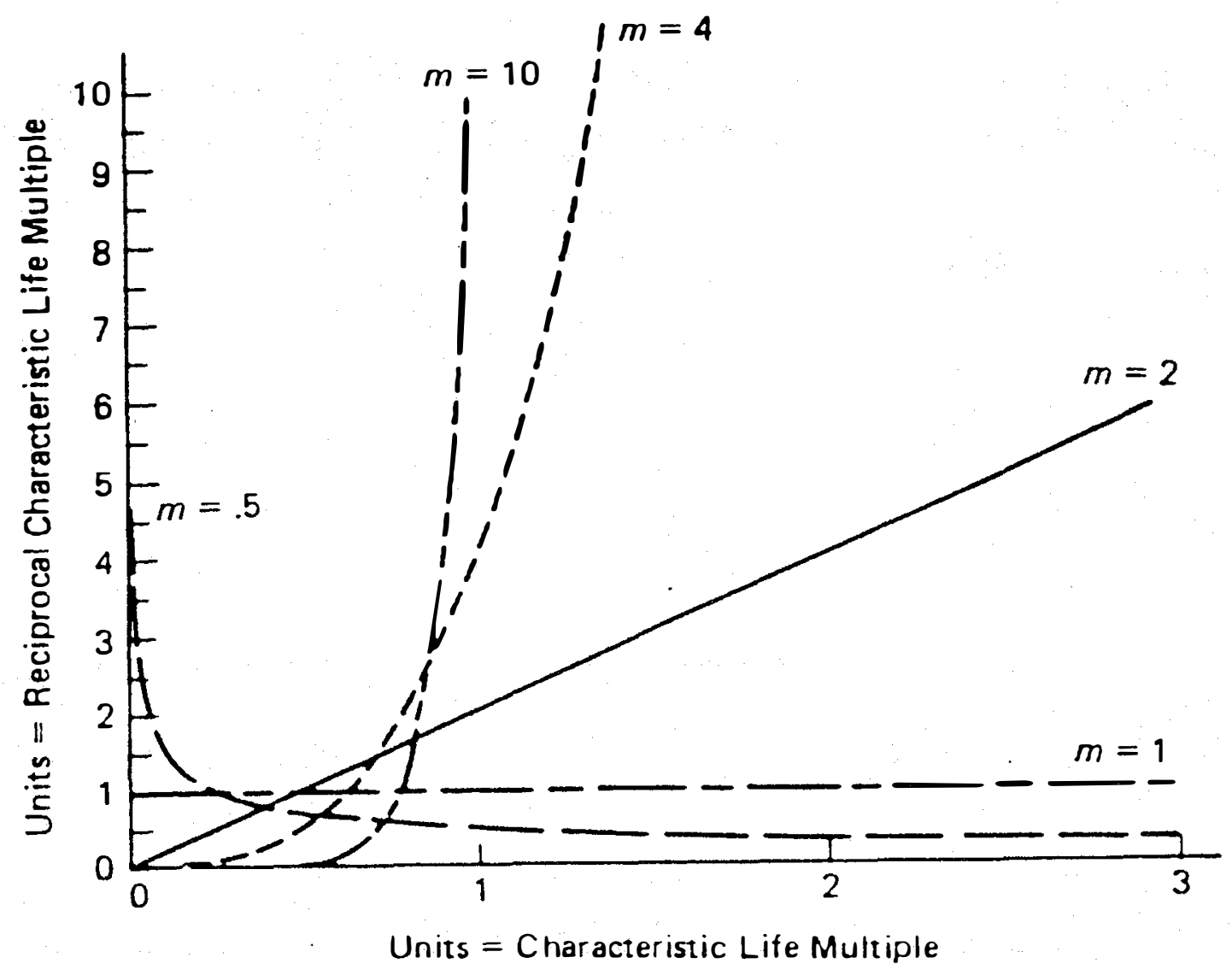

Weibull Failure Rate (Hazard) [ 


\section{LOG-NORMAL DISTRIBUTION}

- Very flexible; wide variety of possible failure rate profiles

- Derivable from a multiplicative (or proportional) growth model

- At any given instant of time, unit undergoes a random increase of degradation proportional to its present state

- Multiplicative effect of all these random and (assumed) independent growths eventually results in failure

- Model applicable for many chemical/physical processes

- Corrosion

- Diffusion

- Electromigration

- Crack growth propagation

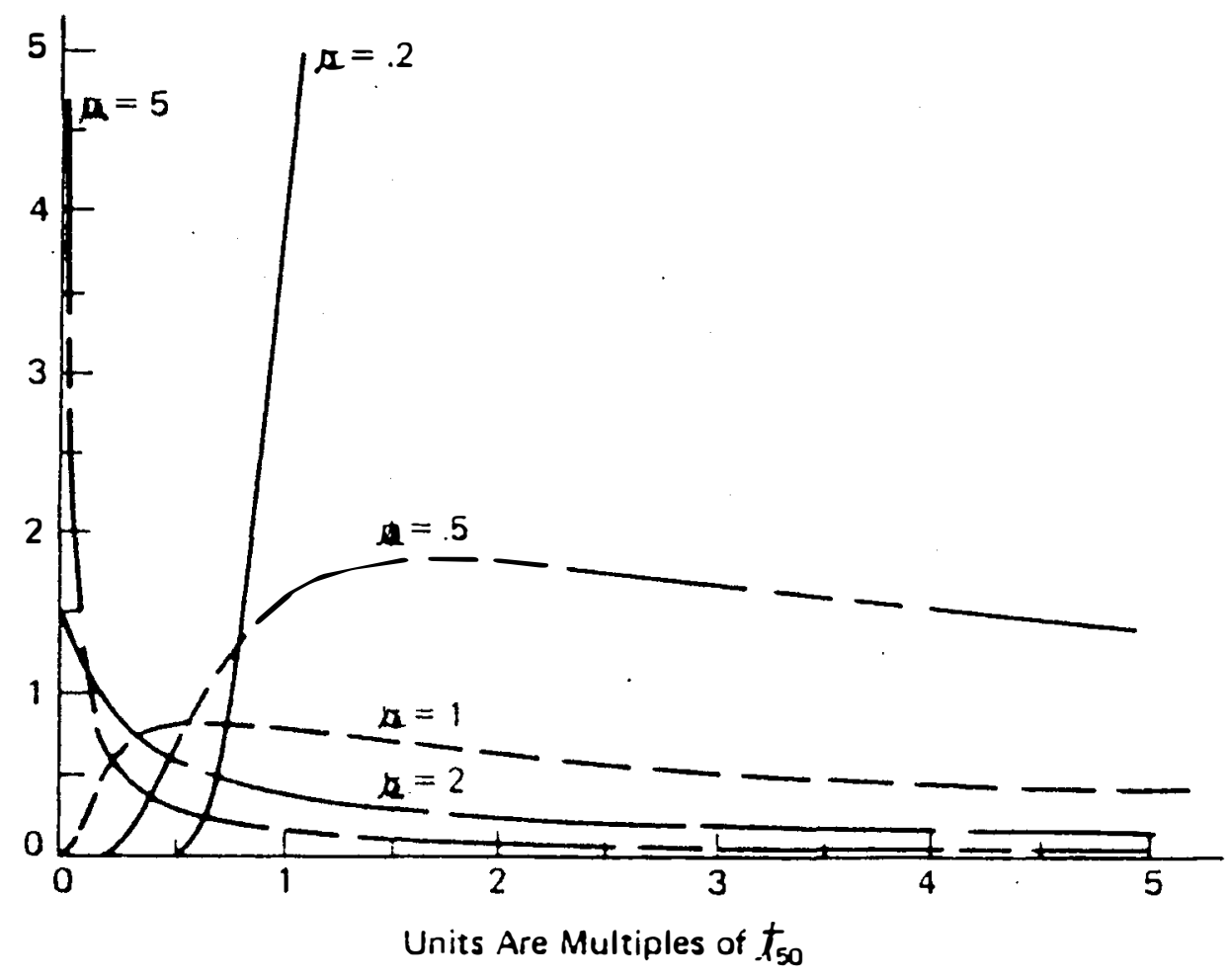

Lognormal Distribution Failure 2992 


\section{SELECTION of LIFE DISTRIBUTION MODEL}

- Necessity of parametric model

- To project to earlier times when small percentile (say, $0.001 \%$ ) of population might fail

- To estimate a proportion of failures for a time much smaller than the time of the first observed failure

- Use life distribution model primarily because it works

- Fits data well

- Leads to reasonable projections when extrapolating beyond range of data

- Weibull and log-normal often fit same set of data equally well; plot histogram of logarithm of the data

- If symmetrical or bell-shaped, use log-normal distribution

- If left-skewed, use Weibull distribution

- Justify on basis of theoretical considerations 
ACCELERATION SCALE FACTOR RELATIONSHIPS [7]

- Time to failure:

$$
t_{u}=a t_{s}
$$

- Density function:

$$
f_{u}(t)=1 / a f_{s}(t / a)
$$

- Failure probability:

$$
F_{u}(t)=F_{s}(t / a)
$$

- Failure rate:

$$
h_{u}(t)=1 / a h_{s}(t / a)
$$

where:

$$
\begin{aligned}
& \mathbf{u}=\text { use condition } \\
& \mathbf{s}=\text { stressed condition } \\
& \mathbf{a}=\text { linear acceleration factor }
\end{aligned}
$$




\section{ACCELERATION SCALE FACTORS}

\begin{tabular}{|c|c|c|}
\hline Type of Stress & Acceleration Factor & Ref. \\
\hline Mechanical & $\mathbf{a}_{\sigma}=\left(\sigma_{s} / \sigma_{u}\right)^{k}$ & 1 \\
\hline Thermal & $\begin{array}{ll}a_{T}=\exp \left[-E\left(1 / T_{s}-1 / T_{U}\right)\right] & \text { (Arrhenius) } \\
a_{T}=\left(T_{s} / T_{\psi}\right)^{w} \cdot \exp \left[-E\left(1 / T_{s}-1 / T_{W}\right)\right] & \text { (Eyring) }\end{array}$ & 4 \\
\hline Electrical & $a_{E}=\left(V_{s} V_{W}\right)^{p}$ & 4 \\
\hline Chemical & $a_{c}=\left(C_{i, s} / C_{i, u}\right)^{n} \cdot\left(C_{i, s} / C_{i, u}\right)^{m} \cdots \cdot$ & 1 \\
\hline Photodegradation & $a_{1}=\left(I_{s} / I_{u}\right)^{2}$ & 4 \\
\hline $\begin{array}{l}\text { Electro- } \\
\text { migration }\end{array}$ & $a_{J}=\left(J_{s} / J_{u}\right)^{q} \cdot \exp \left[-E\left(1 / T_{s}-1 / T_{u}\right)\right]$ & 7 \\
\hline
\end{tabular}

where:

$$
\begin{aligned}
& \mathbf{u}=\text { use condition } \\
& \mathbf{s}=\text { stressed condition }
\end{aligned}
$$




\section{SYSTEM MODELS and GENERAL RELIABILITY ALGORITHM}

- The probability of failure of each component can be represented as a mixture of appropriately weighted terms representing, for example, a small proportion of components susceptible to manufacturing defects and a larger population that follows normal competing failure modes:

$$
F_{\text {Tot }}(t)=\alpha F_{d}(t)+(1-\alpha) F_{N}(t)
$$

Then the failure rate of the mixture CDF will have a "bathtub" shape given by:

$$
h_{\text {Tot }}(t)=\left\{\alpha f_{d}(t)+(1-\alpha) f_{N}(t)\right\} /\left\{1-\left[\alpha F_{d}(t)+(1-\alpha) F_{N}(t)\right]\right\}
$$

- If a system is comprised of $\mathbf{n}$ independent components, all of which must operate for the system to properly function, then the system failure rate is:

$$
h_{\text {sys }}(t)=\sum_{i=1}^{n} h_{i}(t)
$$




\section{POSSIBLE DEGRADATION MODES Of PV MODULES [2]}

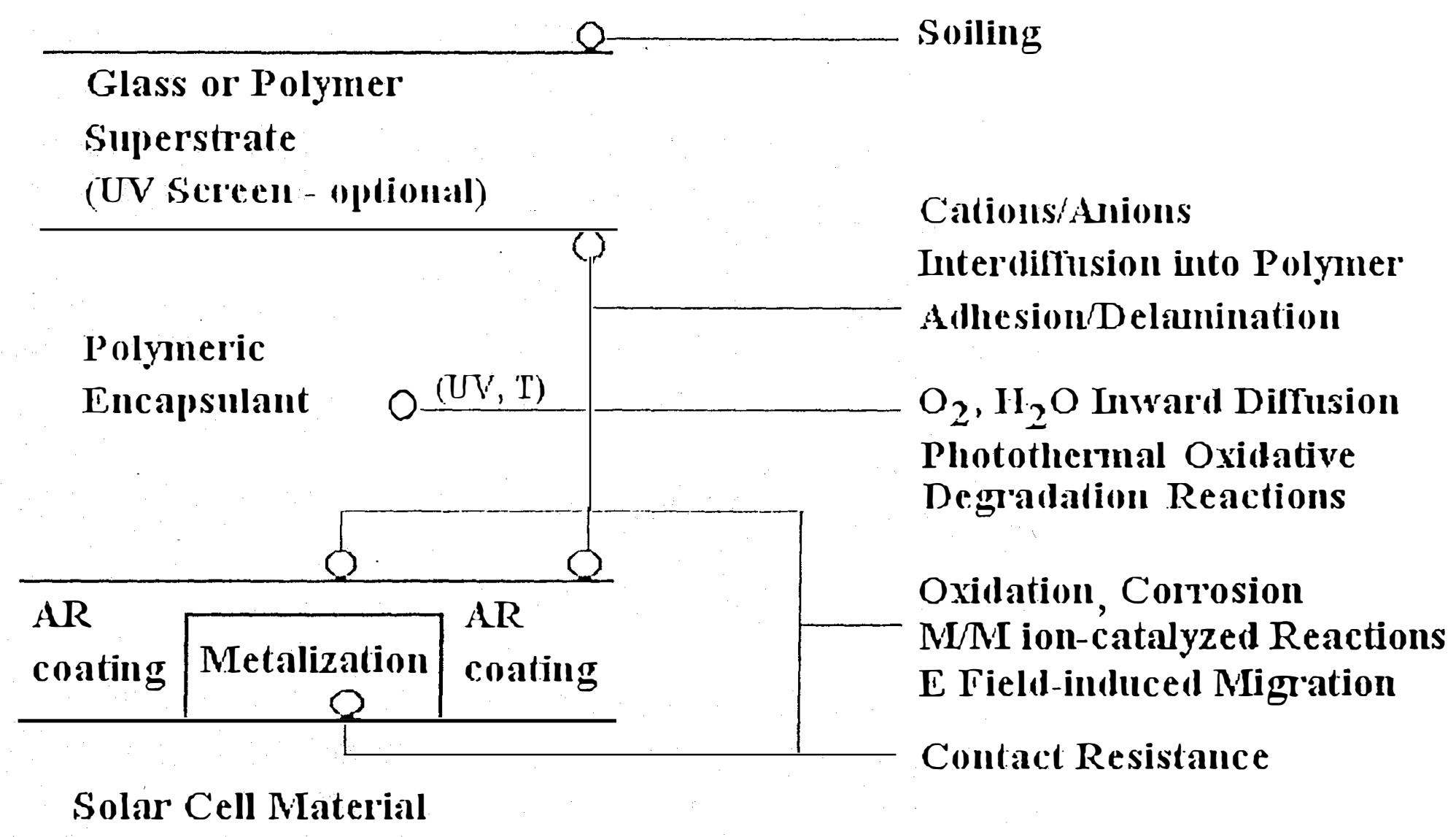

Polymeric Encapsilant

Sulostrate 


\section{APPLICATION to PV MODULES and SYSTEMS}

- Identify and isolate each failure mode separately

- Design and perform applicable AET

- Use appropriate distributions to model specific failure rates (fit data)

- Choose and apply relevant acceleration models to transform failure rates

- Different failure mechanisms follow different life distributions

- Different failure mechanisms have different acceleration models

- Derive total module (or system) failure rate as a sum of individual rates; for example:

$$
h_{\text {module }}(t)=h_{\text {electromigration }}(t)+h_{\text {corrosion }}(t)+h_{\text {fatigue }}(t)+\cdots
$$

or:

$$
h_{\text {system }}(t)=h_{\text {module }}(t)+h_{\text {battery }}(t)+h_{\text {controller }}(t)+h_{\text {inverter }}(t)+\cdots \cdot
$$




\section{REFERENCES}

1. "Survey of Service Life Prediction Methods for Materials in Solar Heating and Cooling", IEA Solar Heating and Cooling Program Task X "Solar Materials Research and Development", B. Carlsson, editor, Document D16:1989, Swedish Council for Building Research, Stockholm, Sweden, 1989.

2. Czanderna, A.W., and Pern, J., Solar Energy Materials and Solar Cells, Vol.43, 1996, pp. 101-183.

3. Fischer, R., "Accelerated Weathering Test Development with Fluorescent UVCondensation Devices", Society of Automotive Engineers Tech. Pap. Ser. 841022, 1984.

4. Martin, J.W., "Time Transformation Functions Commonly Used in Life Testing Analysis", Durability of Building Materials, Vol. 1, No.2, 1982, pp. 175-194.

5. Meeker, W.Q., and Escobar, L.A., "A Review of Recent Research and Current Issues in Accelerated Testing", International Statistical Review, Vol. 61, No. 1, 1993, pp. 147-168.

6. Nelson, W., Accelerated Life Testing, John Wiley and Sons, Inc., New York, 1990.

7. Tobias, P.S., and Trindade, D.C., Applied Reliability, Van Nostrand Reinhold, New York, 1995. 


\title{
Stability Issues Related to CdTe PV Modules
}

\author{
Peter V Meyers \\ ITN Energy Systems \\ 12401 W. 49th Ave. \\ Wheat Ridge, CO 80033
}




\section{Stability Issues Related to CdTe PV Modules \\ Peter V. Meyers \\ ITN Energy Systems \\ 12401 W. 49th Ave. \\ Wheat Ridge, $\mathrm{CO} 80033$}

$\mathrm{CdTe} / \mathrm{CdS} \mathrm{PV}$ modules with conversion efficiency of $\sim 8 \%$ have demonstrated stable performance in laboratory and field tests lasting thousands of hours. Furthermore, in spite of attempts to probe for potential degradation mechanisms by stressing devices using combinations of illumination, temperature and voltage bias beyond levels which would be encountered in the field, no fundamental degradation mechanism for $\mathrm{CdTe} / \mathrm{CdS}$ devices has been found. Nonetheless, not all devices display the same degree of stability nor do all devices respond in the same way to stresses. In addition there have been reports of reversible changes in device performance apparently due to illumination or bias. At least some devices apparently require oxygen to ensure stability. Thus analysis of $\mathrm{CdTe} / \mathrm{CdS}$ device stability is complex and there are strong indications that results may be processspecific.

This presentation includes an overview of the available stability testing methods, data and analysis as well as some speculation on possible mechanisms which might explain these results. Much of the speculation concerns the role of the low resistance CdTe-electrode electrical contact, generally believed to be the most delicate feature of the device, but the $\mathrm{CdS} / \mathrm{CdTe}$ junction and bulk CdTe properties may also play a role. Understanding of any degradation mechanism is a prerequisite to the development of credible accelerated life testing procedures. Given the "existence proof" of stable module field performance, it seems likely that stable device performance can be obtained through proper PV device and module design. 


\section{Outline}

\section{Premises}

Existence Proofs

Teaming Activities (US)

Strategy

Field Testing

Search for acceleration factors

Device Studies

Overseas manufacturers

BP Solar

Matsushita

Views and Speculations

Summary 


\section{Premises}

- Onus is on the CdTe community to demonstrate stability

- Not all devices are created equal defects in material or cell configuration or module design can lead to degradation

- Degradation can be accelerated by stress

\section{Internal (cell) \\ $\Rightarrow$ Temperature \\ $\Rightarrow$ Illumination \\ $\Rightarrow$ Electrical bias}

External

$\Rightarrow$ Mechanical - thermal cycling, impact, vibration, loading

$\Rightarrow$ Ambient - oxygen, humidity

$\Rightarrow$ Electrical - across module, module to ground

- Accelerated Life Testing

$\Rightarrow$ facilitates development of more stable devices

$\Rightarrow$ enables prediction of useful life 


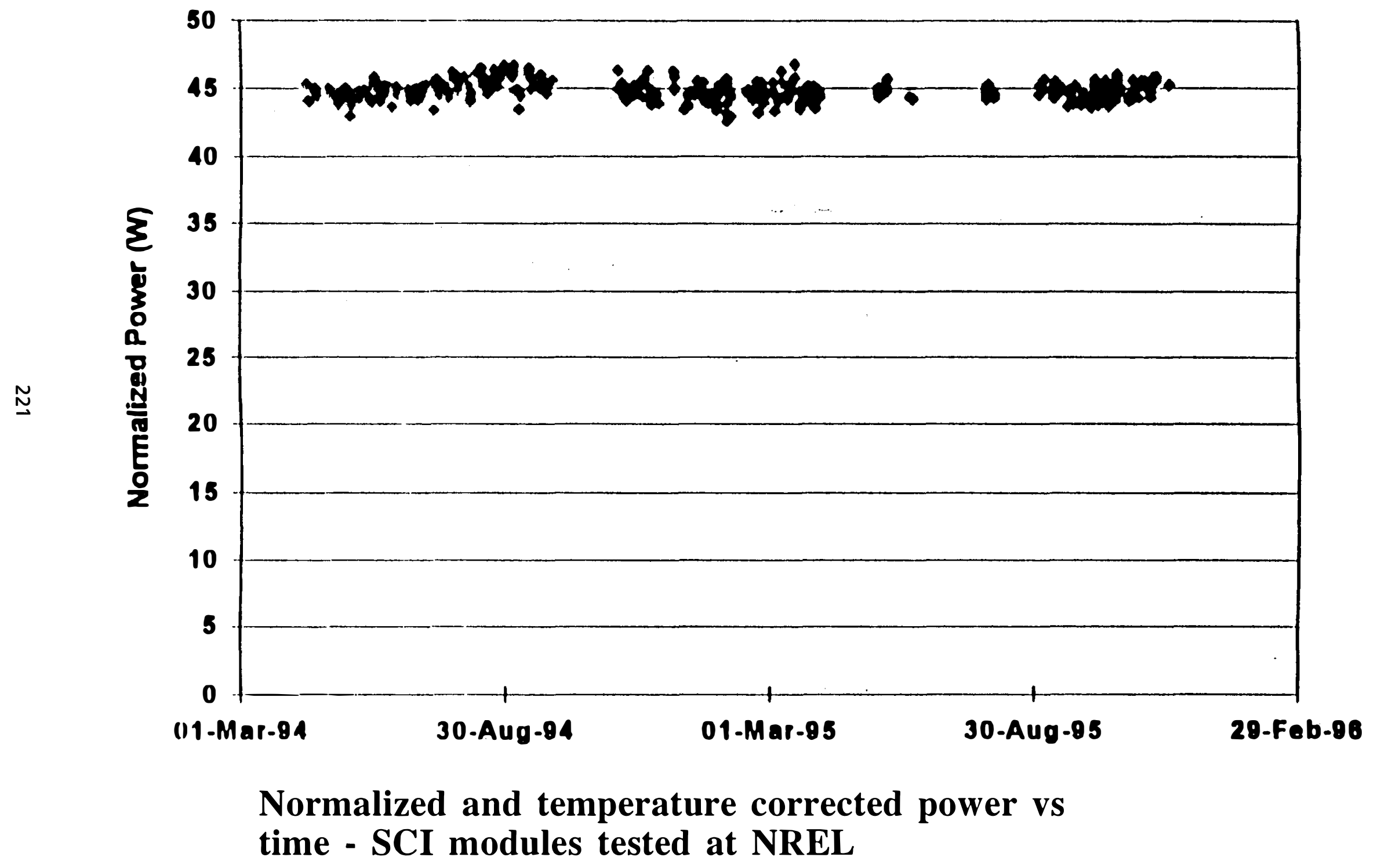

R.C. Powell et al, Proc. 25th IEEE PVSC (1996) 


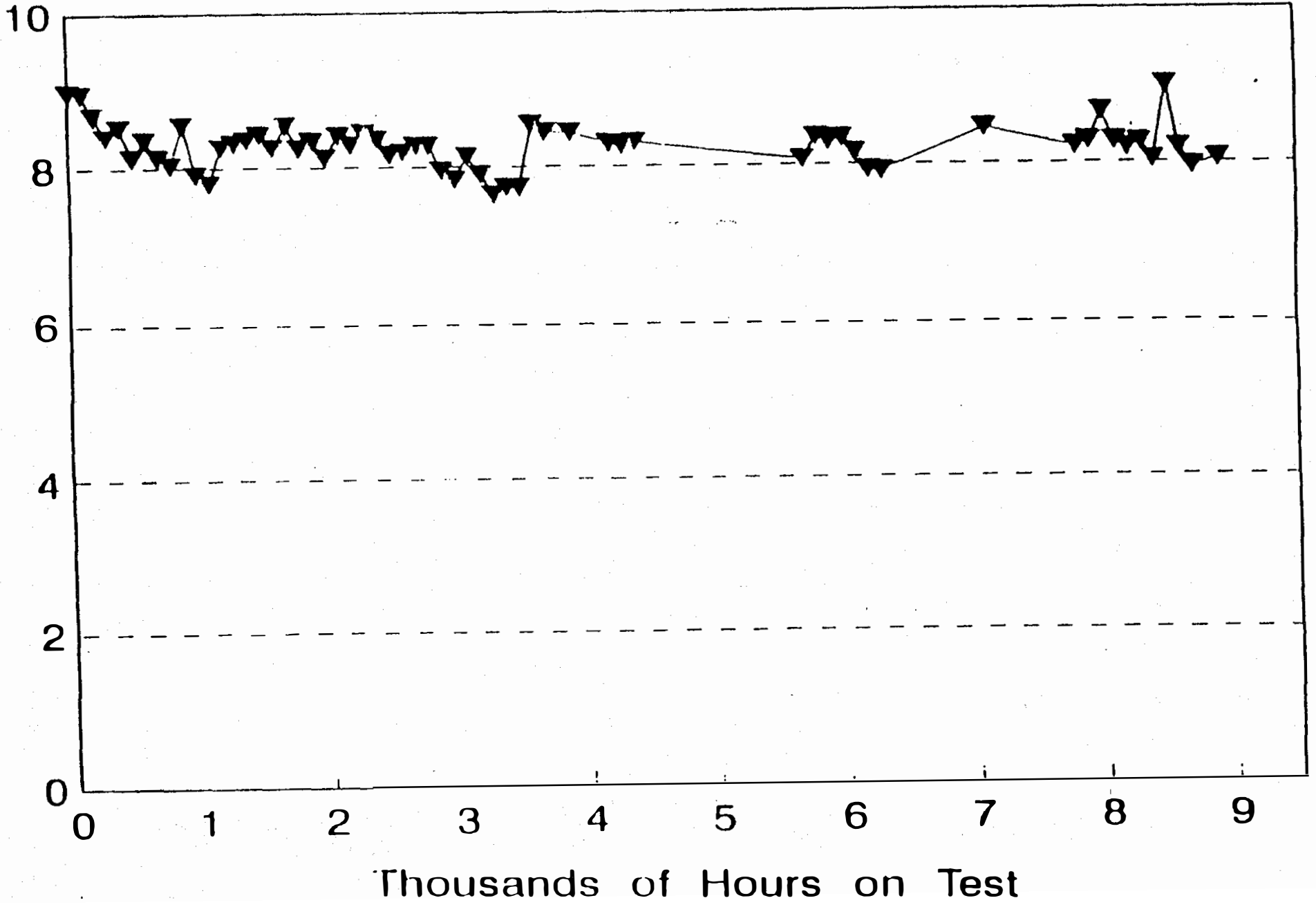

Module efficiency on external test in Spain - BP Solar modules.

A.K. Turner et al.. Solar Energv Materials and Solar Cells 35 (1994) 263- 
Golden Photon, Inc.

\section{Module Output Power vs Time}

Module \#201-29

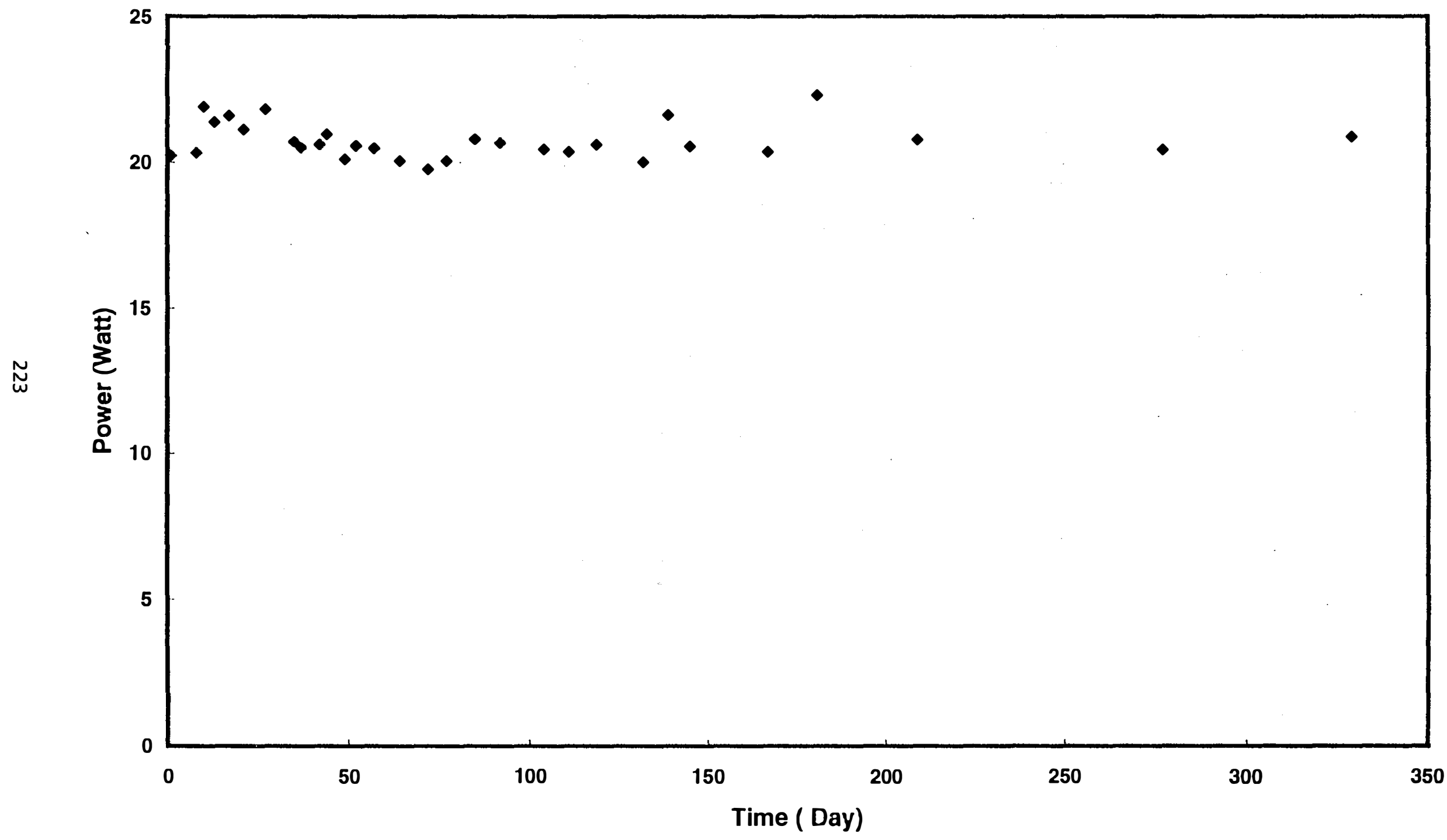




\title{
NREL CdTe Stability Team
}

\author{
Golden Photon, Inc. \\ Institute of Energy Conversion \\ ISET \\ NREL \\ Solar Cells, Inc.
}

Colorado School of Mines

Colorado State University

Florida Solar Energy Center

ITN Energy Systems

Stanford 


\section{Strategy}

Field Tests

Ultimate measure of stability

Only real test conditions

Real time

Stress Tests

Search for acceleration factors

Probe for device weaknesses

Provide timely feedback

Predict useful life

Must be tied to field conditions

Stressed Cell Analysis

Device modelling

Physical and chemical changes

Mechanisms 


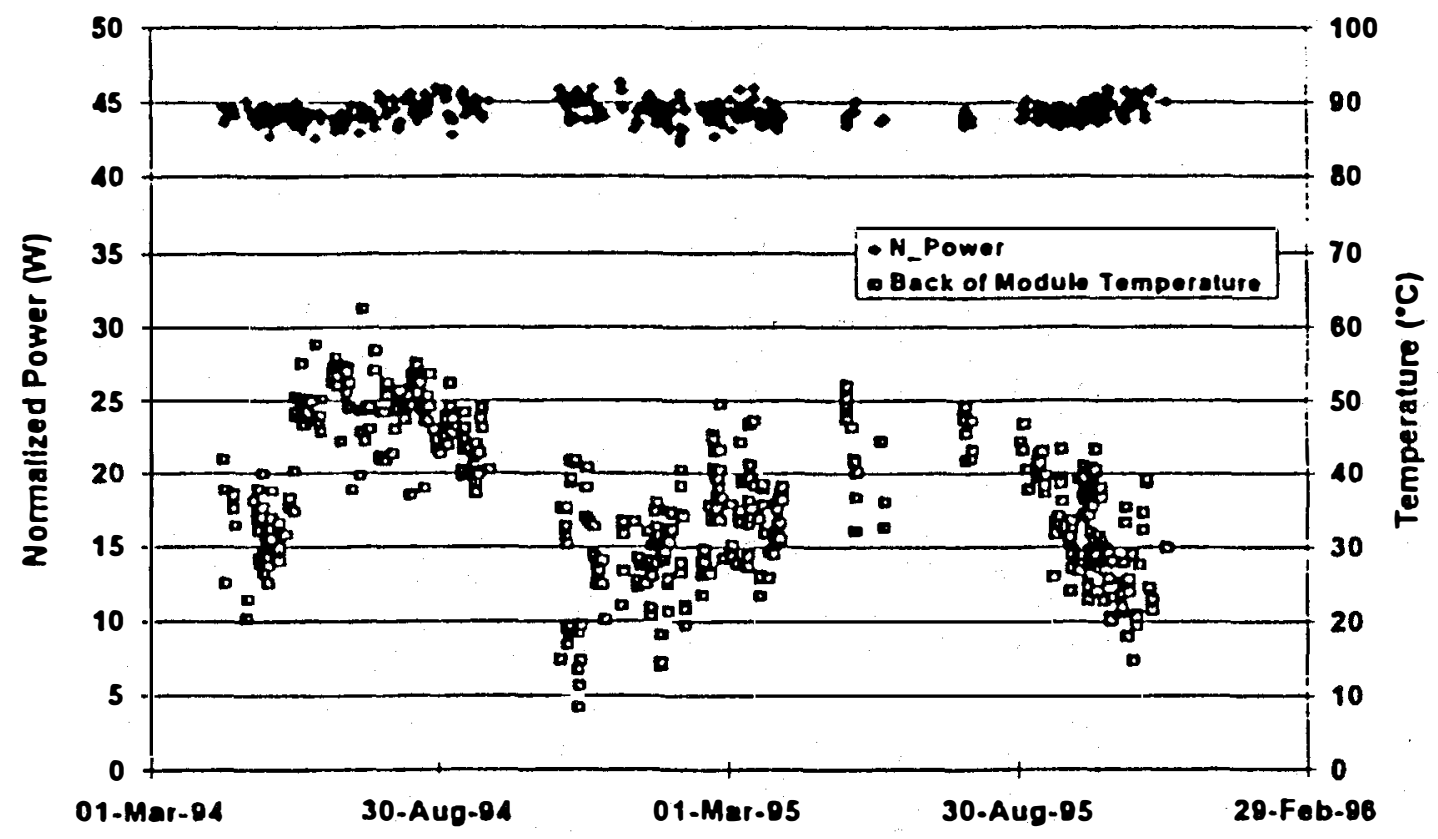

Normalized power and module temperature vs time

- SCI modules tested at NREL

B. Kroposki et al., Proc 25th IEEE PVSC (1996) 
Extended Duration Light Soaking

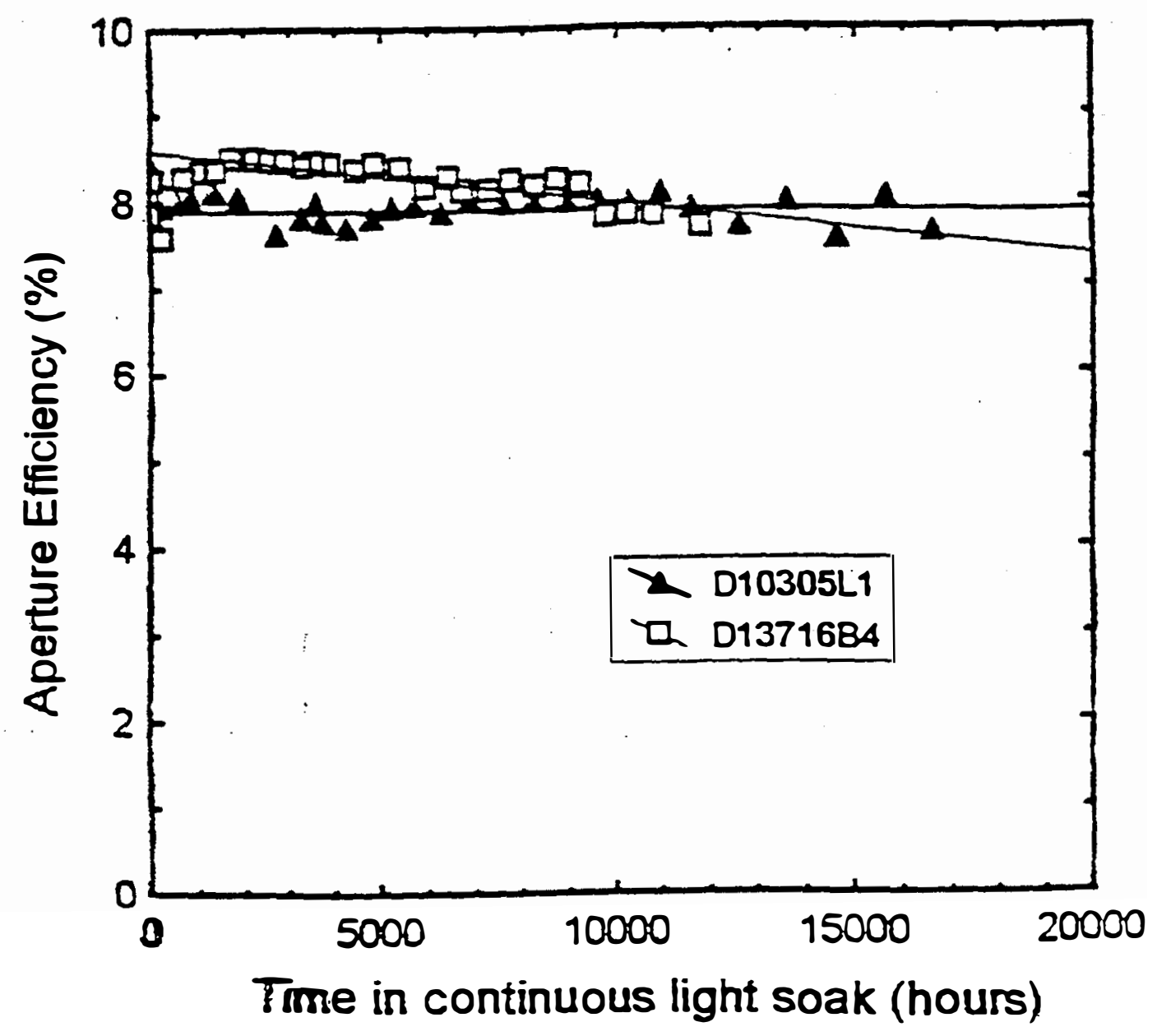

Aperture area efficiency vs time - SCI sub-modules tested at SCI using different fabrication procedures

R.C. Powell et al, Proc. 25th IEEE PVSC (1996) 


\section{RELAXATION CURVES For Pre-Biased Conditions}

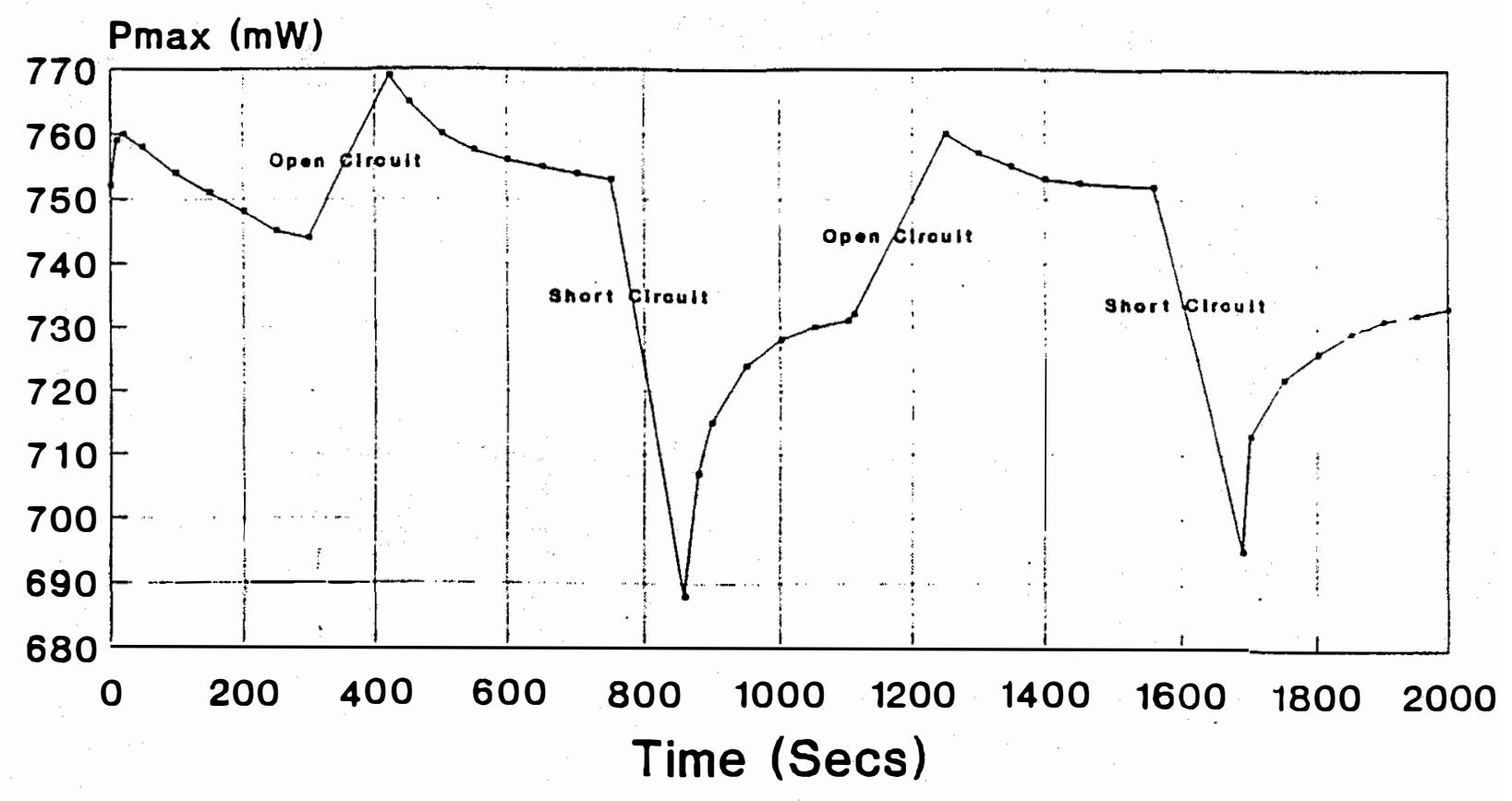

$8 / 19 / 91$

\section{Effect on maximum power of Golden Photon modules vs time of pre-biasing at Voc and Jsc}

S.P. Albright et al., AIP Conference Proceedings 268, PV AR\&D (1992) 


\section{Examples of Accelerated Testing Variables}

SCI - Summary of test conditions used for stress testing modules.

R.C. Powell et al, Proc. 25th IEEE PVSC (1996)

\begin{tabular}{|c|c|c|}
\hline Illumination & Temperature & Bias \\
\hline $815 \mathrm{~W} / \mathrm{m}^{2}$ & $55^{\circ} \mathrm{C}$ & Open Circuit \\
\hline $700 \mathrm{~W} / \mathrm{m}^{2}$ & $75^{\circ} \mathrm{C}$ & Short Circuit \\
& $90^{\circ} \mathrm{C}$ & Resistive Load \\
\hline & $25^{\circ} \mathrm{C}$ & $+0.5 \mathrm{~V} / \mathrm{cell}$ \\
Dark & $60^{\circ} \mathrm{C}$ & Zero \\
& $100^{\circ} \mathrm{C}$ & $-0.5 \mathrm{~V} / \mathrm{cell}$ \\
& $140^{\circ} \mathrm{C}$ & \\
\hline Nominal temperature &
\end{tabular}

Golden Photon, Inc - Accelerated testing variables $65{ }^{\circ} \mathrm{C}$ or $120{ }^{\circ} \mathrm{C}$

Dark or UV illumination forward bias 
Continuous Light Soaking

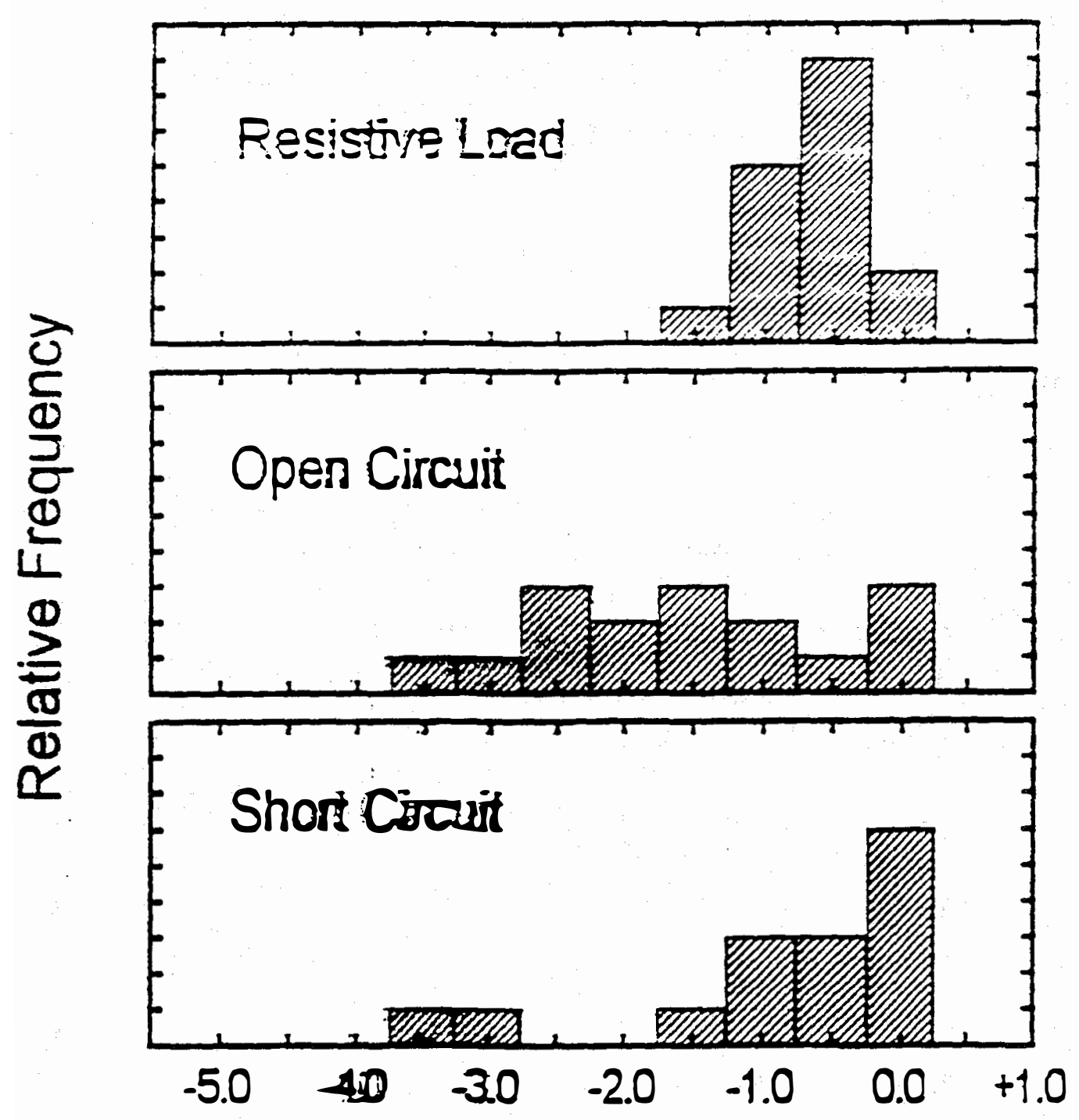

Redative Rate of Change
(\% per 1000 hours)

Bias dependence of rate of efficiency change due to continuous light soak at a nominal temperature of $55{ }^{\circ} \mathrm{C}$. Test durations $\sim 10,000 \mathrm{hrs}$.

R.C. Powell et al, Proc. 25th IEEE PVSC (1996) 

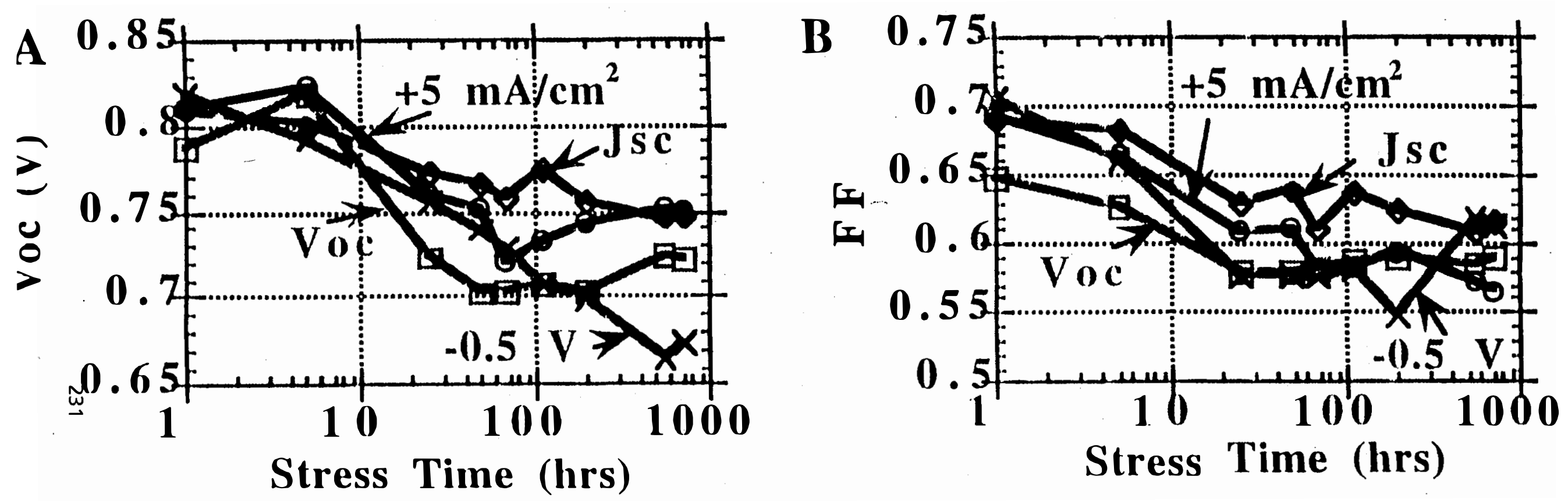

A) Voc and B) FF vs hours under stress for devices held at the indicated bias at $92{ }^{\circ} \mathrm{C}$ and $70 \mathrm{~mW} / \mathrm{cm}^{2}$ illumination 

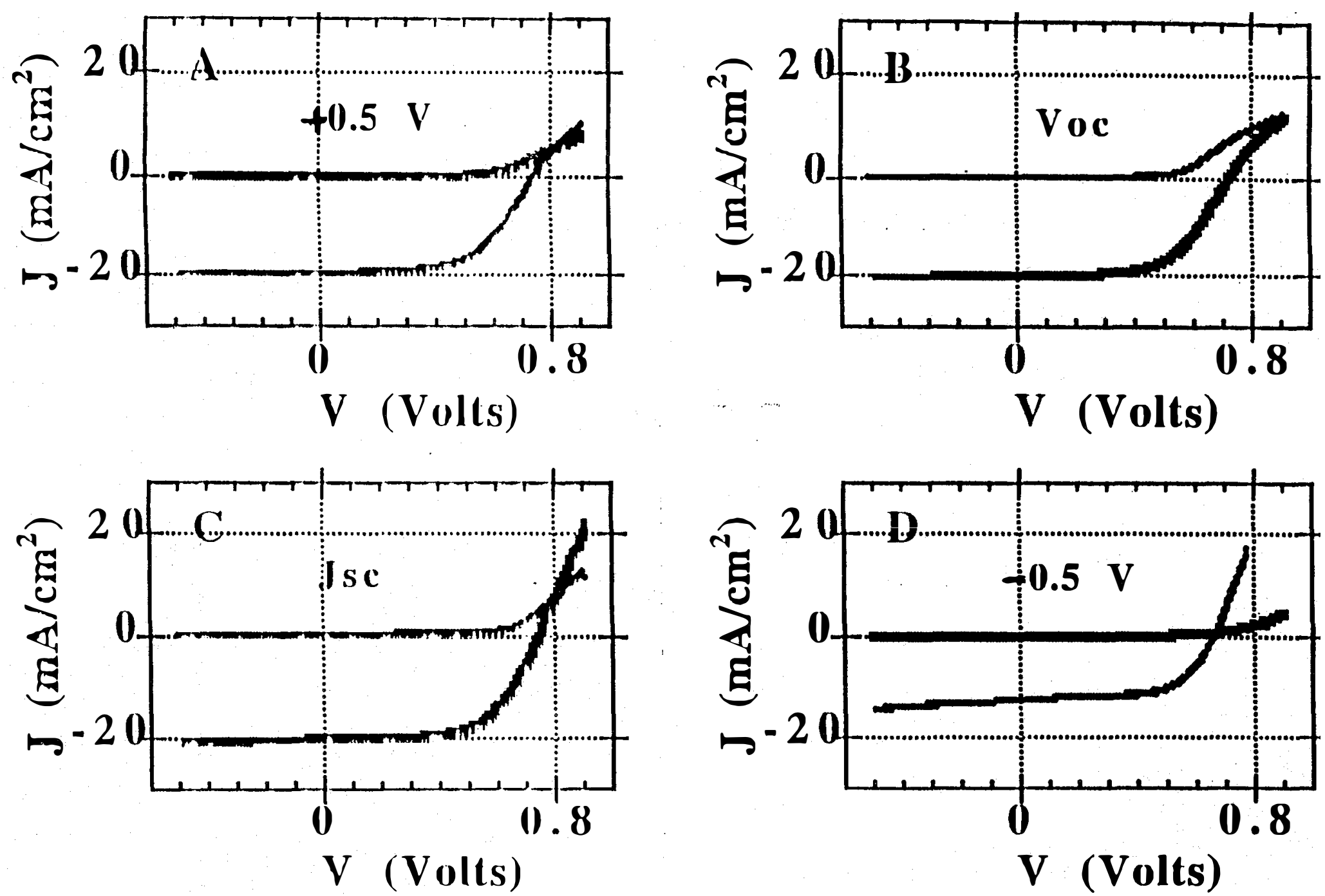

Light and dark $\mathrm{J}-\mathrm{V}$ curves of devices stressed for $550 \mathrm{hrs}$ at $92^{\circ} \mathrm{C}$ and $70 \mathrm{~mW} / \mathrm{cm}^{2}$ illumination with voltage bias of A) $+5 \mathrm{~mA} / \mathrm{cm}^{2}$, B) Voc, C) Jsc, and D) $-0.5 \mathrm{~V}$ 


\section{Estimate $\mathbf{R}$ and $A$}

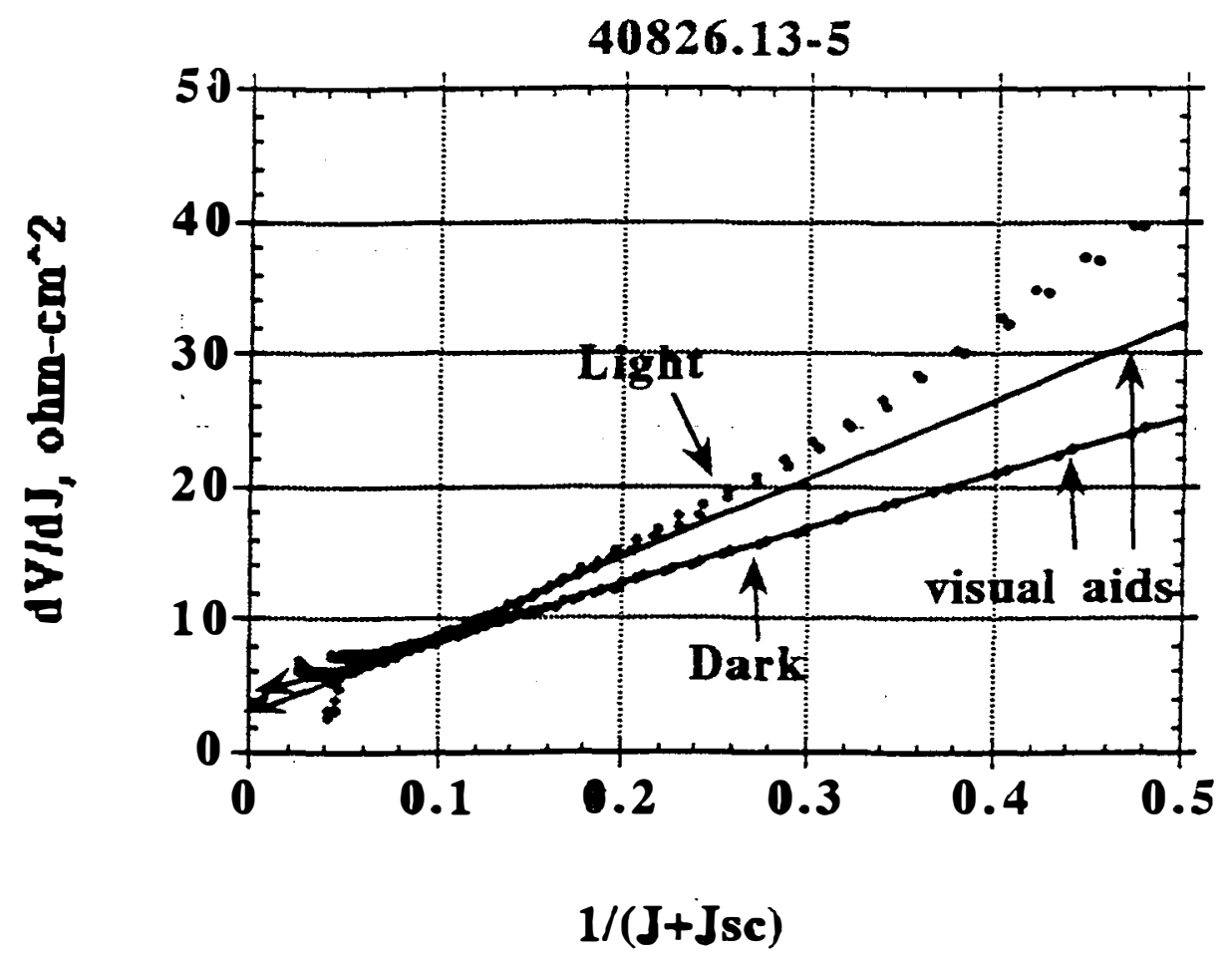

$\mathbf{d V} / \mathbf{d} \mathbf{J}=\mathbf{R}+\left[\mathbf{A} \mathbf{V}_{\mathrm{th}}\right] /\left[\mathbf{J}+\mathrm{J}_{\mathbf{L} 0}\right]$ 

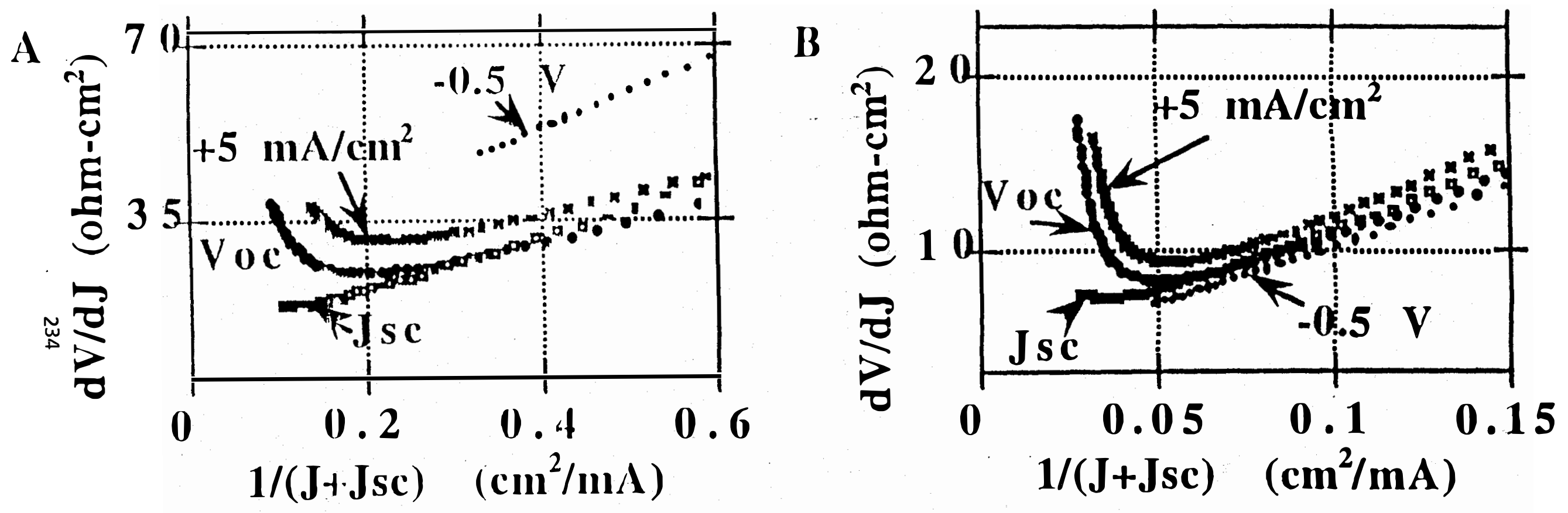

A) Dark and B) Light J-V data - plotted as dV/dJ vs $1 /(\mathrm{J}+\mathrm{Jsc})$ - of devices stressed for $550 \mathrm{hrs}$ at $92^{\circ} \mathrm{C}$ and $70 \mathrm{~mW} / \mathrm{cm}^{2}$ illumination with indicated voltage bias 

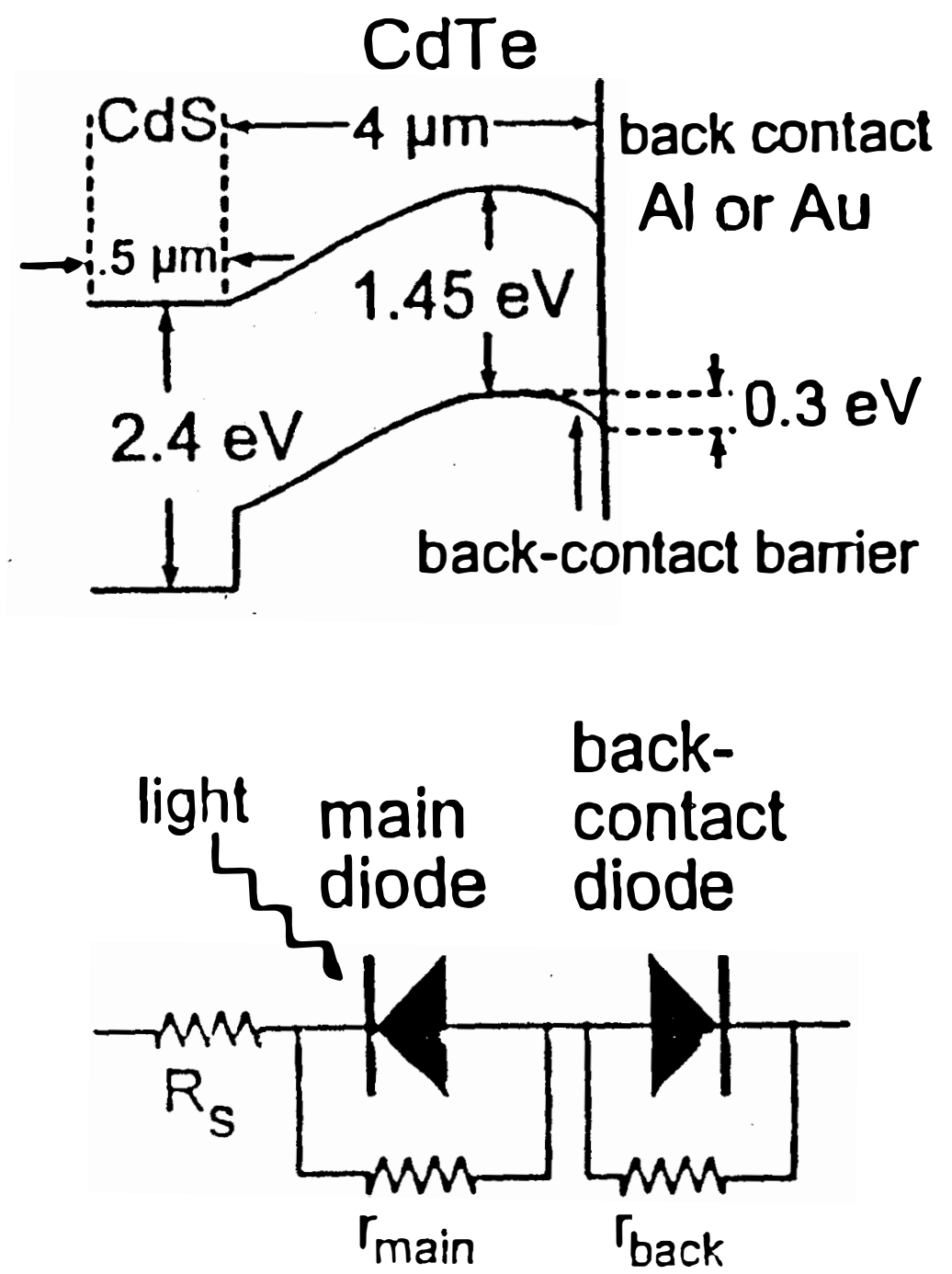

Band model for a CdTe solar cell with a second barrier at the back contact and the circuit model equivalent 

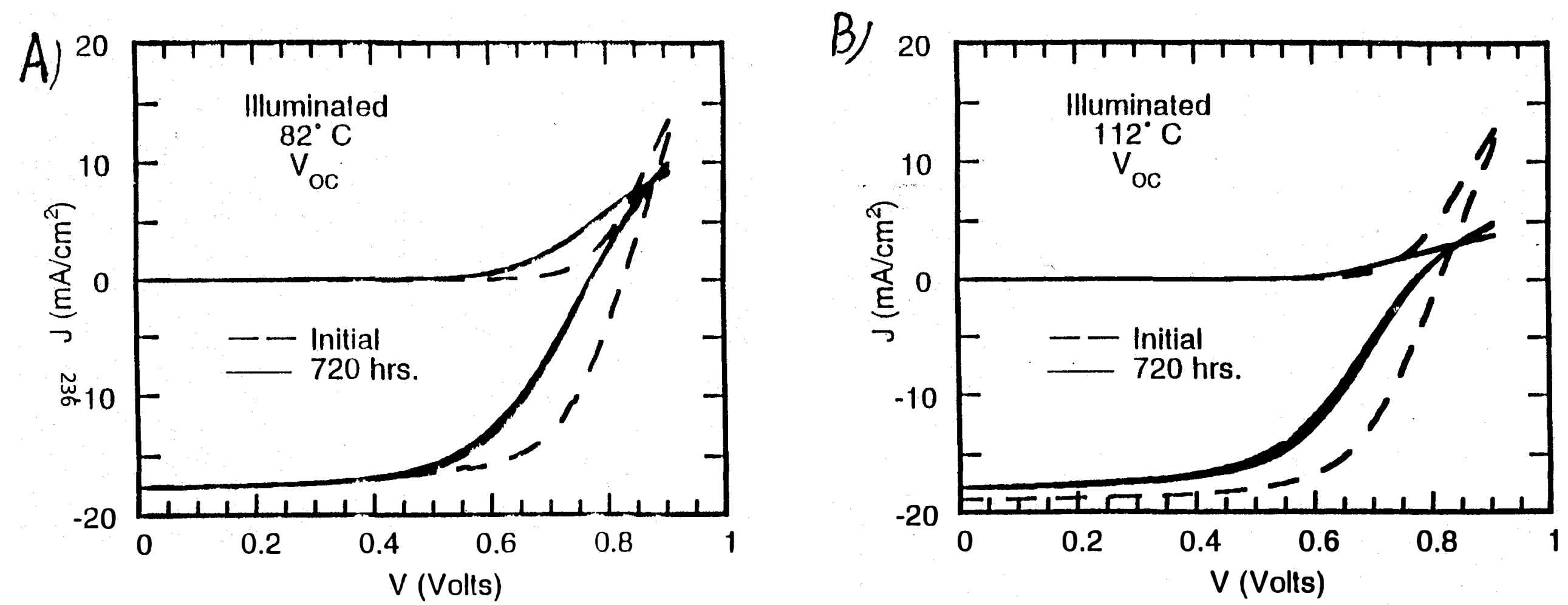

Light and dark $\mathrm{J}-\mathrm{V}$ characteristics before and after 720 hrs stress at A) $82{ }^{\circ} \mathrm{C}$ and B) $112{ }^{\circ} \mathrm{C}$ under illumination while biased at Voc

P.V. Meyers et al., Proc 25th IEEE PVSC (1996) 


\section{Additional CdTe Stability Team Activity}

Evaluate various contacting procedures SCI and GPI supply CdTe/CdS/TCO/glass Team members apply contacts CSM - evaporated ZnTe:Cu IEC - "diffused Cu" NREL - sputtered ZnTe:Cu

CSM performed in-house stability testing $\mathrm{Ni} / \mathrm{ZnTe}$ $\mathrm{Au} / \mathrm{ZnTe}$ (preferred) 


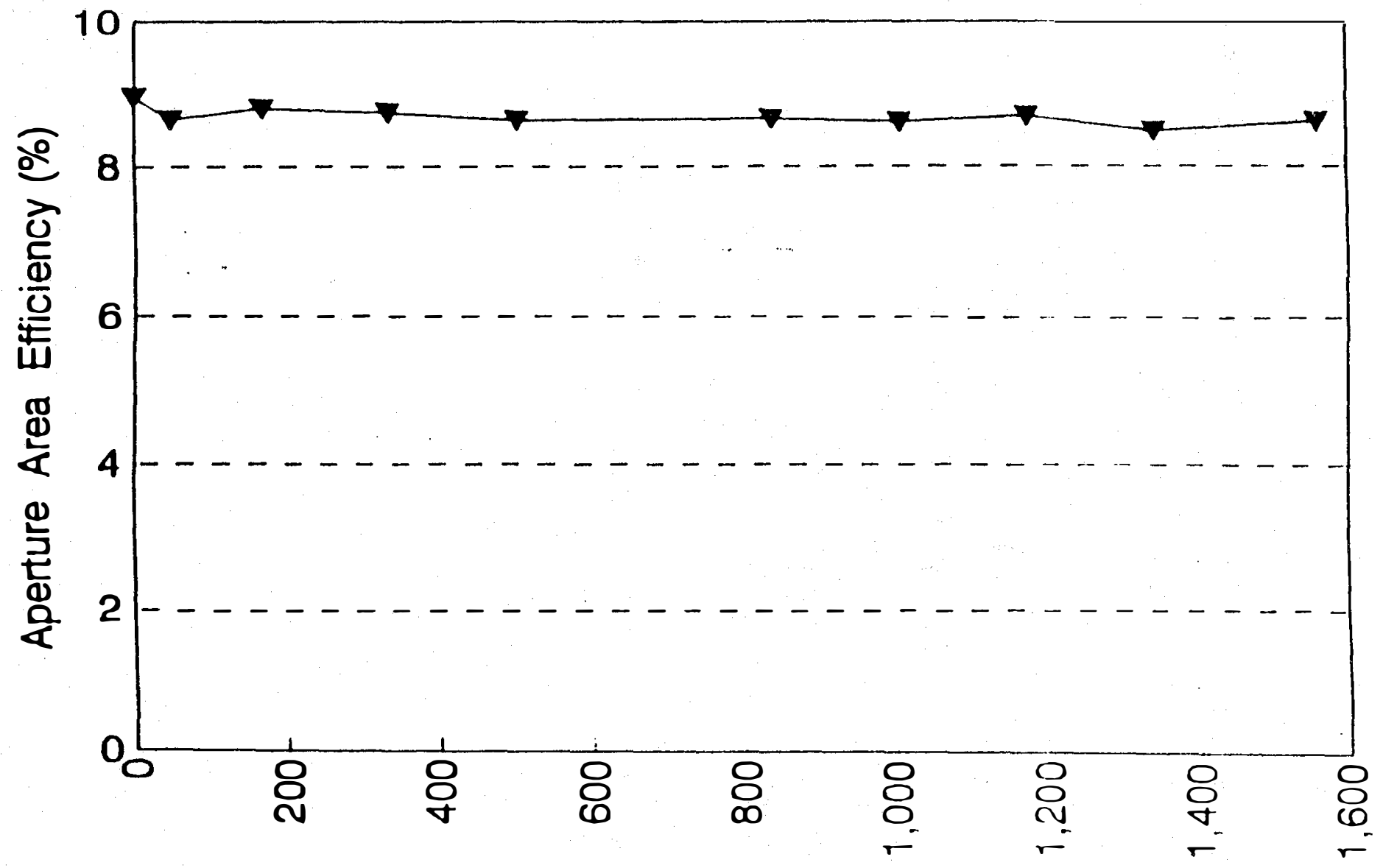

Hours on Lightsoak

Module efficiency of BP Solar modules on internal accelerated test - estimated acceleration factor of 8

- 12 based on total exposure to peak light intensities of more than $50 \mathrm{~mW} / \mathrm{cm}^{2}$

A.K. Turner et al., Solar Energy Materials and Solar Cells 35 (1994) 263- 


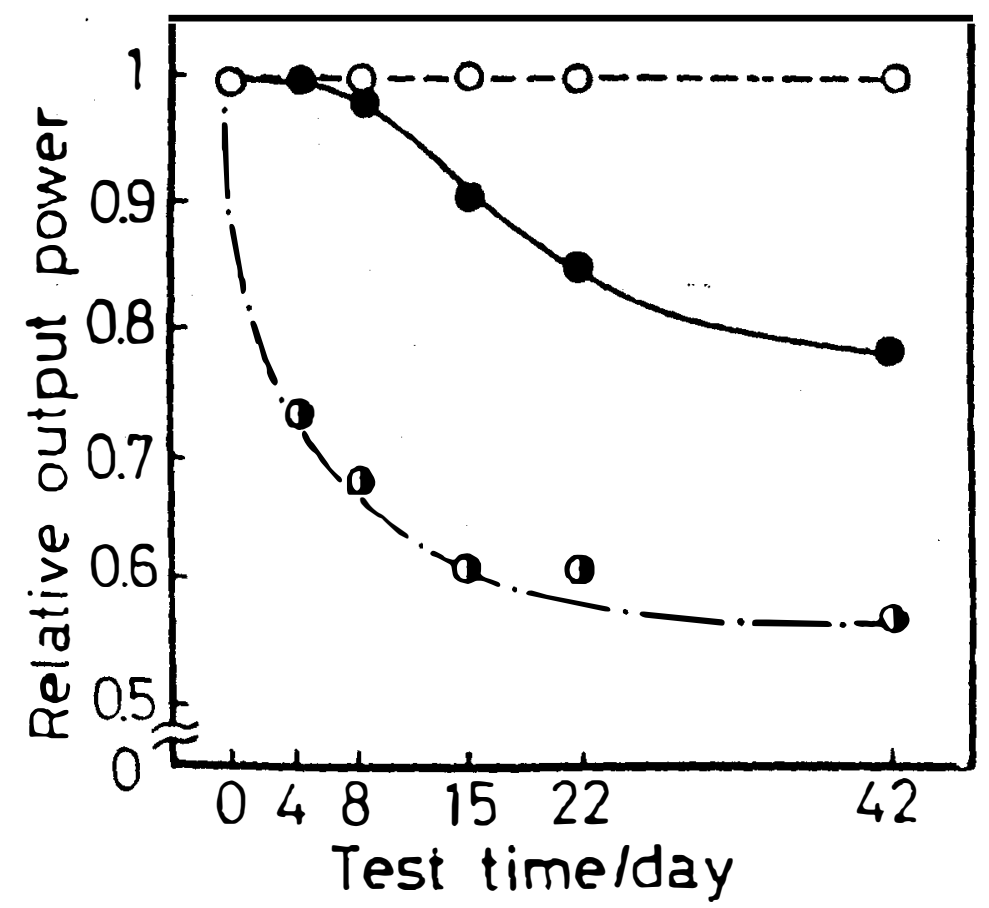

Effect of oxygen in sealed CdS/CdTe Matsushita solar test modules on their reliabilities at $80^{\circ} \mathrm{C}$ :

- Air

C No oxygen

$\mathrm{O}$ Air plus oxygen releasing agent (Zeostar)

S. Ikegami et al., Int. J. Solar Energy, Vol 12 (1992) 53-65 


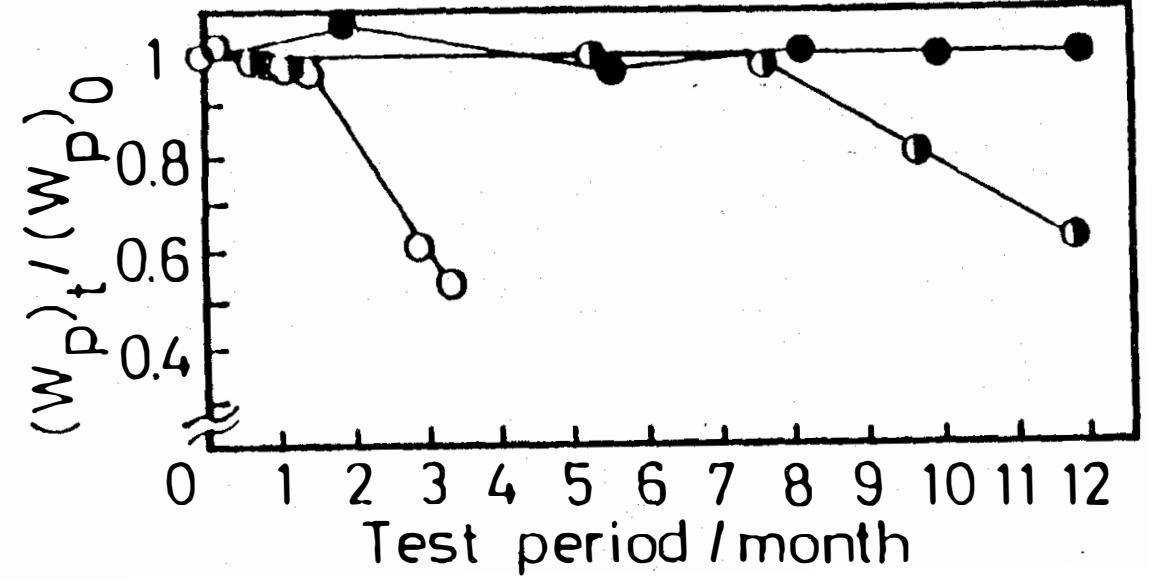

Reliability of Matsushita test modules in a prolonged humidity and temperature cycling test

$\mathrm{O}$ Weather meter (dew cycle)

(1) cycle $-20{ }^{\circ} \mathrm{C}$ to $80{ }^{\circ} \mathrm{C}$ at $85 \% \mathrm{RH}$

- outdoor test

S. Ikegami et al., Int. J. Solar Energy, Vol 12 (1992) 53-65 


\section{Observation - issues are complex}

- Time scale - $\mathrm{ms}$ to years $\left(10^{-2}-10^{8} \mathrm{~s}\right)$

- Reversible vs Permanent

- Role of Oxygen

- Role of Light and Electrical bias

- Cell design and process dependence

- Cell contact vs bulk effects 


\section{Speculation - Possible Multiple Mechanisms}

- $\quad$ Traps

CdS - complex photoconductivity

$\mathrm{CdS}_{1-y} \mathrm{Te}_{\mathrm{y}}$ and $\mathrm{CdTe}_{1-\mathrm{x}} \mathrm{S}_{\mathrm{x}}$ similar?

- Ion migration - $\mathrm{Cu}, \mathrm{O}$ or $\mathrm{Cd}$

- $\quad \mathrm{O}$ and $\mathrm{Cu}$

p-type dopants in CdTe

high resistivity $\mathrm{CdS}$

$\mathrm{TeO}_{2}$ barrier layer

- Grain boundary and interface effects

$\mathrm{p}^{+}$- low loss contacts

passivation - long carrier lifetime

$\mathbf{n}^{+}$- affects Voc 


\section{Summary}

Existence Proofs of Stable Field Performance

$\Rightarrow$ SCI, BP, GPI, Matsushita

Coordinated and Active Investigations

- Accelerated testing

$\Rightarrow$ Light, Bias, Temperature, UV, oxygen, thermal cycling, humidity

$\Rightarrow$ Tens of thousands of hours on hundreds of devices

- Mechanisms - device and chemical analyses

- No fatal errors discovered!

Industry is moving ahead

- Matsushita provides small modules for consumer electronics

- BP Solar is selling 1-6 W modules with a $5 \mathrm{yr}$ limited warranty

- GPI is supplying PV for Neos pumping systems - 15 systems with up to 1 yr in field

- SCI Arrays - NREL, PVUSA, Toledo Edison, China Lake, FSEC 


\section{Encapsulant Adhesion and Solder Bond Integrity in Field-Aged Modules}

\section{Michael A. Quintana and David L. King}

Sandia National Laboratories

Albuquerque, N. M.

Neelkanth G. Dhere

Florida Solar Energy Center

University of Central Florida

Cocoa, Florida

This presentation describes work performed over the past twelve months through a collaborative effort by Sandia and the Florida Solar Energy Center (FSEC) in cooperation with our industry counterparts. The objective of the effort is to develop a comprehensive understanding of degradation mechanisms occurring in photovoltaic modules as a result field aging. 


\section{Improvements in module reliability require feedback from field applications.}

- Reliability results from careful product design followed by iterative manufacturing improvements based on feedback from product applications.

- Sandia and the FSEC have teamed with PV manufacturers to:

» rigorously analyze the effects of field aging

» identify improved manufacturing processes.

Reliability of a photovoltaic module is a result of careful design, iterative design improvement based on feedback from actual applications, and quality control on the manufacturing line. Module reliability affects the performance, product lifetime, product warranty, and life-cycle energy costs. Prior to our effort, the investigation of degradation mechanisms occurring inside field-aged modules had been limited by the lack of a process to effectively extract samples for analysis. Now we are able to characterize new modules off the production line and compare their physical characteristics to those of field-aged modules. 


\section{Extracting cell and encapsulant samples is now an established process.}

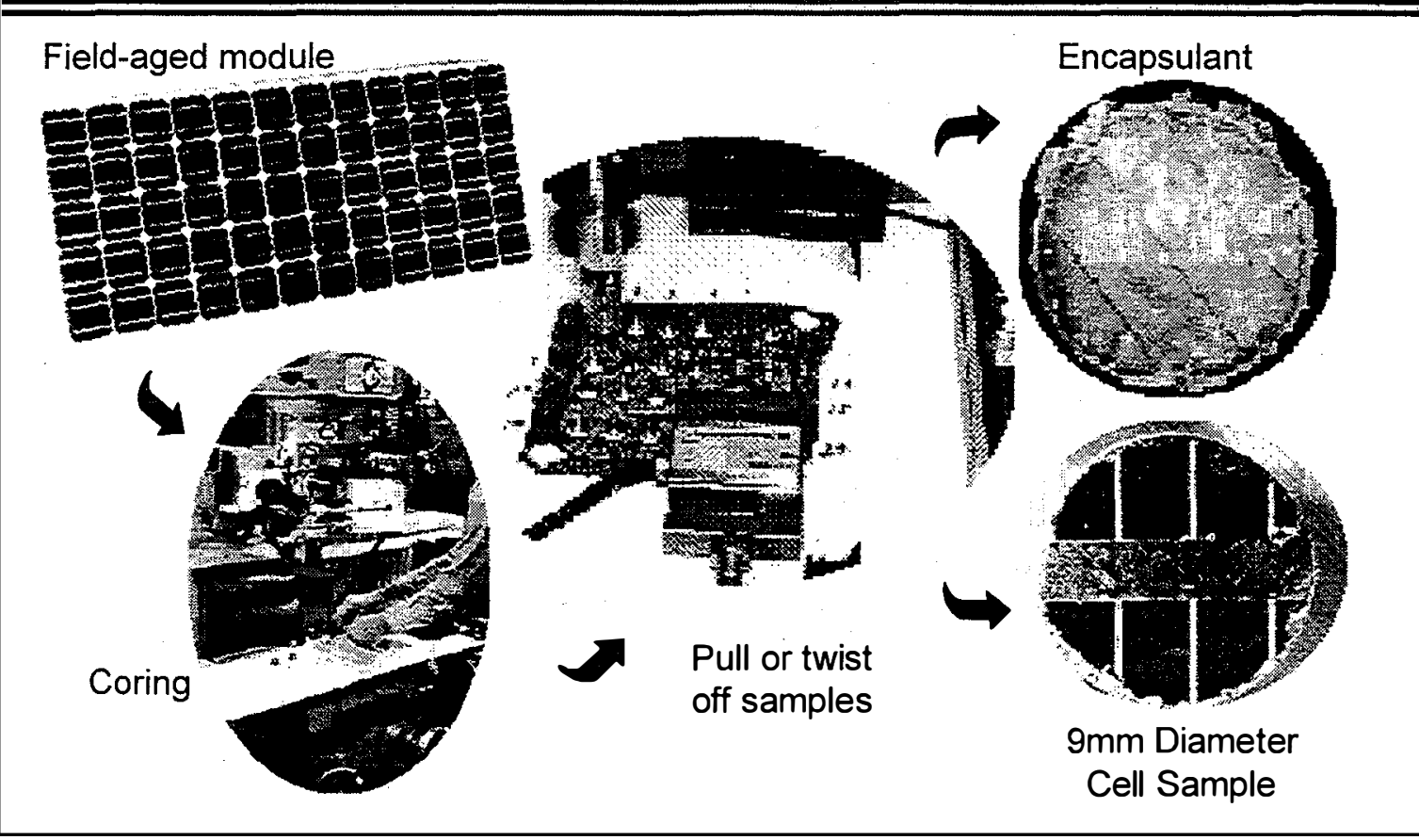

Sandia has developed a practical, repeatable, and versatile method to extract cell, solder bond, and encapsulant samples from field-aged modules. The method uses a milling machine and a variety of inexpensive tools to extract multiple samples from modules. The process uses a a two-fluted milling tool to remove the polymer back layer and the back encapsulant layer to within a few thousands of an inch of the back side of the cell. It is imperative that the milling tool not contact the cell as it can fracture the sample. The remaining encapsulant can be removed by a number of manual techniques; rubbing it with crepe rubber has been very effective.

Once the back side of the cell is completely exposed, cell samples are cored using a diamond-tip coring tool using care not to fracture the tempered glass superstrate. A vacuum system is used to pick up the silicon dust produced by the coring process. The samples are then lightly cleaned with a cotton swab. A flathead screw is then bonded to the sample using a two-part epoxy. After curing, the sample is extracted by pulling or twisting the screw. Sample diameter can be varied depending on the objective of the test. After removal of the cell sample, the front-side encapsulant samples can then be removed from the glass superstrate using a utility knife. This process is now established at both Sandia and FSEC. 


\section{Solder bond integrity is critical to module performance and reliability.}

\section{PV cells are typically assembled into modules by interconnecting the cells with copper ribbons.}

- Ribbons are soldered to metallic pads on cells using common tin-lead solders.

- Solder bonds age due to thermal cycling, resulting in: coarsening, cracking, crack propagation, and failure.

- Solder bond failure causes increased series resistance, localized heating, and increased strain on remaining bonds.

- Metallography techniques are used to investigate effects of thermal cycle fatigue.

Manufacturers typically assemble groups of PV cells into modules by interconnecting the cells with copper ribbons. These ribbons are bonded by a soldering process to previously deposited metallic pads on the cells. Failure of the solder bonds can increase series resistance, cause localized heating, and increase strain on the solder bonds that remain intact. Solder bond samples from both new field-aged modules are extracted and examined using metallography techniques to assess effects of field aging and the manufacturing process itself. 


\section{Metallurgical analysis of solder bonds uses an established technique.}

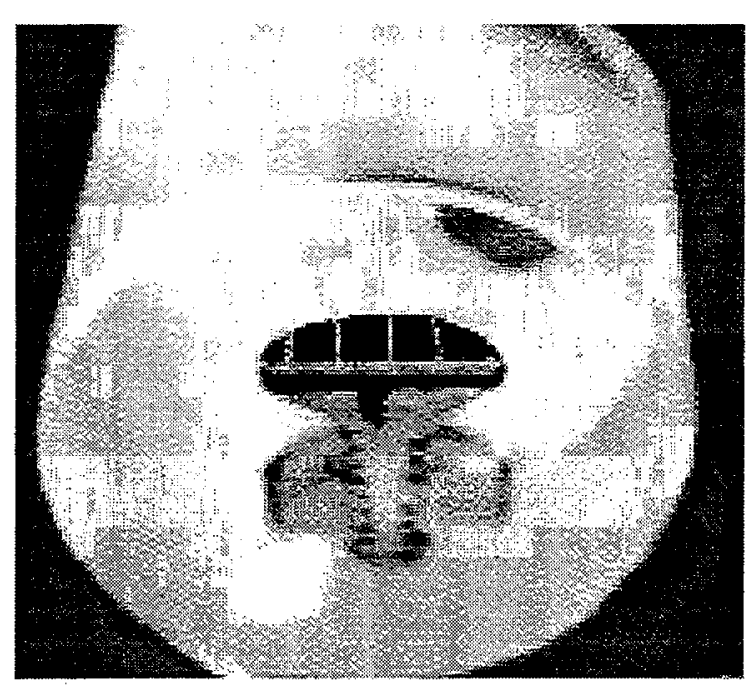

Field-aged solder bond samples are:

- Extracted from module

- Potted in epoxy

- Mechanically polished

- Chemically etched

- Optical micrographs

A true assessment of the durability of specific solder bonds requires the analysis of production solder bonds aged in the actual use environment. Our solder bond extraction process coupled with the metallurgical analysis techniques used by Darrel Frear in Sandia's Mechanical and Corrosion Metallurgy Department have made it possible to conduct comprehensive investigations of production solder bonds in both new and field-aged modules.

The picture above illustrates a $9 \mathrm{~mm}$ diameter cell sample extracted from a module. The sample was oriented and polished to expose a cross-section of the solder bond parallel to and along the center-line of the interconnect ribbon. 


\section{Solder bond analysis identifies each material and interface characteristics.}

\section{Spire Assembler Solder Bonds}

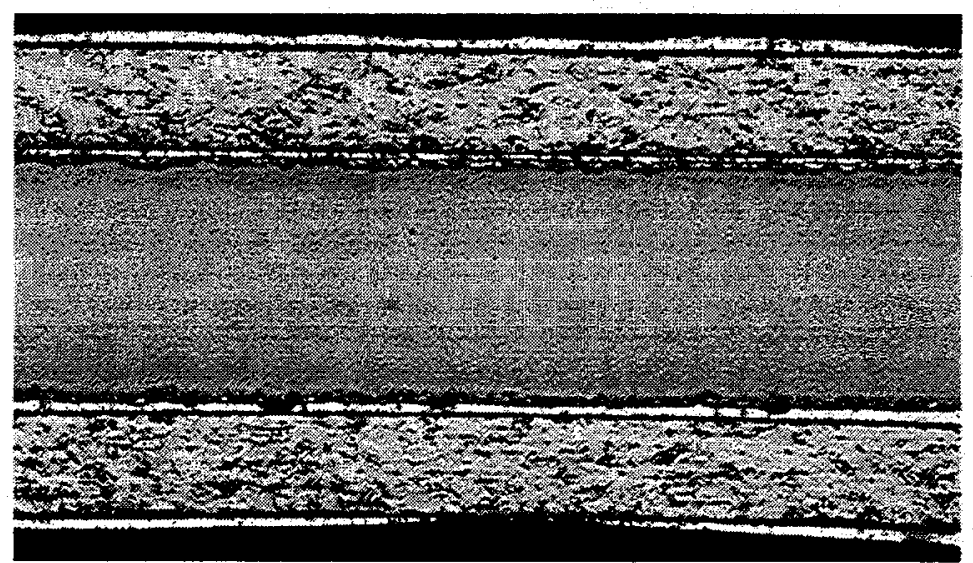

Cross-section of cell and $\mathrm{Cu}$ ribbons
Solder

$\mathrm{Cu}$ Solder

Frit Silicon cell

Frit Solder $\mathrm{Cu}$ Solder

The picture above shows an example of a metallurgical cross-section of a new solder bond from the Spire Assembler equipment developed through the PVMaT program. Solder-coated copper ribbon is used on the top and bottom of the cell. Distinct metallurgical differences between solder, copper, and cell metallization are evident. Metallic grain structure, layer thickness, and the presence of mechanical defects are immediately evident from a micrograph of this type. 


\section{Solder bond integrity depends on manufacturing process and field environment.}

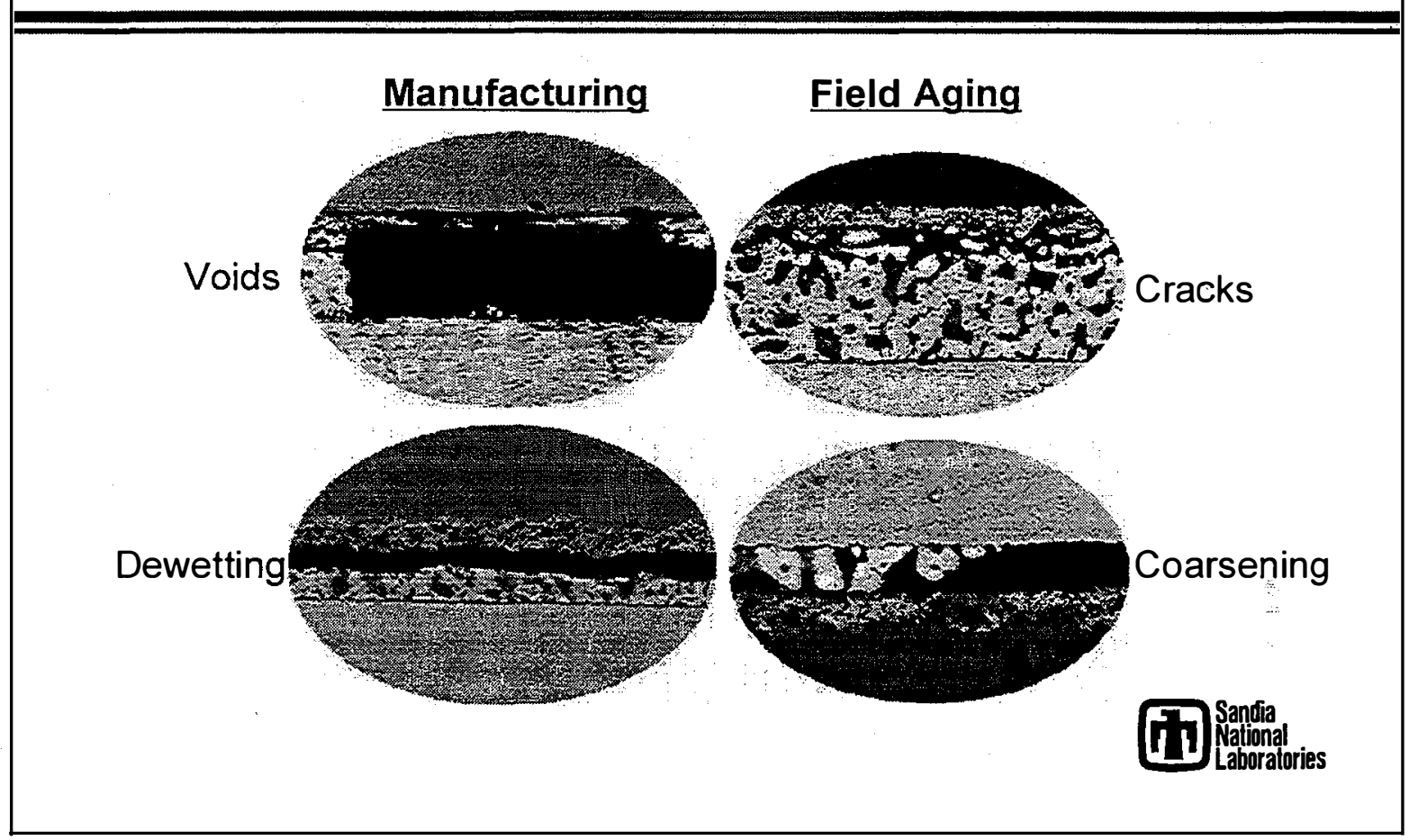

Defects in solder bonds occur as a result of non-optimum manufacturing processes and/or from thermal fatigue in the aging process. Manufacturing techniques can be refined once the nature and extent of defects have been identified.

Darrel Frear of Sandia's Mechanical and Corrosion Metallurgy Department has provided the examples above to illustrate the defects that may be present in solder bonds. For example, "voids" may result from deficient solder paste or inadequate time/temperature. "Dewetting" can occur when the solder melts and flows but there is inadequate mechanical pressure to hold the two surfaces in contact during the cooling process or as a result of uneven heating. Voids and dewetting can only be addressed through manufacturing process optimization. Strain from thermal cycling causes tin and lead in the solder to segregate into increasing grain sizes ("coarsening"). Coarsened grains don't accommodate strain well and eventually crack. The presence of voids and dewetted regions accelerates crack propagation over the entire solder bond area. 


\section{Encapsulant properties also affect module performance and reliability.}

In addition to optical properties, adhesive strength and mechanical properties must be investigated in both new and field-aged modules.

- We now measure adhesive strength (shear or tensile) providing a correlation with age and use environment.

- FTIR spectroscopy is used to evaluate changes in the chemical composition as a result of aging.

- Optical properties (spectral transmittance and reflectance) are readily measured.

- Encapsulant elastic modulus can be measured. 


\section{Adhesive strength is a function of age and environment.}

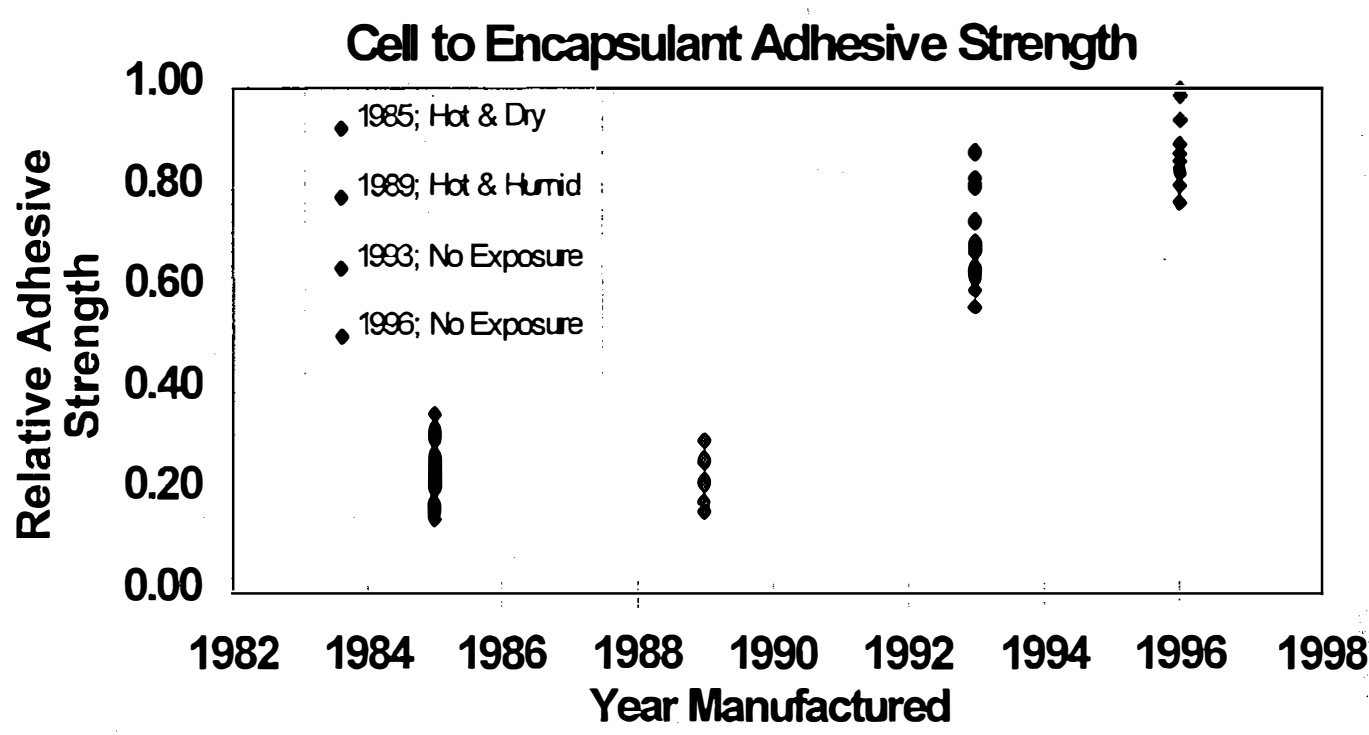

Sandia and FSEC are developing a database of encapsulant shear strength measurements for new and field-aged modules. A correlation between adhesive strength and age and use environment is being developed. Encapsulant and cell samples undergo surface analyses to determine if interactions with adjacent surfaces affect encapsulant adhesion properties. Our shear strength testing typically results in an "adhesive" failure at the cell to encapsulant interface versus a "cohesive" failure in the bulk of the encapsulant.

The figure above illustrates the relative shear strength of the cell/encapsulant interface in two unexposed c-Si modules (1993- and 1996-vintage) compared to 1985- and 1989-vintage modules exposed in a hot\&dry environment and a hot\&humid environment. 


\section{Encapsulant to cell interfaces are the subject of extensive investigation.}

\section{Interface characteristics are influenced by chemical photo, thermal, mechanical, and environmental factors.}

Sandia and FSEC are applying a variety of capabilities:

1) Auger Electron Spectroscopy,

2) X-ray Photoelectron Spectroscopy,

3) FTIR Spectroscopy,

4) Scanning Electron Microscopy,

5) Optical Microscopy,

6) Spectral Transmittance.

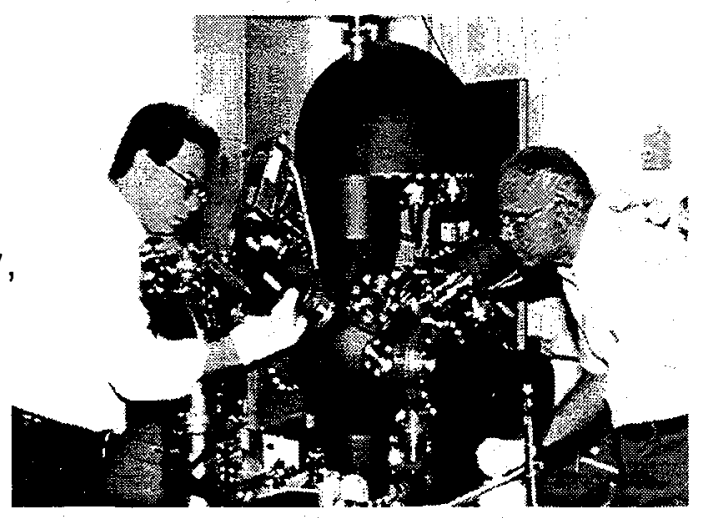

The aging mechanisms occurring at cell to encapsulant interfaces are complex and possibly influenced by chemical, photo, thermal, mechanical, and environmental factors. A comprehensive understanding of the aging processes involved requires the use of a variety of analytical techniques. The photo shows $x$-ray photoelectron spectroscopy (XPS) equipment at FSEC. XPS and Auger analysis allows us to identify elements present at interfaces due to the aging process and manufacturing processes. 


\section{Chemical constituents in the encapsulant can be identified.}

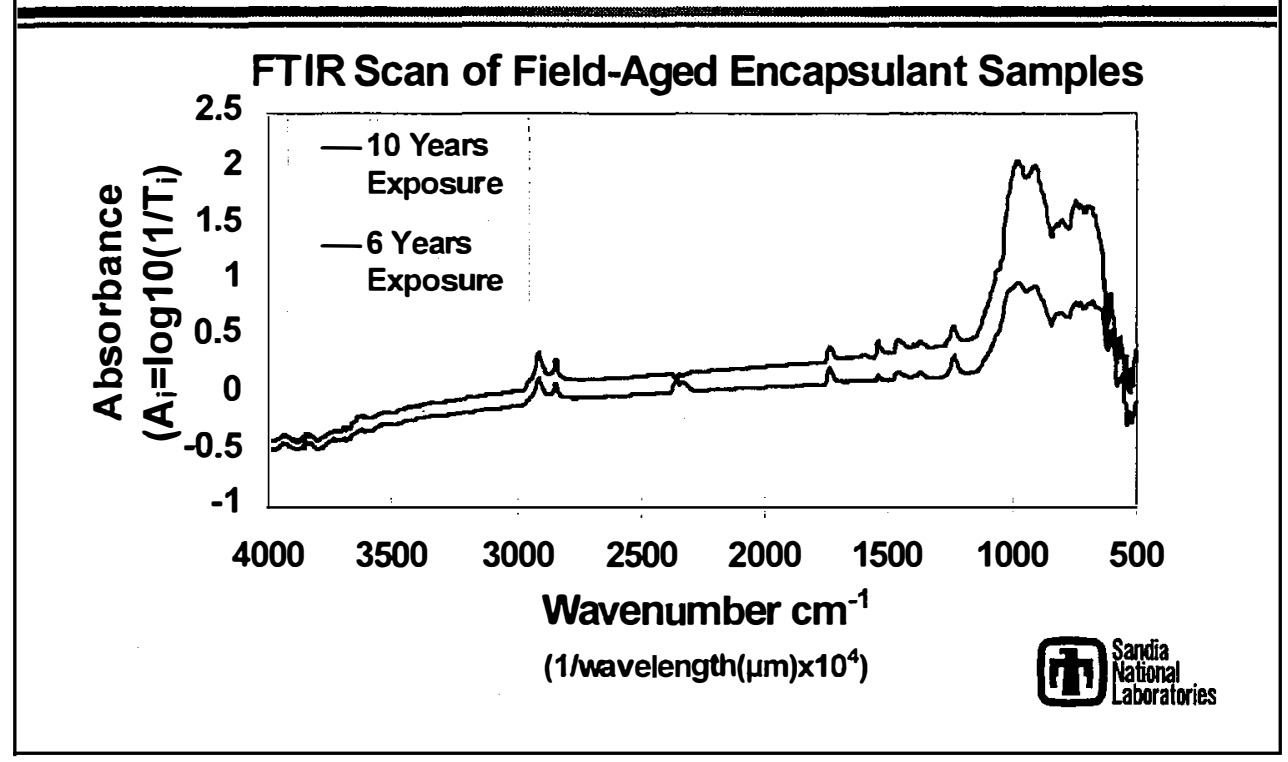

We are using Fourier Transform Infrared Spectroscopy (a BioRad FTS7 with a Pike Attenuated Total Reflectance accessory) to investigate chemical constituents in encapsulant samples. In the plot above above we were interested in determining if hydrolysis had occurred in either of the samples. If hydrolysis had occurred we would have seen a broad, pronounced peak in the $3700-3200 \mathrm{~cm}^{-1}$ range. We are confident that hydrolysis did not occur in these particular samples. 


\section{Surface analysis provides information related to adhesion.}

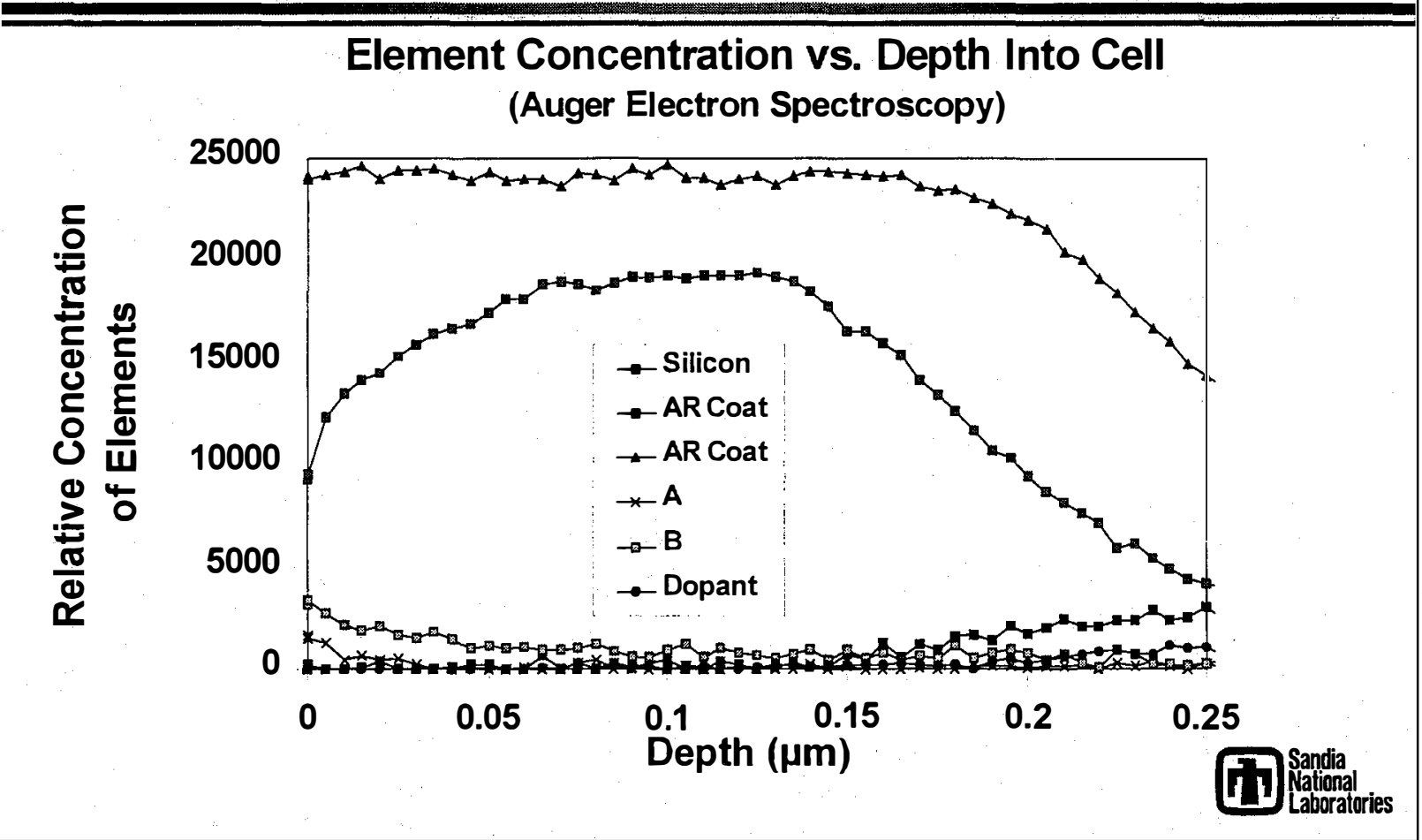

The chart above is an example of a surface analysis performed by FSEC using Auger Electron Spectroscopy (AES). This type of analysis identifies elements and their relative concentrations at the surface; adhesive strength is affected by the reactivity of the elements present. AES allows us to identify elements present due to the manufacturing process and due to the field aging process. Similar chemical analysis is being performed on mating encapsulant surfaces.

Fourier Transformed Infrared (FTIR) spectroscopic analysis through the bulk of encapsulant samples is also being used to evaluate changes in the chemical composition of encapsulants as a function of aging. 


\section{The future success of our effort depends on effective teaming with industry.}

Sandia and FSEC have worked hard to develop an effective collaborative arrangement with industry, providing the complimentary resources required to significantly improve the performance and reliability of photovoltaic modules.

Modules with 30-year effective lifetimes are achievable.

We wish to acknowledge the many people who have helped us either conduct this work or define an effective structure for industry/national-lab collaborations.

Sandia National Laboratories

Darrel Frear

Ginger De Marquis

Ed O'Toole

John Emerson

EG\&G Energy Measurements Group

J. Kurt Snyder

Don Ellibee

Siemens Solar Industries (Don Aldrich, Terry Jester)

ASE Americas (Moneer Azzam, Juris Kalejs)

Solarex Corporation (John Wohlgemuth)
Florida Solar Energy Center

Mark Wollam

Lucy Orozco

Kevin Lynn

Michael Martens

\section{$\cdot$}




\title{
Interconnect Reliability Tests
}

For Alternative Module Construction

\author{
Rob Spotts \\ Photocomm
}




\section{OVERVIEW}

- REASONS FOR CONSIDERING ALTERNATIVES TO GLASS MODULE CONSTRUCTION.

- CHALLENGES OF PRACTICAL ALTERNATIVE DESIGNS.

- THERMAL-CYCLE TESTING.

- MODULE CONSTRUCTION: MATERIALS, INTERCONNECT DESIGNS

- TEST RESULTS

- SUMMARY 


\section{GLASS SUPERSTRATE}

\section{VERSUS}

\section{ALTERNATIVE MATERIAL SUBSTRATE}

- SEVERE SERVICE CONDITIONS DISQUALIFY GLASS SUPERSTRATE.

- SHIPPING AND HANDLING CONSIDERATIONS.

- CUSTOMER PERCEPTION. 


\title{
DESIGN CHALLENGES
}

\author{
OF ALTERNATIVE
}

SOLAR MODULE CONSTRUCTIONS

- INCREASED THERMAL EXPANSION COEFFICIENTS OF ALTERNATIVE SUBSTRATE MATERIALS CAUSE INCREASED STRESS IN MODULE COMPONENTS.

- MANUFACTURING ISSUES: COMPLEXITY, YIELDS, COST 


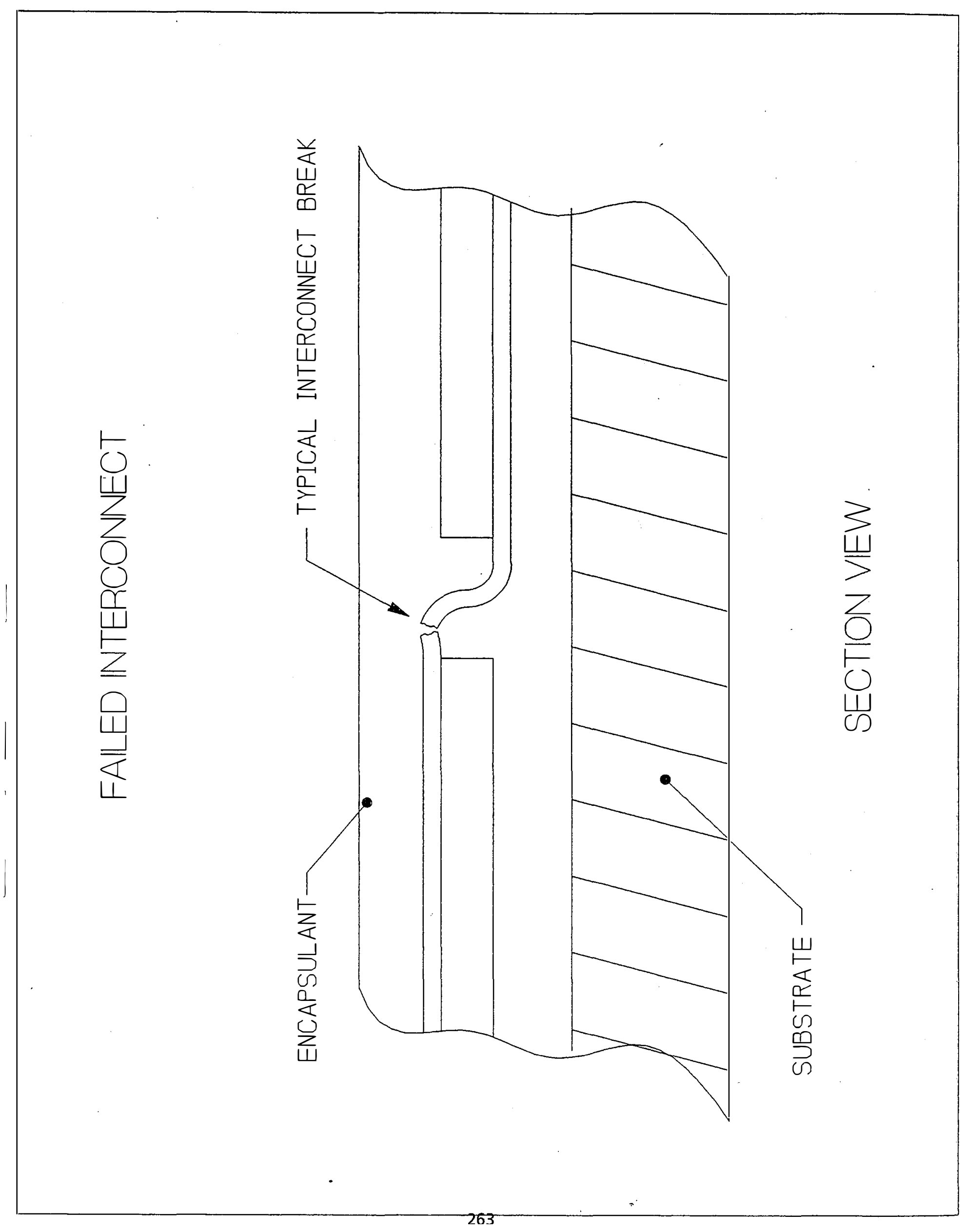




\section{THERMAL-CYCLE TESTING}

- PROVIDES RAPID ASSESSMENT OF CANDIDATE DESIGNS

- ACCELLERATES NORMAL DIURNAL THERMAL EXPANSION AND CONTRACTIONS OF MODULE COMPONENTS.

-THERMAL-CYCLE PROFILE: +90C TO -40C , 20 CYCLES PER DAY. 


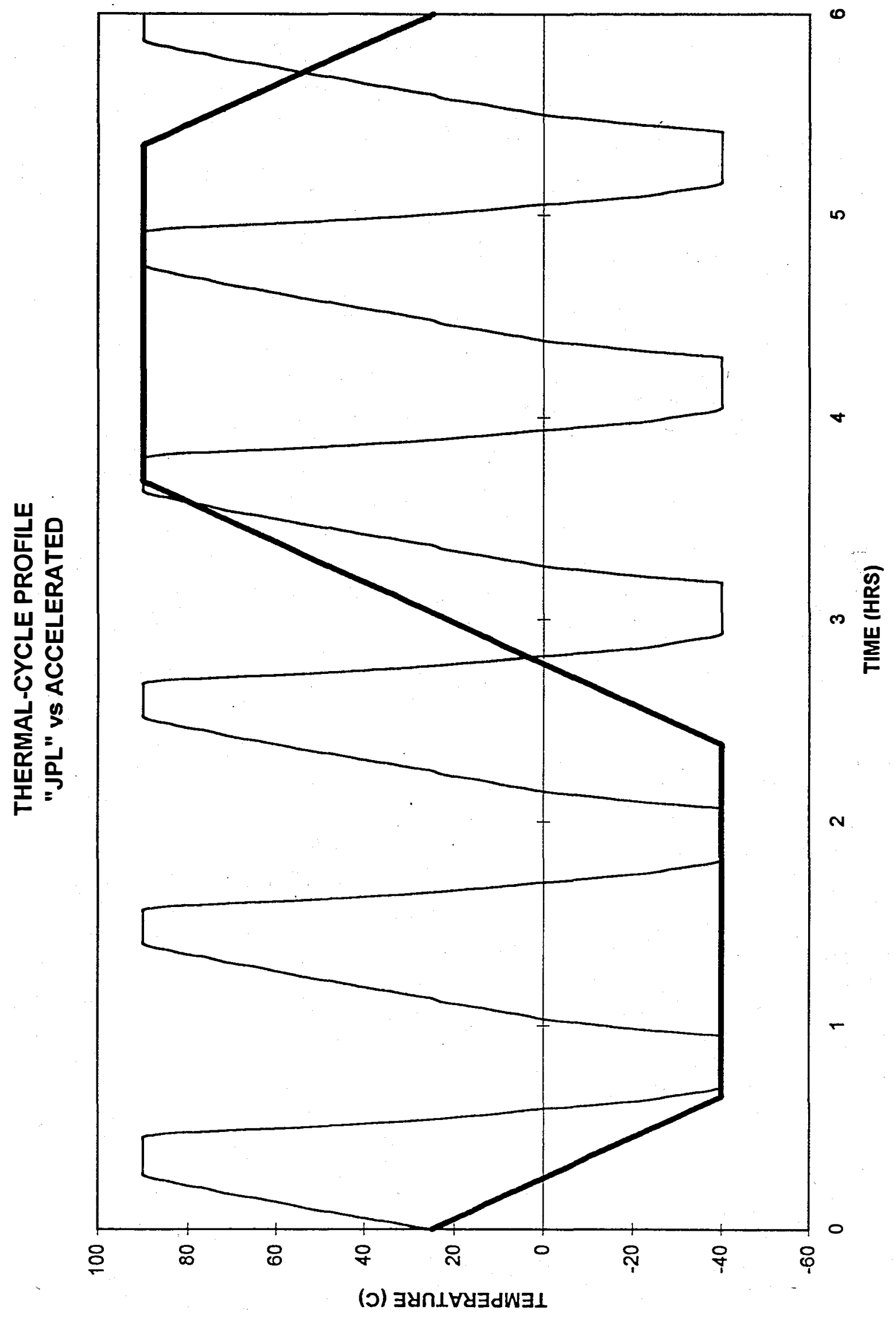




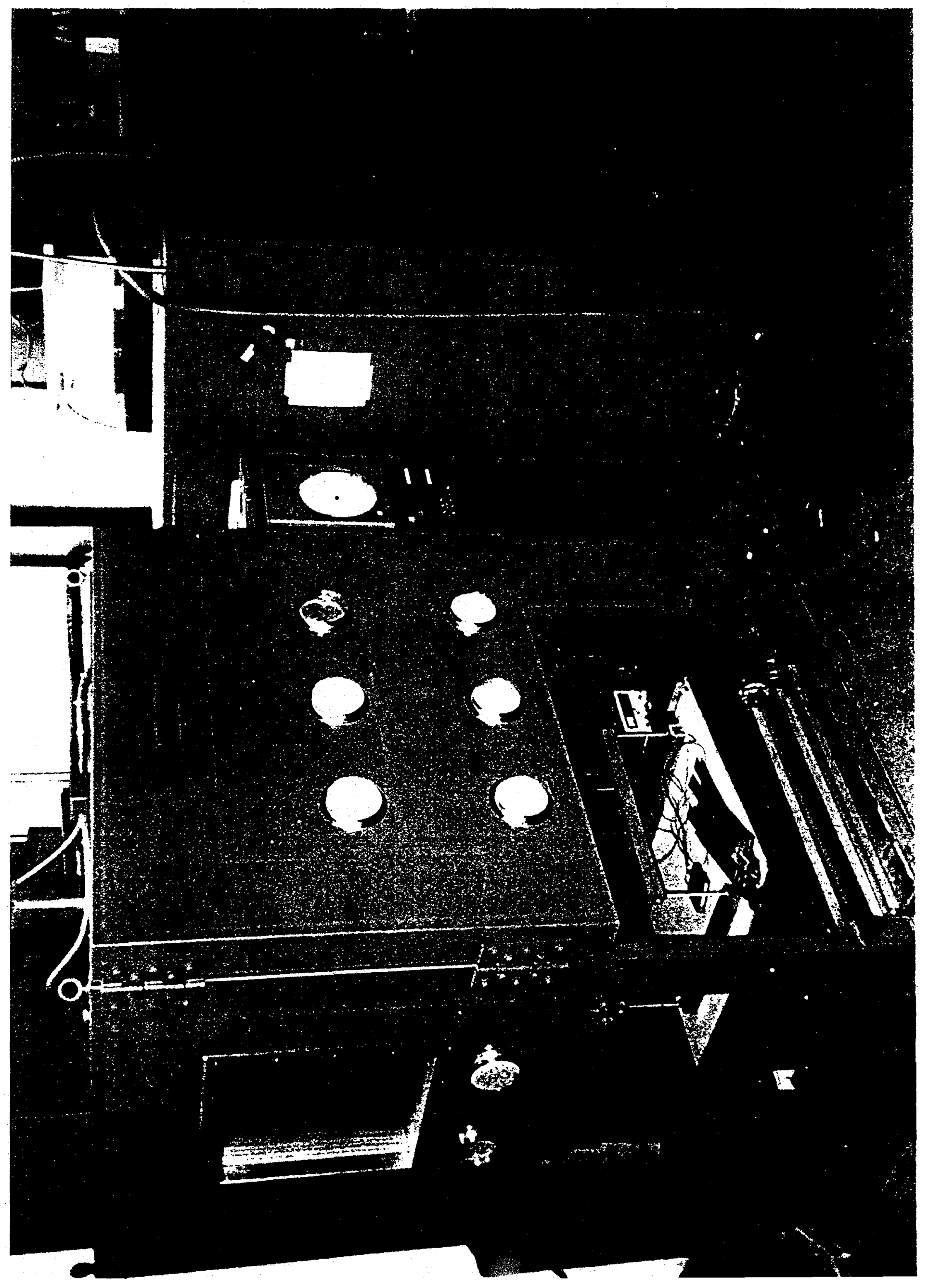




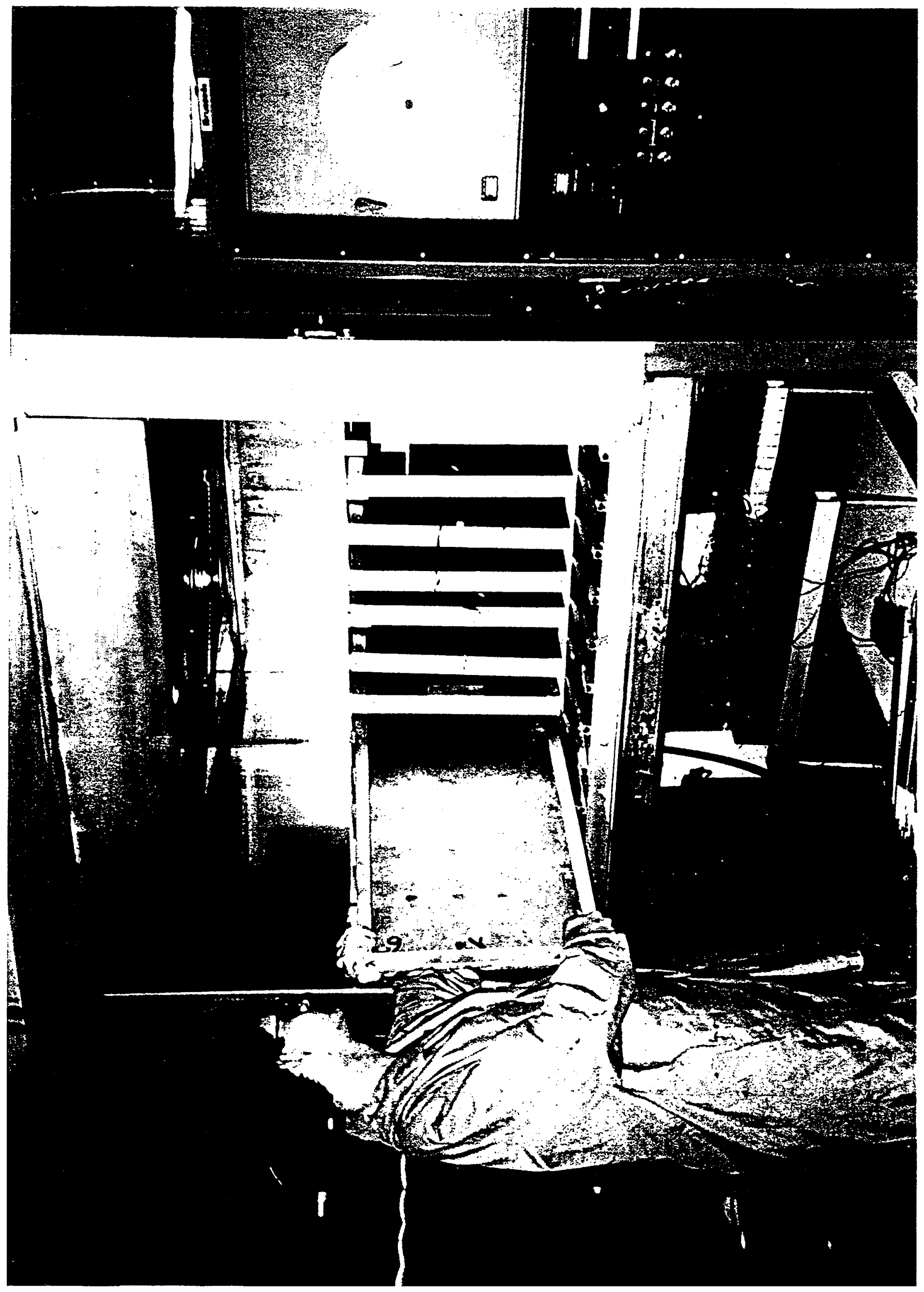




\section{THERMAL-CYCLE MODULE TEST}

- SIDE BY SIDE THERMAL-CYCLE TESTING.

- MODULE POSITION ROTATION WITHIN TEST CHAMBER TO EQUALIZE THERMAL EXPOSURE OVER TEST PERIOD.

- PERIODIC TEST OF MODULES IN SOLAR SIMULATOR ( MODULE TESTED AT $90 \mathrm{C}$ ). 


\section{TEST MODULE}

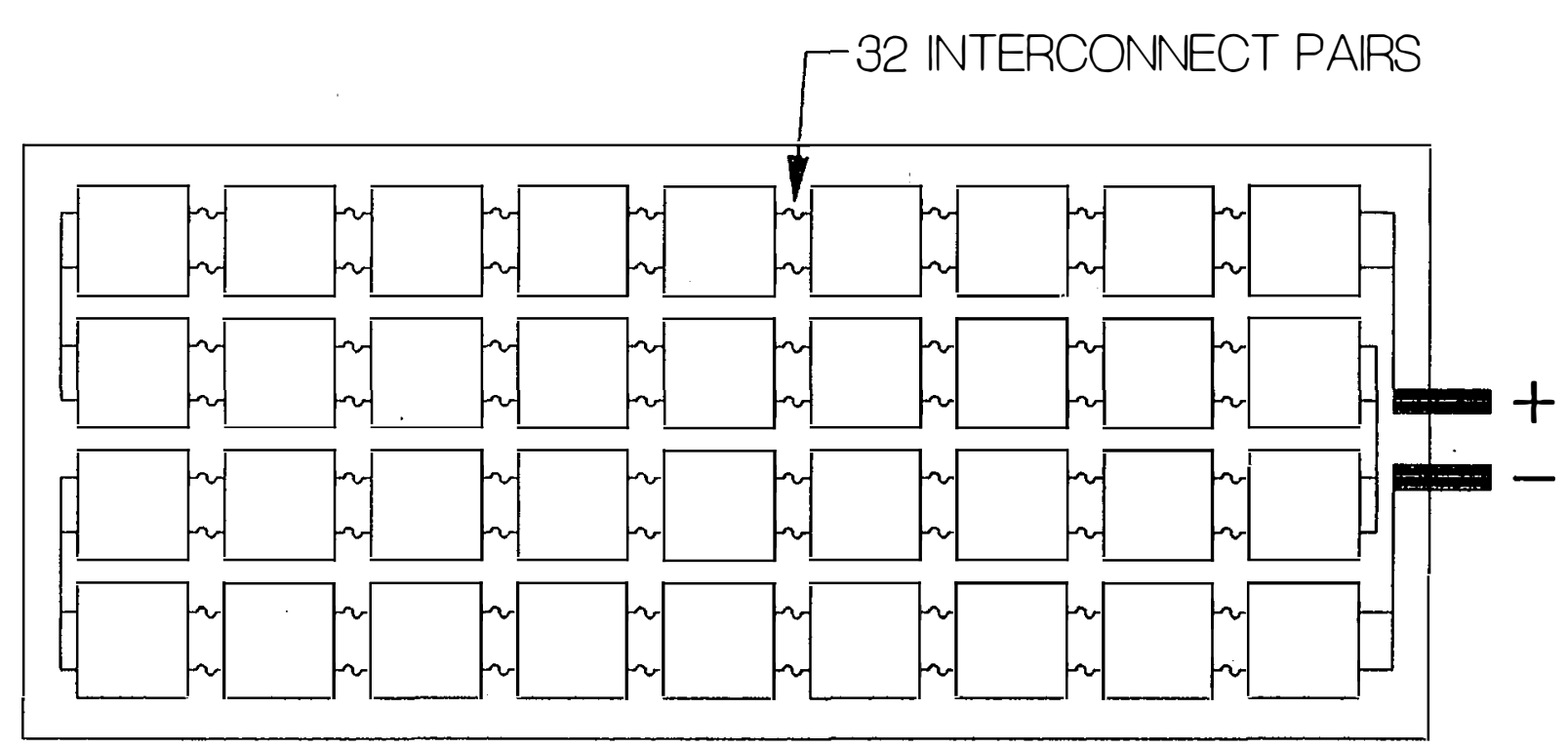

FULL SCALE MODULE CONSTRUICTION

-SOLAR CELL SIZE: 4" × 4"

-ENCAPSULANT: A9918 EVA, STANDARD LAMINATION

-SUBSTRATE: ALUMINUM, STAINLESS STEEL, G10 EPOXY/GLASS

-INTERCONNECT MATERIAL: 1/2HT COPPER, ALLOY X1, ALLOY X2 


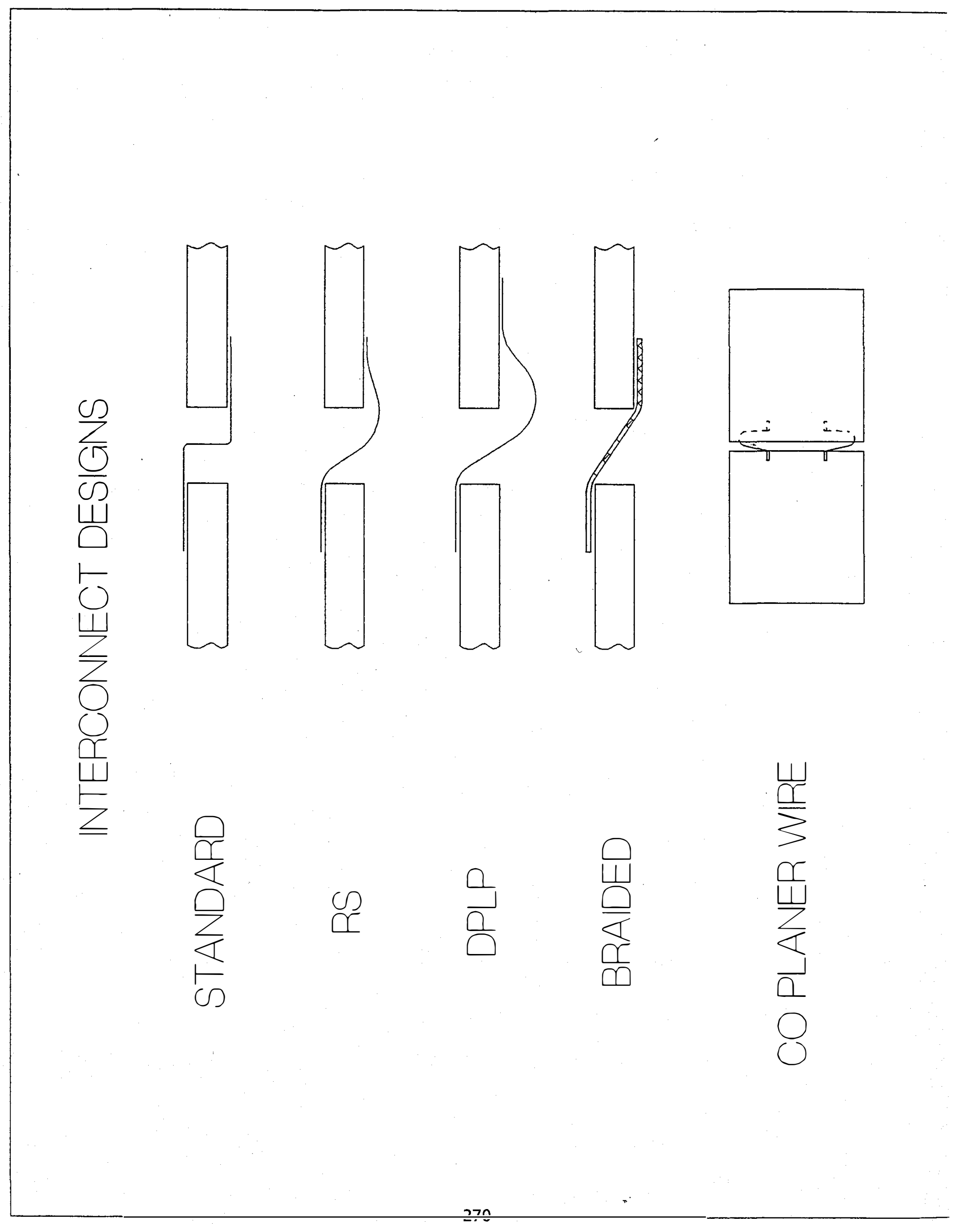


SOLAR MODULE

THERMAL-CYCLE TEST

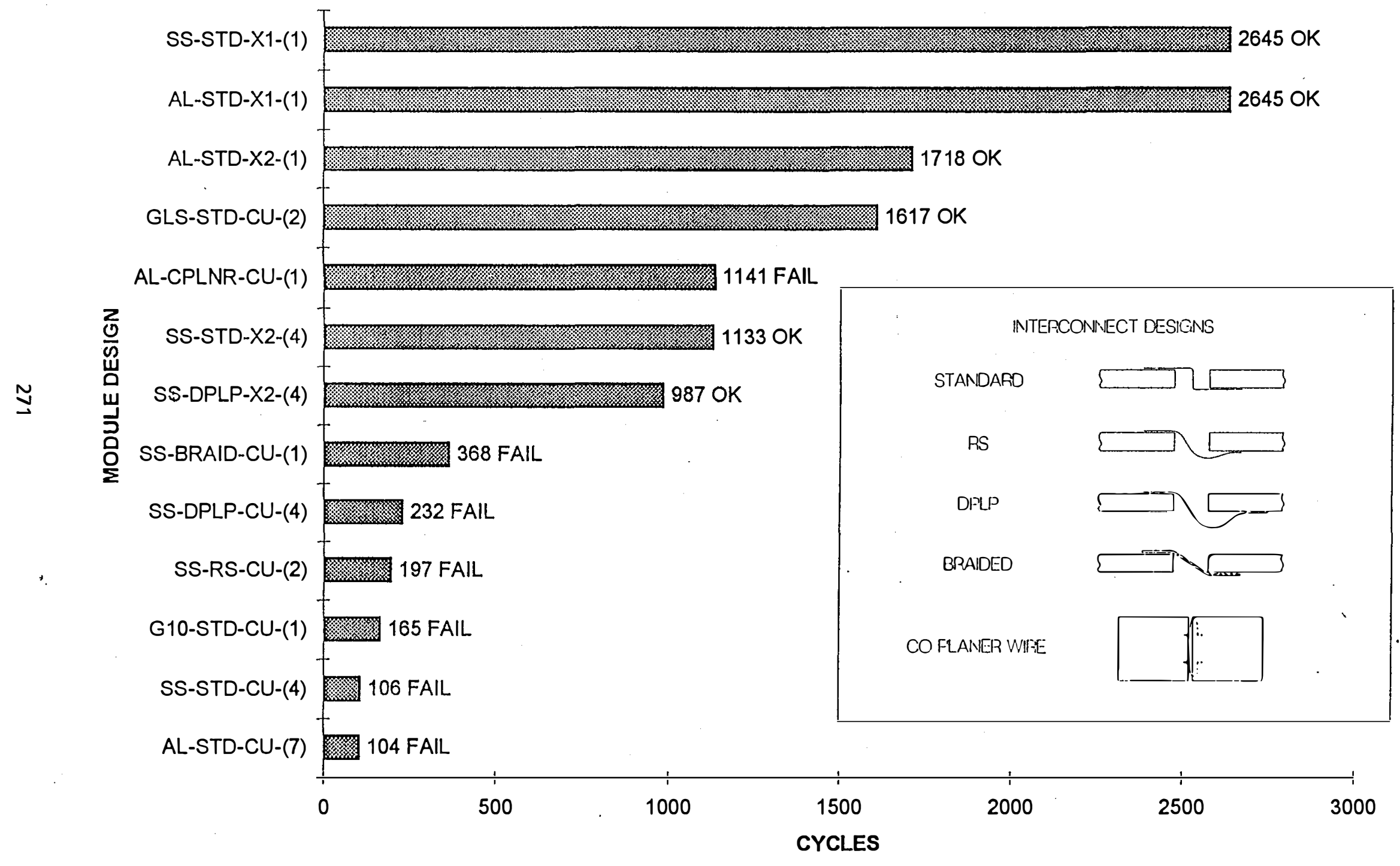




\section{SUMMARY}

- ACCELERATED THERMAL-CYCLE TESTS PROVIDE A RAPID MEANS OF DETERMINING RELATIVE PERFORMANCES OF COMPETING MODULE DESIGNS.

- REDUCING THE SUBSTRATE RANGE OF EXPANSION AND CONTRACTION BY CHOOSING THE MATERIAL WITH LOWEST COFFICIENT OF THERMAL EXPANSION, PROVIDES SOME BENEFIT.

- INTERCONNECT DESIGNS EMPLOYING STRESS RELIEVING "LOOPS" CAN PROVIDE ADDITIONAL INTERCONNECT LONGEVITY.

- ALTERNATE INTERCONNECT MATERIALS PROVIDED THE MOST SUBSTANTIAL INCREASES IN FATIGUE STRENGTHS 


\author{
NREL \\ PHOTOVOLTAIC \\ PERFORMANCE AND RELIABUITY \\ WORKSHOP \\ September 4-6, 1996
}

\title{
PV MODULE QUALIFICATION TEST EXPERIENCES AND RESULTS
}

\author{
Bob Hammond, Kent Whitfield, Liang-Jun Ji \\ Arizona State University \\ Photovoltaic Testing Laboratory
}

\begin{abstract}
In 1992 Arizona State University (ASU) established a goal to develop a PV module qualification test laboratory. By July 1995 the lab was fully equipped to perform all tests required by JPL Block V, NREL IQT, PVUSA, IEEE 1262 and/or UL 1703 (minus the buming brand test). The full test sequence for IEEE and/or UL 1703 (-) was started in July 1995 for four domestic PV module manufacturers. Individual failuresoccurred as the result of the hail impact test, static load test and dynamic load test.

ASU is currently a subcontractor to Springbom Testing and Research, Inc. (SRT) to conduct the IEEE 1262 test (modified Test Sequence A, B, and C) for six PV module manufacturers using for new formulations of EVA (a program sponsored by DoE/NREL). These tests were started July 1, 1996 and will be completed by December 3 1, 1996. Results of current testing (including Damp Heat) are reported herein. In addition to IEEE 1262 testing, ASU, in conjunction with Arizona Public Service (APS), are conducting long-term outdoor exposure testing for modules made with the new EVA formulations at the APS STAR center.
\end{abstract}

ASU has pursued two approaches to reducing qualification testing costs to the manufacturer. First, multi-client testing has been conducted to load the environmental chamber to the maximum usable capacity, which reduces set-up time, labor and energy costs. Secondly, we have tested to IEEE 1262 and UL 1703 simultaneously for some clients, since the most expensive tests (temperature cycling, damp heat and humidity freeze) are nearly identical for both standards.

The next step in improving PV module reliability and durability is for the PV industry to develop a PV module certification and laboratory accreditation program. Product certification will improve PV module quality, reduce overall qualification testing time and costs, and increase sales for the manufacturers that participate. 


\section{ACKNOWLEDGMENTS}

The authors wish to acknowledge both the Department of Energy and the National Renewable Energy Laboratory for sponsoring this workshop and the work discussed herein. Special recognition goes to Ben Kroposki for his efforts in organizing the Workshop.

Much of the information presented herein was developed under an ASU subcontract from Springborn Testing and Research (STR, formerly Springbom Laboratories). We appreciate the fine job that Bill Holley has done in managing this subcontract. We also want to thank the six module manufacturers that provided modules with the new EVA formulations: ASE Americas, AstroPower, Photocomm, Solarex, Solec and Siemens Solar. Arizona Public Service (APS), has been a gracious host with a two-axis tracker at STAR for the long-term outdoor-exposure testing portion of the STR subcontract. Pete Eckert, manager of the STAR facility, has provide valuable support.

We also wish to acknowledge the continued support and encouragement of Dr. Chuck Backus, Provost of the ASU East Campus, and for providing space for our new PV laboratory at ASU-EAST. 


\section{BACKGROUND}

ASU has been conducting research and educational programs in photovoltaic technologies, including concentrator cells, one-sun cells and PV system development, for over 25 years. A commitment was made in January 1992 to establish a PV module qualification test laboratory. The laboratory was fully operational in July 1995, with the full capability to perform all national and international PV module qualification tests, plus UL 1703. In fact, the full IEEE 1262 test sequence and/or UL 1703 were started in July 1995 for four manufacturers.

Major pieces of equipment in this laboratory include two walk-in environmental chambers capable of meeting the requirements of all current PV module qualification standards. An ASU designed state-of-the-art hail impact tester is capable of firing ice balls from 0.75 1.50 inches in diameter at velocities of 27-90 miles per hour. Repeatability of velocity is two percent. Aiming accuracy is $1 \mathrm{~cm}$. A dynamic load tester, also designed and built by ASU, meets all requirements defined by ASTM 201, while leaving the front of the module fully visible for observation during the test. Any size module can be tested by this device.

The lab quality system meets the requirements of PV-1, Criteria for a Model Quality System for Laboratories Engaged in Testing Photovoltaic Modules and PV-1.1, Calibration, Traceability and Statistical Requirements of Testing by Accredited Laboratories in Support of the Photovoltaic Module Certification Program.

The ASU Photovoltaic Testing Laboratory was moved from the main ASU campus to the new ASU EAST campus, previously Williams Air Force Base. This move was completed in July 1996, just in time to begin the Springbom qualification test program.

\section{QUAL TEST RESULTS, JULY 1995 TO JULY 1996}

Figure 1 describes the areas in which modules failed qualification testing during the period July 1995 to July 1996.

FIGURE 1. Qual Test Summary 6/95-6/96

IEEE 1262: One manufacturer
UL 1703: Two manufacturers
$1262 \& 1703$ COMBO: One manufacturer

FAILURES:

Hail impact

J-Box Deformation

Static Load, 1262-5.11

Dynamic Load, 1262-5.11

T-200, 1262-5.7

Damp Heat, 1262-5.13

UL J-Box Pull

Electrical Measurement, 1262-5.2, 1703
Non tempered glass

Non-UL approved plastic

Laminate came out of frame; in adequate adhesive; retest Open circuit

Glass laminate separated from frame

Visual inspection (5.1.2), corrosion of electrical terminals

Failed "as received" pull test

Power loss greater than $10 \%$ for 1262 and 5\% for 1703 
No modules with tempered glass superstrate broke while undergoing hail impact testing during the test period, and only one module out of 13 tested with non-tempered glass broke during hail impact testing.

All module junction boxes that were produced using UL recommended plastics passed the qual test. Those that did not use those materials failed.

The module design that failed dynamic and static load testing has been redesigned and is currently being retested.

\section{SPRINGBORN TESTING AND RESEARCH PROJECT}

Springbom Testing and Research (STR) has developed new formulations of EVA ${ }^{1}$ to eliminate the browning/yellowing problem which has been experienced in some climates during the past. ASU is under contract to STR to a) conduct qualification tests for modules using the new formulations and b) to establish an outdoor exposure test program for these modules.

\section{Qualification Testing}

Six PV module manufacturers has produces modules using samples of four new formulations (Figure 2). ASU is under contract to STR to perform Test Sequence A, B and $C$ of IEEE 1262 (Figure 3) on sample modules produced by the six manufacturers. Results of these Initial Inspections/Tests are shown in Figure 4 and results of Damp Heat are shown in Figure 5.

FIGURE 2. EVA/MODULE SUMMARY

\begin{tabular}{|r|r|c|c|c|c|c|c|r|r|}
\hline \multicolumn{2}{|l|}{ MANUFACTURER } & A & B & C & D & E & F & \\
\hline \multicolumn{2}{|r|}{ ENCAPSULANT } & \multicolumn{6}{|c|}{ NUMBER OF MODULES } & & TOTAL \\
\hline & 9903 & 6 & 0 & 6 & 6 & 0 & 6 & $\mathbf{2 4}$ \\
\hline & 9923 & 0 & 6 & 6 & 6 & 0 & 0 & $\mathbf{1 8}$ \\
\hline & 9933 & 6 & 6 & 6 & 6 & 0 & 6 & $\mathbf{3 0}$ \\
\hline & $\mathbf{1 5 3 0 3}$ & 6 & 6 & 0 & 6 & 6 & 6 & $\mathbf{3 0}$ \\
\hline & TOTAL & 18 & 18 & 18 & 24 & 6 & 18 & $\mathbf{1 0 2}$ \\
\hline
\end{tabular}

All but one (possible two) of the failures shown in Figure 5 were due to reasons other than EVA. All EVA formulations except 9933 survived the 1000 hours of Damp Heat; EVA 9933 turned bright yellow during the 1000 hours of damp heat. Modules from Manufacturer A were received late and were placed in the chamber at 504 hours. Those modules received only 495 hours of damp heat, but were equally bright yellow at the end of the test. EVA 9933 modules which completed 50 Thermal Cycles on August 30 showed, minor yellowing, indicating that moisture is primary cause of the yellowing.

\footnotetext{
'This work has been partially funded by NREL.
} 
FIGURE 3. STR IEEE 1262 TEST SEQUENCE

\section{Springborn IEEE 1262 Project}

Note: the number designated at the right of each box corresponds to the required test or inspection procedure given in clause 5 .

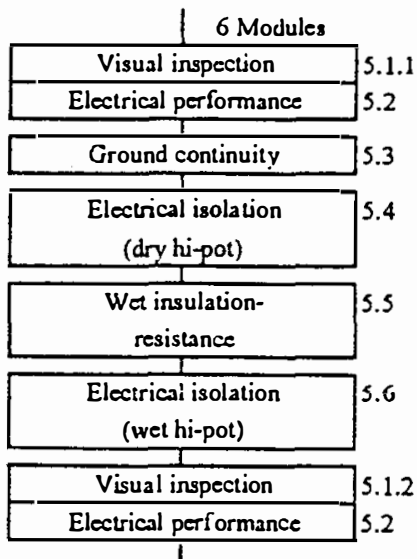

INITIAL

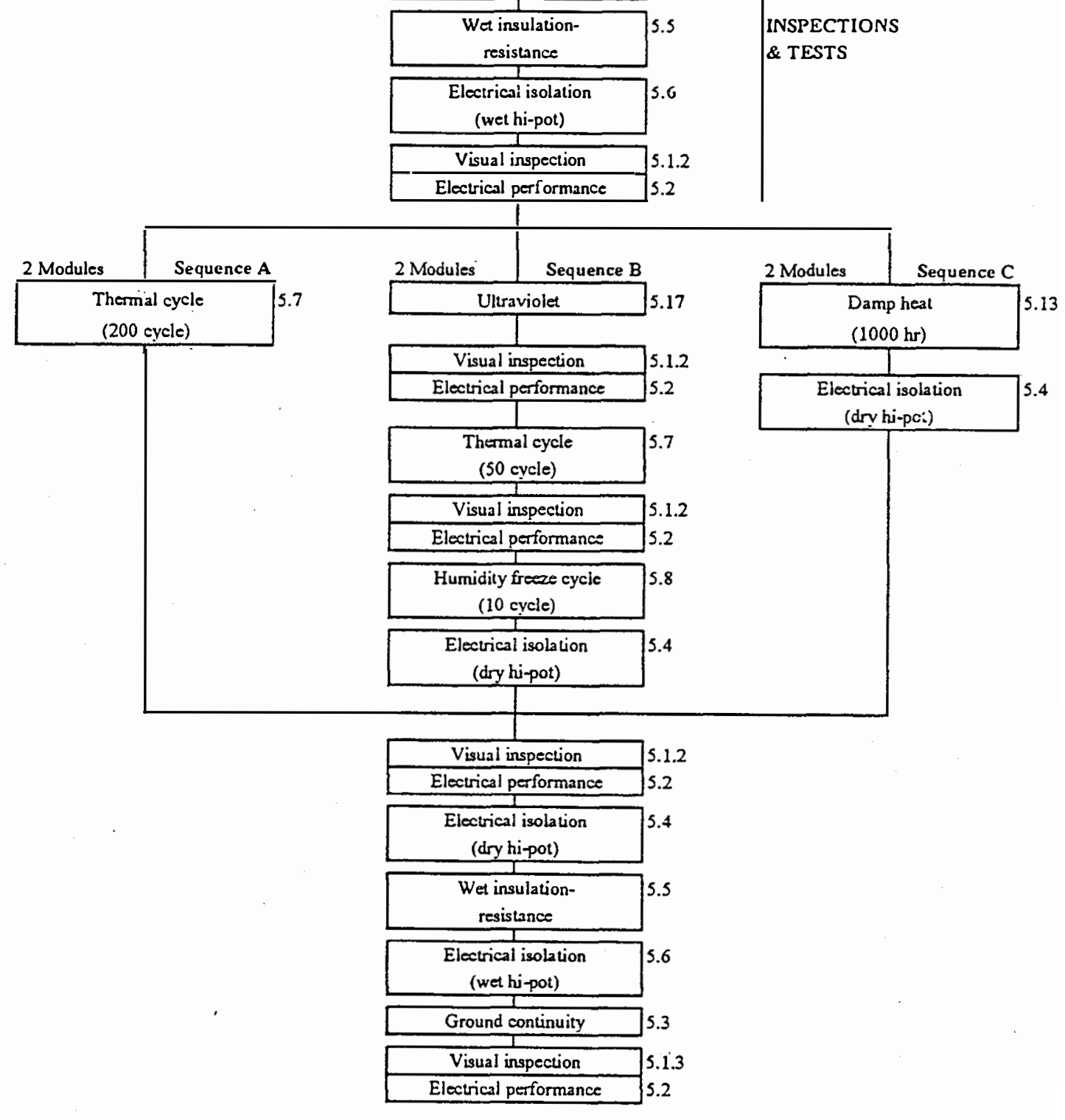


FIGURE 4. INITIAL INSPECTION/TEST RESULTS

\begin{tabular}{|c|c|c|l|c|l|}
\hline & & & \multicolumn{1}{|c|}{ IEEE } & PASS & COMMENTS \\
\hline MFG & S/N & EVA & \multicolumn{1}{|c|}{ TEST } & FAIL & \\
\hline D & 2 & 9903 & 5.6 Wet hi-pot & F & \\
\hline D & 32 & 9933 & 5.6 Wet hi-pot & F & \\
\hline D & 15 & 15303 & 5.6 Wet hi-pot & F & \\
\hline & & & & & \\
\hline E & 24 & 15303 & $5.5,5.6 ;$ Wet insulation \& hi-pot & F/P & scratches on substrate; repaired w/ TEFZEL \& retested \\
\hline E & 25 & 15303 & $5.5,5.6 ;$ Wet insulation \& hi-pot & F/P & scratches on substrate; repaired w/TEFZEL \& retested \\
\hline & & & & & \\
\hline F & 26 & 15303 & $5.5,5.6 ;$ Wet insulation \& hi-pot & F & \\
\hline & 31 & 9903 & $5.5,5.6 ;$ Wet insulation \& hi-pot & F & \\
\hline & 43 & 9933 & $5.5,5.6 ;$ Wet insulation \& hi-pot & F & \\
\hline & 21 & 15303 & $5.3 ;$ Ground Continuitv & F & \\
\hline & 24 & 15303 & $5.3 ;$ Ground Continuity & F & \\
\hline & 26 & 15303 & $5.3 ;$ Ground Continuity & F & \\
\hline & 36 & 9903 & $5.3 ;$ Ground Continuity & F & \\
\hline
\end{tabular}

FIGURE 5. RESULTS OF DAMP HEAT TEST

\begin{tabular}{|c|c|c|c|c|c|c|c|c|}
\hline Leakage & irrent: & 0 micro & $\mathrm{mps} / \mathrm{m} 2$ & or $10 n$ & oapms & whiche & ever is greater & \\
\hline & & & LEA & KAG & CURRE & ET & & \\
\hline & & & & $2-4 \mathrm{hr}$ & $4-5 \mathrm{hrs}$. & PASS & & PASS \\
\hline MFG & $\mathbf{S} / \mathbf{N}$ & EVA & LIMIT & T1 & T2 & FAIL & VISUAL & FAIL \\
\hline A. & 52 & 9903 & 42.8 & 10.5 & 15.0 & $\mathrm{P}$ & J-box def ormed & $F$ \\
\hline A & 61 & 9903 & 42.8 & 16.0 & 36.0 & $\mathrm{P}$ & Edge delam, 22"x.5", J-box deformed & $\mathrm{F}$ \\
\hline A & 41 & 9933 & 43.5 & 13.2 & & $P$ & Encapsulant yellow, full area, J-box deformed & $\mathrm{F}$ \\
\hline A & 59 & 9933 & 42.8 & 19.0 & 36.0 & $P$ & Encapsulant yellow, full area, J-box deformed & $F$ \\
\hline A & 45 & 15303 & 42.8 & 10.0 & & $\mathrm{P}$ & Edge delam, 5"x.5", J-box deformed & $\mathrm{F}$ \\
\hline $\mathbf{A}$ & 47 & 15303 & 42.8 & 6.0 & 12.2 & $\mathbf{P}$ & Edge delam, 12"x.5", J-box deformed & $\mathrm{F}$ \\
\hline & & & & & & & . & 1 \\
\hline $\mathrm{B}$ & 5 & 9923 & 42.8 & 0.2 & & $P$ & |Slight yellowing at mf g's front label & $P$ \\
\hline $\mathrm{B}$ & 6 & 9923 & 42.8 & 0.2 & & $\mathrm{P}$ & IVery slight yellowing at mf g's front label & $\mathrm{P}$ \\
\hline $\mathrm{B}$ & 15 & 9933 & 42.8 & 0.4 & & $P$ & |Yellowing, full surface, possible delam & $\mathrm{F}$ \\
\hline $\mathrm{B}$ & 16 & 9933 & 42.8 & 0.3 & & $\mathrm{P}$ & Yellowing, full surface, possible delam & $F$ \\
\hline $\mathrm{B}$ & 25 & 15303 & 42.8 & 0.2 & & $P$ & 1OK & $\mathrm{P}$ \\
\hline $\mathrm{B}$ & 26 & 15303 & 42.8 & 0.2 & 0.3 & $\mathrm{P}$ & IOK & $\mathrm{P}$ \\
\hline & & & & & & & 1 & \\
\hline $\mathrm{C}$ & 11 & 9903 & 43.5 & 6.8 & & $P$ & White powder on terminals & $\bar{F}$ \\
\hline $\mathrm{C}$ & 15 & 9903 & 43.5 & 4.4 & & $P$ & Terminal screws covered with white powder & $\mathrm{F}$ \\
\hline $\mathrm{C}$ & 14 & 9923 & 43.5 & 7.0 & & $P$ & Metalization (ribbon) discolored above J-box, white powder & $\mathrm{F}$ \\
\hline $\mathrm{C}$ & 17 & 9923 & 43.5 & 6.5 & & $\mathbf{P}$ & |Metalization discolored above J-box, delam, white powder & $F$ \\
\hline $\mathrm{C}$ & 16 & 9933 & 43.5 & 4.0 & 7.9 & $P$ & Yellowing, full surface, terminals - wnite powder & $\mathrm{F}$ \\
\hline $\mathrm{C}$ & 18 & 9933 & 43.5 & 5.0 & & $P$ & |Yellowing, full surface, terminals - white powder & $\mathrm{F}$ \\
\hline & & & & & & & 1 & \\
\hline D & 5 & 9903 & 44.7 & 6.9 & & $P$ & Slight browning, J-box distorted, 30 in^^2 delam & $\mathrm{F}$ \\
\hline $\mathrm{D}$ & 6 & 9903 & 44.7 & 6.9 & & $\mathrm{P}$ & Some browning, J-box distorted, 30 in^2 delam, ribbon corrosion & $F$ \\
\hline $\mathrm{D}$ & 25 & 9923 & 44.7 & arc & & $\mathrm{F}$ & Some browning, J-box distorted 80 in^2 delam & $\mathrm{F}$ \\
\hline $\mathrm{D}$ & 26 & 9923 & 44.7 & 7.8 & & $P$ & Slight browning, J-box distorted, 45 in^ 2 delam, ribbon corrosion & $\mathrm{F}$ \\
\hline $\mathrm{D}$ & 35 & 9933 & 44.7 & arc & & $F$ & All yellow, J-box distorted. 20 in^2 delam & $\mathrm{F}$ \\
\hline $\mathrm{D}$ & 36 & 9933 & 44.7 & 8.0 & & $P$ & All yellow, J-box distorted, & $F$ \\
\hline $\mathrm{D}$ & 15 & 15303 & 44.7 & 5.2 & & $P$ & Some browning, J-box distortod, 24 in^ 2 delam & $\mathrm{F}$ \\
\hline $\mathrm{D}$ & 16 & 15303 & 44.7 & arc & arc & $\mathrm{F}$ & Sorne browning, J-box distorted & $\mathrm{F}$ \\
\hline & & & & & & & $1 \ldots$ & \\
\hline$E$ & 25 & 15303 & 55.7 & 2.5 & & $P$ & Slight browning of ribbon, J-box area & $\mathrm{P}$ \\
\hline$E$ & 26 & 15303 & 55.7 & 5.6 & 8.0 & $P$ & Slight browning of ribbon, J-box area & $\mathrm{P}$ \\
\hline & & & & & & 1 & & \\
\hline $\mathrm{F}$ & 35 & 9903 & 63.3 & 1.9 & & $\mathrm{P}$ & Light browning, all, teminals-white powder & $\mathrm{F}$ \\
\hline $\mathrm{F}$ & 36 & 9903 & 63.3 & 1.1 & & $P$ & Light browning, all, terminals-white powder & $\mathrm{F}$ \\
\hline $\mathrm{F}$ & 45 & 9933 & 63.3 & 1.6 & & $P$ & All yellow, terminals-white powder & $F$ \\
\hline $\mathrm{F}$ & 46 & 9933 & 63.3 & 1.7 & & $P$ & All yellow, term inals-white powder & $\mathrm{F}$ \\
\hline $\mathrm{F}$ & 25 & 15303 & 63.3 & 1.0 & 0.9 & $P$ & |Light browning, all, terminals-white powder & $\mathrm{F}$ \\
\hline $\mathrm{F}$ & 26 & 15303 & 63.3 & 0.7 & & $\mathrm{P}$ & ILight browning, all, terminals-white powder & \\
\hline
\end{tabular}


Manufacturer D used TEFZEL for the module superstrate and six of the eight modules experienced 20-80 in ${ }^{2}$ of delamination of the TEFZEL during Damp Heat. Reason for the delamination are not known at this time.

Ultraviolet, Sequence B, was competed with no failures. Thermal Cycle (50) of Sequence B was completed August 30, but post visual and electrical tests have not been completed.

\section{Outdoor Exposure Testing}

Five of the six manufacturers defined in Figure 2 have provide modules for long-term outdoor exposure testing at the Arizona Public Service STAR center. Forty modules were installed on a Martin Marietta 2-axis tracker between August 20 and August 29. Each module was connected to a variable resistive load such that the module will operate near the peak-power point in September.

Module I-V curves will be taken during the week of September 2, October 1, December 2, March 1, June 16 and then every six months thereafter. Tentative plans are for these data to be taken for 20 years.

A thermal imaging map will be produced for each of the forty modules during the month of September.

Summary daily weather data will be reported from STAR for the following parameters:

- minimum ambient temperature $\left({ }^{\circ} \mathrm{C}\right)$

- maximum ambient temperature $\left({ }^{\circ} \mathrm{C}\right)$

- global solar radiation in the plane of array $\left(\mathrm{kWh} / \mathrm{m}^{2}\right)$

- direct normal solar radiation $\left(\mathrm{kWh} / \mathrm{m}^{2}\right)$

\section{LOW COST QUALIFICATION TESTING}

ASU has pursued two approaches to reducing qualification testing costs to the manufacturer. First, multi-client testing has been conducted to load the environmental chamber to the maximum usable capacity, which reduces set-up time, labor and energy costs. This reduces the cost to the manufacturer by $20-30$ percent. Secondly, we have tested to IEEE 1262 and UL 1703 simultaneously for some clients, since the most expensive tests (temperature cycling, damp heat and humidity freeze) are nearly identical for both standards. This reduces costs for each manufacturer by another 20-30 percent. Additional savings could be achieved by developing more commonality between IEEE 1262, IEC 1215 and UL 1703. 


\section{MODULE CERTIFICATION AND LABORATORY QUALIFICATION}

The next step in improving PV module reliability and durability is for the PV industry to develop a PV module certification and laboratory accreditation program. Such a program, PowerMark Corporation (PMC), has been recently established. This program is the result of a DoE/NREL sponsored contract which developed the criteria for PV module certification and laboratory accreditation.

Product certification involves the formal process of licensing the manufacturer to use a Certificate of Conformity. An integral part of certification is the use of formal quality system criteria for the manufacturer, PMC itself, the testing laboratory authorized to perform testing in support of the program, and the laboratory accreditation body selected by PMC.

Product certification will improve PV module quality, reduce overall qualification testing time and costs, and increase sales for the manufacturers that participate. 


\section{System Reliability}




\title{
Reliability Issues in PV Systems and Components
}

NREL PV Performance \& Reliability Workshop

Lakewood, CO

$$
\text { Sept. 4-6, } 1996
$$

C. Whitaker, A. Reyes, P. Hutchinson, T. Townsend, J. Newmiller Endecon Engineering

\author{
B. Farmer \\ Pacific Gas and Electric Co.
}

PVUSA 


\section{Introduction}

- Provide preliminary diagnosis of June 4 grass fire at PVUSA

- Discuss design and component selection issues related to system reliability

- Update PVUSA status 


\section{High Voltage System/Low Voltage Module}

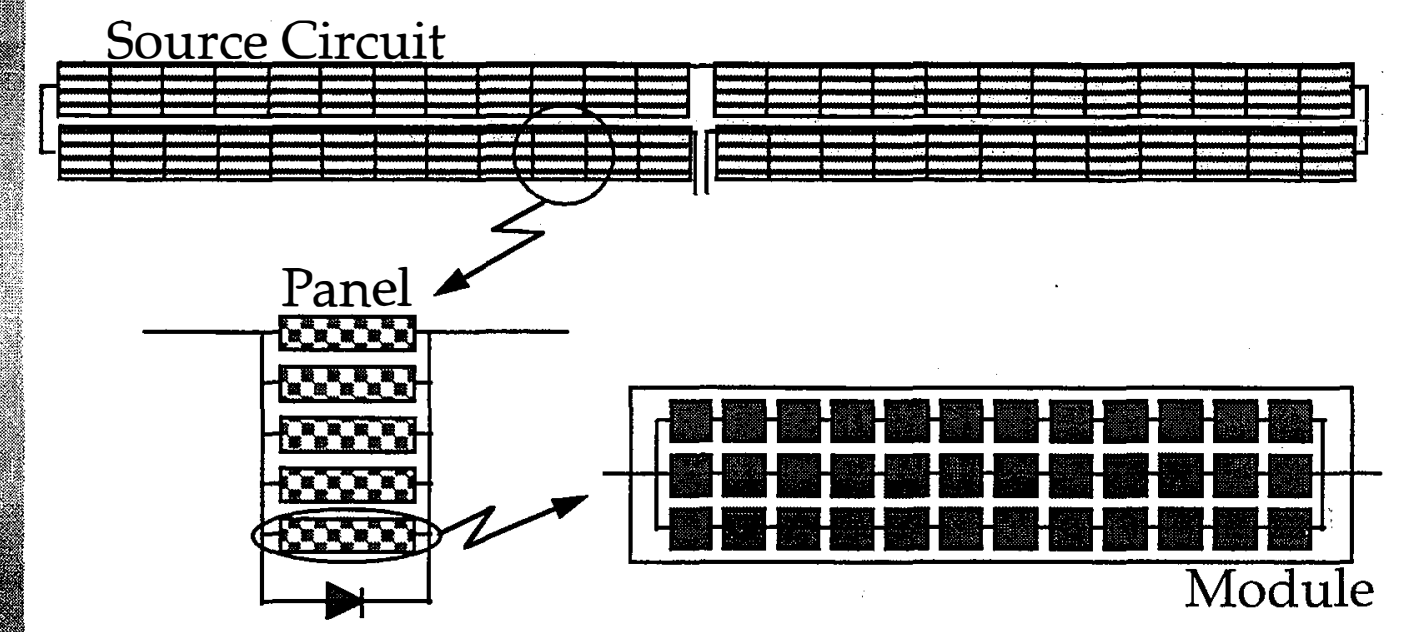

\section{PVUSA}

- Module is a special low voltage/high current model (three parallel strings each with 12 series cells versus standard 36 series cells) with no diodes.

- Panels consist of 4 modules wired in parallel with a single diode to produce desired source circuit current.

- Source circuit consists of panels wired in series to produce desired source circuit voltage. 


\section{Why Low Voltage Modules?}

- Less wire, fewer array combiner boxes

- Fewer diodes and diode connections (1 per 4 to 10 modules vs. 2/module)

- Easier to detect problems (ground faults and open strings)

- Safer to maintain (easy to isolate low voltage segments) 


\section{Disadvantages of Low V Modules}

- Not conducive to small arrays

- Greater impact from single point failures (ground fault or open string)

- Diode failure can lead to multiple module failures

- Limited availability

- Mfgs. reluctant to sell individual diodeless modules 


\section{PVUSA US-1 Failure/Fire}

- A Siemens 4 module sub-panel and bypass diode failed

- Hot materials ejected from module or diode ignited dry grass beneath the array

- Fire did not damage any other structures or components

Details are still under investigation 


\section{PVUSA US-1 Failure}
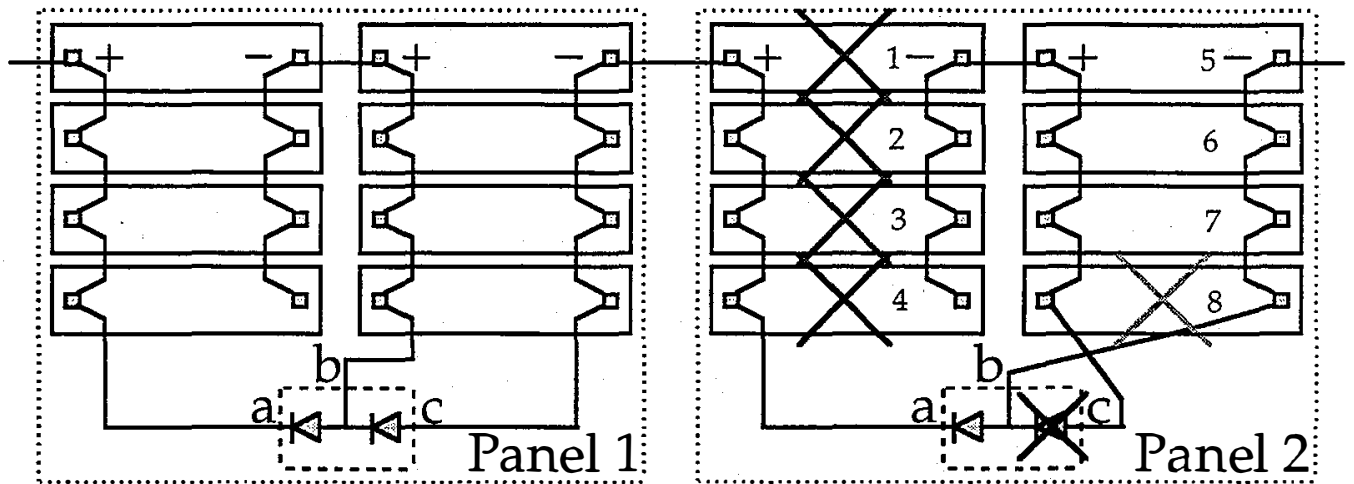

$X$ - failed devices

\section{PVUSA}

Panel 1 - properly connected panel:

- 4-module subpanel wired in parallel with external diode

- Panel = 2 subpanels with a dual diode package

Panel 2 - failed panel:

- Modules 1 through 4 failed

- "b-c" diode failed

- Connections for b-c diode found to be reversed (left sub panel shorted)

- Module 8 damaged by diode failure

- Connections "a" and " $c$ " found shorted to diode case. The diode's metal case is attached to the array structure and thus connected to ground. 


\section{Dual Diode Package}

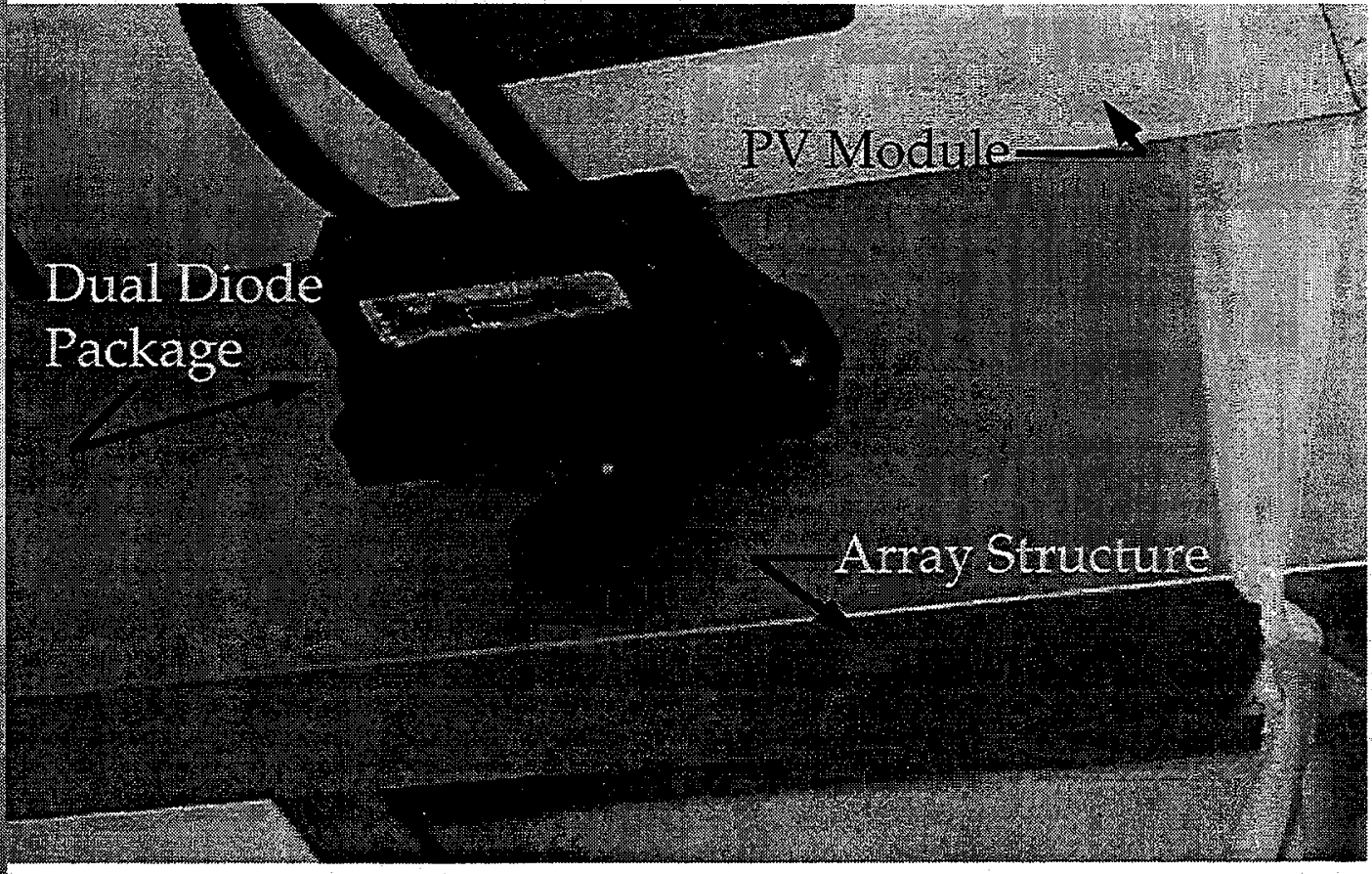

PVUSA

Close up of a dual diode package from the SSI Array

This particular diode was found to have failed shorted. The source circuit that this panel is in is functional 


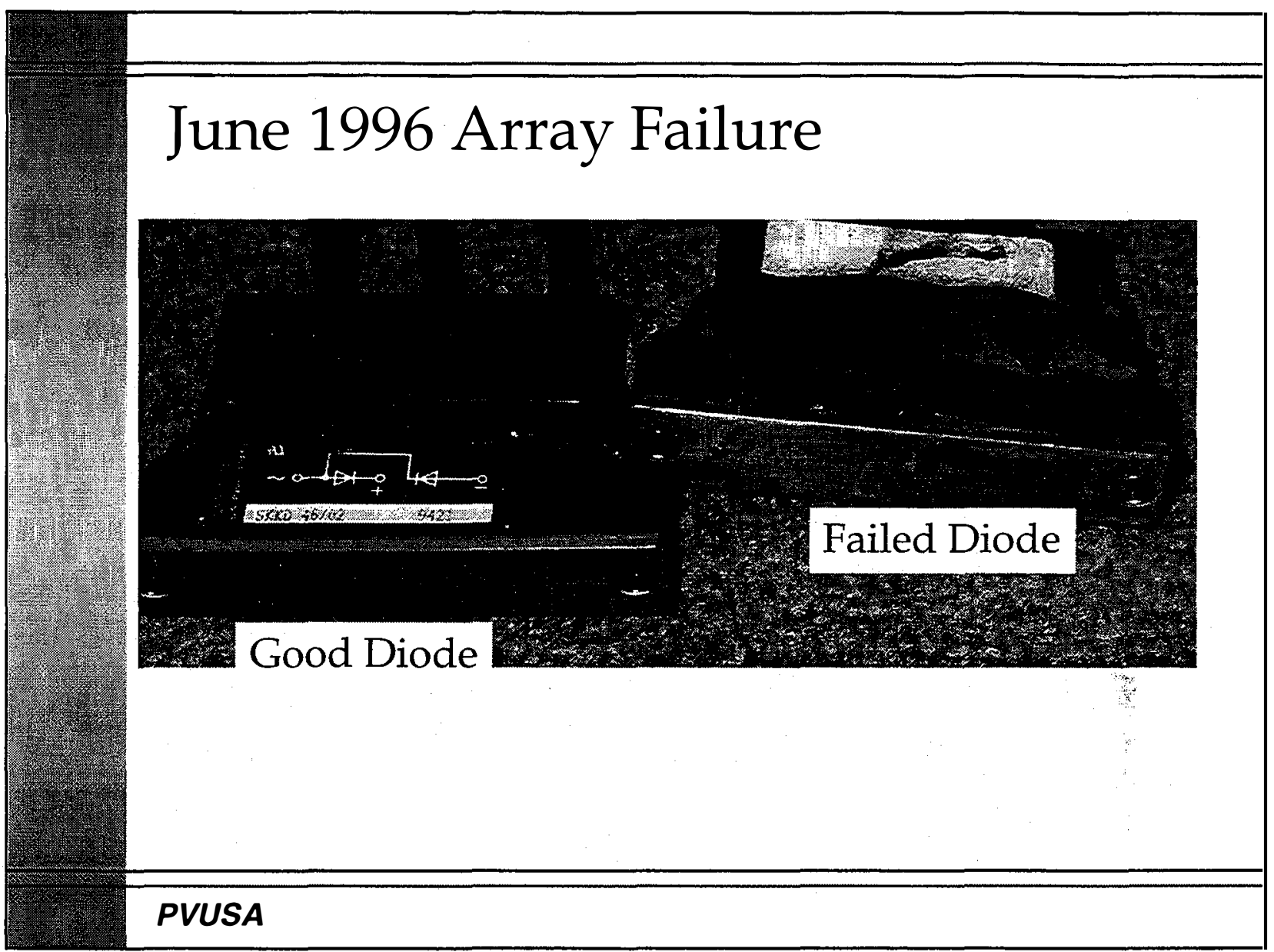

Dual diode package used in PVUSA SSI US-1 array. One diode in the package on the right failed open. The other diode in the package appears to be operational though its positive lead was shorted to the case (connected to ground through contact with structure) as was the negative lead from the first diode 


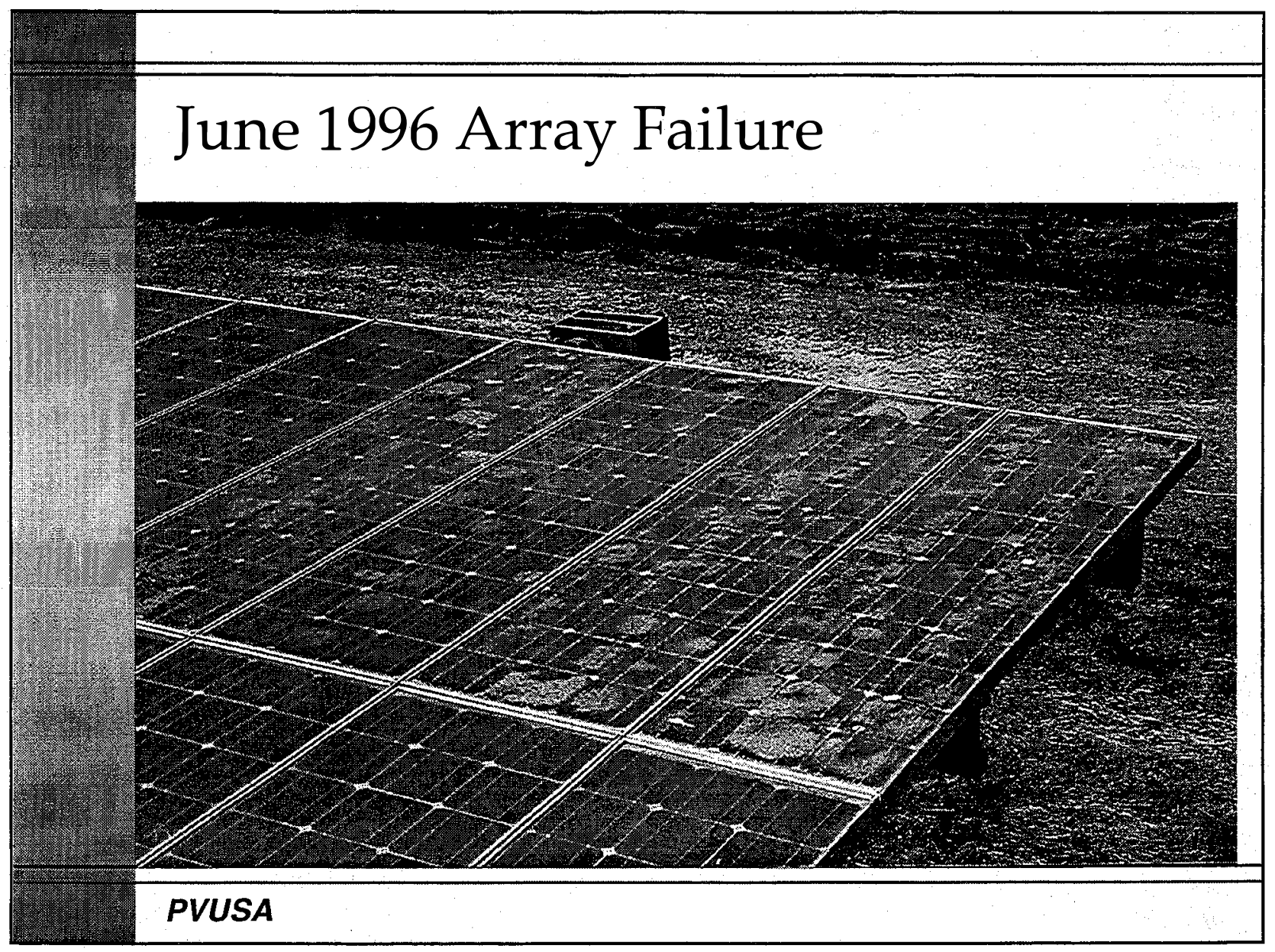

Front view of failed four module subpanel 


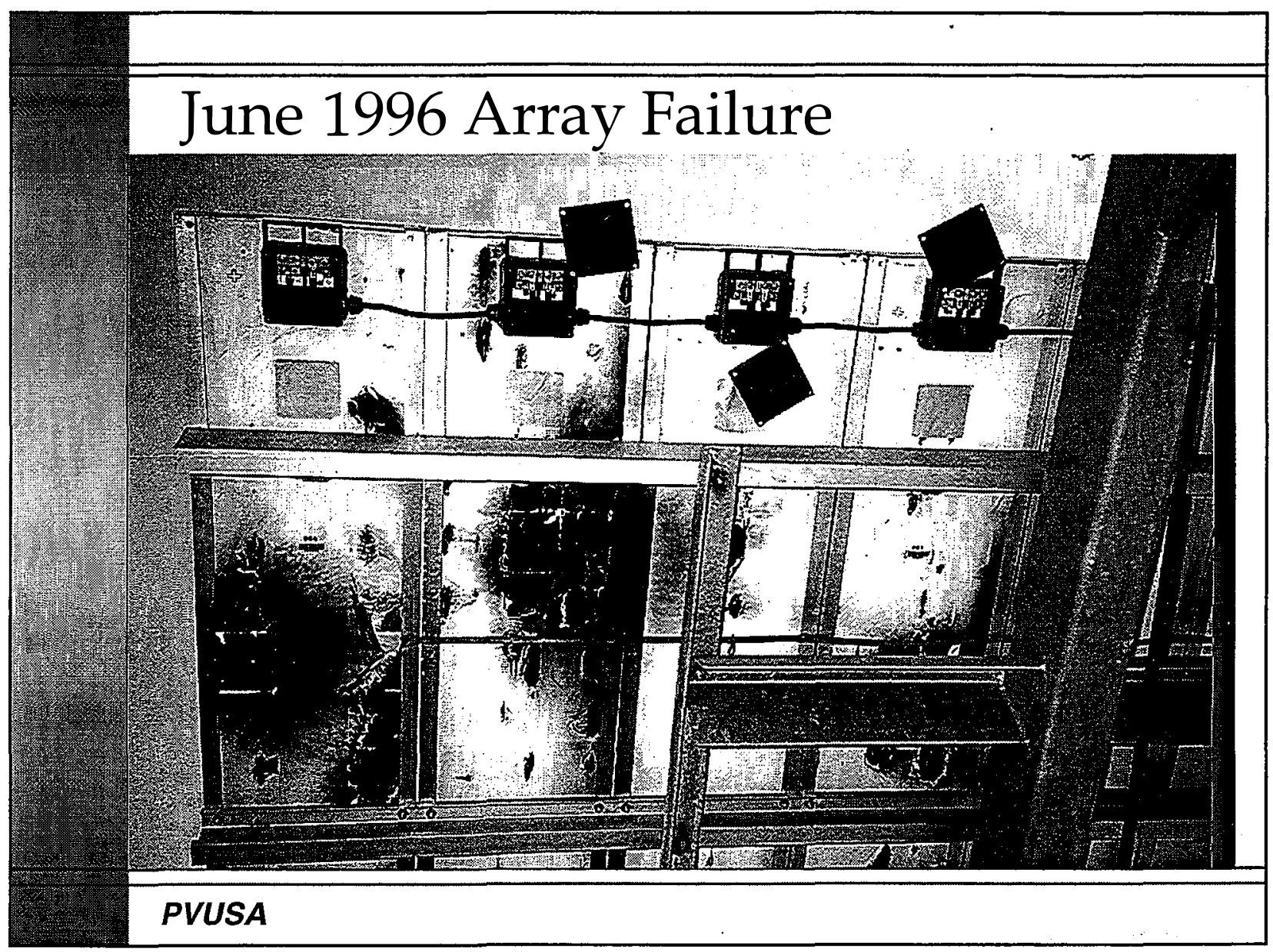

Rear view of failed four module subpanel 


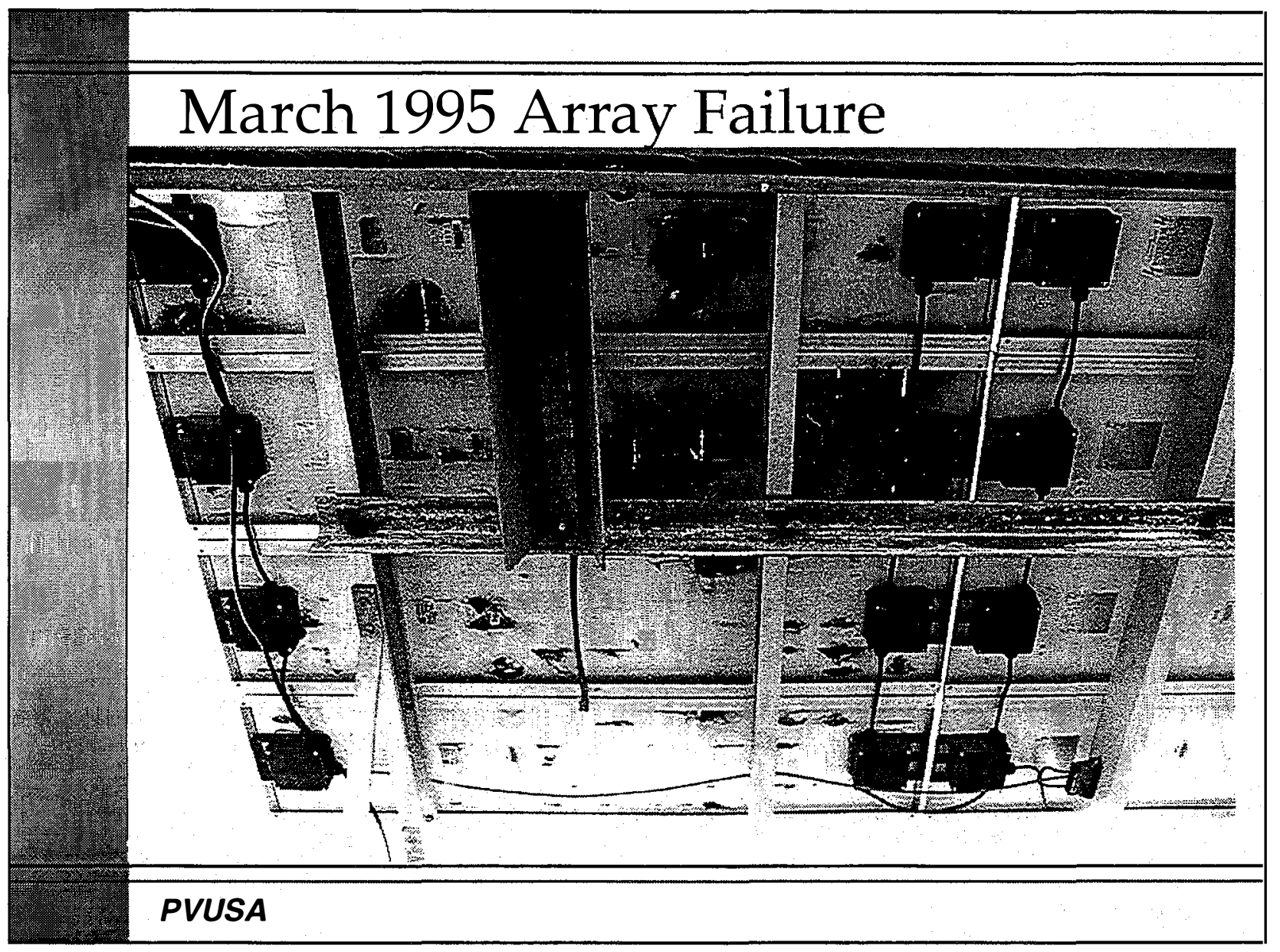

Rear view of failed four module subpanel.

Note that module failure occurs progressively from weakest to strongest. If a diode, which had been conducting due to a weak module, fails, the weak module may fail due to the stress. The string current must then pass through the remaining three modules. The next weakest module will fail next, then the next weakest, and finally the strongest. Each time, the remaining modules must carry significantly more current.

It appears in the above photo that the bottom module shows the least amount of damage and was probably the first to fail (it failed under the lowest current level). The module with the greatest damage appears to be the second from the top. This was likely the last module to go and failed under the highest current level. 


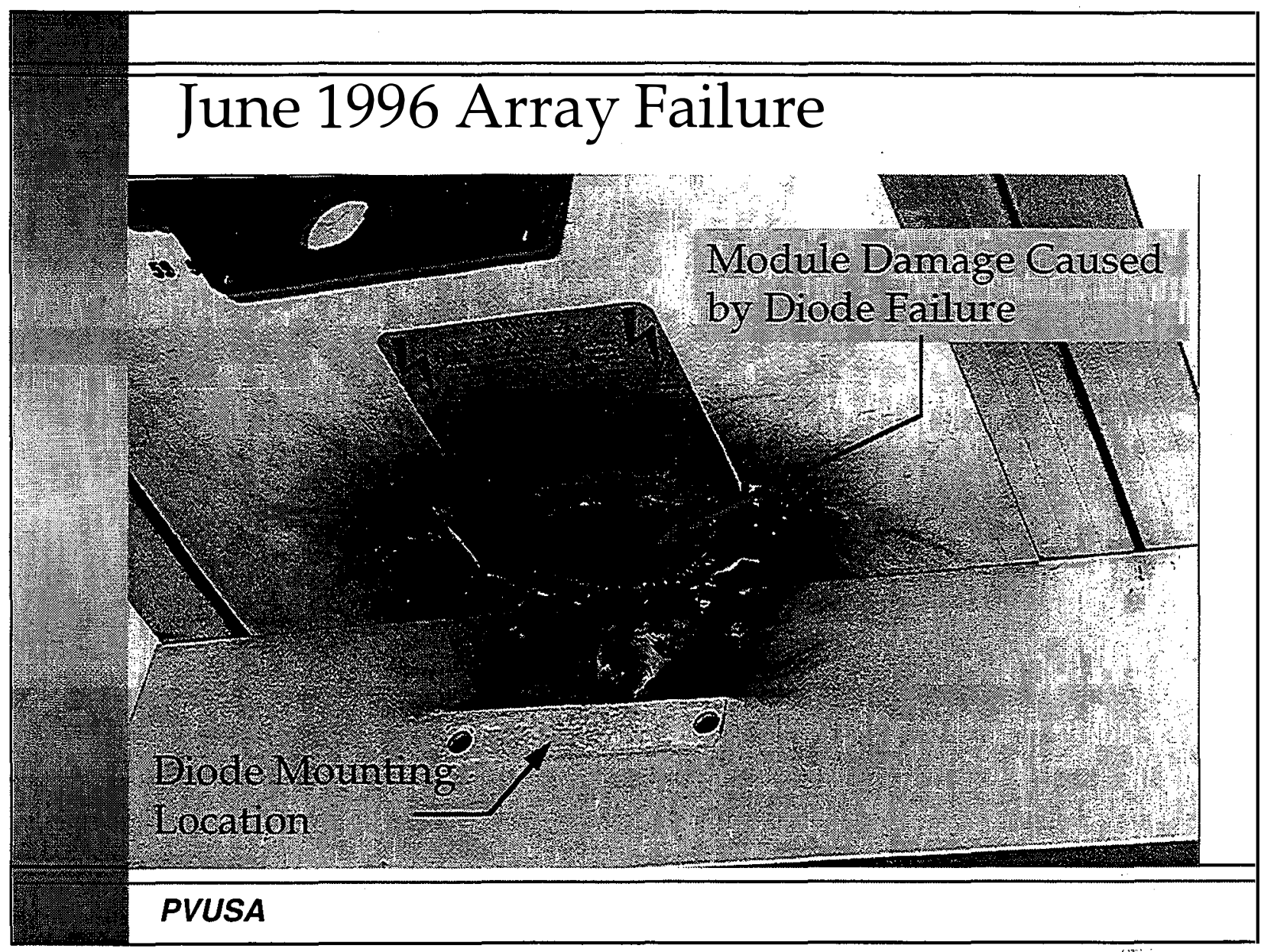

The module mounted directly above the failed diode was damaged by the diode 


\section{PVUSA US-1 Failure Details}

- Reversed diode connection

- Prototype PCU (commutation failures)

- Diode package was modified for use outdoors (significant FWRT failures)

- 4 previous diode/module failures

- 2 shorted diodes recently discovered 


\section{Other Systems with Low V Modules}

- PVUSA Kerman: 5 in parallel; loose connections was a problem, possibly one sub-panel was damaged (warranty repair)

- Austin PV300: 10 in parallel, 1 diode - few diode failures

- JF Long Homes: 10 in parallel 1 diode

- Carrisa: 4 in parallel (intra-module cross-strapping was a problem)

- PVUSA IPC: $\mathrm{SC}=100$ modules in series, 1 diode/module,

- SMUD PV1: 8 in parallel, 1 diode/2 series panels - some diode failures

- SMUD PV2: 9 in parallel, 1diode - few diode failures 


\section{How Do I Avoid The Same Problem?}

- Use 5-10 modules in parallel

- Avoid prototype equipment

- Use outdoor rated diodes or put diodes in enclosure

- Strictly enforce QC program 


\section{Module/Combiner Junction Box Problems}

- Water "pumping" (water vapor gets in but liquid can't get out

- Severe corrosion

- Module j-box cracks

- Loose covers

- Loose terminations 


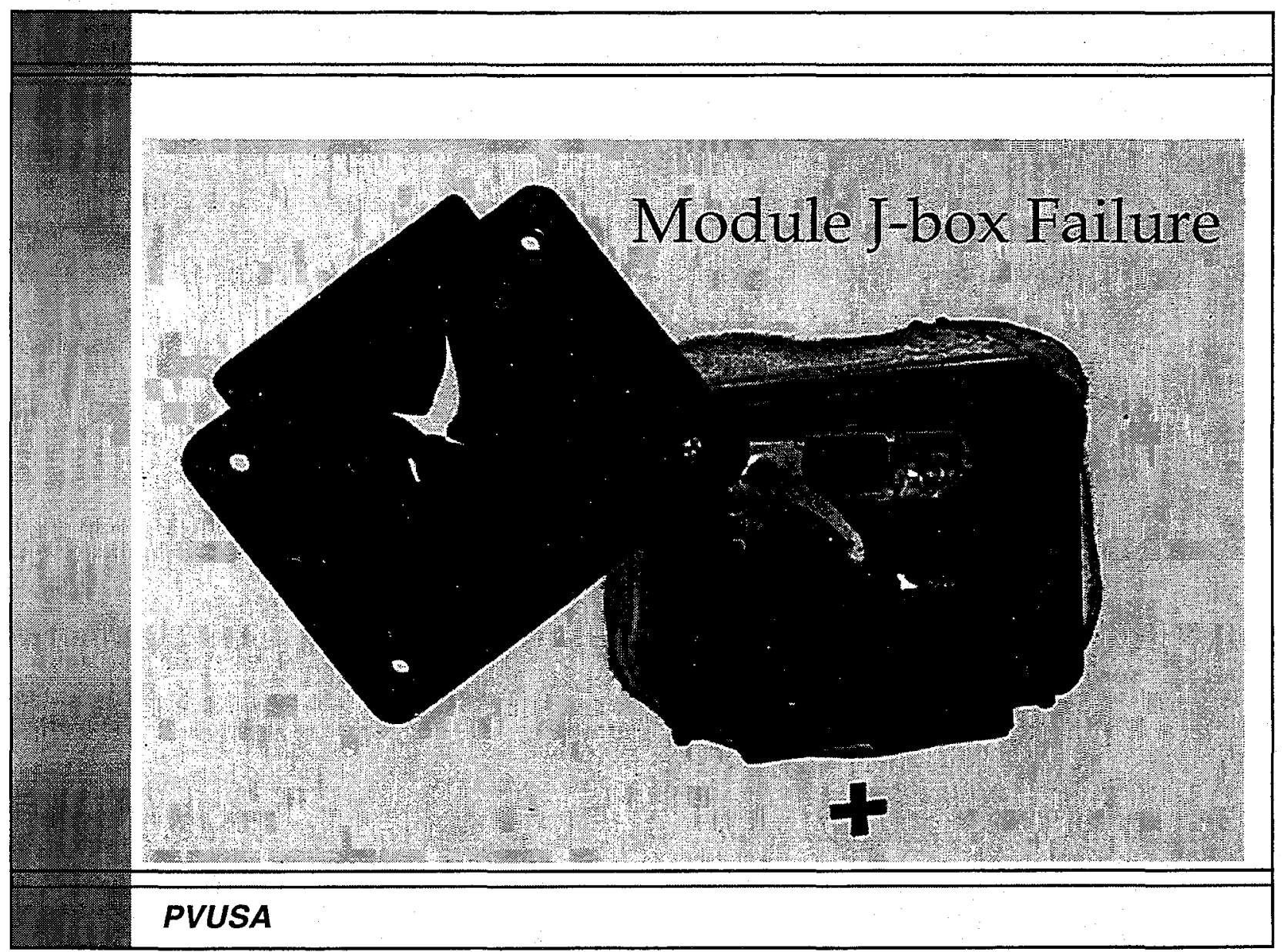

Sample module j-box failure. Corrosion of connection led to increased contact resistance and heating. Module interconnect wire burned and melted. J-box lid deformed and cracked under heat. 


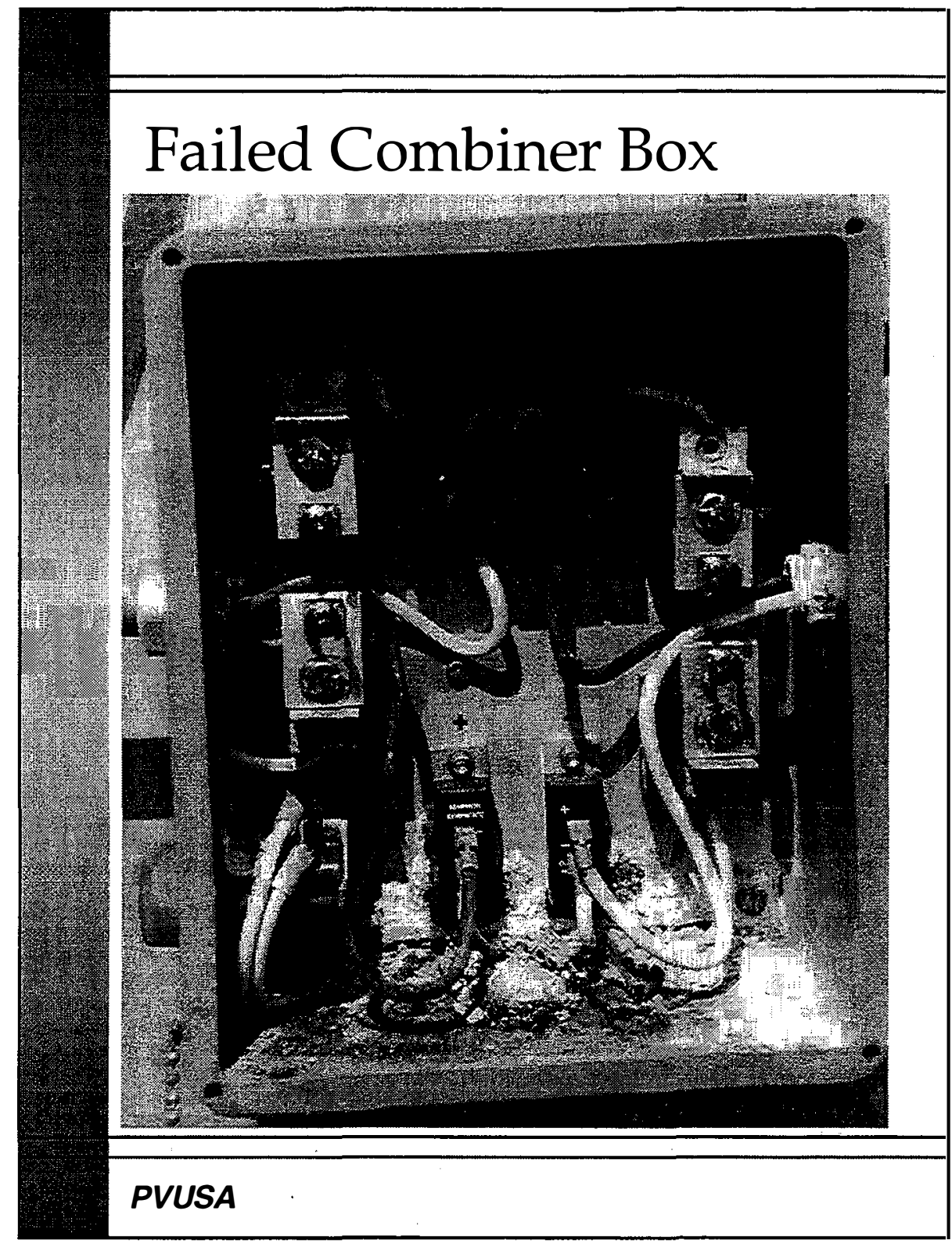

String combiner box allowed water to enter (vapor or liquid) but did not have drain for liquid water to exit. Note accumulation of corrosion oxides on bottom of box, and several inches up aluminum backplate Note also corrosion on most ferrous components. Corrosion led to increased contact resistance and heating of the water creating a "sauna bath" in the enclosure. The rotary switch at the bottom left of the box appears to have been submerged and had burnt contacts and fell apart during removal.

The problem was discovered when an array imbalance was noted in the data. The offending box was easily located as the lid to the box was found $10 \mathrm{~m}$ away! The four screws and a small area of j-box lid around each screw remained attached to the box. Our best guess is that pressure due to steam build-up finally exceeded the strength of lid. 


\section{How Do I Avoid The Same Problem?}

- Find alternative to module j-boxes

- Use bottom entry wherever possible and "vented" enclosures

- Strictly enforce QC program 


\section{Metal Oxide Varistors}

- Connected between current carrying conductors and ground

- Used to shunt voltage transients to ground

- Often give their lives dramatically in the line of duty

- Can take innocent bystanders with them when they go 


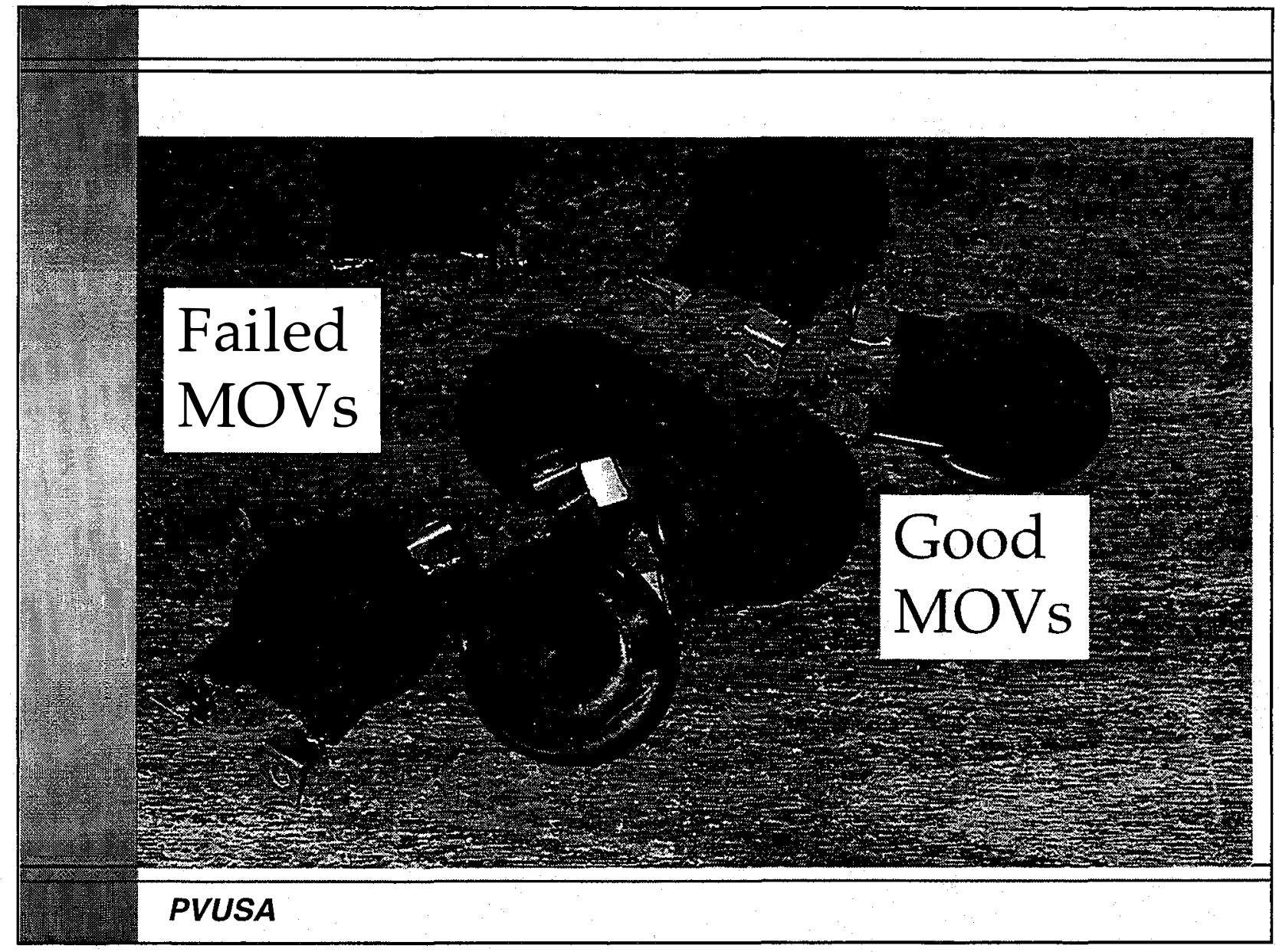

Sample MOVs. The four discolored units on the left failed during a utility line transient. The three units on the right do not appear to be damaged. 


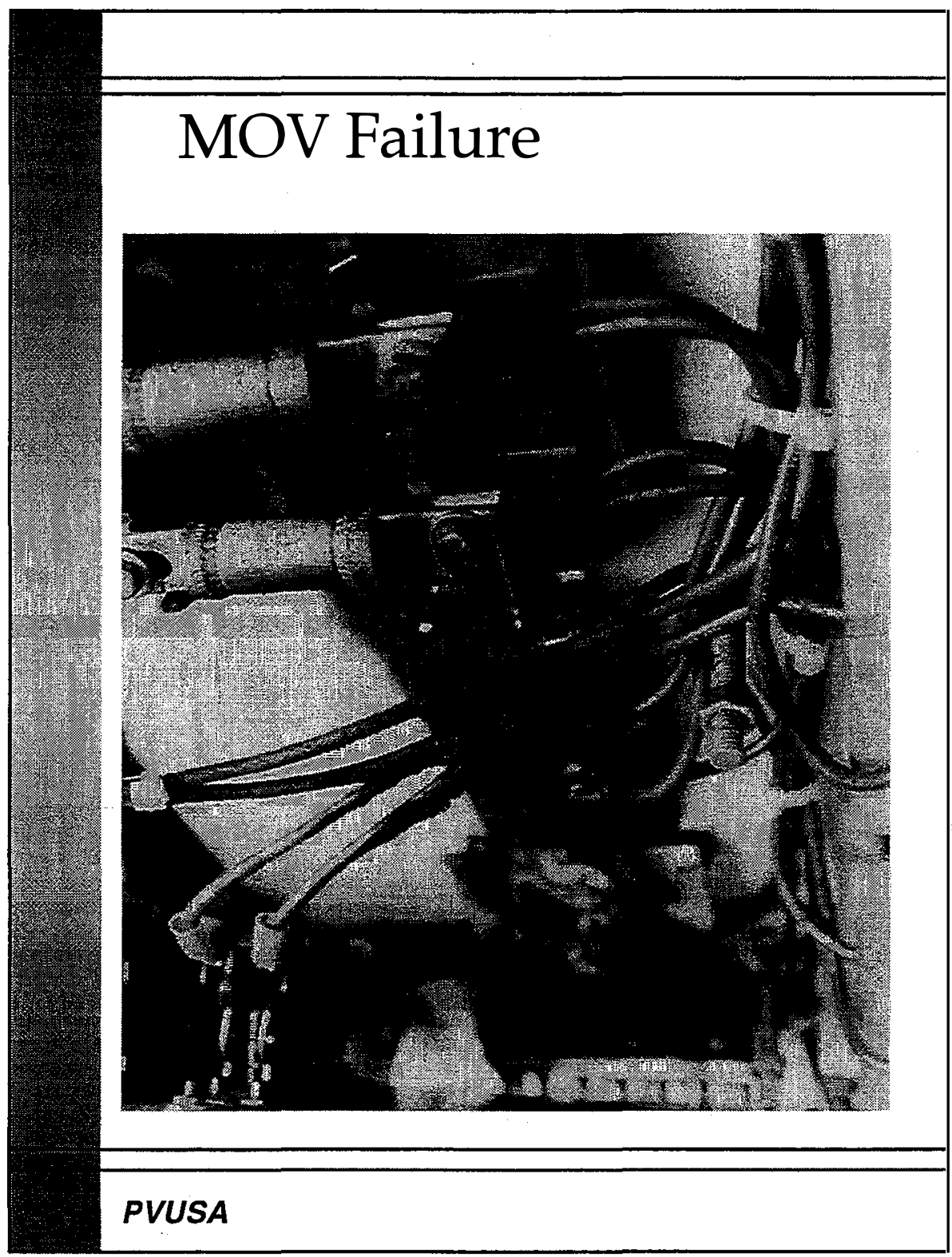

The dark mass near the bottom of the photograph is the remains of several MOVs that failed in this string combiner box. The burning MOVs damaged wiring, a terminal strip, and the fuse block directly above. A replacement combiner box was fabricated with the MOVs in a protective housing to mitigate peripheral damage such as this. 


\section{How Do I Avoid The Same Problem?}

- Segregate MOVs from other components (physical barriers, separate enclosure)

Use fuses? (Increases maintenance)

- Use larger MOVs 


\section{Conclusions}

Most of these potential reliability problems can be eliminated through:

- Good engineering practice (design, component selection, installation)

- Rigorous QC

- Selection of standard, listed, field proven components 


\title{
COST AND PERFORMANCE CONSEQUENCES of NEC and UL REQUIREMENTS
}

\author{
John C. Wiles \\ Southwest Technology Development Institute \\ New Mexico State University \\ Box $30001 /$ Department 3 SOLAR \\ Las Cruces, NM 88003 \\ 505-646-6105
}

\section{Introduction}

PV systems and components may be assembled from components that comply with established standards, and they may be installed in a manner that meets local and national code, or they may be assembled and installed in a manner that does not comply with any code or standard. Users, designers, and manufacturers of PV systems and components make this choice every time they make, install, or buy PV systems. There have been concerns in certain segments of the PV community that compliance with codes costs too much and imposes performance penalties. These concerns are addressed in the following paragraphs.

Terrestrial PV power systems are well into the second decade of widespread application. With the number of PV systems increasing, there has come an expansion in the number and types of codes and standards that apply to PV systems. These codes and standards impact the design, installation, performance, and costs of PV systems.

Many systems use components manufactured and tested to the various standards published by the IEEE, the National Electrical Manufacturers Association (NEMA), and Underwriters Laboratories (UL). On the other hand, there are numerous PV components, both small and large, manufactured without adherence to any standard. While installations with either set of components may result in a similar degree of customer satisfaction, the use of listed (built and tested to a standard) components is rapidly becoming the established and legally required practice.

The National Electrical Code (NEC) and supplemental state, county, and municipal electrical codes govern the legal installation of PV power systems just as they govern the installation of other electrical power systems. Many PV systems are installed in a manner that meets the applicable codes. These systems are required to have components manufactured and tested to UL Standards.

Standards and codes are not developed arbitrarily. They are the product of many people working countless hours using professional experience and a knowledge of the current technology to write requirements and guidelines that will result in safe, durable, and high performance PV systems. These standards and codes are the joint product of a collaboration among the PV industry, standards developers like UL, the academic community, electrical inspection of ficials, and government agencies with input from the end user.

There are costs associated with installing systems that comply with the various codes and standards. There are also benefits for installing such systems, in terms of increased safety for users and maintainers as well as the potential for enhanced performance. On the other hand, there may be penalties for not installing code-compliant systems such as equipment failures, safety hazards, and failure to obtain occupancy permits. 
The system (and equipment) used for the generation, distribution, and end use of electrical power in the United States represents one of the most complex and safest systems in the world. The U.S. electrical power system performance and safety record is judged outstanding. This record is the result of a process of developing and applying safety and performance codes and standards to the electrical power system for over a century.

The end result is that the electrical utility industry uses a number of standards established by the IEEE for the generation, transmission, and distribution of electrical power. At the end-use facility, both the NEC and IEEE Standards apply to the equipment and installation of electrical systems.

The National Electrical Code (NEC-ANSI NFPA 70), published by the National Fire Protection Association (NFPA) establishes requirements for the installation of field-installed and wired electrical power systems. The NEC was first published in 1897 and has been revised and updated on a regular basis since 1911 by the NFPA.

The NEC does not cover electrical utility facilities used for the generation, transmission, and distribution of electrical power that are owned and operated by the utility on utility property. Neither does it cover electrical power systems in automotive vehicles, recreational boats, or railway cars. It does, however, cover house boats and recreational vehicles. Voltage ranges from zero to 40,000 volts and frequencies from direct current (dc) to radio frequencies are covered by the code.

The NEC Committee (charged with developing the code) is composed of a Technical Correlating Committee supervising and integrating the results of twenty NEC Panels that study, evaluate, and revise the entire NEC (over 1000 pages) every three years. The panels are composed of volunteer professionals representing the NFPA, UL, the International Association of Electrical Inspectors (IAEI), electrical equipment manufacturers, electrical installers unions, the academic community, and various other involved parties. Proposals from these panel members, other interested parties, and the general public are used to revise and update the NEC.

Photovoltaic power systems are addressed specifically in Article 690 (10 pages) of the NEC, but 80-90 percent of the rest of the 1000-page NEC applies to PV systems as it does to all electrical power systems. The PV industry, through the support of the Solar Energy Industries Association, has a member on Code Making Panel 3 (CMP-3) who votes on items dealing with PV systems in Article 690 of the NEC.

The NFPA has tasked CMP-3 to establish a Task Group to specifically address issues associated with PV systems for the 1999 NEC. This seven-person Task Group is supported by a Technical Review Committee of about 30 people representing all phases of the PV Industry. They are dealing with the code changes that will be required to implement advanced technologies such as those associated with the AC PV Module and Building Integrated PV Systems. The Task Group is also addressing the safety requirements associated with dc electrical systems that have not been updated in the NEC in recent years. The Task Group has been meeting about three times a year, and the activities will culminate with a set of proposals for the 1999 NEC that will be forwarded to the NFPA in November 1996.

While the NEC is just a published document, it has been adopted as a legal requirement in more than 40 states and in most large cities throughout the U.S. The NEC is supplemented by local jurisdiction codes in many areas. Enforcement of the NEC, where it has been adopted, varies significantly. In some areas only permits are required and the installer is charged with code 
compliance. In many areas, a comprehensive, rigorous inspection system has been established. The more intensive, extensive applications of the code are found in urban areas where high population densities have dictated stricter safety measures.

The NEC represents a set of installation requirements, and establishes requirements for the equipment used. All equipment installed under NEC requirements must be examined for safety. The electrical inspector or other authority having jurisdiction (AHJ) usually interprets this as a requirement that all equipment be tested and listed. Testing and listing is a formalized process, carried out by a few major laboratories, that verifies that the equipment meets standards written and published by UL. The NEC also requires that all equipment be installed in accordance with the conditions established by the listing, any applied markings or labels, and the instructions supplied by the manufacturer. Finally, the NEC requires that good workmanship be used and the inspector makes evaluations based on the experience with numerous non-PV residential and commercial electrical power installations.

The National Electrical Manufacturers Association (NEMA) publishes a number of standards that deal with the manufacture of equipment enclosures, wiring devices (plugs and sockets), batteries, conduits and raceways, and connectors, among other things. The NEMA and UL standards are both written to harmonize with the NEC, and much of the non-PV-related equipment such as enclosures and raceways are made to NEMA Standards.

Federal, state, and local governmental agencies usually specify compliance with certain IEEE Standards as well as with the NEC. These IEEE Standards deal with battery system design and installation, inverter performance, utility-intertie specifications and, in the near future, PV module qualification. The IEEE Standards establish performance as well as safety requirements.

\section{The Impact of Using Listed Components}

There are cost increments inherent in installing PV systems that comply with the NEC. In many jurisdictions, installation of any electrical system requires that permits be applied for and inspections be conducted on the finished work. The local jurisdictions also require that the installer have the appropriate business and professional licenses. Admittedly, permits and licenses cost money and, while the authority having jurisdiction may have less knowledge of PV systems than the installer, there is a strong case for having these PV electrical power systems permitted and inspected like other electrical installations. PV systems are used by and accessible to the untrained general public and must meet the necessary minimum safety standards. The permitting and inspection process provides an extra layer of safety and liability insurance to the installation. In many parts of the country it may be possible to install a PV system without a permit, but to do so in other areas is to break the law.

The NEC requirement that all electrical equipment be listed requires that standards published by UL be used to evaluate the safety of products used in the United States. Products are tested against these standards by UL, ETL, and other testing laboratories recognized by the local jurisdiction. Such mundane items as the twenty-five cent cover plate for the electrical outlet are listed. The costs associated with testing, listing, and follow-up services by these laboratories can vary greatly depending on the product. A PV load center made entirely from components that are themselves listed, may be relatively inexpensive (less than $\$ 10,000$ ) to have tested and listed. A PV charge controller that uses components that are only recognized (a less rigorous category of certification than listing) by the testing laboratories in a newly designed (non-listed) enclosure may require additional testing and additional costs before a listing can be issued. A PV component, such as a PV module, that is manufactured mainly from new (unlisted and unrecognized) components may require significant amounts of testing. Such testing may take 
more than a year, require the services of many people working in a number of different testing laboratories, and is not cheap.

It is not always easy to conform with the requirements of the published standards or the listing process. The component design must be relatively mature since any change, however small, in the materials or design must be reevaluated by the testing laboratory. Another point is that, unfortunately, some current PV components are not able to meet the safety standards without a complete redesign. The use of exposed terminals and flammable materials are generally not allowed in electrical power equipment.

The listing of all components is an NEC requirement and is being enforced by increasing numbers of jurisdictions. If no listed equipment is available in a particular category, the inspector may issue a waiver that allows unlisted equipment to be used. For PV systems, however, there are now listed components available in nearly every category, including sourcecircuit combiner boxes, load centers, charge controllers, and inverters, but excluding gasoline/propane/diesel-driven generators and batteries which are generally not listed.

Even in the non-listed category of batteries, there are some manufacturers that are making batteries that are recognized by UL. That means the batteries are made to the manufacturers specification (not to a UL Standard) and UL verifies that the batteries are consistently made to that standard.

While the cost may not be insignificant, the listing process does provide several significant advantages. PV systems that use listed components have access to a greater market than do systems with non-listed components. Listed components provide a well-defined liability trail should a PV system or component fail. When greater market penetration is added to the reduced liability issues associated with marketing a listed product, the costs of such listing are not at all imposing. In fact, the greater sales volume of listed products may allow the manufacturer to keep prices lower, provide newer technologies, and better customer services. Implicit in the listing process is the fact that a third party (the listing laboratory) is watching the manufacturing process very carefully and is very interested in hearing about and correcting faulty products.

\section{The Impact of Complying With the NEC}

Compliance with the NEC requires that proper types of cables, conductor sizes, overcurrent devices, and disconnects be used. A PV system could be assembled meeting none of these requirements (and many have), but safety and common sense seems to indicate that at least these items should be used and used correctly.

\section{Cables}

Increasing the size of the cable to the next larger size to meet the temperature-derated ampacity requirements of the NEC may increase the cost of the system as the table below shows. Using a wet-rated cable such as a THWN-2 conductor in conduit instead of a damp-rated conductor like THHN may cost a little more, but many cables are dual rated THHN/THWN-2 at the same cost as THHN. Most USE cables are triple rated USE-2/RHH/RHW-2, and can be used in free air as module interconnects and as conductors in conduit. 


$\begin{array}{rlr}\text { AWG } & \text { Type } & \text { Cost per 200' } \\ 12 & \text { THHN } & \$ 9.00 \\ 10 & \text { THHN } & 15.00 \\ 8 & \text { THHN } & 23.00 \\ 12 & & \\ 10 & \text { THWN-2 } & \$ 11.00 \\ 8 & \text { THWN-2 } & 17.00 \\ 12 & \text { THWN-2 } & 28.00 \\ 10 & \text { USE-2 } & \\ 8 & \text { USE-2 } & 19.00 \\ & \text { USE-2 } & 42.00\end{array}$

\section{Typical Cable Costs}

While large cables cost more than smaller cables, the use of larger cables results in lower voltage drops and less power loss and this may offset the added costs of the larger cables over a 20-year life of the PV system. The table below assumes that 25 amps of current is flowing from the PV array to the rest of the system over a 100 foot (one-way) length of cable. Number 12,10 , or 8 AWG cables could possibly be used to carry the 25 amps of current although the NEC might require number $8 \mathrm{AWG}$ conductors.

The power lost in each cable is shown in the table below. If the modules are about 50 watts each, the number 12 AWG conductor loses about five modules worth of power, the number 10 AW G cable about three modules worth of power, and the number 8 AWG cable about two modules worth of power. With modules priced at about $\$ 5.00$ per watt, switching from number 12 AWG to number 8 AWG would save about $\$ 600$ (3 modules x 40 watts/module $\times \$ 5 /$ watt). The $\$ 23.00$ price differential for using the number 8 AWG USE-2/RHW-2 is very much less than the $\$ 600$ worth of lost module output.

$\begin{array}{lccccc}\text { AWG } & \text { Current } & \text { Ohms/200' } & \text { Voltage Drop } & \text { Power Lost } & \text { Equivalent Modules } \\ 12 & 25 & 0.396 & 9.9 & 248 & 5 \\ 10 & 25 & 0.248 & 6.2 & 155 & 3 \\ 8 & 25 & 0.1556 & 3.89 & 97 & 2\end{array}$

Power Losses in 200 ' of cable at 25 amps

Overcurrent Protection

The addition of fuses costs more than using no fuses, but there are few PV designers and installers that would be willing to install a PV system without some type of overcurrent protection. DC-rated fuses cost more than ac-rated fuses. In some cases, DC-rated circuit 
breakers like the Square D QO breakers cost less than DC-rated fuses and fuse holders. When Square D QO circuit breakers are used on 12-volt PV systems, the total cost of the breaker and the enclosure is usually less than the cost of a similarly rated fuse, fuse holder, and enclosure. The installation of the circuit breaker is considerably easier also.

PV systems with batteries can deliver very high short-circuit current, so the battery circuits should always contain current-limiting fuses to protect other circuits and components. In some cases, these fuses can be eliminated by installing circuit breakers with high interrupt capabilities (such as the Heinemann E-Frame units) throughout the system. Original Equipment Manufacturers (OEM) can implement cost-effective solutions such as these because custom enclosures are required.

\section{Performance Impact}

The impact on performance that compliance with the NEC and other standards may have has been the subject of much discussion. Several areas that have received attention are discussed below.

Code compliance requires that several devices be added to the system that may affect performance. The NEC requires that all conductors be protected from overcurrents from all sources. It also requires that disconnects be provided so that all sources of power can be disconnected from the system; and requires that system components can be isolated from all sources of power during servicing. These safety requirements are specified so that the unqualified (untrained, general public) person can safely operate the equipment without electrical shock hazards and that faults in the field-installed wiring will trip the appropriate protective device with little damage to the equipment or surroundings. The NEC requirements are also designed to allow the unqualified person to reset or replace tripped overcurrent devices without coming into contact with electrically live contacts.

These extra components may create losses in the system. Admittedly, each electrical component that is added to a PV system such as a diode, switch, fuse, or circuit breaker has some resistance that results in a measurable voltage drop and some measurable power loss. In small, 12-volt systems that are used for remote, stand-alone power, these losses may pose problems - especially where adequate attention has not been given to the overall system design. In these systems, night-time battery voltages are normally below 12 volts, and excessive voltage drops can affect the operation of 12-volt, dc appliances.

However, with proper design and suitable components, even in 12-volt systems, these voltage drops and losses can be tolerated. In the larger, higher voltage systems (or systems with inverters), these small losses are not as critical, and the overall design process usually takes them into account. Often, adherence to NEC requirements may result in enhanced, rather than reduced, system performance.

Circuit breakers generally have less power losses and voltage drops than fuse/switch combinations because the circuit breakers have fewer contacts and connections. The use of higher-quality, magnetic-trip circuit breakers can result in less losses than the use of thermal-trip circuit breakers because the internal resistances are lower.

The NEC requires that all conductors be large enough in size (American Wire Gage-AWG) so that they never carry more than $80 \%$ of their rated current (ampacity) on a continuous basis. The NEC also requires that conductors be derated (oversized) for the ambient operating temperature, which in the case of PV modules may be as high as $70-80^{\circ} \mathrm{C}$. Both of these requirements result in conductor sizes that are larger than would otherwise be installed. The larger conductors yield 
better performance through lower voltage drops and less power loss as shown in the tables above.

A listing by a testing organization indicates that a component has passed a number of rigorous safety tests which results in fewer problems in the field. While these tests may not be directly related to performance, they do ensure that the components are robust enough to withstand heavy-duty usage (e.g., the interrupting of direct-current (dc) circuits). A robust construction will result in better performance (lower losses) than can be obtained with a component that is not designed well enough to pass the listing tests. For example, a few installers (mostly do-it-yourself homeowners) have used switches rated for ac-only in the dc circuits of PV systems. These switches quickly develop high resistance and fail to operate on the dc circuits. Switches rated and listed for operation on DC circuits do not experience such problems.

The use of automotive electrical components such as the inexpensive plastic-bodied automotive fuse may reduce cost, but may also reduce performance and create significant safety problems. These fuses, and the earlier glass and ceramic auto fuses, are designed to operate in relatively high resistance circuits where the available short-circuit currents are low. They have little interrupt capability and, when called upon to open a high-current fault on a low-resistance renewable energy system, they may explode, melt or catch fire.

Proper grounding of the PV system, as required by the NEC, may also result in enhanced performance from reduced radio frequency interference (from inverters and fluorescent lamps) and better protection from lightning-induced surges. Equipment grounding of the metal housings on 12-volt fluorescent lamps has been shown to improve lamp starting at low voltages.

Surge suppressers (required by the NEC) do not, when properly rated, result in any deterioration in the performance of a PV system and may reduce damage to conductors and equipment when nearby lightning strikes occur. Surge suppressers, when used in conjunction with blocking diodes and the NEC-required overcurrent devices, may provide even more system protection.

\section{Safety vs. Performance}

Performance must be balanced with the need for safety and reliable operation. Safety is one of the first requirements for any PV installation that is going to be accessible to the general public. The PV system must be at least as safe as any other electrical power system.

Safety must also be addressed as it impacts the normal operation and maintenance of the system. Although a qualified, well-trained, and experienced person might install the system, there is little reason to expect that operation and maintenance will be carried out by such a person. Since the installer is not continually on-site, the system must stand alone not only in an operational sense, but in a safety sense. Following NEC requirements will result in a system design that can be operated and maintained in a relatively safe manner.

There are, however, exceptions from certain safety requirements in the NEC if it can be ensured that the system is accessible only to qualified persons. This generally points to the PV system that can be fenced and locked so that the general public and untrained persons do not have access under any condition. The NEC does, however, dictate some safety requirements to allow for safe system maintenance, even by qualified persons. For example, there should be adequate working clearances around the storage batteries used in PV systems so that water can be added and the terminals tightened without danger of shocks, acid splashes, or short circuits. 


\section{The Bottom Line}

In a system using listed components that has been installed following the requirements of the National Electrical Code, safeguards are available that minimize the hazards to persons and the damage to equipment when these unexpected events occur. There will be a battery disconnect switch that can be quickly opened when the batteries in the garage are hit by an automobile. Overcurrent devices automatically open when cables are accidentally shorted by a nail in a wall. The fire department will have access to switches that can be used to shut down the system if necessary in the case of fires. During normal operation by the untrained, unqualified user, switches are available that allow the batteries, fuses, and other components to be safely serviced.

Systems are not always installed or operated in optimum or benign environments. Insulation on conductors may be accidentally damaged during installation or at a later time by environmental factors or mechanical abuse. Components may be stressed physically or electrically by unanticipated operating or environmental conditions. Thermal cycling, inherent in the daily operation of a PV system, may pose unanticipated stresses on the system.

PV systems may certainly be designed and installed without regard to any codes or standards and without the use of any listed components. Such systems may operate satisfactorily for years. There are no guarantees that a system that is installed with listed components in full compliance with the NEC and other applicable standards will operate reliably and perform at high levels. In each case, the basic system design usually determines the level of performance.

In the non code-compliant system, few, if any, safeguards are available. There may be no way for the user or the maintainer to shut the system down for normal repairs or for an emergency. In the event of system failure and/or damage to property, there is no well-defined legal chain of liability.

In the code-compliant system, the following all work in a carefully defined, integrated manner to ensure the success and durability of the PV system:

- Developers of the standards

- Testing and listing agencies

- Manufacturers of listed components

- Developers of the NEC and other codes and standards

- Licensed installer who follows the NEC

- Permitting authority

- Local jurisd iction

- Electrical inspector

- Insurance company

PV systems that are designed and installed in full compliance with the NEC by licensed installers and fully inspected will receive wider acceptance by the general public and the institutional customer. Photovoltaic power systems have the highest probability of success when they are planned and installed by a team consisting of the owner/user, the PV designer, a licensed installer, and the electrical inspector. 


\section{References}

National Electrical Code ${ }^{\circledR}$ and NEC ${ }^{\circledR}$ are registered trademarks of The National Fire Protection Association. The 1996 NEC and the NEC Handbook are available from the NFPA • 1 Batterymarch Park • Quincy, MA 02269-9101 • 800 344-3555 • 617-770-3000.

UL is a registered trademark of Underwriters Laboratories • 333 Pfingsten Road $\bullet$ Northbrook, IL 60062.

IEEE Standards are published by the Institute of Electrical and Electronics Engineers $\bullet 445$ Hoes Lane $\bullet$ Piscataway, NJ 08855.

NEMA Standards are published by the National Electrical Manufacturers Association • $2101 \mathrm{~L}$ Street NW • Suite 300 • Washington, DC 20037. 


\section{Advanced Test and Burn-in Program for Photovoltaic Inverters}

\section{Christopher Freitas}

Trace Engineering Company, Inc.

Arlington, WA 98223 


\title{
Advanced Test and Burn-in Program for PV Inverters
}

\author{
What? What is an "advanced" test and burn-in program? \\ Why? Why do we need it? \\ How? How will it be done? \\ When? When will the it be implemented?
}

This test and burn-in program will be used with the SW series inverter/charger currently in production

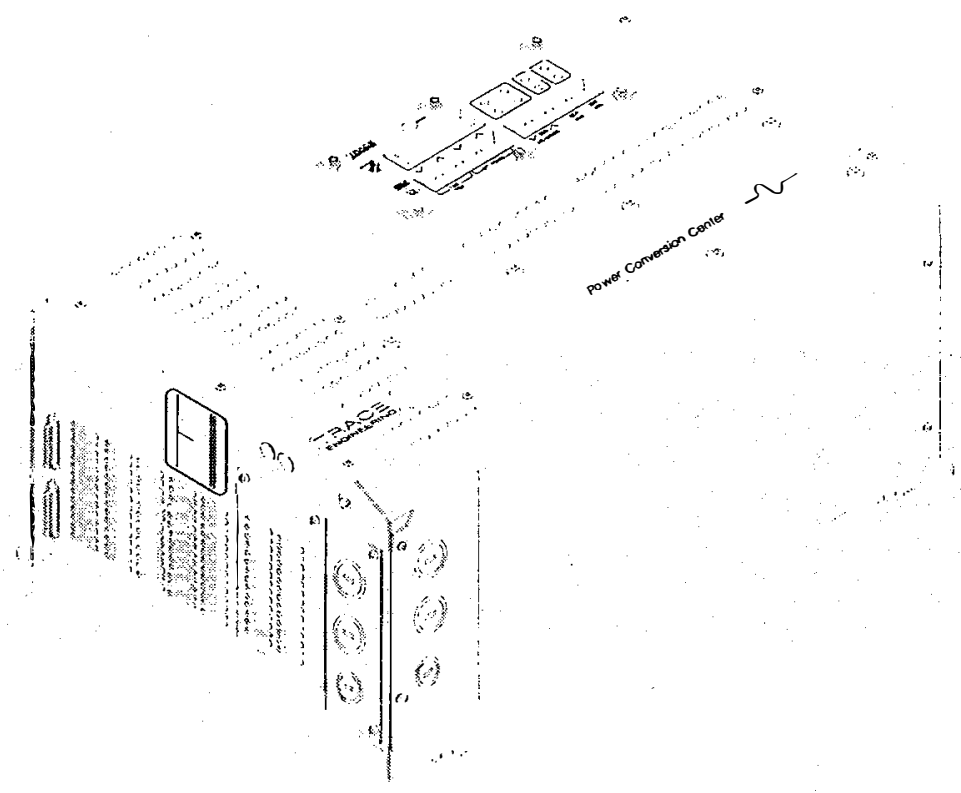




\section{What is an advanced test and burn-in program?}

Our Definition of an advanced test and burn-in program is one that is ...

- Automated - computer controlled

- Monitored - critical variables are measured

- Extensive - involves all the operating modes

- Includes Data Collection - enables comparisons

The tests will be completed by a computer controlled system together with the inverter's built in hardware and software systems. 


\section{Why do we need an advanced test and burn-in program?}

Increased Product Complexity

- three microprocessors

- three power sections

- two AC inputs (grid and generator)

- multiple operating modes (inverting, charging, selling ...)

$\underset{\text { w }}{w} \quad$ Limited Number of Technicians

- steep learning curve for new technicians

- testing is often the biggest bottleneck for production

- reduces possibility of human error 


\section{Why do we need an advanced test and burn-in program?}

Increases Product Quality

- allows more test to be done

- enables monitoring of more variables

- reduces possibility of missed problems

Lower Cost

- will be cheaper to have a computer do the tests

- allows fewer technicians

- reduces overtime (able to test 24 hours a day)

Reduces Product Variability

- allows monitoring of product variations

- ensures consistent quality 


\section{How will the advanced test and burn-in be done?}

New Serial Communications Adapter

- provides RS-232 serial communications between an inverter and a $P C$ type computer's serial port

- includes addressing to allow up to 127 inverters on a single serial port

- already developed - plugs into existing remote port

- low cost, surface mount design uses standard phone connectors

- includes EEPROM memory for loading settings needed for the tests

Why communications was NOT built into the inverter originally

- reduced the complexity of the inverter

- allowed faster development

- reduced cost (if not needed)

The separate adapter allows testing of previously built SW series inverters and is retrofittable in the field for upgrading existing systems with communications or non-volatile memory for the programmable settings 


\section{How will the advanced test and burn-in be done?}

Variables monitored and recorded by the computer during test and burn-in

- $A C$ voltages at input and output

- AC current in and out of inverter

- battery or PV array DC voltage

- main transformer temperature

- transistor heatsink temperature

- fan speed

- error flags (over-current, over-temperature, out of regulation ...)

- operating mode (charging, inverting, selling ...)

- relay operation

- internal supply voltages 


\section{How will the advanced test and burn-in be done?}

Initial testing completed by technician (approximately 10 minutes)

- visual inspection (subassembly ID numbers, terminal blocks, wires ...)

- low power testing (waveform, regulation, relays, fans, idle current ...)

- high power testing of basic modes (inverting, charging, motor start ...)

- testing of protection systems (over-current, backfeed, islanding ...)

ज Extensive testing completed via the computer interface (4 to 24 hours)

- repetitive cycling on - off ( +100 times)

- continuous high power inverting

- continuous high power charging

Results of the testing

- pass / fail tests (on/off cycling, regulation, meters, error flags)

- thermal signature print-out and pass/fail determination 


\section{What is a Thermal Signature?}

A graphical representation of the internal temperatures over time during the burnin process. It provides a simple way to check the inverter's construction and performance.

TYPICAL THERMAL SIGNATURE OF AN SW SERIES

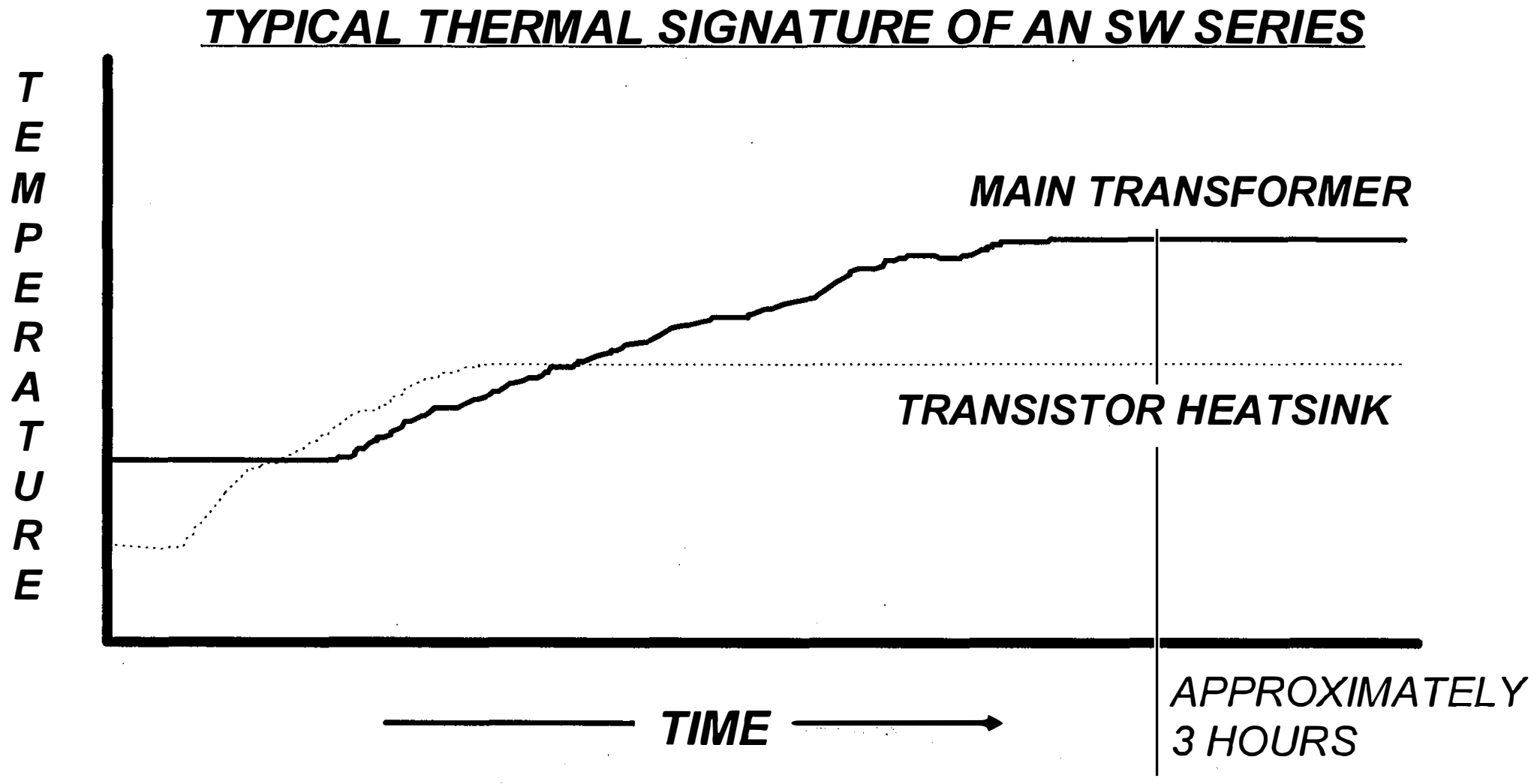




\section{Why use a Thermal Signature?}

\section{Several Advantages}

- easy to understand and evaluate

- some components are only easily measured by this method

(such as paralleled MOSFETs and transformer construction)

- can be used to spot a component failure during burn-in

- provides verification of the burn-in process to customer

- provides a "history" of inverter performance for future comparison

- construction problems reduce efficiency which shows up as heat

- provides continuous "feed back" from production to engineering 


\section{Test and Burn-in Configuration}

Uses pairs of inverter connected together

- AC output of the "inverter" is connected to AC input of the "charger" (small DC source makes up for losses in inverter/chargers)

- one inverts while the other battery charges

- positions are swapped during burn-in

- reduces energy consumption

- allows testing of unusual AC output models - $50 \mathrm{~Hz}, 100 \mathrm{VAC}$ etc.

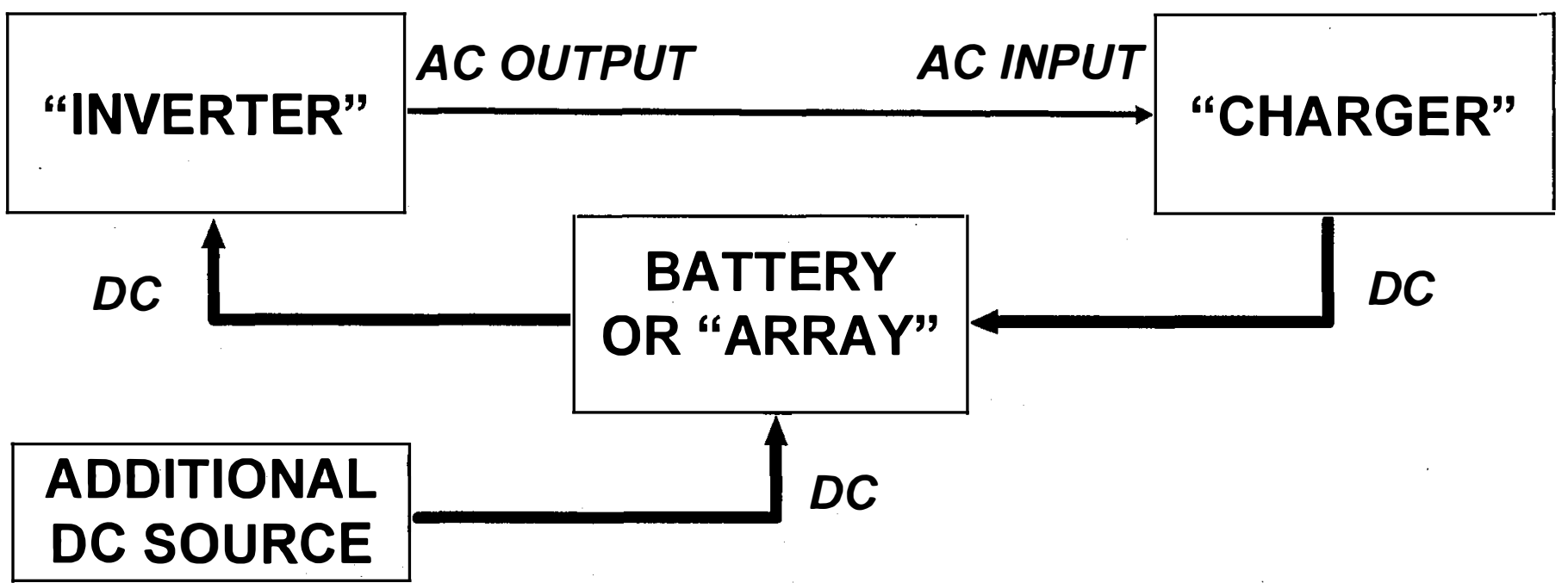




\section{Summary}

An advanced testing and burn-in program will allow ...

- higher quality products

- better reliability

- lower cost

- increased production capacity

- tracking of quality and performance variability

Is based on existing hardware

- reduces implementation cost and difficulty

Will be implemented in the winter of 1996

- for the PV only version of the SW series inverter first, then all SW series inverters

This program is the result of development work continued by Trace Engineering from projects funded by the Department of Energy through Sandia National Labs and the National Renewable Energy Laboratory 


\title{
OMNION POWER ENGINEERING CORP.
}

The PCS - An integral component of system performance and reliability.

NREL

PV Performance and Reliability Workshop

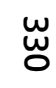

\author{
Sheraton Hotel \\ Lakewood, Colorado \\ September 5, 1996
}

OMNION 
The PCS Impact on System Performance/Reliability:

-vital and complex link

-overview of PCS related to systems

-performance

-system availability

-How PCS (System) Reliability/Performance can be Improved:

-NREL - PVMAT program

-Sandia - support

-UPVG - support

-PV industry- support

x: 
-Learning and Educating

-UPVG (utility input on power systems)

-Utility expected robustness

-utility protective requirements

-system integrators

-PCS manufacturers (project design support)

-utility (project design support) 
BOS/PCS Advancement:

-What's been done

-manufacturing

-industry

-National Laboratories

-What's being done

-manufacturing

-industry

-National Laboratories

-What's needed to continue the journey

-manufacturing

-industry.

-National Laboratories 
System Design Impacts on the PCS:

-Electrical

-PV parameters

-utility grid considerations

-Physical

-installation

-start-up

-Maintenance

-How forming teams minimizes impact 


\section{PCS - Failure vs. Shutdown:}

-Shutdowns

-system not available

-causes

-specifications/requirements

-system parameters

-education/communication

-PV variances

-utility requirements

$\stackrel{w}{\sim}$

-Faults

-system not available

-PCS reliability

-understanding system parameters 
PCS and Overall System Performance:

-PCS Performance

-efficiency

-standards (IEEE, FCC, P.F.)

-robustness - utility grade

-new technologies

-System Performance Dependent on PCS Parameters

-efficiency

-utility grid parameters

-PCS/System Safety

-UL

-NEC

-Independent Performance and Reliability Certification 
PCS Improving Reliability:

-manufacturing database

-manufacturing QA/Reliability

implementation (design to operation)

-standardization of product vs. custom designs

-manufacturing process and QA/QC

(volume vs. custom)

-continuous improvement cycles

-robustness

-utility grade

-less sensitive

-self protective

-utility input required 
Typical Field Failure Analysis Database

(31 systems, 83 machine years, 1990 - 1996)

Type

Component

Site/Application

$\stackrel{w}{\infty}$

PCS Design

Manufacturing

Process

Other

OMNION
Occurrences

24

5

3

Unanticipated events.

3

2

Mfg. and customer
non-conformance.

Cause

Component failure.

Not determined.

Vendor \& mfg. assembly.

Mfg. and customer non-conformance.
Solution

Mfg. QA/QC

$\&$ lab support.

Education/ teaming/ lab support.

Mfg. QA/QC $\&$ lab support.

Mfg. QA/QC and lab support.

Mfg. QA/QC customer interaction. 
PCS System Availability Improvement:

-PCS reliability

-PCS specified protection/control

-utility requirements (lockout vs. restart)

-standardization

-Utility grid POC

-outages

-transients

-local loads

-protective relay coordination 
Where we are at:

-Present - QA/QC

-on-going field failure analysis

-on-going factory failure analysis

-on-going vendor supply non-conformances

-continuous improvement

-Future

-Continued work with NREL, SNL, UPVG

-Continued team efforts with system integrators

-Manufacturing analysis and implementation of corrective actions

-Manufacturing volume of standard product

-Manufacturing QA/QC (design - system operation) 
Summary:

-Field failure recording/analysis

-Extensive design testing (standard product)

-Standardization of product

-Minimize component count

-Manufacturing line process

-Comprehensive unit testing

-Quality assurance and reliability standards

-implemented in all corporate processes

-design - system operation

-Continued support for PCS reliability/performance

-System design support by PCS manufacturer and utility

education (system integrator development team)

-Define protective schemes

-Certification process

-External impacts 


\title{
PHOTOVOLTAIC HYBRID SYSTEM PERFORMANCE COMPARISONS: PREDICTION VERSUS FIELD RESULTS
}

\author{
Steven Durand - Andrew Rosenthal \\ Southwest Technology Development Institute, Las Cruces, NM \\ Mike Thomas, Sandia National Laboratories, Albuquerque, NM
}

\begin{abstract}
A photovoltaic hybrid power system consists of a PV array and inverter that operate either alternately or in parallel with a conventional engine-driven generator. At present, hybrid power systems are being used to supply singlefamily residential, communications, and village power. This paper analyzes the various design constraints of such systems and suggests design changes that can improve overall system performance in some cases.

The Southwest Technology Development Institute (New Mexico State University), under contract to Sandia National Laboratories and the National Renewable Energy Laboratory has installed data acquisition systems (DAS) on a number of hybrid PV power systems. These range from small residential systems to village-scale systems. A present, even larger systems are being installed with hundreds of kilowatts of PV modules, multiple wind machines, and multiple diesel generators.
\end{abstract}

\subsection{Potential Advantages}

The goal of most hybrid-system designs is to make practical and efficient use of each subsystem while minimizing the disadvantages of having potentially redundant generation capacity. Compared to conventional, diesel-only generation, some of the potential advantages of hybrid systems include reduced fuel requirements, lower maintenance costs, and improved system availability.

Hybrid power systems reduce fuel consumption in two ways. First, the use of renewable energy generation offsets some of the fossil fuel requirements. Second, hybrid systems can be designed to operate the generator at higher, more fuel-efficient output levels.

System availability may be improved by the inherent redundancy offered by hybrid power systems. If sized correctly, either the inverter or the generator can be used to meet the critical loads during unscheduled maintenance. Often, this requires automatic alarms that notify maintenance personnel when prompt repair is necessary.

Lower operation and maintenance costs are obtained by reducing the number of diesel generator runtime hours and by being better able to predict when maintenance is required. Automatic or unmanned operation also has the potential for reducing costs.

The following sections review data from a number of installed hybrid systems to examine how well various designs have been able to realize these potential advantages. Evaluating hybrid systems by operational mode will also be introduced as a method of determining total system performance.

\subsection{Evaluating Hybrid Systems by Operational Mode}

The operation of the different elements of a hybrid power system vary with time. Assessing system performance characteristics by operational mode is useful for understanding hybrid system performance under widely variable loading. The first five modes of operation listed in Table 1 are normal hybrid operational states. The sixth mode represents operating periods not easily placed in any of the other operational states and includes nonhybrid, transitional, and fault operation. System operation is categorized into particular modes by determining the energy path. As an example, Mode 2 operation is selected when the PV array and the battery are both supplying power to the facility load through the inverter.

Table 1. Hybrid System Operational Modes

\begin{tabular}{|c|l|}
\hline \hline Mode & \multicolumn{1}{|c|}{ Description } \\
\hline 1 & $\begin{array}{l}\text { Source = Battery } \\
\text { Load = Facility }\end{array}$ \\
\hline 3 & $\begin{array}{l}\text { Source = PV + Battery } \\
\text { Load = Facility }\end{array}$ \\
\hline 4 & $\begin{array}{l}\text { Source = PV } \\
\text { Load = Facility + Battery } \\
\text { Source = PV + Generator } \\
\text { Load = Facility + Battery }\end{array}$ \\
\hline 5 & $\begin{array}{l}\text { Source = Generator } \\
\text { Load = Facility + Battery }\end{array}$ \\
\hline 6 & Faults and Non-hybrid Operation \\
\hline
\end{tabular}

System performance efficiency in any one the modes becomes important as the time and energy transferred in that mode increase. An example of this type of analysis is given for the Carol Spring Mountain system. 


\subsection{Carol Spring Mountain Example}

The Carol Spring Mountain (CMS) photovoltaic hybrid system is located in the Salt River Canyon Wilderness, about 22 miles northeast of Globe, Arizona, along US Route 60 . The site is located at latitude $33.67^{\circ}$, longitude $110.57^{\circ}$, and altitude $2012 \mathrm{~m}$. A variety of telecommunication loads are located on the top of Carol Spring Mountain including telephone and television repeaters. Arizona Public Service Company (ASP) has historically provided power to the facility using a diesel generator for customers such as AT\&T, Bell Atlantic, US West, Salt River Project, Department of Public Safety, and NewsWeek-Post cable television. A $25 \mathrm{~kW}$ photovoltaic system was installed on the south rim of the peak in July 1995.

The CSM hybrid system consists of the following equipment:

- An Abacus 639-4RA Bimode, three-phase, $30 \mathrm{~kW}$ (120/208 volts) inverter and battery charger

- A $53 \mathrm{~kW}$ diesel generator

- An Abacus maximum power tracker array controller

- $\quad 96$ GNB Absolite IIP type 1-100A51 batteries

- 90 ASE Americas (ASE-300-DG/50) PV modules

Data collection from an on-site Data Acquisition System (DAS) started in January 1996. The DAS not only collects hourly performance data but also monitors system operation by mode. Figure 1 shows the percentage of time the system operated in each of the six modes for March 11-31,1996.

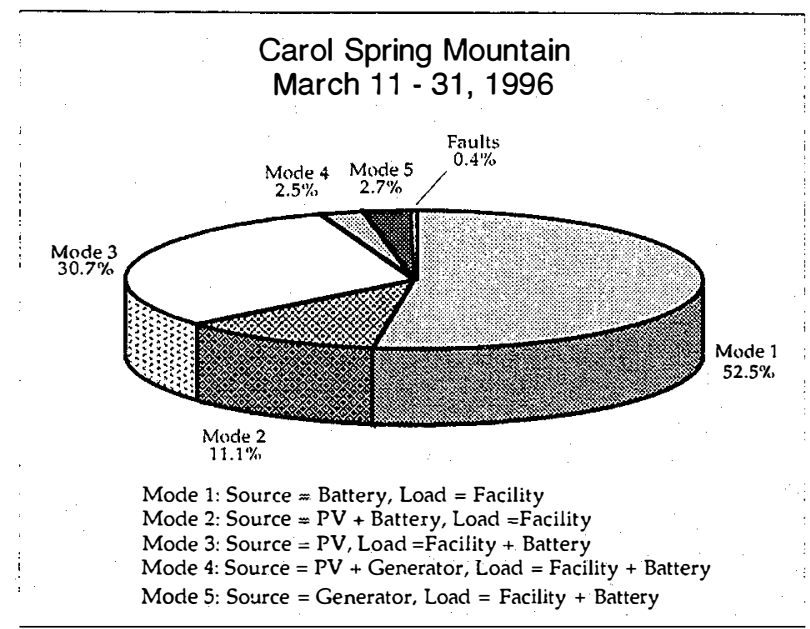

Figure 1. Percentage of Operating Time

Figure 2 shows the energy transferred in each of five hybrid modes. Total system efficiency for the period monitored was $71 \%$. Of the $4,420 \mathrm{kWh}$ produced by the
PV array and the diesel generator, 3,140 kWh were supplied to the facility load, while 1,280 kWh were dissipated in system losses, including battery roundtrip efficiency losses. To investigate the cause of these energy losses, the system performance by mode is examined.

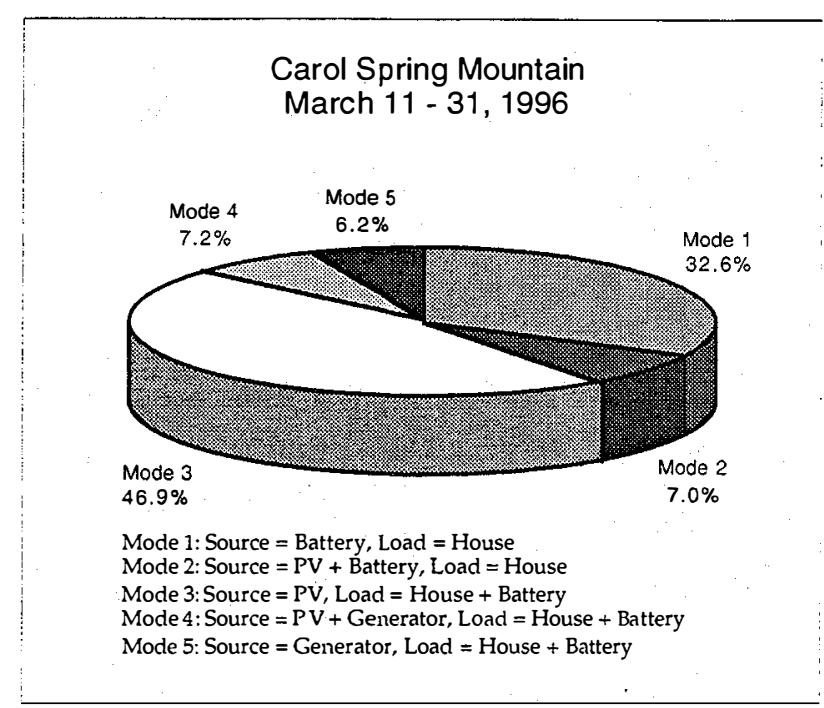

Figure 2. Energy Transferred by Mode

The system operated $52.5 \%$ of the time and transferred $32.6 \%$ of the energy in Mode 1 . Mode 1 is primarily nighttime operation at Carol Spring Mountain. This means the battery is being discharged and the ac load is being supplied solely by the inverter. The system efficiency in Mode 1 is $75 \%$ and is basically equal to the efficiency of the inverter. The inverter is being operated at only $22 \%$ loading $(6.2 \mathrm{~kW}$ out of $30 \mathrm{~kW})$ during the monitored period, which explains the relatively low inverter efficiency.

The percentage of operational time and energy transferred recorded for all five modes of operation are given in Table 2. (Modes 2 and 4 are basically combinations of Modes 1 , 3 , and 5.) One issue illustrated by this example is that the hybrid system was successful in reducing the engine runtime. The generator operated less than $6 \%$ of the time.

Table 2. Carol Spring Mountain Performance by Mode

\begin{tabular}{|c|l|c|c|}
\hline Mode & \multicolumn{1}{|c|}{ Description } & $\begin{array}{l}\% \text { of } \\
\text { Op } \\
\text { Time }\end{array}$ & $\begin{array}{l}\% \text { of } \\
\text { Energy } \\
\text { Transferred }\end{array}$ \\
\hline \hline 1 & $\begin{array}{l}\text { Source = Battery } \\
\text { Load = Facility }\end{array}$ & 32.5 \\
\hline 2 & $\begin{array}{l}\text { Source = PV + Battery } \\
\text { Load = Facility }\end{array}$ & 11.1 & 7.0 \\
\hline 3 & $\begin{array}{l}\text { Source = PV } \\
\text { Load = Facility + Battery }\end{array}$ & 30.7 & 46.9 \\
\hline 4 & $\begin{array}{l}\text { Source = PV + } \\
\text { Generator } \\
\text { Load = Facility + Battery }\end{array}$ & 2.5 & 7.2 \\
\hline 5 & $\begin{array}{l}\text { Source = Generator } \\
\text { Load = Facility + Battery }\end{array}$ & 2.7 & 6.2 \\
\hline
\end{tabular}




\subsection{Desert Studies Example}

Southern California Edison installed a $10 \mathrm{~kW}$ photovoltaic/propane hybrid system at the Desert Studies Research site near Zzyzx, California. The research facility was previously powered by a single diesel generator. The system consists of a $20 \mathrm{~kW}$ Onan propane generator, a 10 $\mathrm{kW}$ photovoltaic array composed of 160 Solarex MSX60 modules, a 48-volt, 5180 amp-hour battery bank composed of 32 GNB 3-85A31 assemblies, and two $8 \mathrm{~kW}$ Dimensions Unlimited inverters. The load consists of 5 residences and two laboratories. The system provides power 24 hours/day and has about 10 days of battery storage.

The total system efficiency for the period of January 1995 through December 1995 was 55\%. This low efficiency is primarily the result of very low inverter loading. The average load is about $2 \mathrm{~kW}$. This means that the two 8 $\mathrm{kW}$ inverters are only loaded to about $12 \%$ of their rated power.

\subsection{NYPA Hybrid Site Example}

The New York State Research and Development Division, in conjunction with the New York Power Authority, installed a photovoltaic/propane hybrid system at a private residence near Ticonderoga, New York. The system is nominally comprised of a $5 \mathrm{kVA}$ Onan propane generator, a $1 \mathrm{~kW}$ array consisting of 16 Siemens modules, a 48-volt, 450 amp-hour battery bank consisting of twenty four IBE $75 \mathrm{~N}-13$ cells, an Ananda Power Technologies system controller, and two $2.5 \mathrm{~kW}$ Trace Engineering Company, Model U2548SB inverter/battery chargers. The system was installed in late 1993 and has about one day of battery storage.

In this case, the total system efficiency for the two-year period, January 1994 through December 1995, was 53\%. As in the case of Desert Studies, this efficiency value is primarily a function of the average load size. The average load for the period is about $0.3 \mathrm{~kW}$. This loads the two 2.5 $\mathrm{kW}$ Trace inverters to about $6 \%$ of their rated output. The recorded inverter efficiency curve of the NYPA system for May 1994 is shown in Figure 4. These data show that the combined inverters operated below 600 watts $92 \%$ of the time.

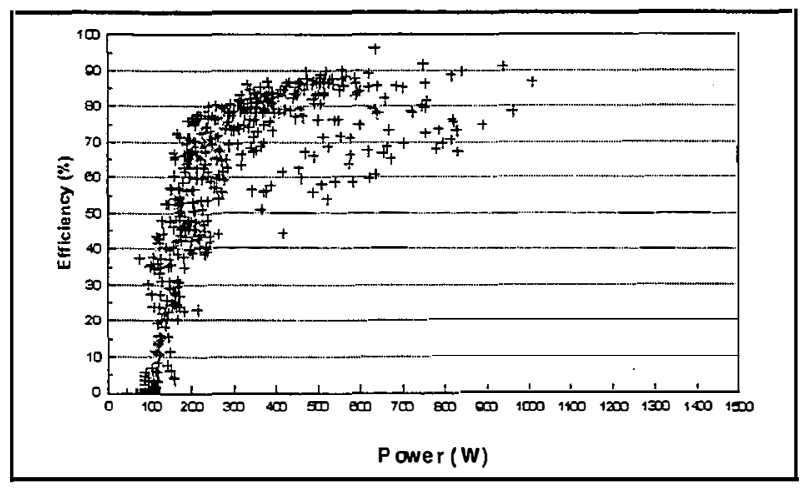

Figure 3. NYPA Site Trace inverter efficiency for May 1994

\subsection{NYSEG}

The New York State Research and Development Division, in conjunction with New York State Energy and Gas (NYSEG), installed a photovoltaic/propane hybrid system at a private residence near Plattsburg, New York. The system is nominally comprised of a $4 \mathrm{kVA}$ Kohler propane generator, a $900 \mathrm{~W}$ array consisting of 12 Siemens PC4F75, 75-watt modules, a 48-volt, 450 amp-hour battery bank consisting of twenty four IBE $75 \mathrm{~N}-13$ cells, an Ananda Power Technologies system controller, and a 4 kW Trace Engineering Company, Model SW4048 inverter/battery charger. The system was installed in 1994 and has about one day of battery storage.

For this system, the overall operating efficiency for the period of January 1995 through December 1995 was 70\%. This is higher than the NYPA system efficiency previously mentioned. The average load was again about $0.3 \mathrm{~kW}$. The $4 \mathrm{~kW}$ Trace inverter was loaded on average to about $7 \%$. This inverter has higher efficiency at low loading, which greatly impacts the total system efficiency.

\subsection{General System Performance}

The total-system efficiencies for the four systems, including battery losses are shown in Table 3 . All of the listed systems are well designed and built and are operating as designed. The low efficiencies are observed because, in all cases, the installed inverters and generators were each sized to meet the peak load with no regard to power factor or power quality.

Table 3. Measured System Efficiencies

\begin{tabular}{|l|c|c|}
\hline $\begin{array}{l}\text { Site Name/ } \\
\text { Location }\end{array}$ & Data Period & $\begin{array}{l}\text { Total System } \\
\% \text { Efficiency }\end{array}$ \\
\hline \hline $\begin{array}{l}\text { Carol Spring } \\
\text { Mountain, AZ }\end{array}$ & March 96 & 71 \\
\hline Desert Studies, CA & Jan 95- Dec 95 & 55 \\
\hline NYPA, NY & Jan 94 - Dec 95 & 53 \\
\hline NYSEG, NY & Jan 95 - Dec 95 & 70 \\
\hline
\end{tabular}

\subsection{Effects of Subsystem Performance on Total System Performance.}

Typically, for diesel-only systems, the diesel generators operate on the low end of the efficiency curve most of the time, Figure 4. Fuel efficiencies of lower than 5 $\mathrm{kWh} /$ gallon are not uncommon. When these systems are included in a hybrid system, the diesel generators are used primarily to charge the batteries and are operated at higher loads in a more fuel efficient manner, Figure 4. Fuel efficiencies of greater than $10 \mathrm{kWh} /$ gallon are attainable. This results in an approximate doubling of the useful energy produced for the same quantity of fuel consumed. 


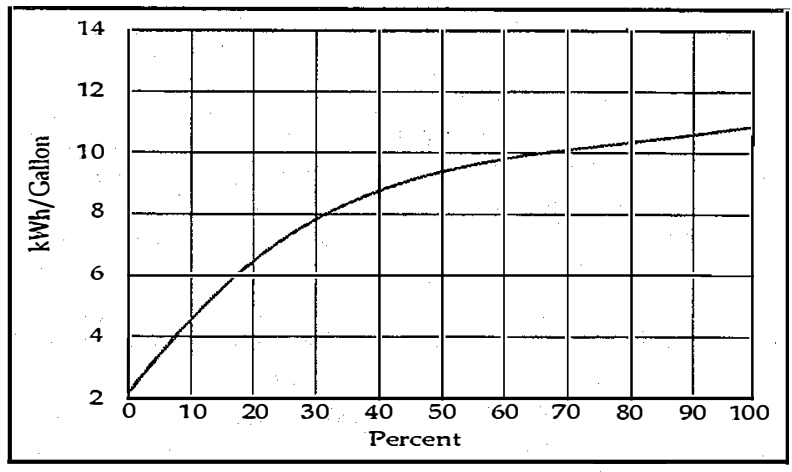

Figure 4. General Diesel Generator Fuel Efficiencies

\subsection{Conclusions}

The goal of installing a hybrid system is to realize the potential advantages of reduced fuel use, lower operation and maintenance cost, and greater availability than dieselonly systems. The installed hybrid systems investigated in this study do realize some of these potential advantages but have lower total system efficiencies than expected. To investigate the determining factors of total system efficiency, the relationship of fuel consumption to renewable energy production was determined, Figure 5. To generate these data the following assumptions were used: the diesel generator fuel efficiency (as a diesel-only system) averaged $5.5 \mathrm{kWh} /$ gallon; the diesel generator fuel efficiency (as a hybrid system) averaged 10.0 $\mathrm{kWh}$ /gallon. These numbers were obtained from generalized Caterpillar production curves for a model C398 diesel generator.

Figure 5 indicates that if the original goal was to reduce fuel consumption by $50 \%$ compared with the diesel-only system and the total system efficiency of the hybrid system is about $55 \%$ (similar to the Desert Studies system discussed earlier), then the renewable production required is about $90 \%$ of the pre-existing load. If the total system efficiency is improved to $70 \%$, then the renewable production required can be reduced to about $50 \%$ of the pre-existing load.

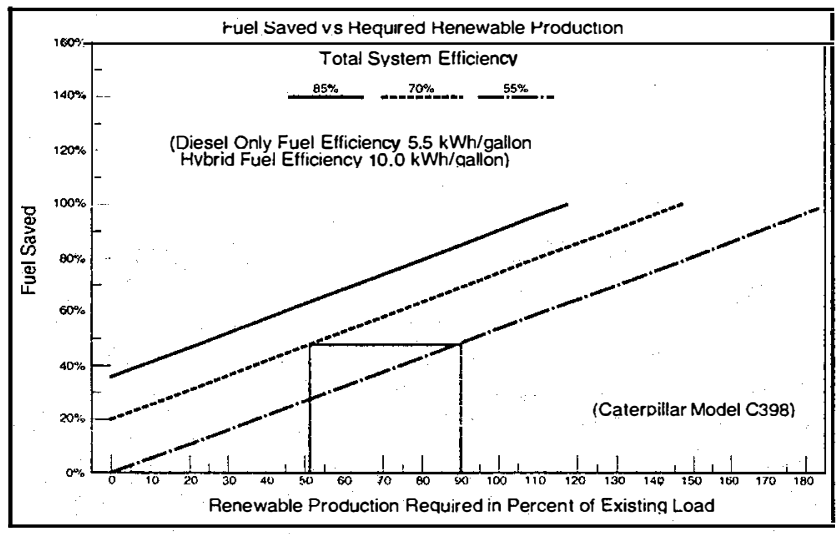

Figure 5. Fuel Saved vs. Required Renewable Production

\subsection{Recommendations}

To improve hybrid system cost competitiveness, the overall system efficiency of the installed system must be kept as high as possible. This can be accomplished by implementing some of the following design changes.

Power conditioning systems should be designed to have higher efficiencies at the low end of their operating range. One obvious solution would be to develop inverters with greater than $95 \%$ efficiency from $1 \%$ to $20 \%$ loading. At the present time, such hardware is not available. Until such equipment is available, the following alternative design strategies may be considered.

The power conditioning system could consist of two differently sized inverters, one that has high efficiency at light system loads and another that has high efficiency at high system loads. The PCS controller could automatically switch between the two inverters or even operate them in parallel, as needed.

Another configuration could use a single small inverter with sufficient over-load capability to allow time for the generator to start during peak-load periods. Present inverters can produce about $200 \%$ of full load for about 30 seconds. This capability often allows enough time to switch on generator operation.

In some cases, the peak load periods are well defined and can be predicted. In other cases, an anticipation signal can be generated a few minutes before loads are increased or started. These anticipation signals could be used to start the generators and transfer operation from the inverters.

\section{References:}

1. Manwell, James F. et al, "Hybrid Systems Modeling: Development and Validation," pp 657 - 666. American Wind energy Association WINDPOWER '94 Proceedings. May 10-13, 1994.

2. Ramsey, Kay. New York State Research \& Development Authority System Monitoring, New York State Electric \& Gas Corporation (NYSEG) Site, Monthly Performance Report. Southwest Technology Development Institute, December 1995.

3. Durand, Steven and Hagee, Warren. Sandia National Laboratories Photovoltaic Design Assistance Center Hybrid Monitoring Program Preliminary Results Xcalak, Mexico - SCE Desert Studies - NYR\&D NYPA Site. Southwest Technology Development Institute, July 1994.

4. Durand, Steven and Sansing, Bethany. New York State Research \& Development Authority System Monitoring New York Power Authority (NYPA) Site, Interim Report 1994, Residential Photovoltaic/Propane Hybrid Power Generation System. Southwest Technology Development Institute, May 1995.

5. King, David L.; Ellis, Abraham; and Eckert, Peter E. Carol Spring Mountain PV Array - Initial Performance Characterization. Sandia National Laboratories, September 24, 1995. 

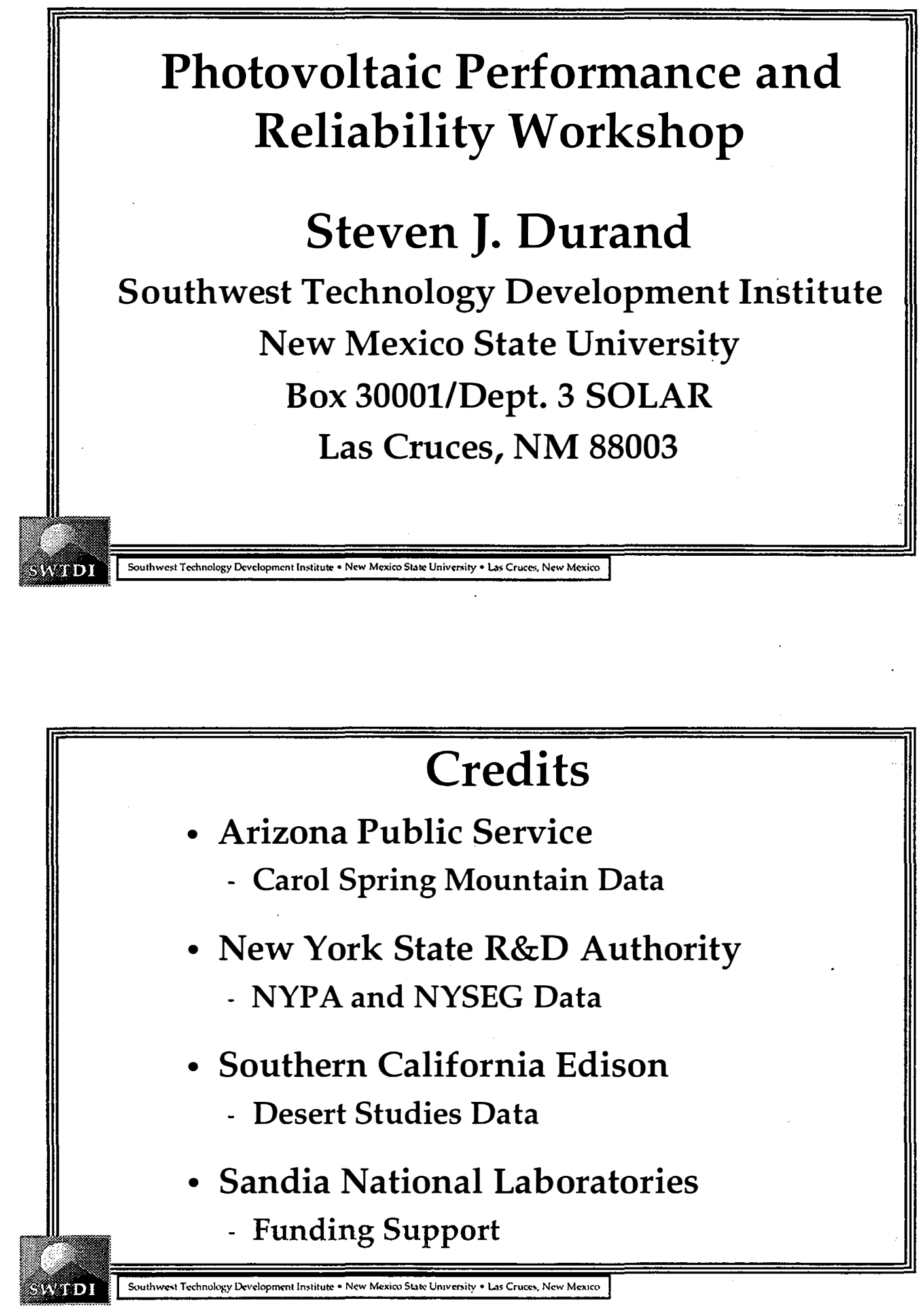


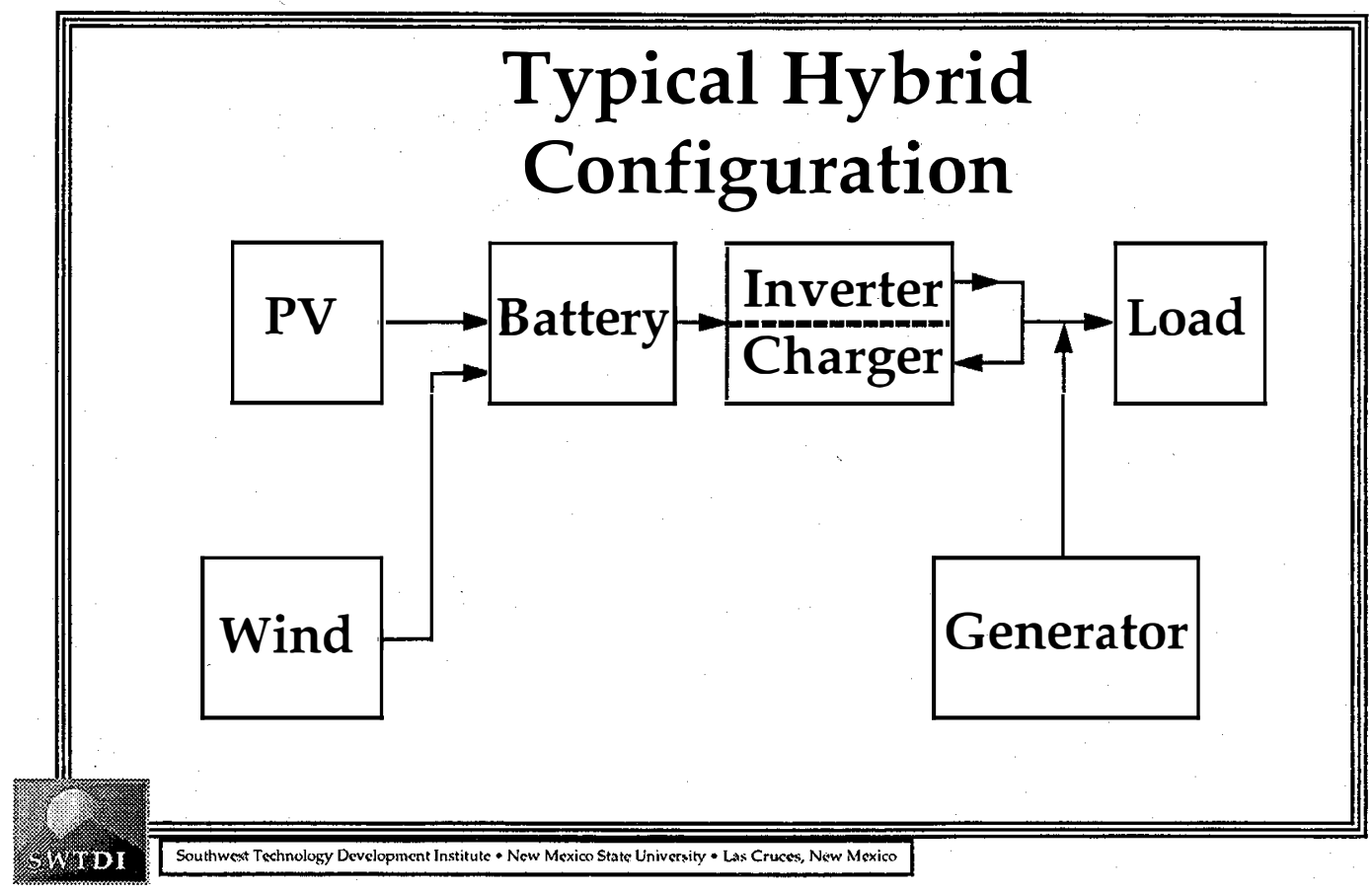

\section{Potential Hybrid Advantages}

- Reduced Engine Runtime

- Reduced Operation and Maintenance

- Reduced Fuel Consumption

- Reduced Pollution/Greenhouse Gas Emissions 


\section{Engine Runtime}

NYPA

NYSEG

Desert Studies

Carol Spring Mountain
880 Hours (1994) $\quad 10 \%$

1400 Hours (1995) $\quad 16 \%$

1240 Hours (1995) $\quad 14 \%$

Estimated

\section{Realized Hybrid Advantages}

- Reduced Engine Runtime

- Reduced Operation and Maintenance

- Reduced Fuel Comsumption

Reduced Polluhom/orathoure Cas marsentrs 


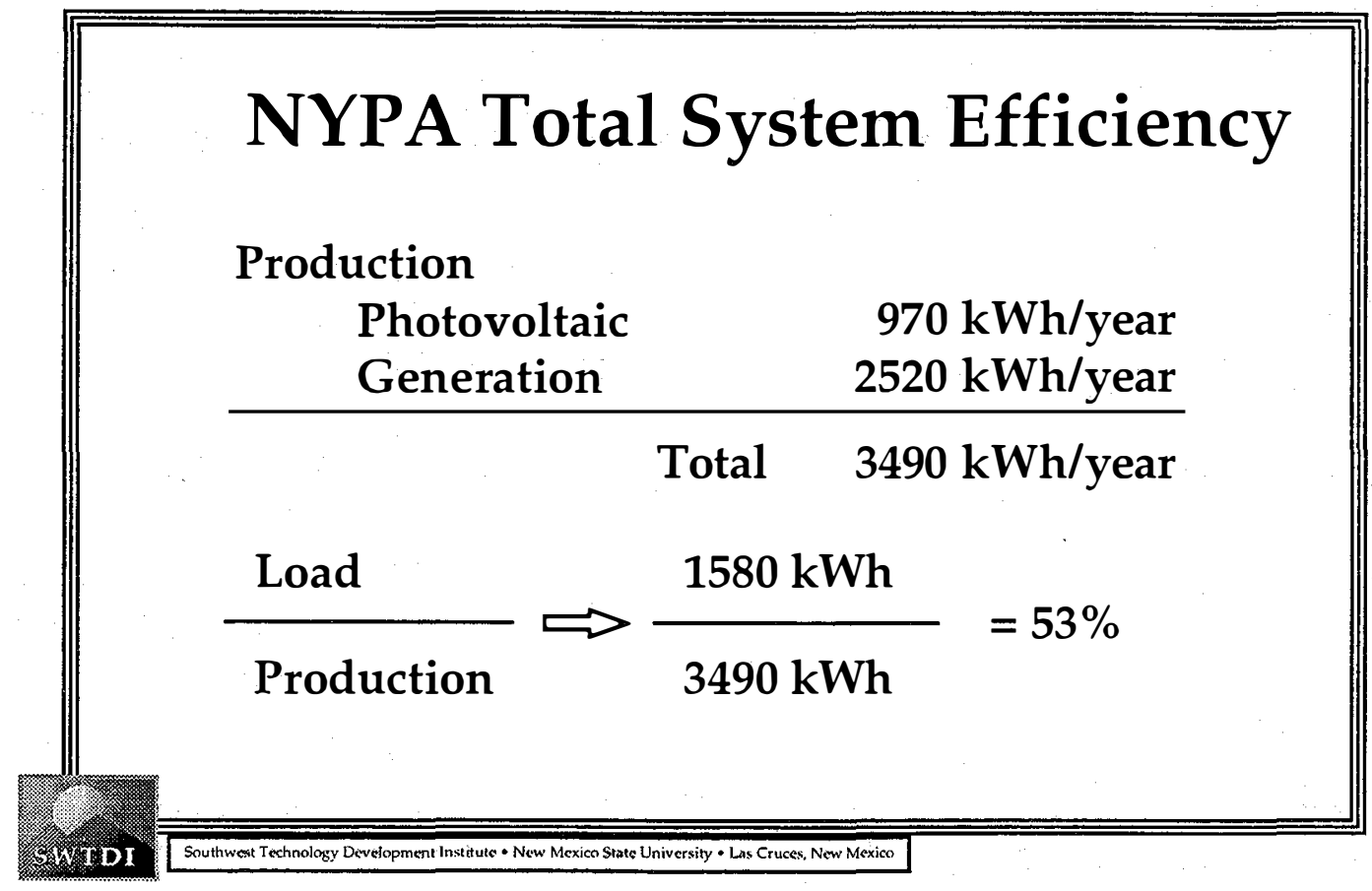

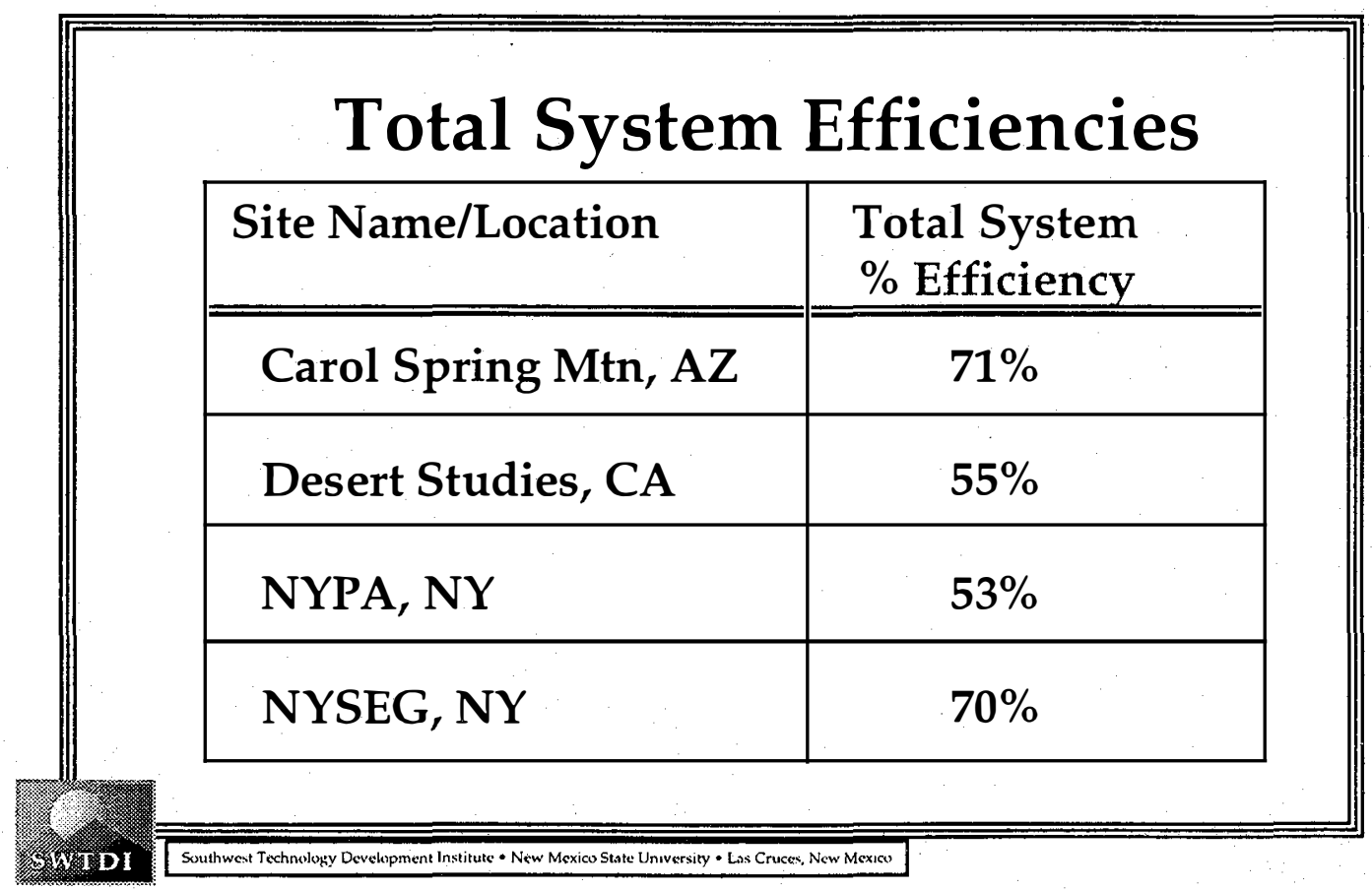




\section{Diesel Generator Fuel Efficiency}

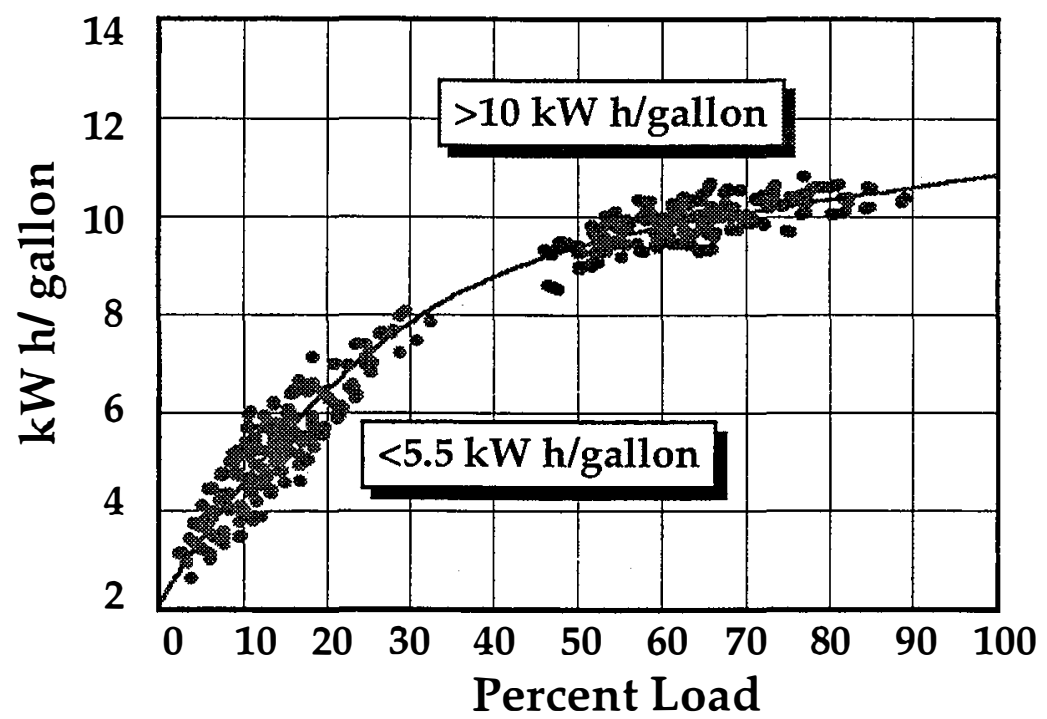

\section{Realized Hybrid Advantages}

- Reduced Engine Runtime

- Reduced Operation and Maintenance

- Reduced Fuel Consumption

- Reduced Pollution/Greenhouse Gas Emissions 

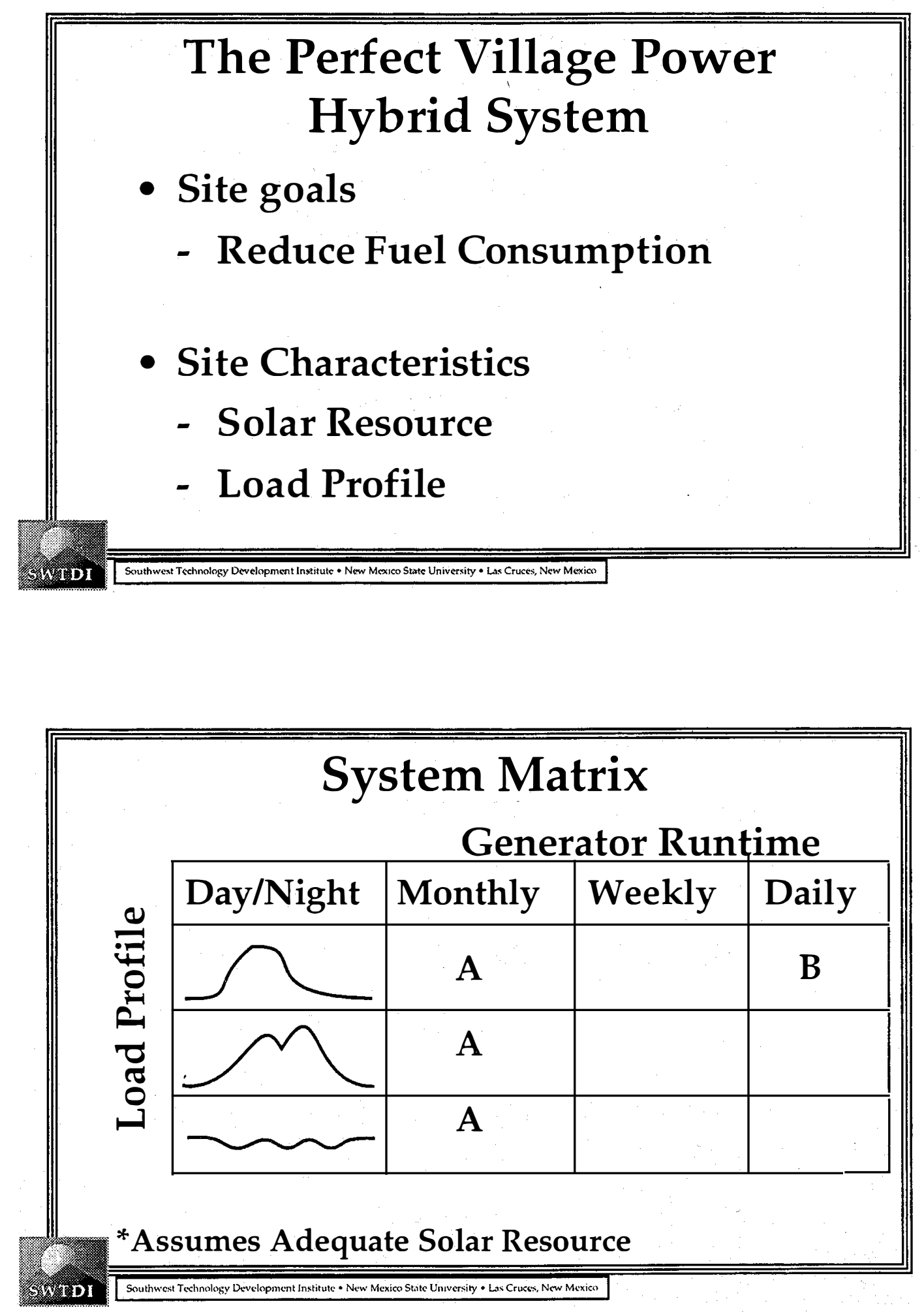


\section{"A" Type System Goals}

- Minimize Battery Cycles

- Minimize Generator Runtime

\section{"A" Type System Implementation}

- Array output is used to charge batteries

- Battery storage is $<7$ days of autonomy

- Generator is used to equalize batteries and provides power during bad weather 


\section{"B" Type System Goals}

- Reduce Fuel Consumption by $50 \%$

- Generators must be capable of carrying maximum system load

- Minimize Life-Cycle Cost

\section{“B" Type System Implementation}

- Array output supplies load directly; mimimal battery charging

- Battery storage $\approx 1$ day of storage

- Generator is used to charge batteries each night 


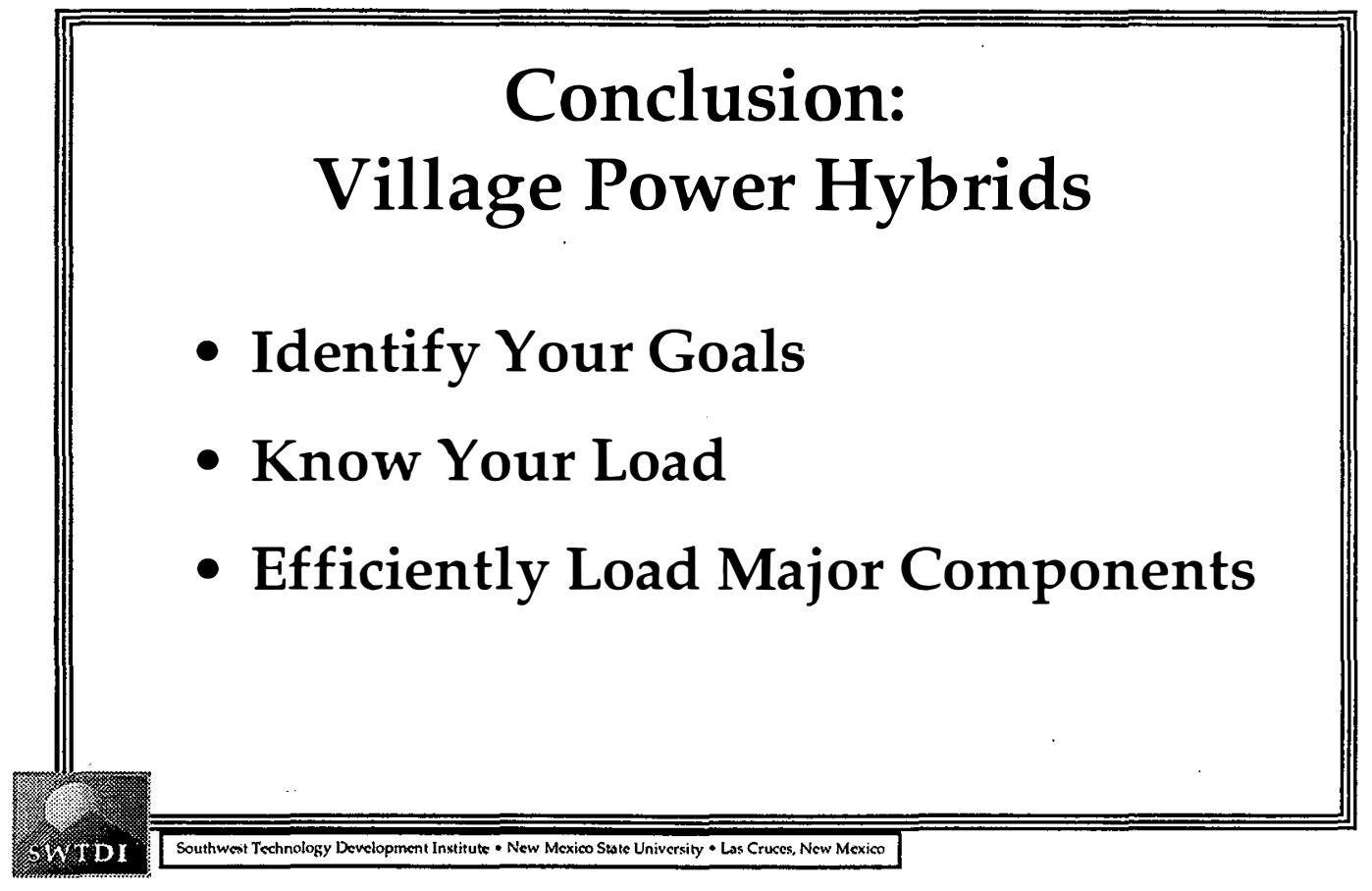




\section{PV Applications \\ and Field Experience}




\title{
PSN's Recent Experience
}

\author{
NREL PV Performance \& Reliability Workshop
}

September 6, 1996

Cary Lane

\section{PSN's Recent Experience}

- PSN background or update

- Product List Catalog

- Residential systems

- Water pumping systems

- Grid-tied systems

- PSN future 


\section{Photovoltaic Service Network}

Non-profit organization of utilities for purpose of promoting PV Technology

- Utility involvement in PV through education \& training

- Market development through utility PV services

- Aggregated purchasing as a "buyers cooperative"

\section{PSN Objectives}

- Utility involvement in PV through education \& training

* Provide education \& training to utilities, local PV contractors, and consumers

* Create a forum for information exchange between utilities and PV industry

* Pursue alliances with other organizations and user groups interested in PV 


\section{PSN Objectives}

- Market development through utility PV services

* Identify and address market barriers for successful utility PV services

* Create PV system standards for a variety of off-grid applications

* Coordinate PV product purchases for participating utilities and end user groups

PSN

\section{PSN Membership Status}

- Board of Directors

* 7 utility members (6 co-ops \& $1 \mathrm{IOU}$ )

$* 2$ non-utility members (WAPA \& NRECA)

- 50 utility members to date * 37 RECs, 9 IOUs, 4 G\&Ts

- 6 sponsors (UPVG, DOE, NREL, Sandia, US CERL, CO-OEC) 


\section{PSN Product List Catalog}

Only known list of pre-qualified packaged "utility grade" PV systems

* Meet strict minimum standards

* All system fully integrated and preassembled for quick installation
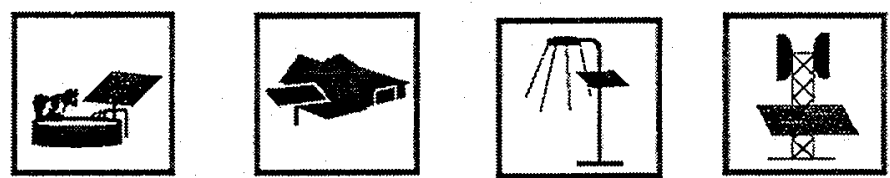

PSN

\section{PSN Product List Catalog Benefits Include:}

- Easy comparisons of systems and suppliers "one stop shopping":

- Standard system specifications and warranties (2-yr.. system warranties)

- Volume pricing-quantity discounts

- Simplified Procurement- Competitive bidding process already completed 


\section{PSN Product List}

\section{Development}

- Implementation Steps

* Step 1: Information gathering

* Step 2: System/supplier evaluation \& selection

* Step 3: Product list publication \& distribution

* Step 4: Periodic product list updates

- Development funded by Sandia PVDAC, UPVG, and cost-sharing from 17 utility members

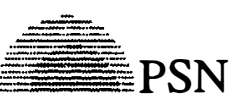

\section{PSN Product List}

\section{Step 1: Information Gathering}

- Pumping and residential solicitations developed with assistance from utility members, PV industry, Sandia, etc.

\section{- Solicitation process}

* Notice of solicitation mailed to over 200 prospective $\mathrm{PV}$ industry companies

* Solicitations requested by and mailed to 60 companies in early November 1995

* 14 water pumping \& 12 residential proposals received in early December 1995 


\section{PSN Product List}

Step 2: System/Supplier Evaluation \& Selection

- Evaluation team: PSN staff and Sandia PVDAC

- All systems and suppliers were screened for minimum requirements

- Desired results:

* High quality (i.e., "utility grade") systems and suppliers

* A variety of system types and suppliers from which to choose

* Competitive prices

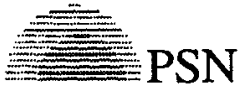

\section{PSN Packaged Systems}

Remote Residential

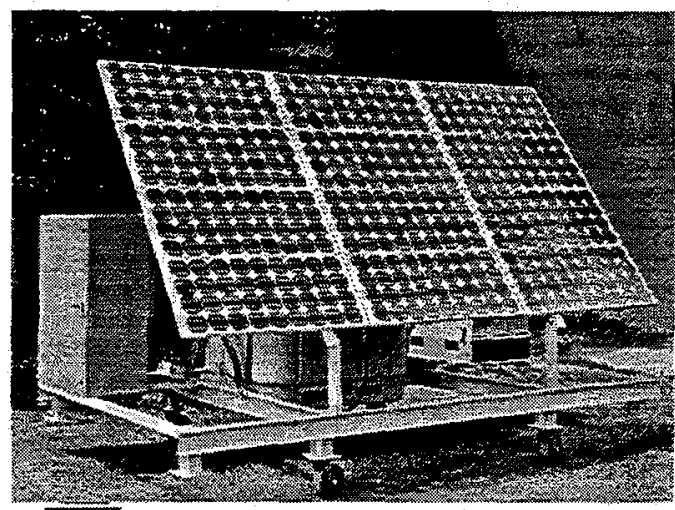

Water Pumping

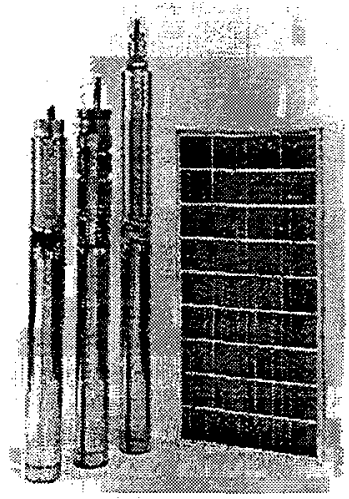




\section{Water Pumping Product List Description}

- Systems include two distinct subsystems

* Fully integrated PV power supply incl. all hardware (excl. downhole hardware) necessary for installation

* Pump/motor unit

- Subsystems can be purchased separately as required

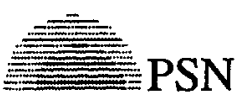

\section{Water Pumping Product List}

\section{Key Minimum Requirements}

- Systems meet National Electric Code requirements

- Minimum 2 year system warranty

- PV modules meet

* IEEE standards (i.e., JPL or PVUSA equiv.)

* UL standards

* Minimum warranty of $90 \%$ power for 10 years

- All systems supplied with O\&M and user manuals

- All prices guaranteed for 12 months 


\section{example pumping product list}

\section{Remote Residential Product List}

\section{Description}

- Standard pre-integrated AC PV power supplies

- Design features:

* Sinewave 120 Volt, $60 \mathrm{~Hz}$

* Self-contained, easily transported

* Easily installed by 2 person crew with minimal site work

* Power connection similar to traditional service drop

* Pre-integrated: major components factory pre-wired

* All systems accept auxiliary AC Power input

* Transportable for easy re-application 


\section{Remote Residential Product List}

\section{Key Minimum Requirements}

- Systems meet National Electric Code requirements for residential applications

- Minimum 2 year system warranty

- PV modules meet

* IEEE performance standards (i.e., JPL or PVUSA equiv.)

* UL standards

* Minimum warranty of $90 \%$ power for 10 years

- Three days battery storage (@ kWh/day load)

- 20-year life expectancy

- All systems supplied with O\&M and user manuals

- All prices guaranteed for 12 months (i.e., December 1996)

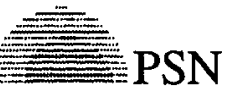

\section{example residential product list}




\section{Product List Issues}

- Performance match (or location) not exact

* Select nearest system

* PSN will adjust performance estimate rather than "re-size" system

- PSN Product List available to

* Utility members

* "Authorized local contractors" as approved by utility member

- Rely on "third party" information for future system and supplier evaluations

PSN

\section{Product List Summary}

- Product Lists benefit both utilities (and their customers) and PV industry companies

- PV industry has "come to play"

- Product Lists distributed initially to PSN utility members only

- Product Lists packaged so

* other applications (e.g., lighting) easily added in future

* PV system purchases handled as easy as other utility hardware purchases (i.e.., "off-the-shelf" system spec's and prices) 


\section{example system pictures}

- Plumas_Sierra

\section{Plumas-Sierra Installation}

- Installed by local PV contractor

- Issues (all have been resolved with supplier):

* Pre-assembled systems require large trucks which contractors may not have

* Not all required components were delivered with the system

F Missing: manuals, in-house monitor, transfer switch

* Not all components were NEC compliant

$F$ Generator interface was under-rated 


\section{example system pictures}

- water pumping picture

\section{Water Pumping Systems}

- 32 PV pumping systems have been purchased through the PSN

- Failed components replaced under warranty:

* 2 pumps failed after 1 day (diaphragms)

* 2 controllers never worked (diaphragms)

- 6 pumps have been replaced on non-Product List systems (all centrifugals) 


\section{PSN Utilities - New Option}

- Customers are encouraged to use utilities for all PV systems and service

* system sales

* lease (finance) systems - stretch capital budget versus annual O\&M

* service, maintenance and component replacement agreements

* complete PV energy services

\section{Focus on End User Groups}

- Federal Agencies

* National Park Service

$*$ US Forest Service

$*$ DOD

* Natural Resources Conservation Service

- State Agencies

- Nature Conservancy

- Private Organizations 


\section{Federal PV Procurement}

- GSA Schedules

* Schedules list PV components

* No available design, installation or maintenance support

- Private Vendors

* Private company product catalogs

* Competitive bidding required

* Service contracts or in-house expertise required (learning curve expensive)

\section{PSN's Support of Grid-Tied Roof Top Systems}

- West Plains Electric

- Nevada Power

- Public Service of Colorado 


\section{Grid-Tied Installations}

Complete kits; all necessary components

- No component failures

E. Minor problems - all quickly addressed and fixed by system supplier

* Delivered old version ground fault protection circuit

* Delivered conduit \& wire not up to code

* Battery disconnect switch delivered with wrong system

- Blocking diode placement disables function of by-pass diodes on the end module

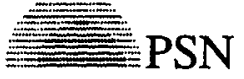

\section{Battery Back-up Option Issues}

- array not operated at peak power

$* 10 \%-15 \%$ power loss

- no fail-safe charge controller

* large array compared to battery bank size

* inverter must detect; trip relay, GFP board must detect, trip relay

- manual transfer switch for primary loads and demonstration 


\section{PSN Future Efforts}

- Standardize systems

* Utilities will only offer selected systems

- Coordinated utility purchases

* Focus on commercial systems

- Product testing \& evaluation

* Focus on emerging systems

- Repeat commercialization process for other applications

* lighting

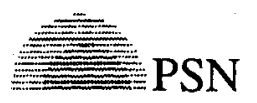

\section{Future Efforts \\ PV System Testing Facility}

- Develop test parameters

* Industry agreement

- Verify performance of all systems * "Consumer Report" type testing

- Feedback for manufacturers 


\title{
Energy Utilization in PV Systems
}

\author{
Hybrid and Stand-Alone Systems
}

John Stevens

Sandia National Laboratories

\section{Hybrid Systems}

Where do we lose energy?

- Oversized inverter

- Serving real-world loads instead of resistors

- Running at low engine output to tapercharge batteries

- High battery charging losses at high states of charge 


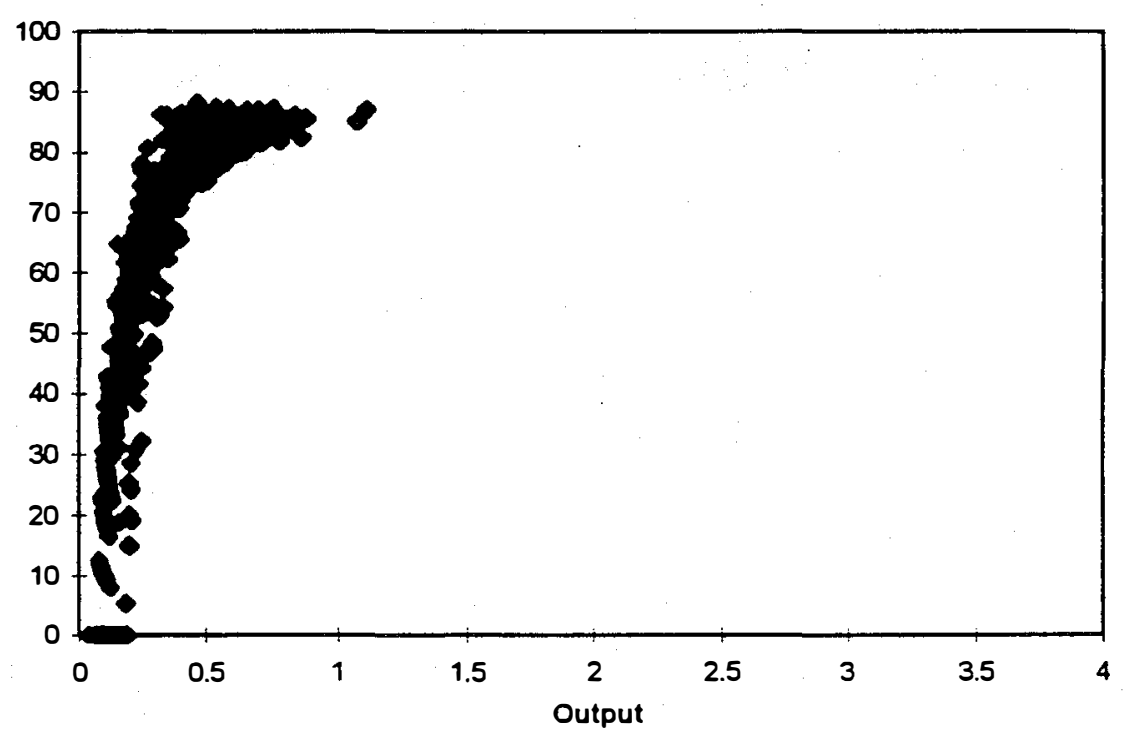

\section{A Common Inverter Sizing Problem}

- Question--“"How do you size inverters for surge currents such as the 6 to 8 times running current normally assumed for motor starting?"

- Answer --Motors can be started with less than 6 to 8 times current, it just takes a little longer. Ask Russ Bonn for Testing Brief .

- All inverters have surge ratings. The inverter manufacturer should be consulted regarding the surge capability of a specific unit.

- Voltage drop during starting can be an issue.

- Use a reduced voltage starter if appropriate. 


\section{What Do You Mean "Real-World Loads"?}

- Load factors that influence inverter efficiency:

- power factor

- distortion

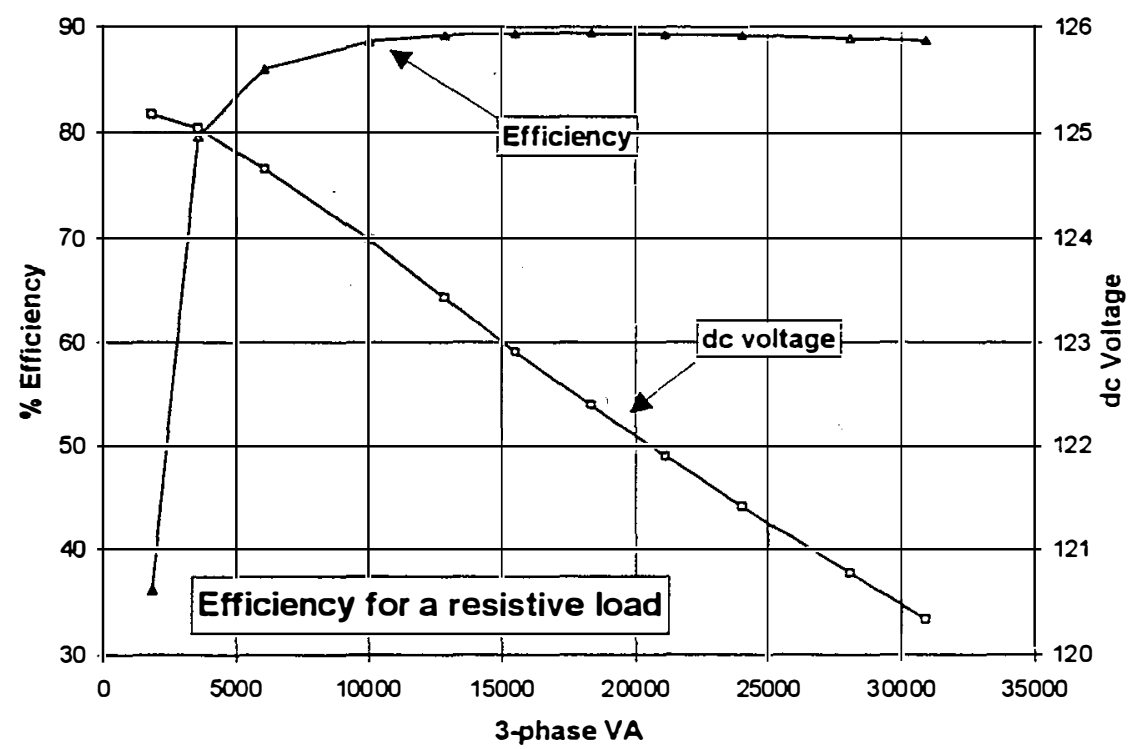



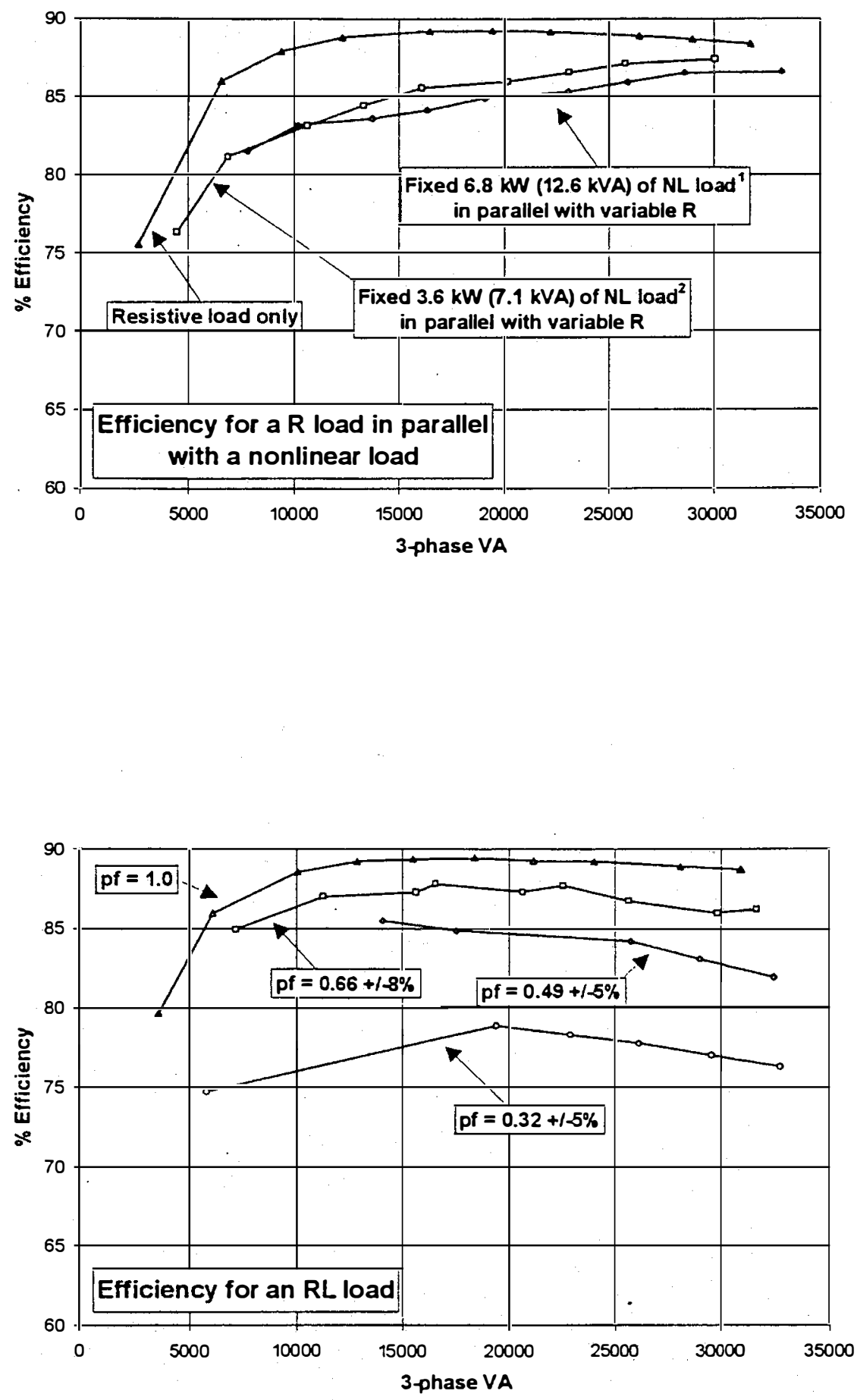


\section{What Can Be Done About Efficiency Reduction Due to Non-Resistive Loads?}

Not much--so account for it in design

Perhaps the use of shunt capacitors to improve power factor should be investigated. (But not casually!)

\section{Fully Charging Batteries has Double Impact on Efficiency}

- Taper-charging requires the engine to run at low output (low fuel efficiency)

- Battery efficiency drops off at high states of charge (low energy efficiency) 


\section{Typical Diesel Generator Efficiency}

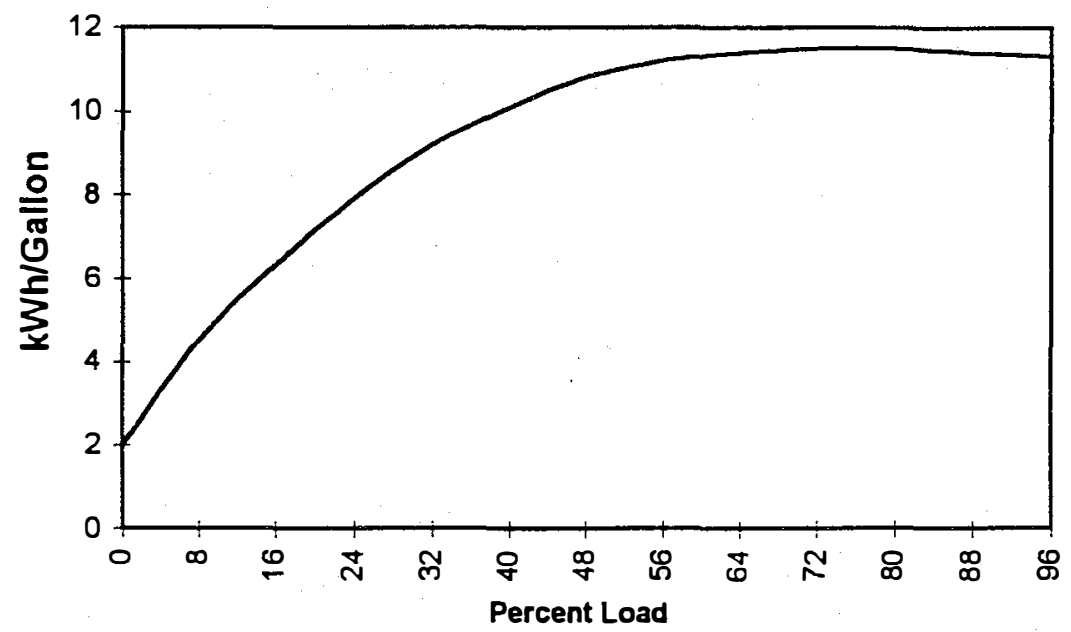

\section{Battery Losses Are Highest At High States of Charge}

Trojan 30XHS Battery

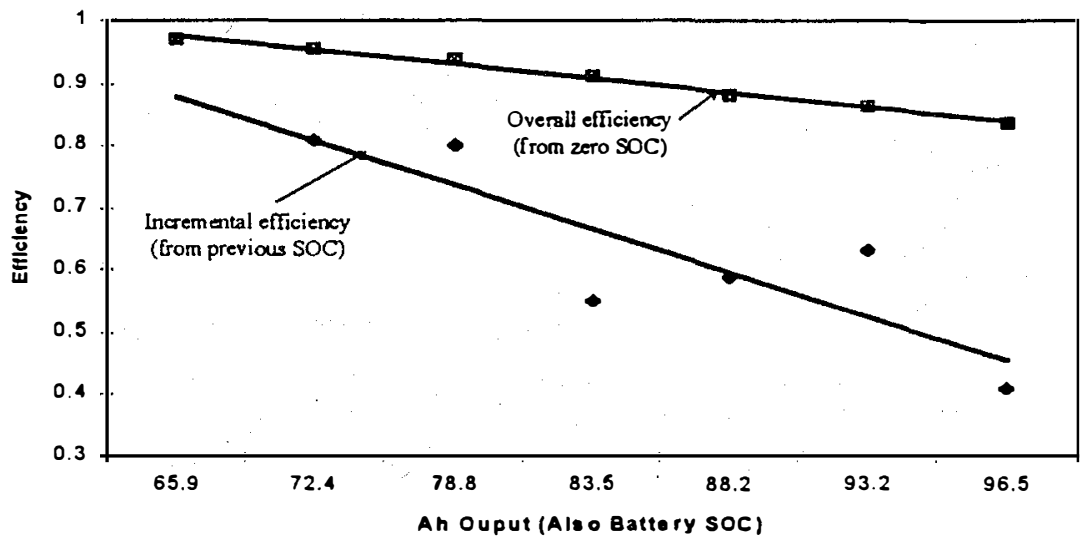




\section{Is it Important to Fully Charge Batteries? OR}

Do we really need to throw away all that energy?

That depends--Are you willing to sacrifice battery life?

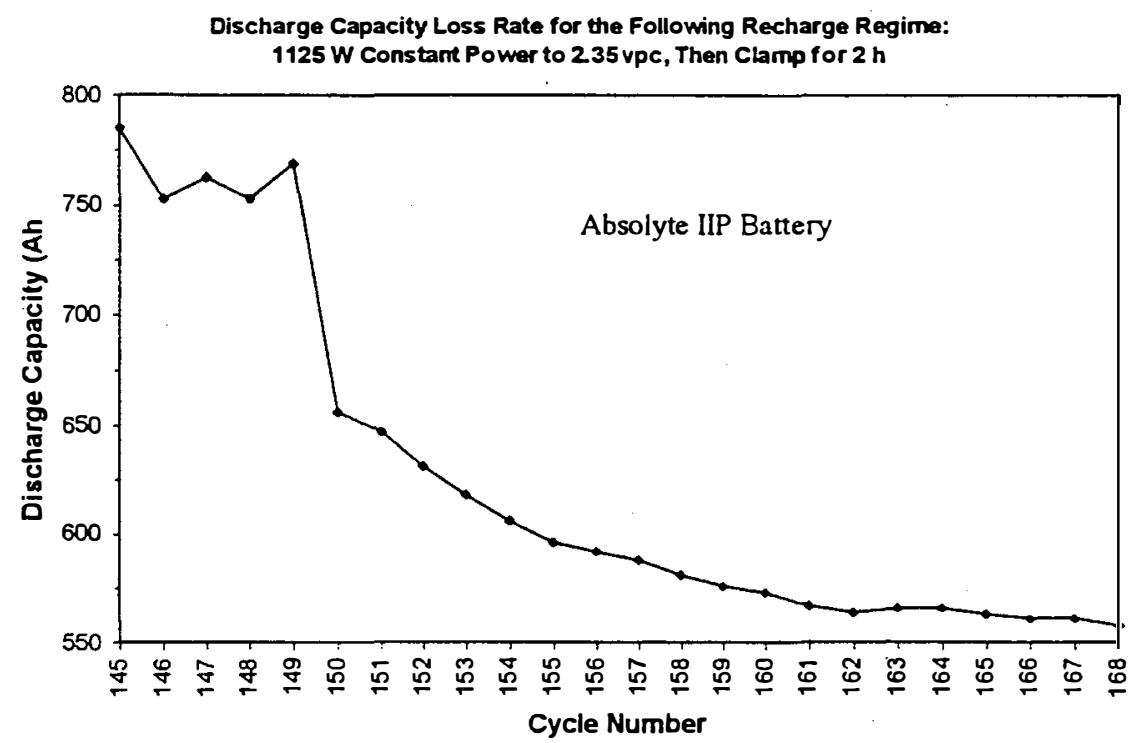




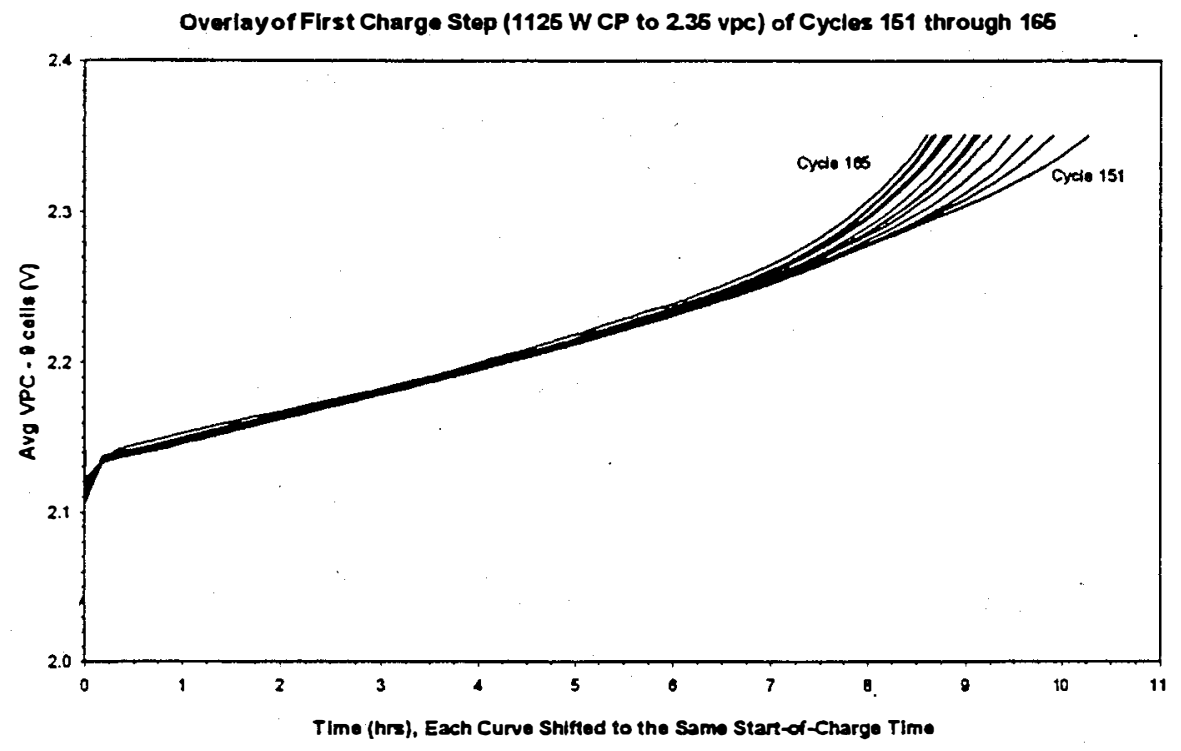

\section{How Does GNB Say You Should Charge an Absolyte IIP?}

- Full available current to 2.35 volts per cell

- Taper current to maintain 2.35 volts per cell until current stabilizes (may take many hours)

- Hold this condition for three hours

- If you need to equalize, then hold it for an additional 12 hours 


\section{Is This Lengthy Taper-Charge Also Necessary for a Flooded Battery?}

- Finish charging a flooded battery can be done at a higher rate (therefore, more rapidly and at higher engine efficiency) at the expense of increased watering requirements (that is, trading water and labor for fuel and fuel transportation) than with VRLA batteries.

\section{So, What's The Best Kind Of Battery To Use?}

VRLA

+ high charge efficiency + can be charged more

+ no watering

- highly temperature sensitive

- highly charge scheme sensitive quickly (fuel eff.)

+ better charge and temperature tolerance

- lower charge efficiency.

- higher maintenance (good water available) 


\section{So, What Can We Do About Those Hybrid System Losses?}

- Size inverters more knowledgeably

- Understand losses associated with nonresistive loads and battery charging and include these losses in initial design calculations

\section{Stand-Alone Systems 35W LPS Lighting 100A-h, flooded lead-acid battery}

\begin{tabular}{c|c|c|}
\multicolumn{1}{c}{ on-off } & \multicolumn{1}{c}{1 battery } & 2 battery \\
\cline { 2 - 3 } & system 1 & system 2 \\
\cline { 2 - 3 } $\begin{array}{c}\text { constant } \\
\text { voltage" }\end{array}$ & system 3 & system 4 \\
\cline { 2 - 3 } & & \\
\cline { 2 - 3 } & &
\end{tabular}




\section{What is the Question?}

Can we make effective use of the PV energy during that time of the year when we need it most?

\section{Starting Point for Discussion Cedro Campground}

- Systems installed in June, 1991

- Performance documented in IEEE PVSC paper in 1993 (Louisville)

- After six months of operation (June to December, 1991)

- Batteries' apparent capacity substantially reduced

- Inspection reveals sulfation and stratification in all systems

- Systems retrofit in May, 1995 


\section{Battery Voltage While Controller is Regulating Old Setpoints}

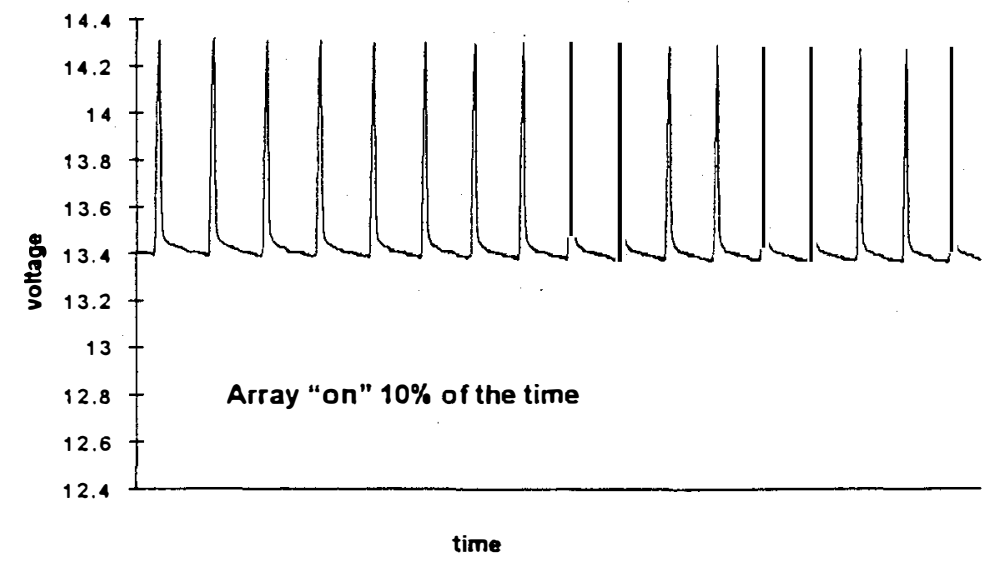

1/4 second sample rate (over about 15 minutes)

Cedro Irradiance, Dec 10-20 '91

227A- $h$ available from arrays

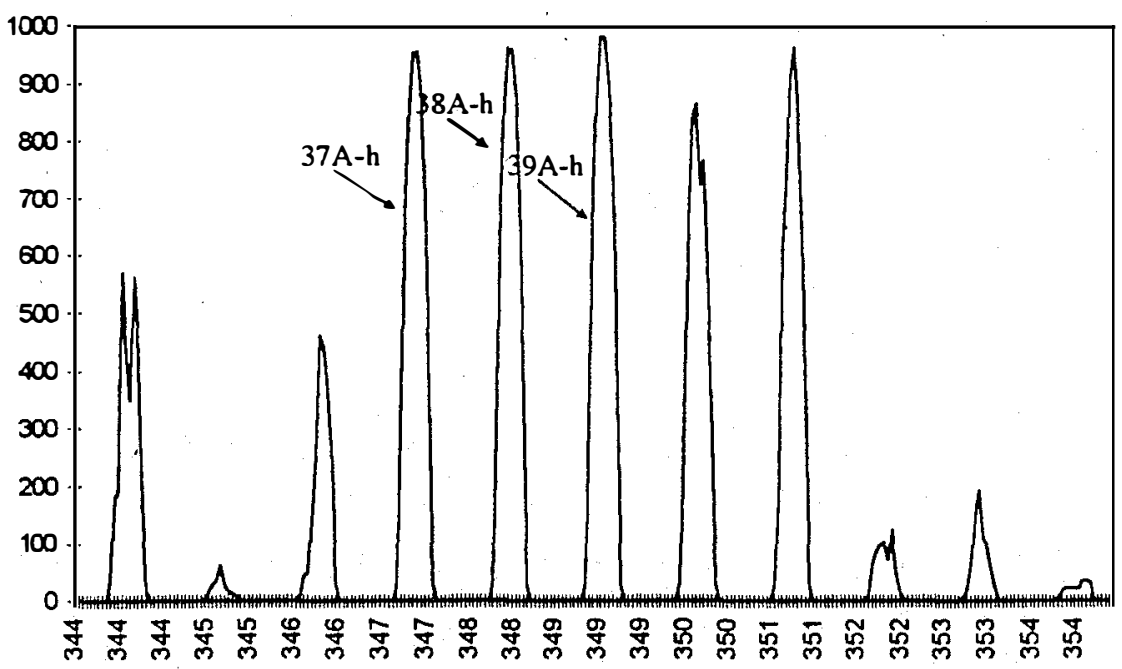




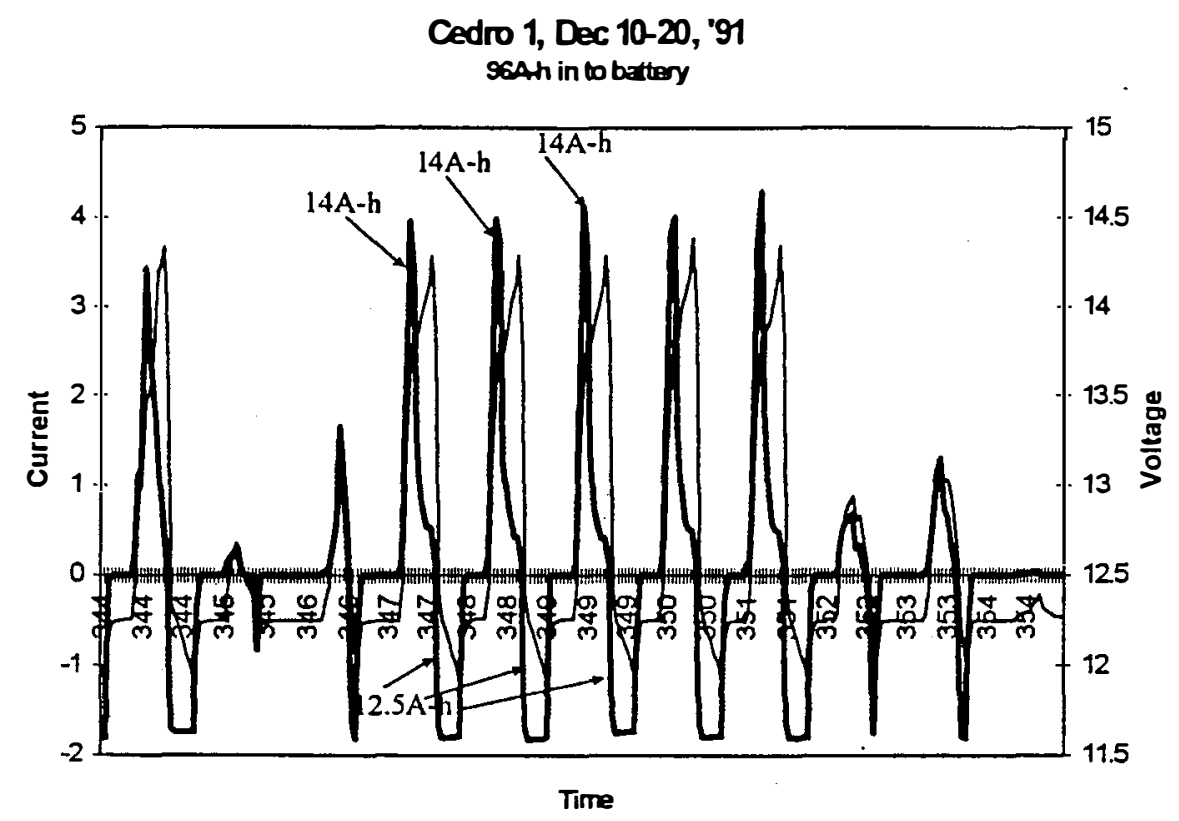

Old Setpoints Resulted in:

- $90 \%$ of available energy not used even though needed $\longrightarrow$ wasted array investment

- Battery not brought above about $90 \%$ SOC $\rightarrow$ sulfation from undercharge

- Gassing voltage not sustained long enough to mix electrolyte $\rightarrow$ stratification 


\section{Cedro Setpoints}

- Old Setpoints $\quad \mathrm{Vr}=14.5, \quad \mathrm{Vrr}=13.4$

- New Setpoints

-on-off $\quad \mathrm{Vr}=15.0, \quad \mathrm{Vrr}=14.3$

- constant voltage $\mathrm{Vr}=15.0$

\section{Voltage During Regulation New Setpoints}

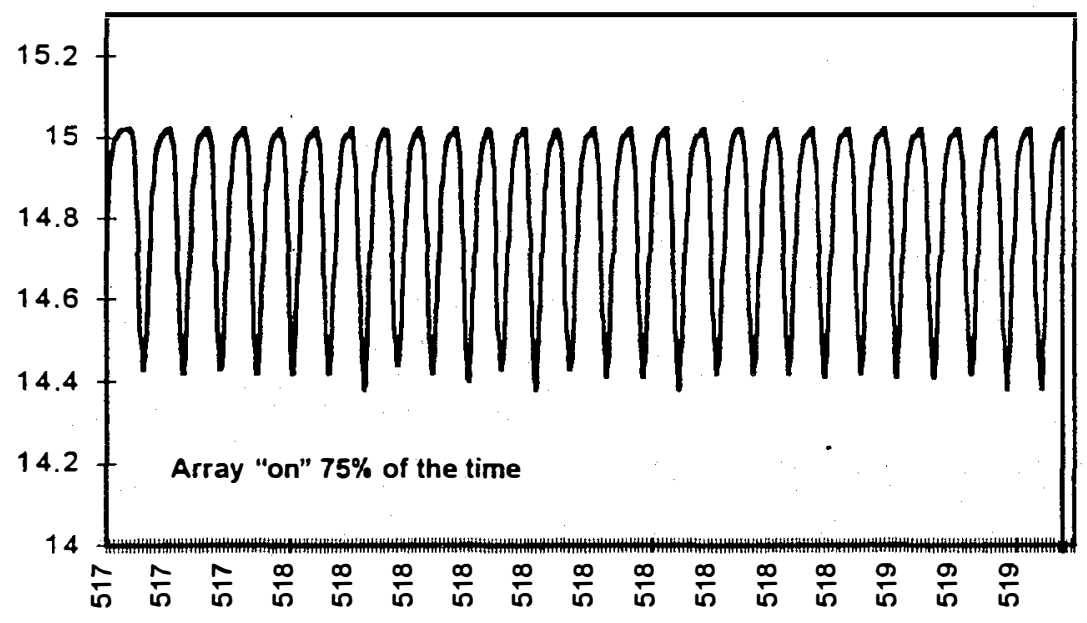




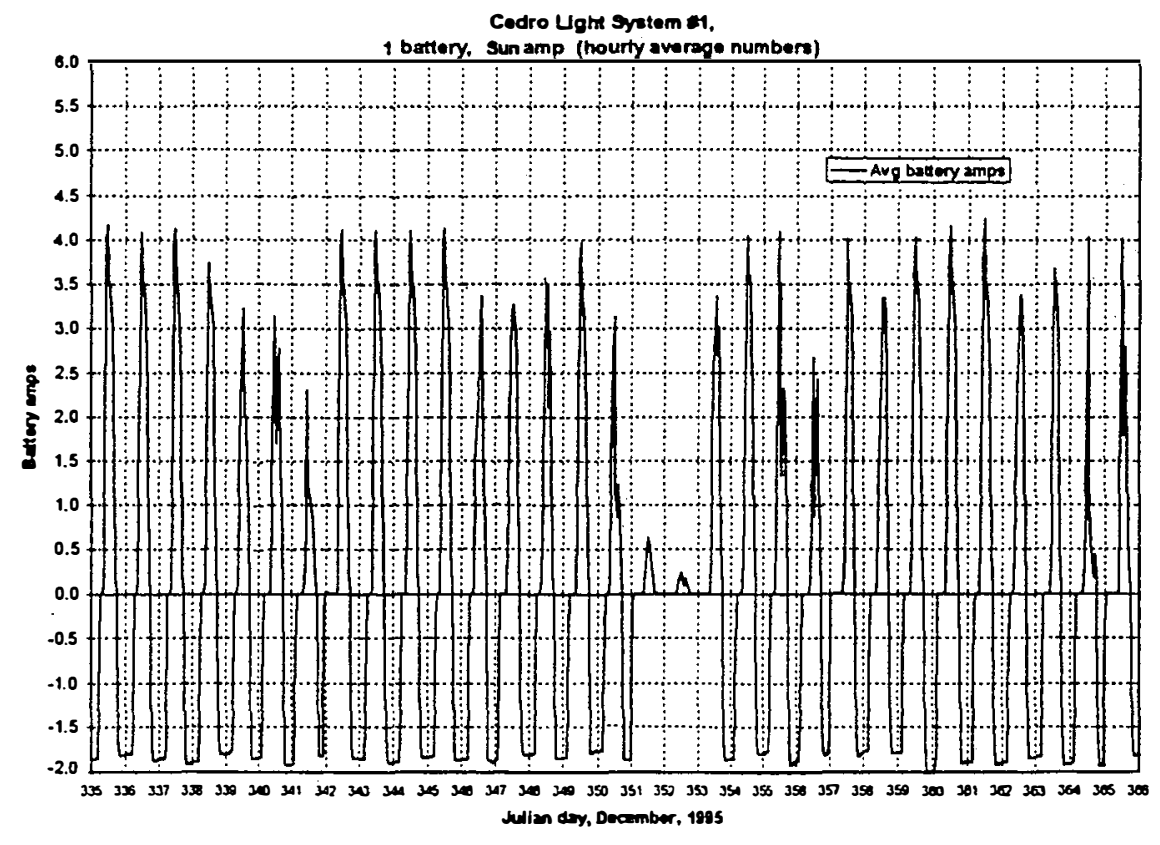

\section{Available Battery Capacity December}

Available capacity is derated for temperature and reduced by low-voltage disconnect point.

$$
\begin{gathered}
\text { cap }=0.7(100 / 1.3)=\underline{54 \mathrm{~A}-\mathrm{h}} \\
\text { load }=30 \mathrm{~A}-\mathrm{h} / \text { night }
\end{gathered}
$$




\section{Cedro Irradiance, Dec 17-22, 95}

1394h bed availatie from arays

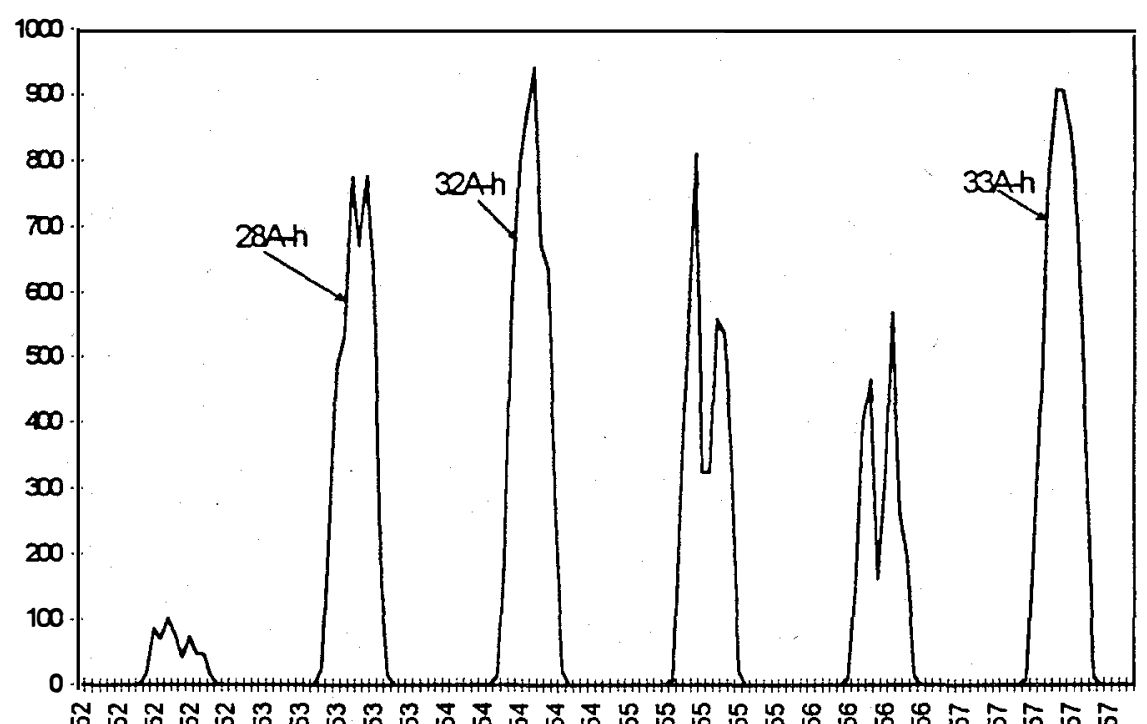

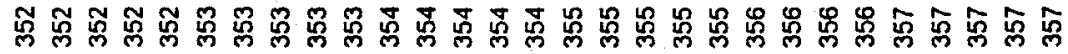

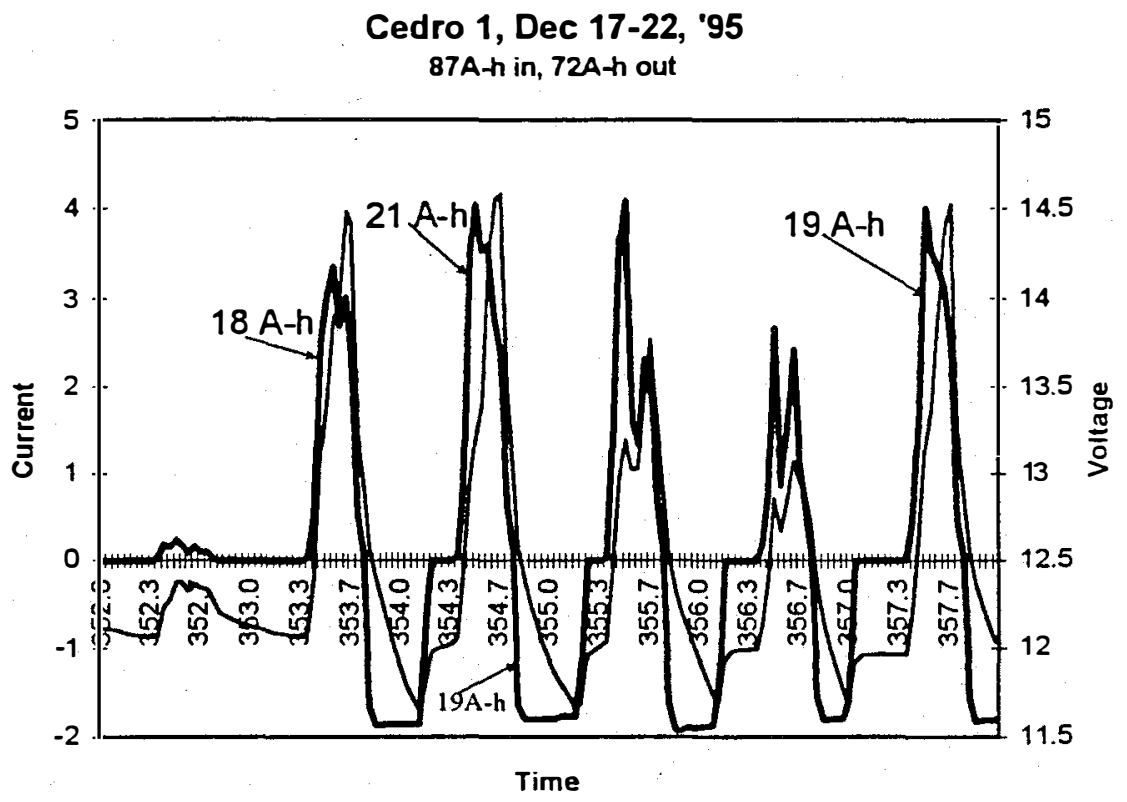



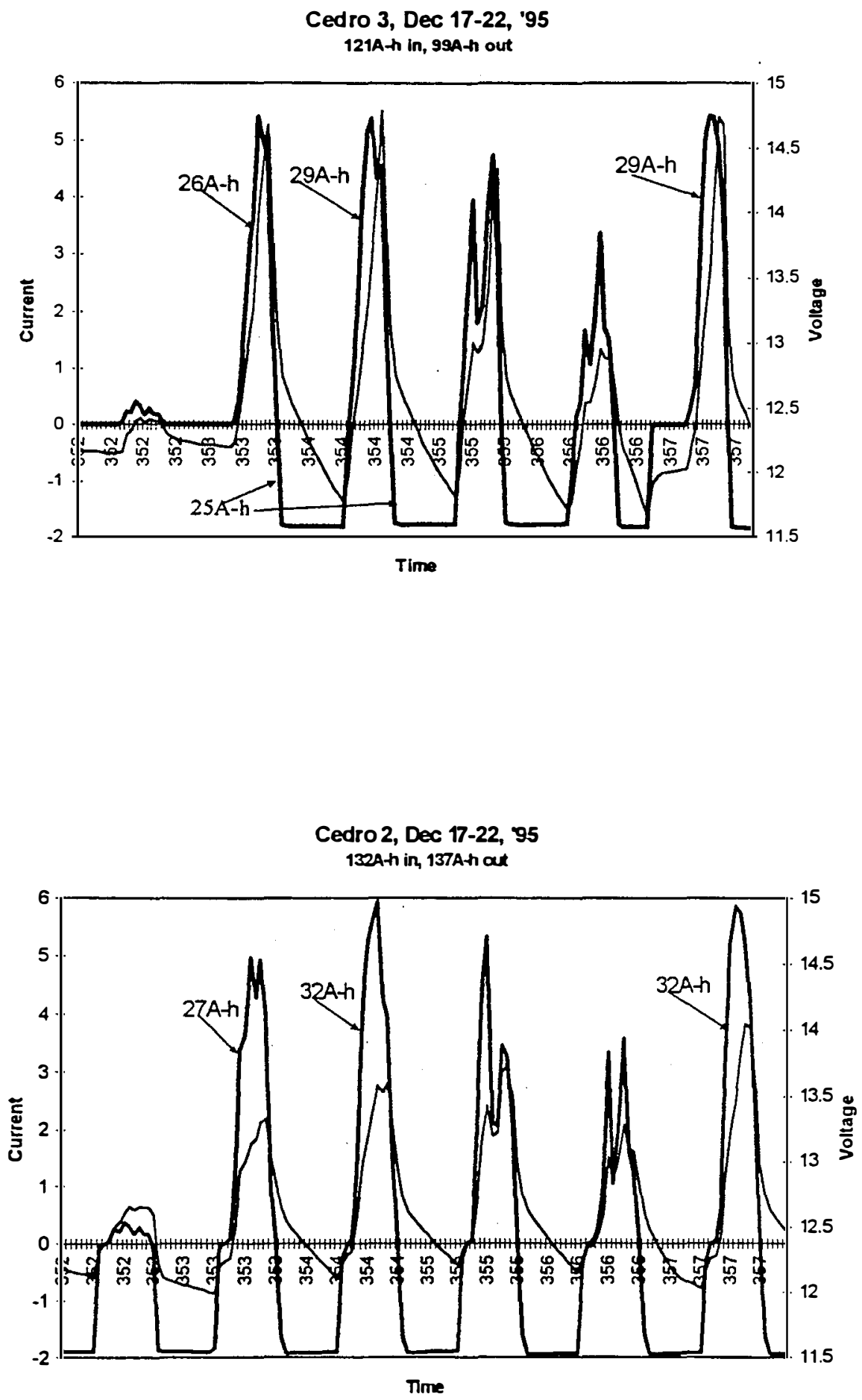


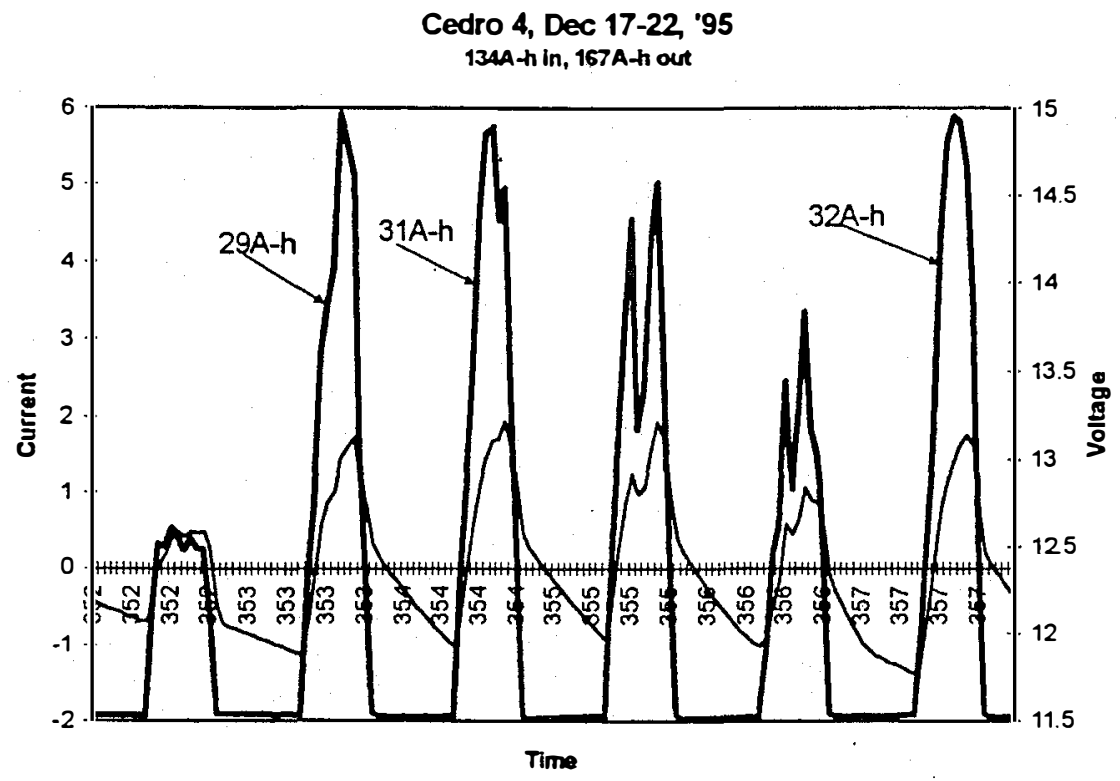

\section{Battery Sizing Using Derated Battery Capacity}

- For this application, derated battery capacity is about $55 \%$ of nameplate capacity

- Derated capacity of about 1.7 times daily load does not reliably carry the load.

- Derated capacity of about 3.4 times daily load works well. 


\section{December '95 Summary New Setpoints had Definite Positive Impact}

- Both 2-battery systems performed well, with constant-voltage controller marginally better.

- 1-battery system with c-v controller not bad

- 1-battery system with on-off controller worst (but not a total disaster) 


\title{
EXPERIENCES WITH UPPER GREAT LAKES STAND-ALONE SYSTEMS
}

\author{
Cedric G. Currin \\ Currin Corporation, Midland, Michigan
}

The upper Great Lakes, from $45^{\circ} \mathrm{N}$ latitude to the Canadian border and from Lake Huron to western Lake Superior, is a popular four-season recreation area of forests, lakes, beaches, streams, and hills. This paper relates experiences since 1985 with stand-alone PV systems to meet needs for power in nine national and state parks and forests, primarily for remote campgrounds. Most of these systems are for providing potable water and ventilation of vault toilets.

\section{General Conditions}

The average daily insolation in the upper Great Lakes region ranges from $\sim 1.5$ to $6.0 \mathrm{kWh} / \mathrm{m}^{2}$, with the minimum from mid-November to mid-January and the maximum in late June and July. The proximity of the Great Lakes causes long cloudy periods, frequently over seven days, during much of the year except for June to August. The ambient temperature typically ranges from -35 to $+35^{\circ} \mathrm{C}$ and snow depths reach 2.0 meters in some locations; there is snow cover from December through March in most areas.

Other factors affecting the design of stand-alone PV power systems relate to the nature of the specific park or forest area. The primary season when power is required extends from May through September and, in some locations, October, when the insolation has decreased substantially. Normally the PV array must not intrude in the natural visual environment and can not be installed on historic buildings which would alter the building's appearance. Trees normally can not be removed to obtain solar access. The PV system installation can not disturb rare or endangered species or archeological sites. The systems must operate unattended and are frequently inaccessible during winter months for monitoring or maintenance.

\section{Potable Water Systems}

PV-powered pressurized water systems have been installed at approximately 35 sites to assure the availability of potable water meeting EPA requirements. All of these PV systems are battery systems since extended cloud cover is frequently experienced. The quantity of water that is required was initially not known precisely, which resulted in solar pump systems being designed with excess capacity. During the last three years water measurements show that a camper typically uses 10 liters/day. Both lower-cost submersible diaphragm and higher pumping capacity submersible turbine pumps are used at dc voltages from 12 to 72 volts. A few shallow-well centrifugal or centrifugal-jet pumps are also used. Where there are multiple campsites, the submersible diaphragm pumps are operated at 24 or higher voltage to obtain a sufficient pumping rate during peak water use periods. Very few systems pump more than 1000 liters (260 gallons) per day.

Most PV arrays of one to four PV panels are pole-mounted adjacent to a wooded area, or sometimes in the wooded area, so that they are not readily visible. PV panels with blackanodized frames are preferred. Those responsible for the pump systems are frequently not 
initially aware of the distance that the PV array may be located from the pump and batteries so that the array is not visible but yet has adequate solar access. Of the $\sim 80 \mathrm{PV}$ panels installed for pump systems over the past ten years, five have been damaged by vandalism and one other failed approximately nine years after installation.

Both flooded and immobilized electrolyte lead-acid batteries are used; typically the battery bank capacity is 10 to 15 times the maximum expected daily pumping energy. Since many pump systems were designed for a much greater pumping capacity than is used, the batteries are normally fully charged except during a long cloudy period. The failure of low voltage load disconnect functions of charge controllers severely damaged or destroyed battery banks at two sites. Otherwise, flooded batteries typically perform for 5 to 6 years, gelled electrolyte batteries for more than 4 years (no failures yet), and at two sites, AGM batteries continue to perform after 9 years of service.

Most charge controllers are temperature compensated; at most sites the batteries remain under solar charge during the winter and spring months to maintain a full charge and avoid freezing. Four controller failures have been observed; two failures were controller low voltage disconnect circuit failures, one was a cold solder joint, and the fourth was a defective digital voltmeter connector.

\section{Vault Toilet Ventilation}

There are more than 20 panel-direct solar fans for removing odors from remote vault toilets. Typically a 10 watt 6 volt PV panel powers a small 1.6 watt dc turbofan which is placed in the vent stack. The PV panel is normally roof-mounted. The fan normally starts when the insolation reaches $0.2 \mathrm{~kW} / \mathrm{m}^{2}$ and continues until the insolation decreases in the late afternoon below $0.1 \mathrm{~kW} / \mathrm{m}^{2}$. Of the 20 systems monitored during the past five years, there have been no failures. The response of users of these remote comfort stations has been very favorable.

Three other vault toilet systems are continuously vented using a small dedicated PV battery power supply or enlarged solar power systems for water pumping. Since the fan current is less than $0.2 \mathrm{~A}$, the fans in two comfort stations are adequately powered from a solar pump system more than 30 meters (100 feet) away from the comfort stations. One system installed six years ago on a composting toilet on the south shore of Lake Superior continues to perform from May to October each year with the original gelled-electrolyte battery. The only failure was a fan after a rodent chewed the polymeric fan blade one winter.

Other Stand-Alone Systems

Stand-alone PV power systems have also been installed for a National Forest Service telephone repeater station, for lighting a historic lighthouse, and for providing $\sim 30 \mathrm{kWh} /$ day of ac power to a small island community. 
The PV system for the telephone repeater station was designed for operation throughout the year, including the winter months when the average daily insolation is typically $1.5 \mathrm{kWh} / \mathrm{m}^{2}$. Five $64 \mathrm{~W}_{\mathrm{p}} \mathrm{PV}$ panels are mounted on the antenna tower, with a $70^{\circ}$ tilt to shed snow, to provide $135 \mathrm{Wh}$ of energy per day. Six $90 \mathrm{Ah}$ gelled-electrolyte batteries are used; calculations show that daily insolation at $0.5 \mathrm{kWh} / \mathrm{m}^{2}$ during cloudy periods is sufficient to keep the batteries from freezing for at least two weeks. This system was installed in late 1995 and has performed adequately.

The initial PV lighting system installed several years ago in a historic lighthouse at the Straits of Mackinac failed within a few months due to excessive battery discharge. The flooded battery then froze during the winter months, cracked the case, and spilled corrosive electrolyte, causing substantial damage to the floor in this lighthouse. The PV system was replaced in 1996 using a system controller with a low voltage disconnect function and a gelled-electrolyte battery.

A $11 \mathrm{~kW}_{\mathrm{p}}$ PV array with a $288 \mathrm{kWh}$ battery bank and a $15 \mathrm{~kW}$ sinewave inverter was installed on North Manitou Island (Sleeping Bear Dunes National Lakeshore) this year as part of a $\mathrm{PV} /$ diesel hybrid power system for the island's small village of park personnel. This PV power system will totally eliminate evening operation of the diesel generators and will normally eliminate generator use from May through August, the primary season. The PV array consists of three subarrays, each of eight strings with nine $53 \mathrm{~W}_{\mathrm{p}} \mathrm{PV}$ panels per string. A major factor in the design of the PV array was to screen it from visibility from the lake, dock, and historic village, and to avoid disturbance of an archeological site. The array structure was designed to withstand a load of 1.0 meter ( 40 inches) of snow.

The large battery bank consists of two strings of 1200 Ah AGM cells; the capacity is sufficient to provide power during long cloudy periods during the primary season and to minimize normal daily depth of discharge for maximum battery bank life. The bimodal sinewave inverter charges the battery bank when a generator is used to power the village.

Startup of this PV system, among the largest in the midwest, is in September, 1996.

\section{Lessons Learned}

The major lessons learned from experience with stand-alone PV systems in the upper Great Lakes region are:

1. Frequently the expected loads are not known;

2. Frequently there are misconceptions to be overcome regarding limitations on locating the PV array;

3. The PV array can usually be located, even in a forested area, to receive sufficient insolation and yet be screened from view;

4. Battery banks should be sized for typically $8 \%$ daily discharge to have sufficient capacity for long cloudy periods and long life;

5. Both flooded and immobilized electrolyte batteries have provided good performance;

6. Low voltage load disconnect circuits are highly recommended;

7. Installation, operation, and maintenance instructions are sometimes not followed or are not clear. 


\title{
Photovoltaic Performance and Reliability Workshop \\ SEPTEMBER 4-6, 1996 \\ SHERATON DENVER WEST HOTEL LAKEWOOD, COLORADO
}

\section{Photovoltaic-Diesel HybRID Power System \\ Carol Spring Mountain Telecommunications Site}

\author{
by Richard $\mathbf{A}$. Lambeth
}

\begin{abstract}
Arizona Public Service Company (APS) contracted with Scientific Engineering, Inc. of Montgomery, Alabama to design and build a Photovoltaic-Diesel Hybrid Power System. The new system serves seven APS telecommunications customers atop the 6,600 foot Carol Spring Mountain, located 115 miles east of Phoenix, Arizona. The PV-Diesel Power System was put in service in October 1995 after a three month construction period and replaces the ten year old diesel-generator power system. Using a sealed battery storage system, the $25.6 \mathrm{~kW}$ fixed-array photovoltaic provides about 70 percent of the annual kilowatt-hour requirement. A $53 \mathrm{~kW}$ diesel generator supplies the remaining kilowatt-hours while running only 800 hours annually and using a fraction of the old system's fuel requirement (1/6). Analysis indicates that the $\$ / \mathrm{kWh}$ cost for the PV-diesel system will be approximately 50 percent more than a conventional diesel-generator system.
\end{abstract}

Since startup last October, the system has produced $21,510 \mathrm{kWh}$ of solar energy and $27,696 \mathrm{kWh}$ of diesel-electric energy. The system has used about 3,200 gallons of diesel fuel or about $28 \%$ of the fuel required when the diesel was the primary source. The system is currently not meeting the design target of $70 \%$ solar energy production because of 3 inverter/controller failures. We hope to work through these problems and have the system back in service early in September. By the way, when the inverter fails, the customers are served by the diesel powered generator and are not without power for an extended period.

Richard A. Lambeth, Senior Engineer

Arizona Public Service Company

P.O. Box 53933 Mail Station 3035

Phoenix, Arizona 85072-3933

Phone: (602) 371-6628

FAX: (602) 371-7717

E-Mail: rlambeth@apsc.com 

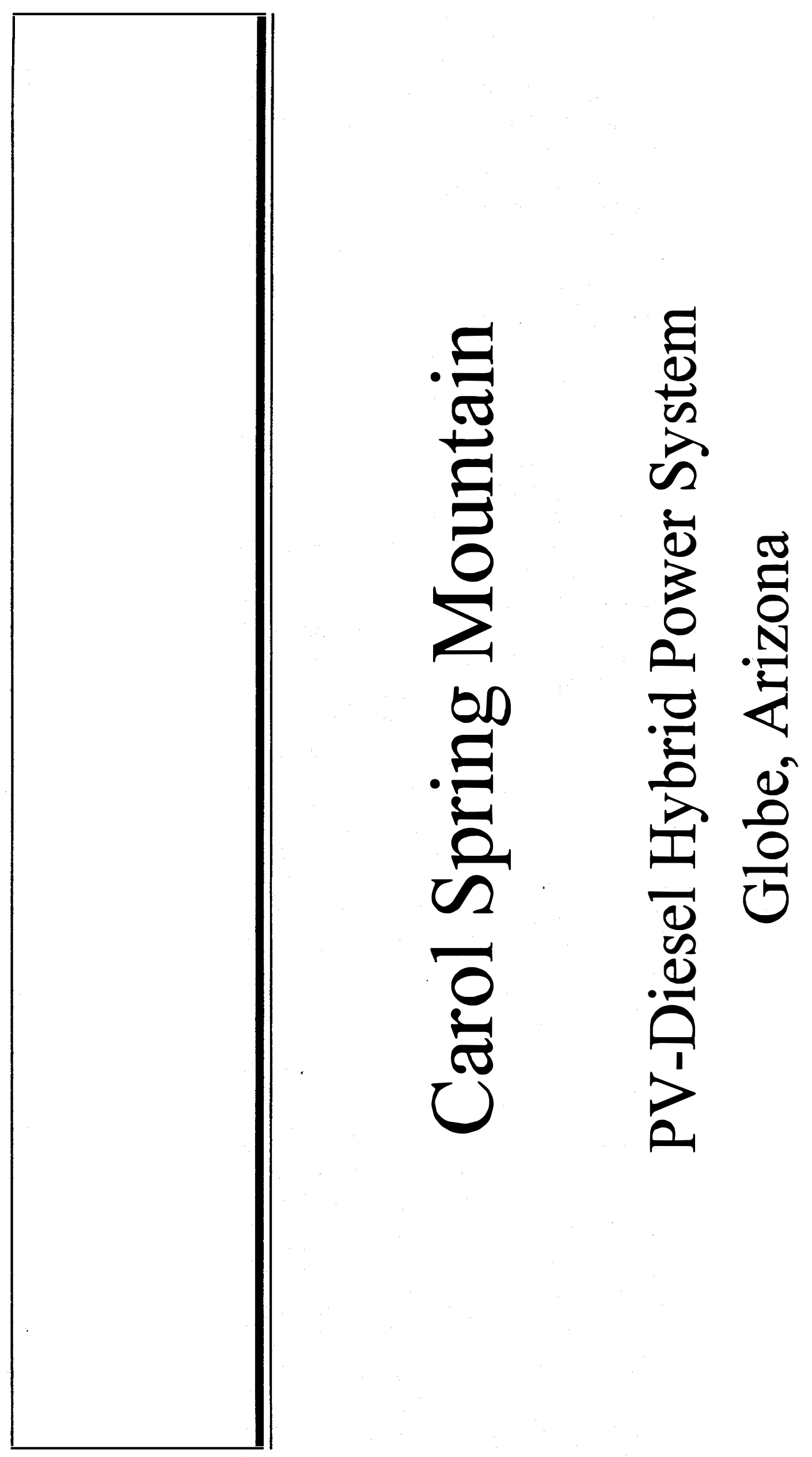


\section{System Components}

- $25.6 \mathrm{~kW}$ fixed array, 35 degree tilt.

- Aluminum support structure $\mathrm{w} /$ concrete piers.

- $600 \mathrm{kWh}$ sealed battery, $21 \%$ avg. DOD, 13 year est. life.

- $30 \mathrm{~kW}$ (cont.) Bi-Mode Inverter, Max Power Tracker.

- $53 \mathrm{~kW}$ turbo diesel w/120/208v, 3-phase generator.

- 830 gallon fuel tank, containment basin, \& service panel.

- $12^{\prime} \times 24^{\prime}$ steel building (battery/controls).

- 400 foot perimeter fence (6 foot chain-link).

- 5-status alarms via RTU w/ microwave channel.

- SNL Data Acquisition System w/ microwave channel. 


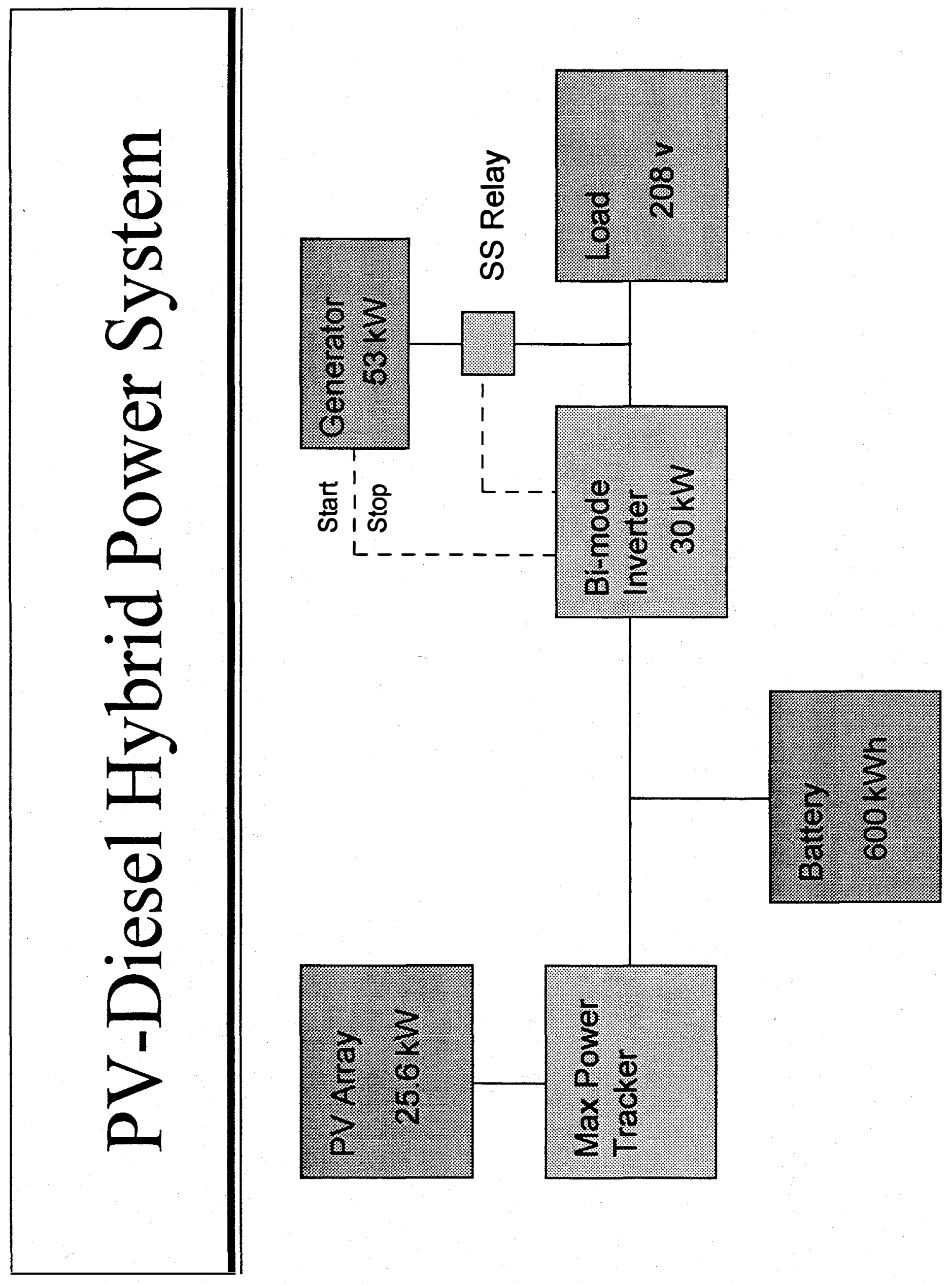




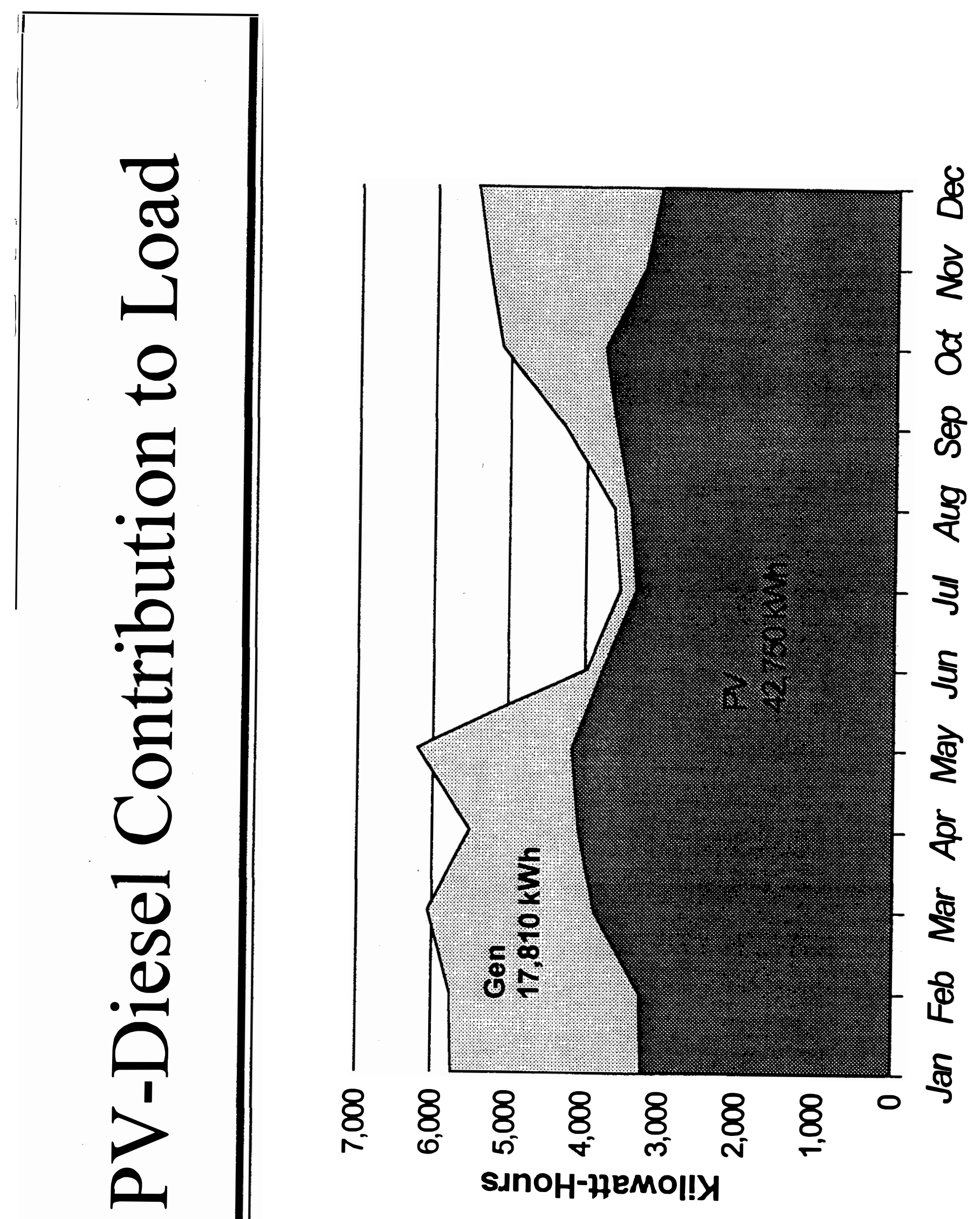


CAROL SPRING MOUNTAIN HYBRID POWER SYSTEM

Sunday, April 14, 1996

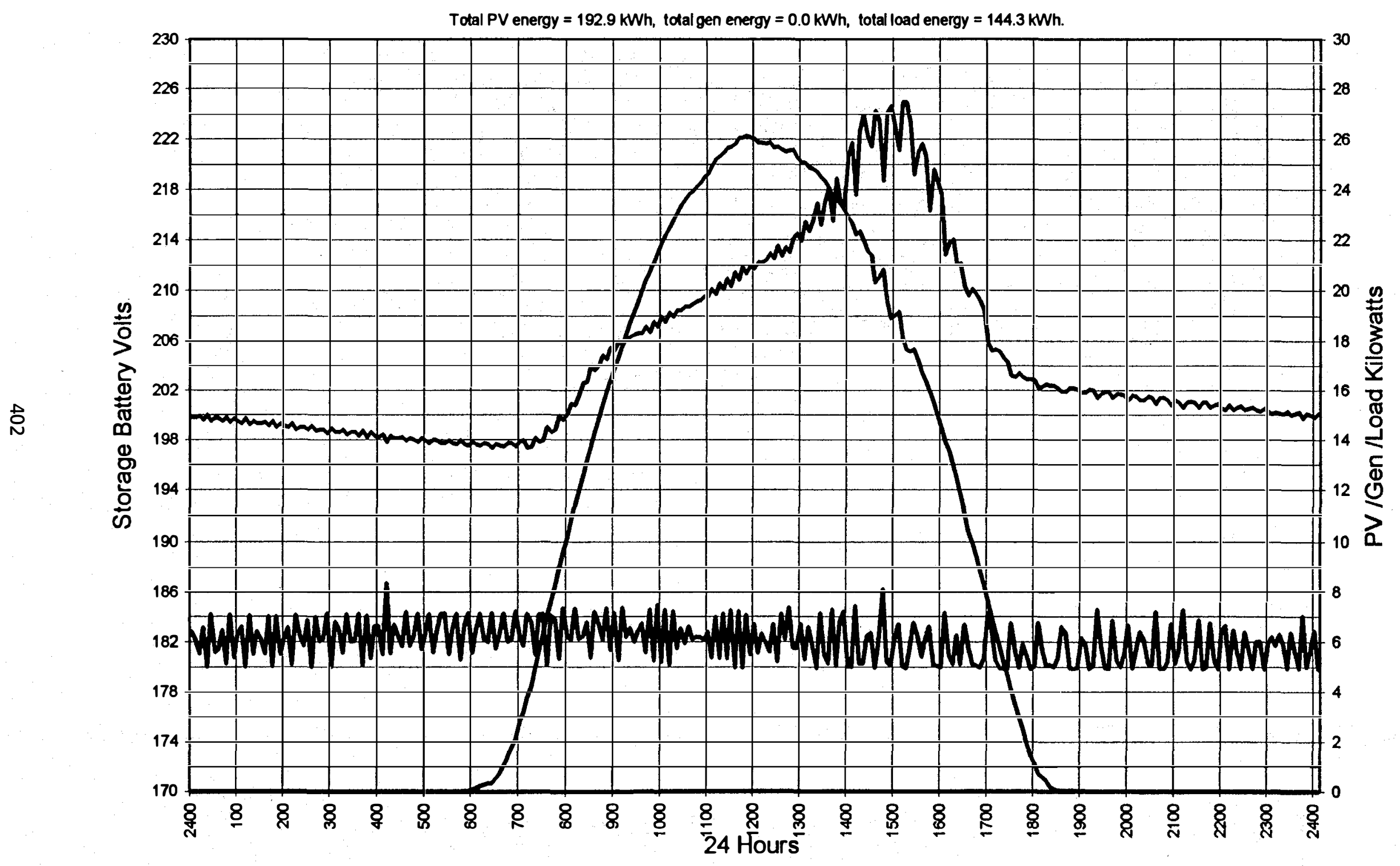

- VOLTS BATT -TOTAL POWER ARRAY TOTAL POWER GEN —TOTAL POWER LOAD 
CAROL SPRING MOUNTAIN HYBRID POWER SYSTEM

Friday, April 12, 1996

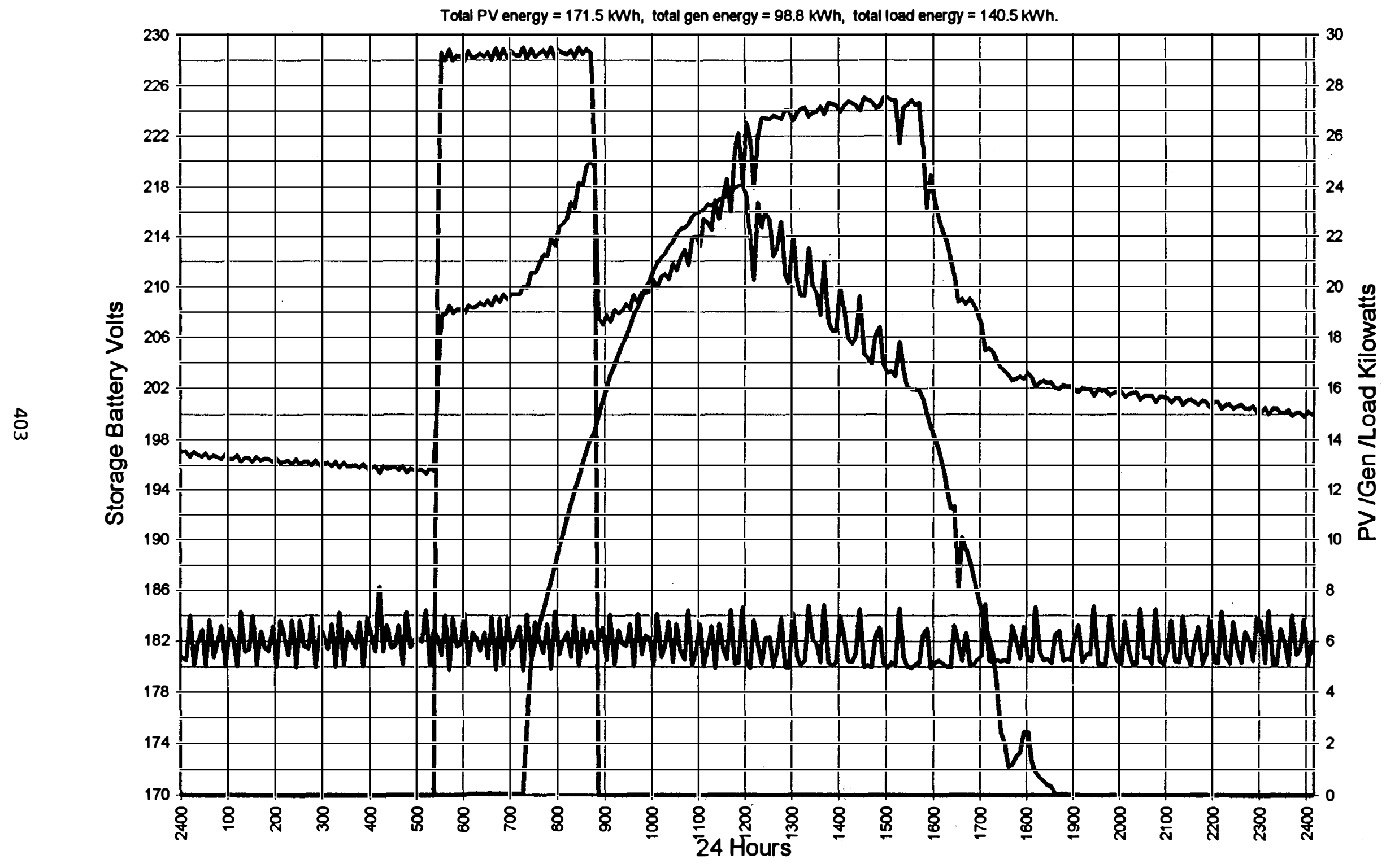

VOLTS BATT TOTAL POWER ARRAY TOTAL POWER GEN TOTAL POWER LOAD 


\begin{tabular}{|c|c|c|c|c|c|c|c|c|c|c|c|c|c|}
\hline \multicolumn{14}{|c|}{ Monthly Operating Summary } \\
\hline Year & \multicolumn{2}{|c|}{ Month } & $\begin{array}{c}\text { Solar } \\
\text { Production } \\
(\mathrm{kWh})\end{array}$ & $\begin{array}{c}\text { Generator } \\
\text { Production } \\
(\mathrm{kWh})\end{array}$ & $\begin{array}{l}\text { System } \\
\text { Load } \\
(\mathrm{kWh}) \\
\end{array}$ & $\begin{array}{c}\text { Battery } \\
\text { Net } \\
(\mathrm{kWh})[1]\end{array}$ & $\begin{array}{c}\text { Percent } \\
\text { Efficiency } \\
{[2]}\end{array}$ & $\begin{array}{c}\text { Generator } \\
\text { Run } \\
\text { Hours }\end{array}$ & $\begin{array}{c}\text { Generator } \\
\text { Starts }\end{array}$ & $\begin{array}{c}\text { Max } \\
\text { Ambient } \\
\text { Temp }{ }^{\circ} \mathrm{C} \\
\end{array}$ & $\begin{array}{c}\text { Min } \\
\text { Ambient } \\
\text { Temp }{ }^{\circ} \mathrm{C} \\
\end{array}$ & $\begin{array}{c}\text { Max } \\
\text { Wind Speed } \\
(\mathrm{m} / \mathrm{s})\end{array}$ & $\begin{array}{l}\text { Equiv. Hours } \\
\text { of Full Sun } \\
\left(\mathrm{POA}, 34^{\circ}\right)\end{array}$ \\
\hline 1995 & Oct & [3] & 2067 & 884 & 2049 & -69 & $71 \%$ & 34.4 & 3 & 23.4 & 1.4 & 11.2 & 7.1 \\
\hline 1995 & Nov & [4] & 3526 & 2010 & 3907 & -17 & $71 \%$ & 78.9 & 13 & 19.1 & -1.3 & 11.5 & 6.4 \\
\hline 1995 & Dec & [5] & 2027 & 3228 & 4502 & 21 & $85 \%$ & 372.6 & 11 & 16.4 & -4.8 & 11.0 & 5.4 \\
\hline 1996 & Jan & [6] & 2404 & 2678 & 4306 & 48 & $84 \%$ & 365.8 & 3 & 14.8 & -6.6 & 12.7 & 6.1 \\
\hline 1996 & Feb & [7] & 99 & 3779 & 4082 & 340 & $97 \%$ & 639.0 & 3 & 17.8 & -7.9 & 12.5 & 5.6 \\
\hline 1996 & Mar & [8] & 4269 & 1647 & 4416 & -144 & $77 \%$ & 142.0 & 10 & 18.8 & -4.3 & 11.2 & 7.1 \\
\hline 1996 & Apr & [9] & 3861 & 1465 & 4199 & 33 & $78 \%$ & 189.0 & 5 & 26.4 & -0.8 & 14.5 & 7.7 \\
\hline 1996 & May & & 0 & 4376 & 4376 & 110 & $98 \%$ & 743.2 & 0 & 31.9 & 2.6 & 9.6 & 7.5 \\
\hline 1996 & Jun & {$[10]$} & 746 & 4116 & 4534 & 111 & $91 \%$ & 599.0 & 4 & 31.9 & 11.0 & 9.2 & 6.5 \\
\hline 1996 & Jul & & 2511 & 3513 & 4609 & -141 & $77 \%$ & 357.0 & 10 & 32.3 & 13.0 & 13.7 & 6.1 . \\
\hline 1996 & Aug & & & & & & & & & & & & \\
\hline 1996 & Sept & & & & & & & & & & & & \\
\hline 1996 & Oct & & & & & & & & & & & & \\
\hline 1996 & Nov & & & & & & & & & & & & \\
\hline 1996 & Dec & & & & & & & & & & & & \\
\hline & Total & & 21510 & 27696 & 40980 & 292 & & 3521 & 62 & & & & \\
\hline & Average & & & & & & $83 \%$ & & & & & & 6.6 \\
\hline & $\operatorname{Max} / \mathrm{M}$ & & & & & & & & & 32.3 & -7.9 & 14.5 & \\
\hline
\end{tabular}

Note: 1. A positive sign indicates energy removed, a negative sign indicates energy added.

2. The efficiency is calculated by dividing: (System Load) / (PV Prod + Gen Prod + Net Batt).

3. Hybrid system began operation on October 16th, 1995.

4. New boards w/modifications to the set points installed on November 16th, 1995.

5. DAS adjustment on December 13th. Phase $C$ inverter failed on December 18th, 1995.

6. Phase $C$ inverter repaired and set point adjustments made on January 6th, 1996.

Phase C inverter failed on January 19th, 1996.

7. Inverter was out of service during Febnuary 1996.

8. The system was returned to service on March 5th, 1996.

9. Inverter failed in battery charge mode on April 19th, 1996.

10. Inverter back on-line

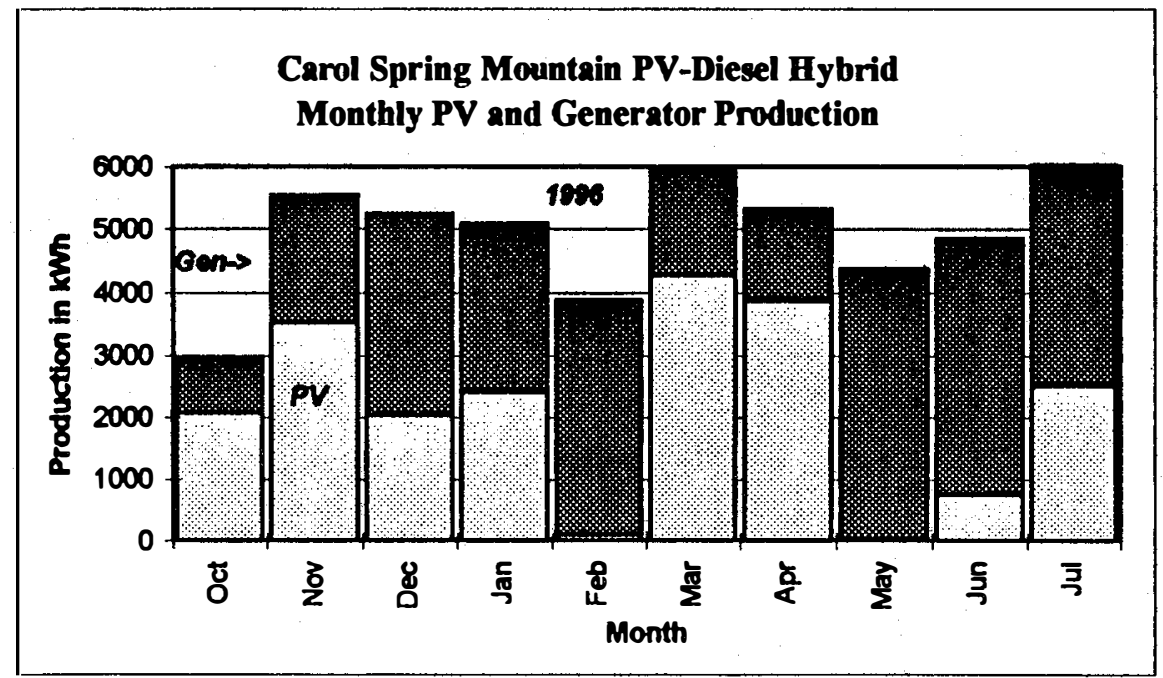




\section{CAROL SPRING MOUNTAIN PV-DIESEL POWER SYSTEM}

1996 MAINTENANCE REPORT

\begin{tabular}{|c|c|c|c|c|c|c|c|c|c|c|c|c|c|c|c|c|c|c|c|}
\hline \multirow{3}{*}{$\frac{\text { Start }}{\text { Jan }}$} & \multicolumn{2}{|c|}{$\begin{array}{l}\text { Labor } \\
\text { Routines }\end{array}$} & \multirow[t]{2}{*}{ oil } & \multirow[t]{2}{*}{$\begin{array}{l}\text { Man } \\
\text { Hrs }\end{array}$} & \multirow{2}{*}{\multicolumn{2}{|c|}{$\begin{array}{l}\text { Repair } \\
\text { Eckert }\end{array}$}} & \multirow{2}{*}{\multicolumn{2}{|c|}{$\begin{array}{l}\text { Repair } \\
\text { Tomlinson }\end{array}$}} & \multicolumn{2}{|c|}{ Others } & \multicolumn{2}{|c|}{ Total Labor } & \multicolumn{2}{|c|}{ Fuel } & \multicolumn{2}{|c|}{$\begin{array}{l}\text { Misc } \\
\text { (oil, filters) }\end{array}$} & \multicolumn{2}{|c|}{ Grand Total } & \multirow[b]{2}{*}{1995 ending balance } \\
\hline & & & & & & & & & & & & & & & & & $\$$ & $4,466.98$ & \\
\hline & $\$$ & 253.80 & 1 & 9.0 & $\$$ & 874.22 & $\$$ & - & $\$$ & - & $\$$ & $1,128.02$ & $\$$ & - & $\$$ & - & $\$$ & $1,128.02$ & repair Inv Jan Gh, 2nd outage Jan 22nd remove Inv \\
\hline Feb & \$ & 459.28 & 4 & 17.0 & \$ & - & $\$$ & 270.00 & $\$$ & - & $\$$ & 729.28 & \$ & $2,153.43$ & $\$$ & - & $\$$ & $2,882.71$ & 4 oil changes \\
\hline Mar & \$ & 581.64 & 1 & 20.5 & $\$$ & - & $\$$ & $1,432.82$ & $\mathbf{s}$ & 226.98 & $\$$ & $2,241.44$ & \$ & - & \$ & 75.39 & $\$$ & $2,316.83$ & Install inverter, calib gov \& restart March 5th \\
\hline Apr & \$ & 544.65 & 2 & 18.5 & $\$$ & - & $\$$ & - & $\$$ & $2,040.00$ & $\$$ & $2,584.65$ & \$ & - & $\$$ & 130.15 & $\$$ & $2,714.80$ & disable MPT, gen check, remove boards, Abacus travel \\
\hline May & \$ & 593.42 & 3 & 20.0 & \$ & - & $\$$ & - & $\mathbf{s}$ & 672.57 & $\$$ & $1,265.99$ & $\mathbf{S}$ & $1,133.91$ & $\$$ & - & $\mathbf{s}$ & $2,399.90$ & \\
\hline Jun & \$ & 480.94 & 2 & 16.5 & $\$$ & - & $\$$ & 349.77 & $\mathbf{s}$ & - & $\$$ & 630.71 & s & - & $\$$ & 89.16 & $\$$ & 919.87 & attempts were made to restore the inverter \\
\hline Jul & \$ & 654.21 & 2 & 15.5 & $\$$ & - & s & - & $\$$ & $1,287.32$ & $\$$ & $1,941.53$ & \$ & 720.49 & $\$$ & $4,339.13$ & $\$$ & $7,001.15$ & $\$ 3,645=$ DART, WIIliams $=\$ 580$ \\
\hline Aug & \$ & - & & & $\$$ & - & $\$$ & - & $\$$ & - & $\$$ & - & \$ & - & $\$$ & - & $\$$ & - & \\
\hline Sep & \$ & - & & & \$ & - & $\$$ & - & $\$$ & - & $\$$ & - & \$ & - & $\$$ & - & $\$$ & - & \\
\hline Oct & $\$$ & - & & & $\$$ & - & $\$$ & - & $\$$ & - & $\$$ & - & $\$$ & - & $\$$ & - & $\$$ & - & \\
\hline Nov & \$ & - & & & $\$$ & - & $\$$ & - & $\$$ & - & \$ & - & $\$$ & - & $\$$ & - & $\$$ & - & \\
\hline \multirow[t]{2}{*}{ Dec } & $\$$ & - & & & $\$$ & - & $\$$ & - & $\$$ & - & $\$$ & - & $\$$ & - & $\boldsymbol{s}$ & - & $\$$ & - & \\
\hline & $\$$ & $3,567.94$ & & 117.0 & $\$$ & 874.22 & $\$$ & $2,052.59$ & $\$$ & $4,226.87$ & $\$$ & $10,721.62$ & $\$$ & $4,007.83$ & $\$$ & $4,633.83$ & $\$$ & $19,363.28$ & \\
\hline
\end{tabular}

오ํ

\begin{tabular}{cccccccccc} 
Fuel Purch & \multicolumn{2}{c}{ Total } & \multicolumn{2}{c}{ Delivery } & \multicolumn{2}{l}{ Fuel } & Per Unit & Gallons & Total Gals \\
\hline $12-15-95$ & $\$$ & 698.99 & $\$$ & 162.50 & $\$$ & 536.49 & 0.86250 & 622 & \\
$1-5-96$ & $\$$ & 653.34 & $\$$ & 162.50 & $\$$ & 490.84 & 0.89390 & 549 & +130 from Dec Purch \\
$1-28-96$ & $\$$ & 105.92 & & & $\$$ & 105.92 & 1.21000 & 88 & \\
$2-7-96$ & $\$$ & 695.16 & $\$$ & 162.50 & $\$$ & 532.68 & 0.89390 & 596 & 1,363 \\
$4-30-96$ & $\$$ & 793.59 & $\$$ & 162.50 & $\$$ & 631.09 & 1.09243 & 545 & 1,908 \\
$5-23-96$ & $\$$ & 911.54 & $\$$ & 162.50 & $\$$ & 749.04 & 1.08714 & 650 & 2,558 \\
$6-15-96$ & $\$$ & 720.49 & $\$$ & 162.50 & $\$$ & 557.99 & 0.89985 & 585 & $3,143<-1996$ usege
\end{tabular}

S 4,579.05 Nole: All the fuel charges showed up in the February accounting report. 
